\title{
Measurement of human energy expenditure
}

\author{
Citation for published version (APA):
}

Schoffelen, P. F. M. (2017). Measurement of human energy expenditure: biological variability and technical validity. [Doctoral Thesis, Maastricht University]. Datawyse / Universitaire Pers Maastricht. https://doi.org/10.26481/dis.20170914ps

Document status and date:

Published: 01/01/2017

DOI:

10.26481/dis.20170914ps

Document Version:

Publisher's PDF, also known as Version of record

\section{Please check the document version of this publication:}

- A submitted manuscript is the version of the article upon submission and before peer-review. There can be important differences between the submitted version and the official published version of record.

People interested in the research are advised to contact the author for the final version of the publication, or visit the DOI to the publisher's website.

- The final author version and the galley proof are versions of the publication after peer review.

- The final published version features the final layout of the paper including the volume, issue and page numbers.

Link to publication

\footnotetext{
General rights rights.

- You may freely distribute the URL identifying the publication in the public portal. please follow below link for the End User Agreement:

www.umlib.nl/taverne-license

Take down policy

If you believe that this document breaches copyright please contact us at:

repository@maastrichtuniversity.nl

providing details and we will investigate your claim.
}

Copyright and moral rights for the publications made accessible in the public portal are retained by the authors and/or other copyright owners and it is a condition of accessing publications that users recognise and abide by the legal requirements associated with these

- Users may download and print one copy of any publication from the public portal for the purpose of private study or research.

- You may not further distribute the material or use it for any profit-making activity or commercial gain

If the publication is distributed under the terms of Article $25 \mathrm{fa}$ of the Dutch Copyright Act, indicated by the "Taverne" license above, 


\section{Measurement of Human Energy Expenditure}

biological variability and technical validity

\section{Paul F.M. Schoffelen}

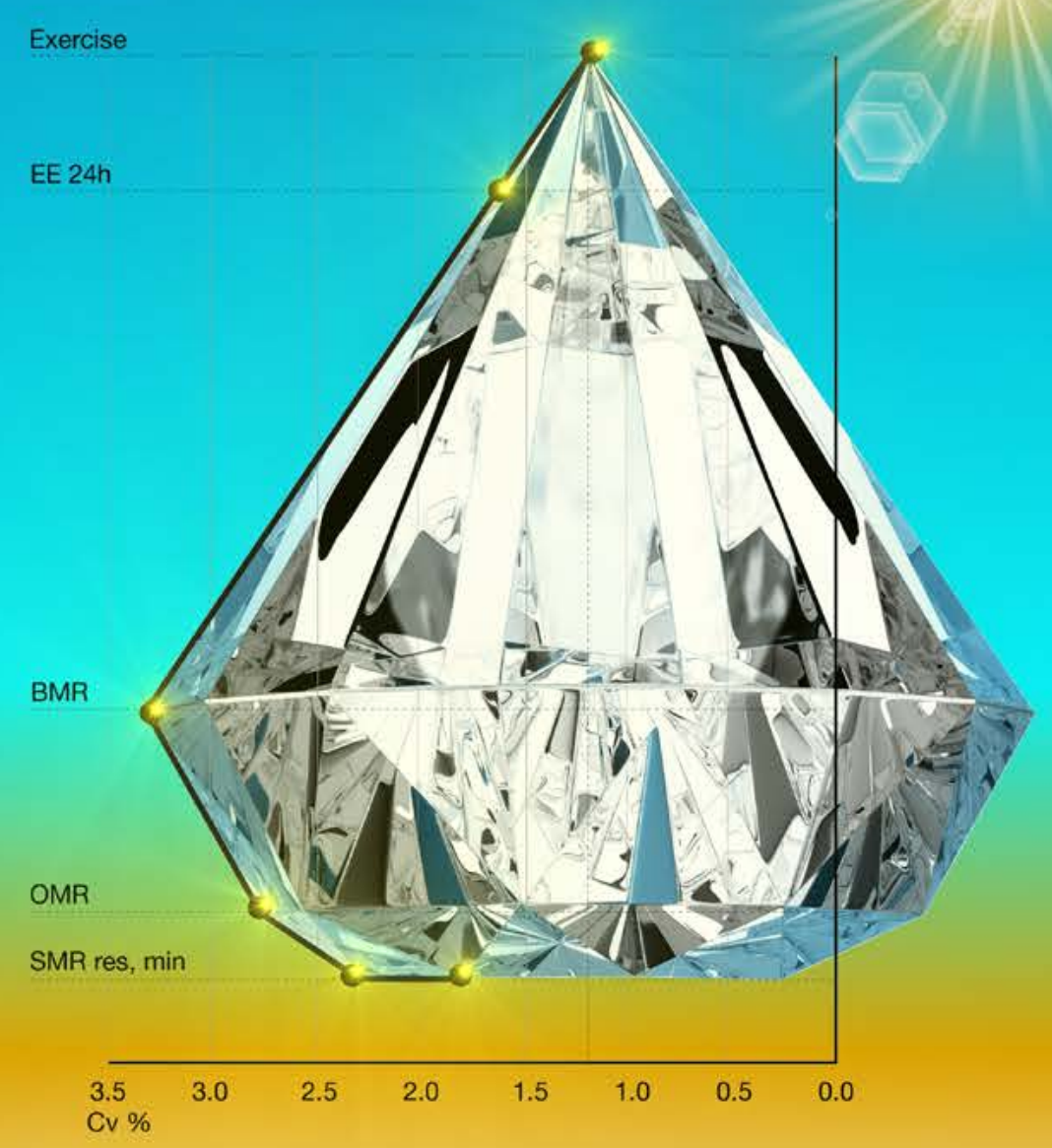




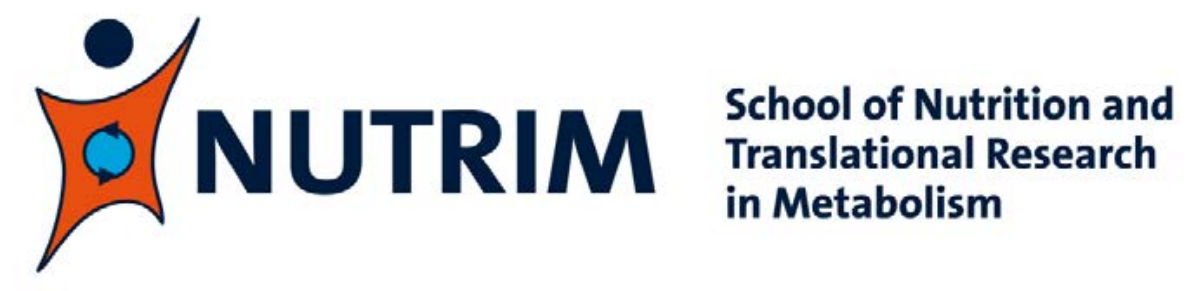

(C) copyright Paul F.M. Schoffelen, Maastricht 2017

Printing: Datawyse | Universitaire Pers Maastricht

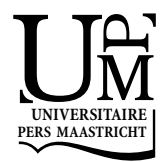

ISBN 9789461597403 


\title{
Measurement of Human Energy Expenditure
}

\section{biological variability and technical validity}

\author{
Proefschrift \\ ter verkrijging van de graad van doctor \\ aan de Universiteit Maastricht \\ op gezag van de Rector Magnificus, \\ Prof. dr. Rianne M. Letschert \\ volgens het besluit van het College van Decanen, \\ in het openbaar te verdedigen \\ op donderdag 14 september 2017 om 14:00 uur \\ door \\ Paul Franciscus Maria Schoffelen \\ Geboren te Brunssum op 29 januari 1957
}


Promotoren

Prof. dr. ir. W.H.M. Saris

Prof. dr. K.R. Westerterp

\section{Co-promotor}

Dr. G. Plasqui

\section{Beoordelingscommissie}

Prof. dr. W.D. van Marken Lichtenbeld (voorzitter)

Dr. K.Y. Chen (NIDDK, Bethesda MD, USA)

Prof. dr. L.J.C. van Loon

Dr. P.R. Murgatroyd (NIHR, Cambridge, UK)

Prof. dr. P.A.J. Schrauwen 


\section{Table of contents}

Chapter 1 Introduction

Chapter 2 The work of walking: a calorimetric study

Chapter 3 Utilization of different formulae to calculate energy expenditure from gas exchange and substrate oxidation; an updated equation for indirect calorimetry

Chapter 4 A dual-respiration chamber system with automated calibration

Chapter 5 Intra-individual variability and adaptation of overnight- and sleeping metabolic rate

Chapter 6 Intra-individual variation of basal metabolic rate and the influence of daily habitual physical activity before testing

Chapter 7 Test-retest variability of $\mathrm{VO}_{2 \max }$ using total-capture indirect calorimetry reveals linear relationship of $\mathrm{VO}_{2}$ and Power

Chapter 8 Measurement of respiratory gas exchange: derivation of equations for- and comments on true molar balance in whole room calorimetry

Chapter 9 General discussion

Summary 191

Samenvatting

Valorisation

Aknowledgements

About the author

Publications 

Chapter 1

Introduction 



\section{HISTORICAL OVERVIEW OF MEASUREMENT OF HUMAN ENERGY EXPENDITURE}

Over centuries there has been great interest in human energy expenditure (EE) as well as animal EE. This interest was driven by pure scientific interest regarding biology [1-3] and disease [4], as well as for direct practical purposes like military performance [5], sports performance [6], or feeding efficiency in live-stock [7-10]. To measure EE during these past times, one needed to apply laborious methods, mostly of a coarse yet reliable nature while adhering to established rules of physics and chemistry of the period.

Energy has many forms, and it can be stored, transferred and converted in at least as many ways. A few examples are energy in the form of heat, radiation (light), and movement. Storage examples are food, oil, hydro- and nuclear power, batteries etc. Energy can be transferred and converted from one form into another, which for instance will involve chemical reactions or mechanical work. The international system of units (SI) [11] defined energy in Joule [J] expressed as "energy, work or amount of heat". Power was defined as energy per unit of time defined in watt [W] i.e. joule per second [J•s-1]. The well-known calorie is similar to joule, also expressing "energy, work or amount of heat" with the conversion 1 calorie $=4.184$ joule (chemical) [12]. In this thesis, with its historical context, the reader will encounter variations in the expression of energy, specifically energy, heat and work with unit joule, watt and calorie. Please be aware that these all denote energy in a broader perspective.

The first calorimeter with correct physics, in this instance for a small animal, was built in the $18^{\text {th }}$ century. In 1780 Lavoisier and Laplace [1, 13-15] published details of the famous "ice-calorimeter" (Figure 1), a precise instrument even to today's standards. It measured energy in the form of heat. 


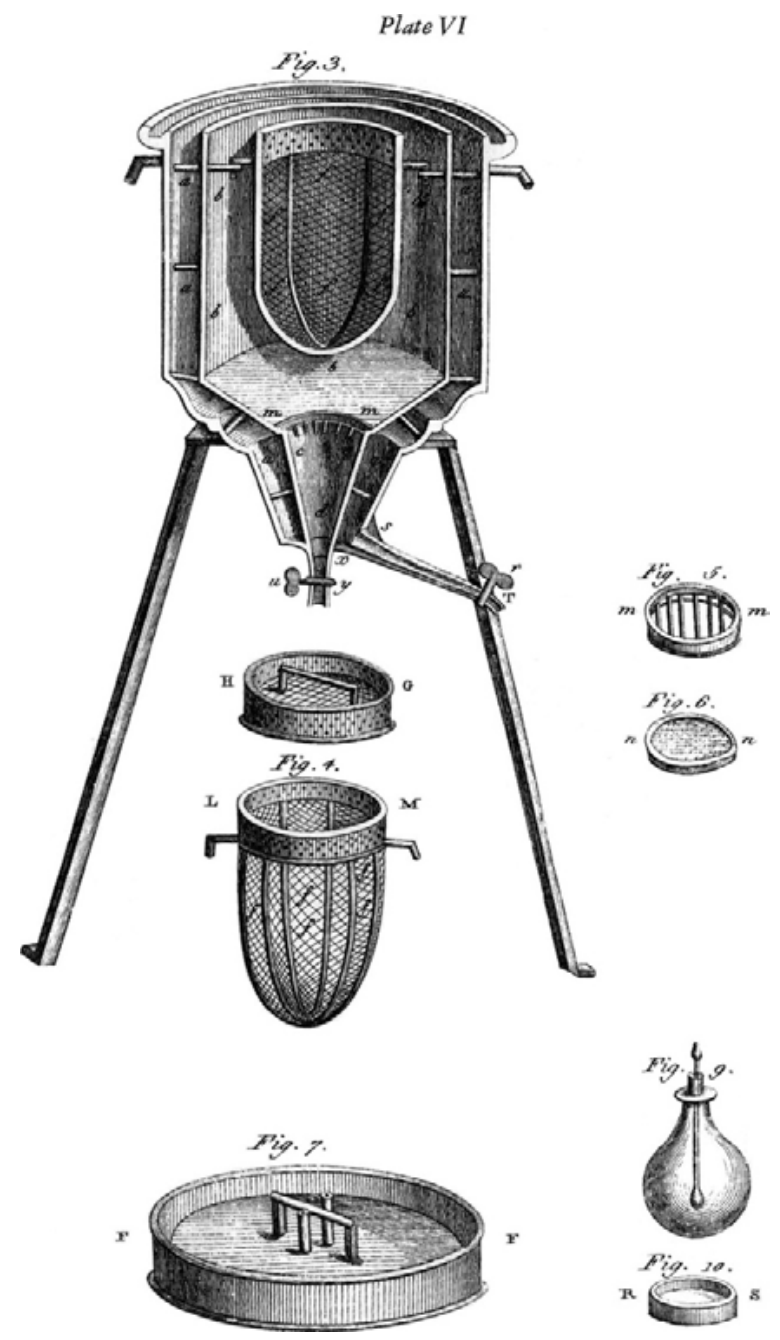

Figure 1. Ice calorimeter by Antoine-Laurent Lavoisier and Pierre-Simon de Laplace as drawn by Marie-Anne Lavoisier in 1780 [14, 15], shown here as a historical reference without legend.

It used the properties of melting ice regarding its stability of temperature (Figure 2) [16], today $0{ }^{\circ} \mathrm{C} e l s i u s$, and its ability to absorb heat by converting ice into meltwater. Adjacent layers of melting ice had an identical reference temperature of $0^{\circ} \mathrm{C}$ (isothermal or zero-gradient), and therefore no heat was transferred either way (adiabatic process). This near-perfect insulation for heat was instrumental to the design of the icecalorimeter. 


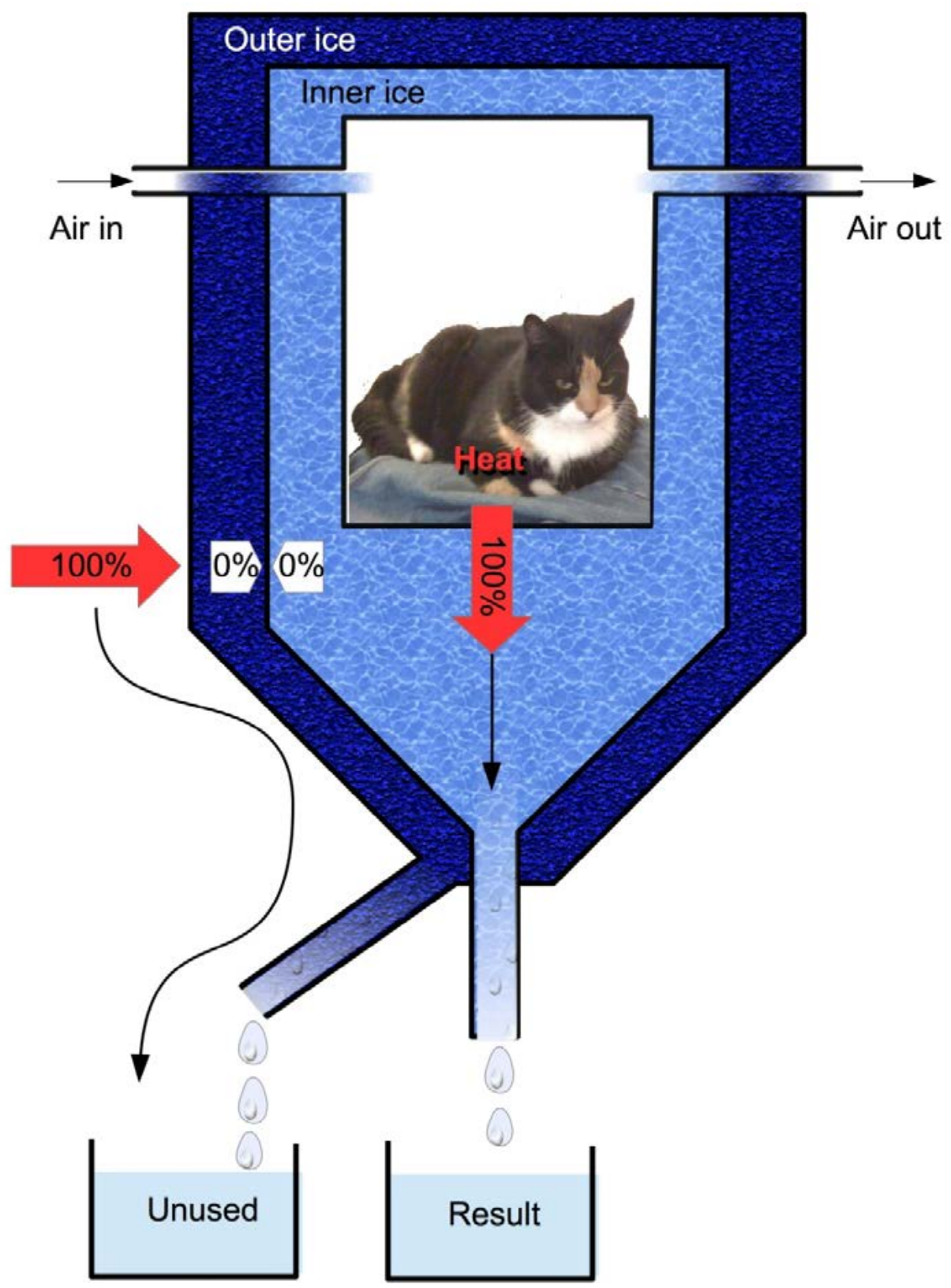

Figure 2. An animal occupied a small space surrounded by an inner layer of ice, heat produced by the animal inside converted this inner ice into meltwater. Importantly, to prevent the surrounding laboratory from contributing unrelated heat, an outer layer of ice was applied. Its purpose was to achieve complete insulation, zero-gradient, for the inner layer of ice. Thus, the inner ice was exclusively exposed to heat produced inside. The result was a quantity of meltwater from inner ice that could be precisely measured. The meltwater from the outer ice was unused, as it was not related to heat produced inside. 
The design of the ice calorimeter was both correct and elegant, with its near-perfect zero-gradient adiabatic insulation and its conversion of internal heat into a separated amount of meltwater. The internal meltwater was fully captured and was precisely measured, it revealed the amount of heat produced inside the space of the icecalorimeter. Measuring heat made this "ice-calorimeter" what nowadays is known as a "direct calorimeter". Using established rules of physics, it could determine all heat released inside the calorimeter in a "direct" way.

This calorimeter was further used to determine the energy content of food, and together with other experiments regarding gas-exchange $[2,14]$ provided for the first time a quantified link between heat and gas-exchange (Figure 3). Nowadays measurement of gas exchange is called indirect calorimetry, though Lavoisier only measured quantities of gas exchange and did not yet resolve the complete link.

\section{Nutrient $+\mathrm{O} 2 \longrightarrow \mathrm{CO} 2+\mathrm{H} 2 \mathrm{O}+$ Heat (internal work)

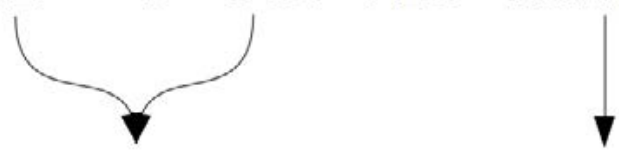 \\ Indirect calorimetry $=$ Direct calorimetry \\ Measurement of \\ Gas-exchange Measurement of Heat produced}

Figure 3. Human calorimetry measures the energy obtained from oxidizing food (gas exchange) and converting this energy into heat by means of internal work.

Lavoisier summarized his findings in the famous sentence: "La respiration n'est qu'une combustion lente de carbone et d'hydrogène, qui est semblable en tout á celle qui s'opère dans une lampe ou dans une bougie allumée, et que, sous ce point de vue, les animaux qui respirent sont de véritables corps combustibles qui brûlent et se consument." [14]. Lavoisier and co-workers had established that heat produced by a living being is comparable to the chemical reaction of burning food using an open fire, though the process was slower. They were able to determine oxygen consumption, i.e. gasexchange, and heat production. Yet EE (of an animal) could only be determined by measured heat.

It took another 100 years, well into the $19^{\text {th }}$ century, before scientists were able to start larger scale research into the relation of work, heat and respiration [5, 7-9, 17-22]. Importantly, the composition of food from three basic substrates fat, protein and carbohydrates was analyzed and their chemical reaction with oxygen resulting in carbon dioxide and energy was determined [5, 23] (Table 1). 
Table 1. $\mathrm{O}_{2}$ uptake (liter), $\mathrm{CO}_{2}$ production (liter) and $\mathrm{EE}$ (kcal) per gram of substrates carbohydrate, protein and fat, including correction of EE (kcal) per gram of urinary nitrogen katabolized (loss of energy in urea and creatinine).

\begin{tabular}{lllll}
\hline $\begin{array}{l}\text { Substrate } \\
\text { 1 gram }\end{array}$ & $\begin{array}{l}\text { O2 uptake } \\
\text { Carbohydrate }\end{array}$ & $\begin{array}{l}\text { CO2 production } \\
{[\mathrm{L}]}\end{array}$ & $\begin{array}{l}\text { EE } \\
{[\mathrm{kcal}]}\end{array}$ & Reference \\
\cline { 2 - 4 } Protein & 0.8288 & 0.8288 & 4.182 & Zuntz 1897 [5] \\
N2-urin katabolized & 0.967 & 0.7752 & 4.316 & Loewy-Lusk 1928 [24] \\
Fat & - & - & -2.17 & Weir 1949 [25] \\
\hline
\end{tabular}

This allowed calculation of human EE from gas exchange including the variable contribution of carbon dioxide production and the correction for loss of energy in urine (e.g. urea and creatinine) (Table 1) [5, 25, 27-30]. After mathematical derivation, a resulting formula for converting gas exchange values into human EE was written as:

$$
\mathrm{EE}[\mathrm{kcal}]=3.941 \bullet \mathrm{O} 2[\mathrm{l}]+1.106 \bullet \mathrm{CO} 2[\mathrm{l}]-2.17 \bullet \mathrm{N} 2[\mathrm{~g}] \quad \text { (Weir 1949) [25] }
$$

This calculation of EE from gas exchange did not involve measuring heat. It was completely based on measured gas quantities for Oxygen consumed and Carbon-dioxide produced (formula 1.). In the absence of any "direct" measurement of heat this method based on gas-exchange became therefore known as "indirect calorimetry".

Measuring human EE became possible with both direct and/or indirect calorimetry.

For most of the $20^{\text {th }}$ century measuring human EE with direct- and indirect calorimeters remained a physical demanding effort. Computers and electronic equipment were not available or in early development stages, analysis of gasses required specialized technicians performing chemical procedures to determine values for a single gas sample at a time [31, 32], while electronic sensors were manually logged or plotted using chart recorders (Figure 4). 


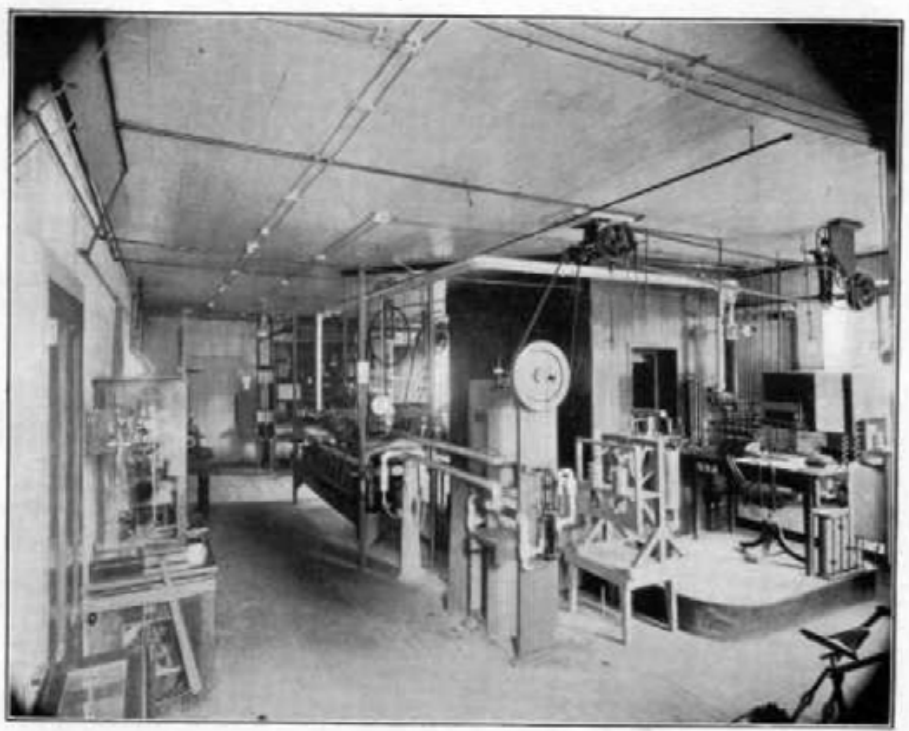

Figure 4. The respiration calorimeter by Atwater in 1905 [33]

These efforts of reputable research groups resulted in truly excellent work, for the greater part still applicable today. They provided validated methods for measuring heat (direct) and gas-exchange (indirect). And they measured caloric values of the macronutrients protein, carbohydrates and fat, which resulted in formulae for calculating $\mathrm{EE}$ from gas-exchange and measured urinary nitrogen [5, 9, 13, 17, 34, 35].

\section{DIRECT AND INDIRECT CALORIMETRY}

Direct and indirect calorimeters were fundamentally different and both showed specific advantages as well as disadvantages.

\section{Fundamental differences}

A first fundamental difference concerned the definition of work in the context of calorimetry. In figure 3, the energy calculated from gas exchange (indirect calorimetry) was defined equal to the energy measured as heat (direct calorimetry). Note that heat was explicitly generated by "internal work", referring to the fact that this equality of indirect- and direct calorimetry is only valid if no energy is transported to outside of the body i.e. external work is zero. Since energy may be stored inside the body, for example in fat-stores or in an elevated body-temperature, for clarity of this introduction energy storage was assumed to be in balance over time. 
The term work is interchangeable with energy, and the human body used the available energy for both internal work and external work [13, 36, 37]. Internal work, considered to be the sum of work of all internal processes including body-functions at rest, in the end leaves the body in the form of heat (Figure 3). In contrast, external work is all nonheat energy the body transferred to the environment (Figure 5), for instance the work transferred to the pedals of a bike or stones lifted to a higher level thus gaining potential energy. Since the human body typically is just 20-30 \% efficient in converting energy to external work, all external work is accompanied by internal work for the remaining 70-80\%.

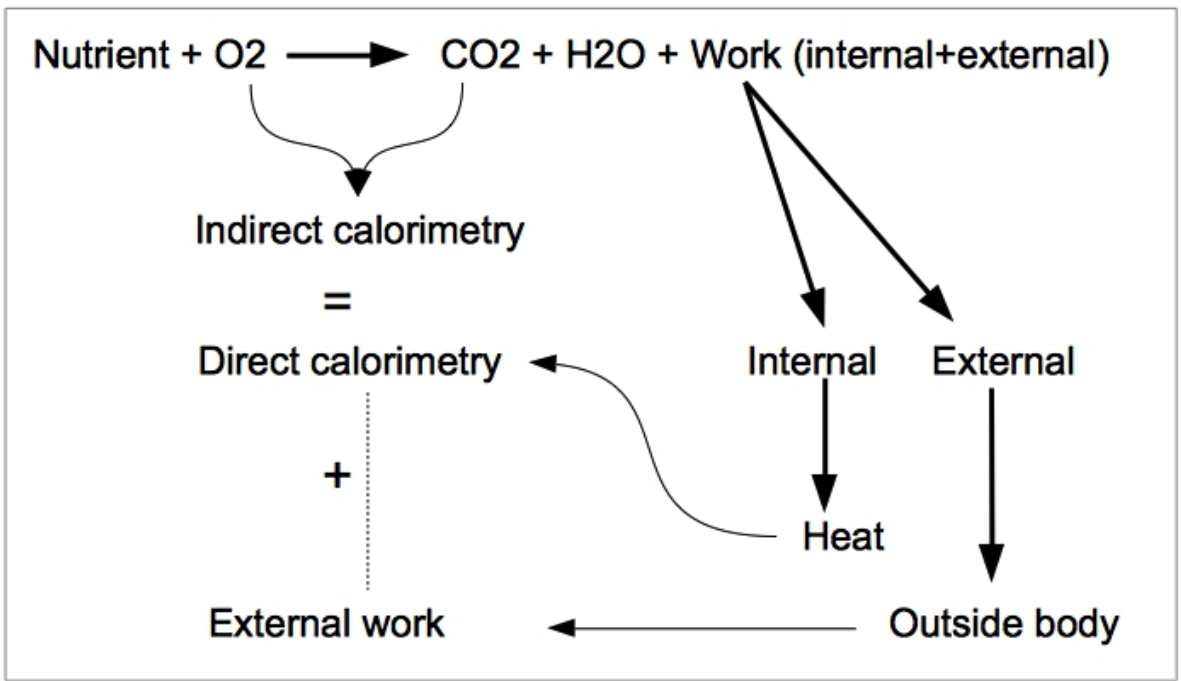

Figure 5. The "external work" processes of calorimetry showing the gaseous exchange measured by indirect calorimetry, the heat produced after bodily functions as internal work and measured by direct calorimetry, and the external work as exported energy not producing heat inside the body. Note that external work will be accompanied by an increase in internal work due to lack of efficiency (not illustrated).

Direct calorimetry exclusively measures heat that leaves the body and excludes external work. In contrast, indirect calorimetry measures total energy expenditure; i.e. the sum of energy measured by direct calorimetry plus external work.

The second fundamental difference concerns the chemical calculations for indirect calorimetry. The ratio of carbon dioxide production and oxygen uptake, i.e. respiratory quotient or $\mathrm{RQ}$, provides information on the kind of food-substrate being metabolized (Table 1); fat, protein or carbohydrates [5, 25, 27-29, 33, 35, 38-40]. This information on substrate use can be obtained by indirect calorimetry and is not available from direct calorimetry. 
In summary, the explanatory definition of the two types of calorimetry can be stated as:

- Direct calorimetry measures all heat leaving the body, excluding external work.

- Indirect calorimetry measures the gas exchange of oxidizing food, no heat is measured, and the energy expenditure determined in this way consists of total energy converted and includes external work.

\section{Advantages and disadvantages}

A significant advantage of a direct calorimeter is that it actually measures EE without interpretation or estimates of a chemical nature, with the inherent disadvantage of lacking information regarding substrate use.

For indirect calorimetry, the advantage of determining substrate use could also be regarded as its main disadvantage, as the numbers in Table 1 were average estimates, and introduce interpretation of substrate composition into the EE result. Effectively there is no 'direct' EE measurement.

For direct calorimetry, further typical disadvantages are the high demands on separation of heat from the (whole) body versus heat from the environment, and the requirement for highly accurate heat-flux measurement devices. These factors cause a higher degree of complexity in comparison to indirect calorimetry, and prevent mobile or bedside application.

Although indirect calorimetry has been broadly accepted for measuring human EE, mainly in the form of metabolic carts, only the combination of direct- and indirect calorimetry has all the advantages mentioned above (Table 2).

Table 2. Overview of advantages and disadvantages of both types of calorimeters and the combination.

\begin{tabular}{lll}
\hline & Advantage & Disadvantage \\
\hline Direct calorimeter & Determines EE (heat) directly & No substrate determination \\
Indirect calorimeter & $\begin{array}{l}\text { Measures total EE } \\
\text { Substrate determination } \\
\text { Allows bedside or mobile application }\end{array}$ & \\
& Interpretive EE formula \\
& $\begin{array}{l}\text { Determines (total) EE, } \\
\text { substrate use, heat-storage, } \\
\end{array}$ & Technologically complex \\
& work efficiency & \\
\hline
\end{tabular}

The combination of direct- and indirect calorimetry provided advantages [36, 41-44], and allowed both actual measurement of $\mathrm{EE}$ (heat) without a substrate interpretive formula, as well as determination of substrate use, internal- and external work, and work efficiency. 


\section{Doubly labeled water - indirect calorimetry in free living conditions}

It would be incorrect to define just two calorimeters as either direct or indirect, as a variation of methods exists. An important exception for indirect calorimetry is not a calorimeter "device" as such, instead it only requires periodical urine samples from free-living subjects after drinking an initial glass of water labeled with the stable isotopes 'deuterium' and 'oxygen-18'. This elegant method uses "doubly labeled" water to determine carbon dioxide production over weekly intervals [45-50]. It has the advantage that only samples of urine are required for analysis, while the subject can be doing anything from complete rest to climbing Mount Everest [46]. This method measures gas exchange for carbon dioxide, excluding oxygen data required for the analysis of substrate use. Results are averages of EE over intervals with a typical duration of 7-14 days. Yet, this remains the only known solution for determining EE in daily life without carrying equipment.

\section{BIOLOGICAL COMPONENTS OF ENERGY EXPENDITURE}

Human EE was considered the sum of EE components stemming from individual biological processes like sleep, rest, activity and food intake. EE was typically divided in three main components, i.e. basal metabolic rate (BMR), diet-induced thermogenesis (DIT), and activity related energy expenditure (AEE). BMR was further subdivided in sleeping metabolic rate (SMR) and arousal, i.e. the energetic cost of being awake (figure 6).

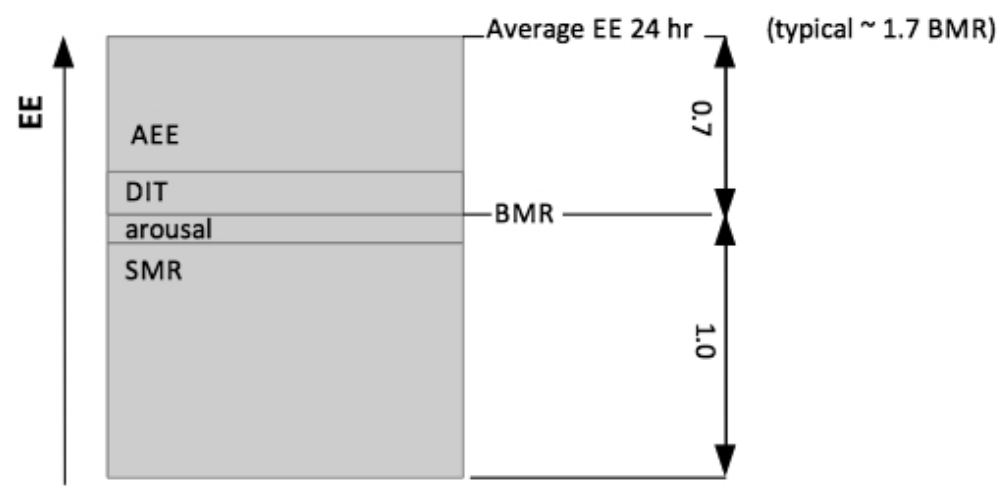

Figure 6: Typical representation of the different components of energy expenditure. In free living conditions the physical activity part including diet effects typically was around 0.7 for a moderately active lifestyle [51], resulting in a physical activity level (PAL) of 1.7

Some confusion may arise as notations for EE components varied in literature, yet with similar meaning. For instance, 'work' and 'activity', 'energy expenditure' and 'metabolic 
Rate', or 'heat' and 'thermogenesis' A brief summary of different notations in literature is presented in Table 3.

Table 3. Examples of EE component notation and definitions in literature.

\begin{tabular}{|c|c|c|}
\hline Component & Abbreviation & Definition \\
\hline $\begin{array}{l}\text { Total Energy Expenditure or } \\
\text { Average Daily Metabolic Rate }\end{array}$ & $\begin{array}{l}\text { TEE } \\
\text { ADMR }\end{array}$ & Total EE over 24 hours \\
\hline Sleeping Metabolic rate & SMR & $\begin{array}{l}\text { Lowest energy expenditure measured during sleep, } \\
\text { typically between 3-6 A.M. }\end{array}$ \\
\hline Overnight Metabolic Rate & OMR & Average EE level over the whole night during sleep \\
\hline Basal Metabolic rate * & BMR & $\begin{array}{l}\text { Energy expenditure measured in the morning after an } \\
\text { overnight fast, lying supine, awake, and thermo- } \\
\text { neutral. }\end{array}$ \\
\hline Arousal & & Difference between SMR and BMR \\
\hline $\begin{array}{l}\text { Diet-induced thermogenesis or } \\
\text { Diet-induced energy expenditure }\end{array}$ & $\begin{array}{l}\text { DIT } \\
\text { DEE }\end{array}$ & $\begin{array}{l}\text { Energy expenditure as a consequence of digestion, } \\
\text { absorption and storage of nutrients after food intake }\end{array}$ \\
\hline $\begin{array}{l}\text { (Physical) Activity related Energy } \\
\text { Expenditure } \\
\text { or }\end{array}$ & (P)AEE & $\begin{array}{l}\text { Energy expenditure as a consequence of physical } \\
\text { activity. Typically calculated as } 0.9 * \text { TEE-BMR (assuming } \\
\text { DIT to be } 10 \% \text { of TEE) }\end{array}$ \\
\hline Work Induced Thermogenesis & WIT & \\
\hline
\end{tabular}

* Often the terms Resting Metabolic Rate (RMR) or Resting Energy Expenditure (REE) were used instead of $B M R$. These terms were less strictly defined and sometimes referred to EE at rest but for example without an overnight fast or sitting instead of lying.

Human EE is not constant, it varies with time of day, level of activity, state of food digestion and other parameters. For each point in time the momentary EE measured equals the sum of EE components. Although these EE components were never measured separately, some of them were individually identified over a specific time-interval, for instance during sleep, rest, activity, meals or over 24 hours (Figure 7).

These individual EE components do not simply start- and stop, in contrast, each component will have an individual response that can be delayed after the start and/or remain active after the end of the interval for a period ranging from minutes up to hours or even days. Given these time-course effects the protocol used is of significant importance for the analysis of EE components regarding reproducibility, as well as for allowing comparison of results to those found in literature. For example, overnight sleep EE values for an $8 \mathrm{~h}$ interval (23:00 - 07:00) was significantly different from EE values of sleep just before awakening, due to effects of food-intake the day before (DIT) and due to decreasing body heat storage during the night (Table 3, Figure 7). The same holds true for BMR and RMR, both providing information on an EE level of rest (remark Table $3^{*}$ ). BMR is in general understood to be the fundamental resting EE while awake; no increase due to prior activities, diet, position, ambient (thermo-neutral) or time of day. This basal EE is typically measured early in the morning after an overnight fasted state while lying awake in supine position. RMR also indicates an EE level of rest, typically when fasted for several non-active hours. However, position, time of day and other 
factors may differ. For example, RMR could be measured several hours after lunch in a sitting position with the subject having been active in the morning, and consequently RMR will be significantly elevated in comparison to BMR.

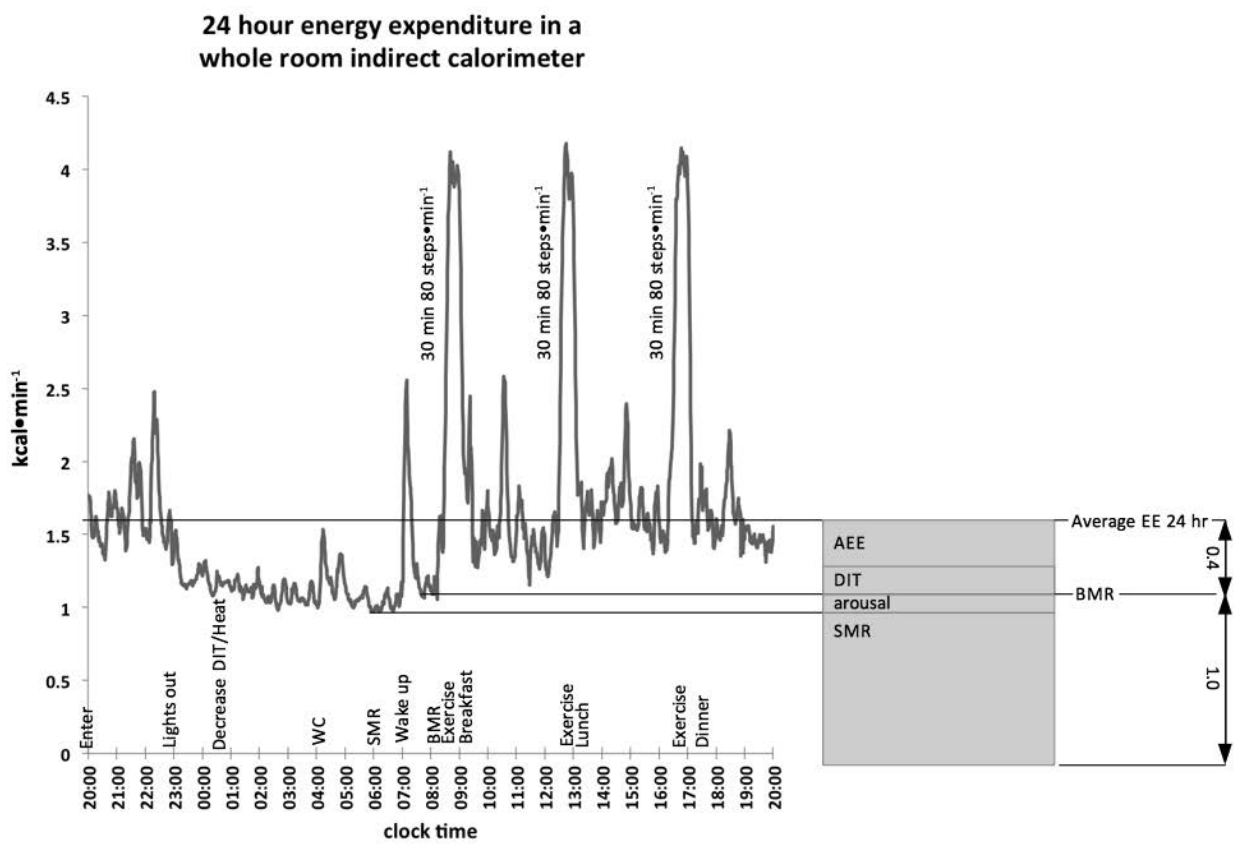

Figure 7. The different EE components as measured during a $24 \mathrm{~h}$ stay in a respiration chamber. The protocol is noted on top of the X-axis clock time, subject entered at 20:00 h and stayed for $24 \mathrm{~h}$. During the night EE decreased as DIT and body-heat decreased; SMR was determined in the last part of the sleeping period. After wake-up, washing and brushing teeth, a rest on the bed (aroused, not sleeping) allowed for the measurement of BMR. In daytime three exercise bouts of 30 min stepping at $80 \mathrm{steps} \bullet \mathrm{min}^{-1}$ were performed, each was followed by a meal. The average EE over 24 hours was $~ 40 \%$ above BMR, caused by diet- and activity related thermogenesis. A physical activity factor of only 1.4 was registered which was typical for a stay in the limited space of a respiration chamber[52].

The terms BMR and RMR are used interchangeable at times, even in manuals of equipment, which may be confusing. This interchangeable use may have been caused by the fact that RMR was sometimes measured using the near-identical protocol as required for BMR, and only in that instance will BMR and RMR be comparable. RMR is the more variable term, and its EE level depends to a larger degree on the protocol definition of the individual study.

In figure 7, measured components of EE were: SMR, BMR and average EE over 24 hours. Values for DIT, AEE and heat storage could not be determined without measuring additional parameters. This particular experiment showed the subject going to the toilet in the middle of the night, illustrating how SMR could be disturbed if activity is not taken 
into account; a typical example of biological variation even found in a strongly controlled environment.

More sources of biological variation exist, for instance seasonal or climate influences, health issues, abnormal activity levels, diet, travel, age, gender, body composition, genetics, choices for repeated visits, etc. [53-67] Knowledge of biological variation is of importance to the design of studies, typically determining the effect of an intervention, i.e. imposed variation, in one group and comparing it to the results of a group without intervention [58, 59, 67-71].

\section{ASPECTS OF BIOLOGICAL VARIABILITY AND TECHNICAL VALIDITY}

\section{Different types of indirect calorimeters}

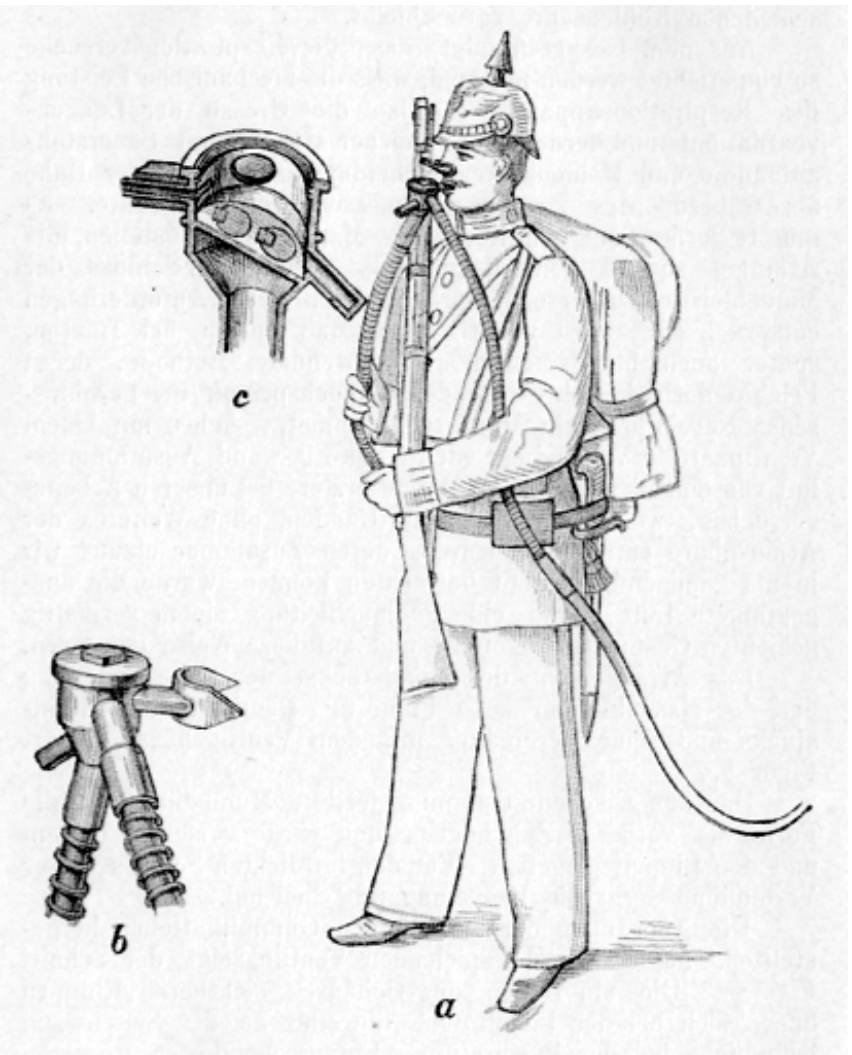

Figure 8. Indirect calorimeter with a mouthpiece $(a, b)$. The breathing valve (c) assures full capture of nondiluted exhaled breath. Zuntz 1901 [5]. 
Proving technical validity is related to the technical principles applied. In today's indirect calorimetry there are three basic types of indirect calorimeters to choose from, recognizable in the way subjects are connected:

- Face-mask or mouthpiece, a fixed connection to the face.

- Full capture of non-diluted exhaled breath (Figure 8).

- Full capture of exhaled air, diluted in a bypass flow (Figure12).

- Breath-by-breath (BxB) analysis for a partial sample of exhaled air.

- Ventilated hood: Full capture of exhaled air, diluted in a bypass flow. A small confined space (Hood) is placed over the subject's head (Figure 9).

- Whole room calorimeter. Full capture of exhaled air, diluted in both a bypass flow and large volume (Room). Subject has the comfort of free-movement (Figure 12).

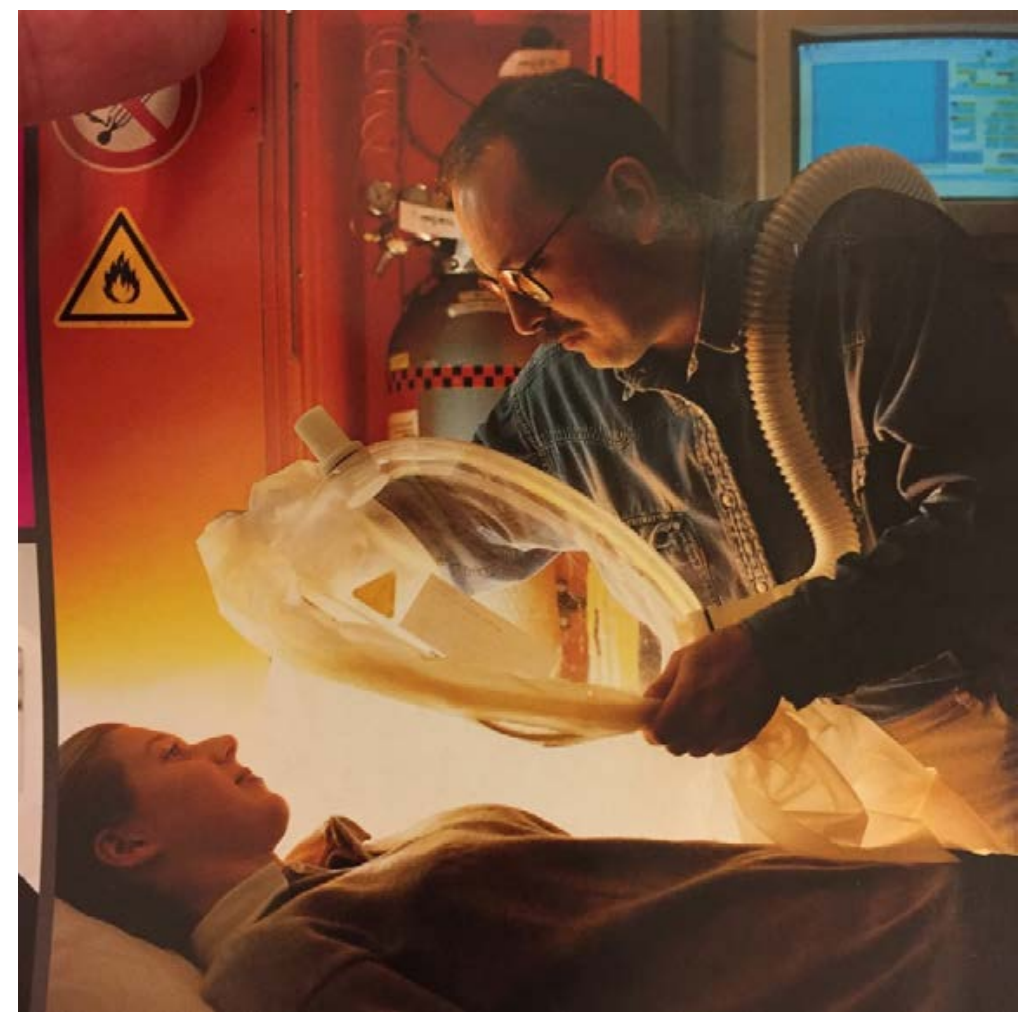

Figure 9. ventilated hood equipment, Maastricht, ca 1997.

The intended research determines the type of calorimeter applicable, with its requirements for resolution of gas analysis, minimum measurement interval or long stay interval, or comfort for the subject (Table 4). 
Table 4. Methods applicable for measuring various EE components.

\begin{tabular}{ll}
\hline EE component & Applicable method \\
\hline SMR, OMR & Room \\
Arousal & Calculated \\
BMR & Hood, Room \\
DIT & Hood, Room (with measured activity) \\
AEE & Calculated \\
TEE & Room, ${ }^{2}{ }_{2}{ }^{18}$ O technique \\
EEsubmax & Room, Face mask, Mouthpiece \\
$\mathrm{VO}_{2}$ max & Face mask, Mouthpiece, Room (optional) \\
\hline
\end{tabular}

SMR, sleeping metabolic rate; OMR, overnight metabolic rate; BMR, basal metabolic rate; DIT, diet induced thermogenesis; $A E E$, activity related energy expenditure; TEE, total energy expenditure; EEsubmax, energy expenditure during submaximal exercise; $\mathrm{VO}_{2} \mathrm{max}$, maximal oxygen consumption

A whole room calorimeter measures EE over long stay intervals, comfortable and without hindrance during sleep or activities. In contrast, the less comfortable facemask or mouthpiece provides measurement of EE for intervals as small as 30 seconds. A ventilated hood may be considered an intermediary type between a whole room and a facemask or mouthpiece. It has the advantage of bedside application in the presence of researchers, while providing the minimum comfort required for measurement of BMR. With the exception of breath-by-breath systems, indirect calorimeters measure over a longer "aggregation" interval of sufficient length. This is typical for full capture of exhaled air, rendering assumptions for synchronization of a single breath's gas analysis and it dynamic flow unnecessary. This may be considered an advantage due to the fact that synchronization was not fully proven or validated, specifically for the higher breathing frequencies [72-78].

\section{Total system validation}

Human calorimeters are inherently technical objects, whichever methodology is used, and they typically consist of several technical subsystems. Furthermore, the correct application of a calorimeter requires knowledge of its suitability (appropriateness) for the intended goal, and this suitability must be valid throughout the duration of use and for all "biological" subjects. Two important goals of technical validation for human calorimeters can therefore be defined as:

- Achieving proof of suitability for the intended research, explicitly including measurements over the full range of biological variability.

- Assuring continuous suitability over the interval of application. 
In this context, and perhaps confusingly, technical validity incorporates aspects of biology and suitability. The technical aspects (capabilities, validation tests) must "match" the biological aspects (demands posed by biological variability).

Technical validity must therefore include the match of the biological and the technical application in its totality.

\section{Calibration is not validation}

The calibration and suitability of subsystems are merely pre-requirements for achieving successful validation. Technical components like flow-meters, gas-analyzers, temperature, humidity and pressure sensors will have been individually calibrated. However, the assembled system may yet contain problems like leakage or mismatch between subsystems, only revealed by testing the completely assembled system and all its connections. Furthermore, the assembled system may impose limitations that decrease suitability for specific "biological" applications, unrelated to calibration of individual subsystems, e.g. $24 \mathrm{~h}$ EE using a breath by breath calorimeter.

\section{Methods for validation}

\section{Alcohol combustion}

A typical validation method for an indirect calorimeter is the combustion of a measured quantity of a high-purity fuel allowing calorimetric results for gas-exchange to be matched to the chemical process for the amount of fuel combusted.

The most common method uses an alcohol burner, burning high purity ethanol or methanol (Figure 10) inside the calorimeter. For hood systems, the standard Plexiglas hood is replaced to allow for the heat of the burning flame. This method also challenges the capability of the calorimeter to cope with both $\mathrm{H}_{2} \mathrm{O}$ and heat produced.

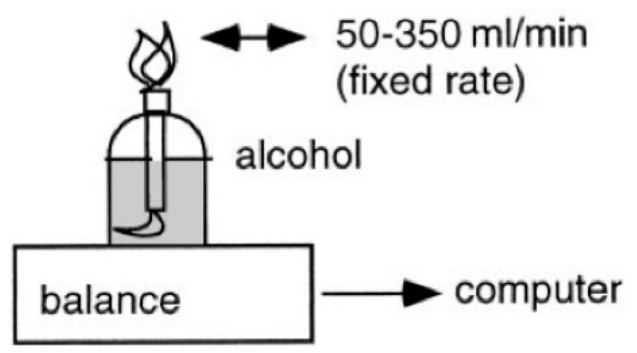

Figure 10. Indirect calorimeters may be validated by combustion of alcohol. The amount of combusted alcohol is calculated from weight change of the burner. Connecting the balance to a computer allows continuous measurement of rate of combustion. 


\section{Gas infusion}

A second method is the infusion of a measured quantity of a high-purity gas, and gasexchange results of the apparatus must match the amount infused.

This process does not produce $\mathrm{H}_{2} \mathrm{O}$ or heat, though cooling due to adiabatic expansion may occur (Figure 11).

The match between infused gas and gas-exchange measurements is easily understood for $\mathrm{CO}_{2}$; an amount of $\mathrm{CO}_{2}$ infused into the calorimeter must register exactly as if it originated from a subject, and at the same time the $\mathrm{O}_{2}$ uptake must remain zero as the total of $\mathrm{CO}_{2}$ infused should be accounted for.

The simulation of $\mathrm{O}_{2}$ consumption is more complex, there cannot be a "negative" infusion of $\mathrm{O}_{2}$ to simulate $\mathrm{O}_{2}$ uptake. Instead an inert gas, typically $\mathrm{N}_{2}$, is infused, diluting the $\mathrm{O}_{2}$ concentration in the outgoing airstream.

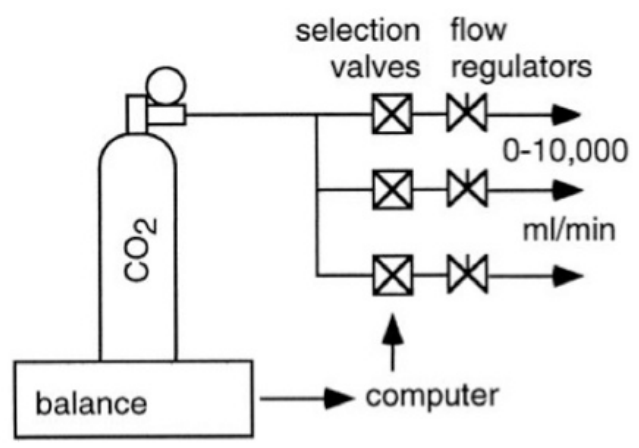

Figure 11. Indirect calorimeters may be validated by gas infusion. The amount of injected gas is calculated from weight change or from volumetric flow. A computer may allow for continuous registration and change in of rate of infusion.

Gas infusion is the method of choice for calorimeters that apply breath-by-breath analysis, measuring inhalation and exhalation separately. In that particular case the infusion must be combined with a realistic lung-simulation for breathing, or else the calorimeter will not function.

Importantly, a combined gas-infusion and realistic lung-simulator is not easily available, preventing on-site validation of breath-by-breath calorimetry. Instead, such calorimeters may be tested only partially in their hood mode with alcohol combustion.

\section{Parallel validation}

A third validation method is realized by combining two methods, one prior validated system and the system under test. The two systems are connected to measure the identical values for measurements, and results are compared. 
In applying this parallel validation great care must be taken to prevent interaction between systems. This must be proven, as well as showing the intact validity of the prior validated system.

Simply interconnecting two devices, of which one "typical" unit was at some point validated in literature, will not suffice. A calorimeter used as reference in such a test must be validated on site, it can't be assumed to perform as a "gold standard" apparatus without checking its individual performance and without checking possible interactions. Note that parallel validation will typically introduce the concept of biological reproducibility, using results of a subject from either parallel or sequential measurements.

\section{Using biological reproducibility for validation}

Consider a technically validated calorimeter failing to show reproducibility for normal healthy subjects within known limits of biological variability. In that case the technical validation method may have failed to sufficiently simulate biology, and the calorimeter is not suitable. It cannot be deemed validated.

Consider a calorimeter showing reproducibility for normal healthy subjects within known limits of biological variability, though its technical validity or "level" of measured value is unknown. In this instance the calorimeter may, or may not, be valid. It too cannot be deemed validated.

Only a technically validated calorimeter also showing reproducibility for normal healthy subjects within known limits of biological variability may be considered a validated calorimeter. It must have proven to measure exact levels of EE as well as its ability to reproduce measurements with subjects.

The paragraphs above provide a limited set of rules, useful for illustrating the value of measuring biological reproducibility as well as applicable for excluding less suitable calorimeters. Yet these rules are not strict enough to include seemingly suitable calorimeters for each and every application. There are cases where additional parameters of a technical and biological nature must be considered.

Successful application of a validation method should achieve the desired proof of suitability for the intended research, and this must include effects of the full range of biological variability expected.

\section{Subsystems in calorimetry}

Technical subsystems in human calorimetry typically consist of flow-meters, gasanalyzers, temperature, humidity and pressure sensors, which all will have been individually calibrated. Their suitability, calibration, interconnection, accuracy and precision are all important for the assembled calorimeter. Furthermore, computer systems and data handling have also been gaining momentum as important "subsystems" themselves. 
As it was impossible to fully describe all these aspects, only four are shortly elaborated upon.

\section{Gas analysis}

An important component of any indirect calorimeter is the equipment that analyses the gasses, formerly done by chemical analysis on a per-sample basis [31, 32, 36, 79], and nowadays performed by electronic equipment [36, 79-87]. More types of analyzers are available than ever before, ranging from small sensor cells to large mass spectrometers. Typically, Metabolic carts apply small sensor cells, while whole room calorimeters typically apply high-resolution, precise and most accurate analyzers. Finding the best possible analyzer can be problematic. A highest quality brand may choose to provide specifications for a broad range of applications, while another brand may provide seemingly better specifications, though more narrowly targeted to a specific application. Only tests may reveal which analyzer is superior regarding achievable level of precision and accuracy for a calorimeter, and such a test-setup must be tuned and optimized for each individual type of analyzer and calorimeter.

\section{Digitizing noise}

Digital electronics inside equipment have been and will remain to be a source of digitizing noise. In 1992, analyzers with digital processing provided a fixed step-size of $0.005 \%$ for the $21 \%$ oxygen range. Limits like these could have become obsolete, which has not happened. Instead, more and more sensors contain digital inner processing, even temperature and humidity sensors. Worse, if a digital "bottleneck" fits the broader specification it may become the only available option. This leaves precision intact or may even improve it, but it also removes resolution (the less precise smaller steps). However, Resolution is useful in data analysis (trend analysis). Fortunately, some brands choose to allow the precision and resolution of the analog process to be fully resolved.

In this respect, specifications have become suspect, as inner workings tend to be considered trade secrets and are almost never fully disclosed.

\section{Data handling}

With the advent of powerful computers at every desktop, it has become possible to calculate all kinds of responses, statistics, z-transforms, zero-phase filters and more and without effort. This has resulted in using the classic whole room calorimeter balance equations with enhanced data, i.e. data that is corrected for known internal aspects of response and timing. In simple terms: by knowing the outcome of a "standard" dynamic response, the dynamic subject responses can be reverse engineered to reveal the original dynamic subject EE input. This poses a problem when standard responses were measured in another state of the calorimeter, i.e. impact of variation of flow, temperature, humidity and all other parameters may as yet be unaccounted for. 
However, measuring responses is a standard technique for assessment of internal processes within defined limits of variation, inspecting the true physics of these internal processes and allowing their transfer characteristics to be used in a grander simulation. These techniques can be useful, but only when applied while taking into account the variation of state of all (intermediary) technical and biological parameters involved.

\section{Physics}

The classic calorimeter balance equations remain valid, also with the enhanced data techniques and precision. Yet, they may be improved by allowing the equations to be more correct in details regarding physics and interval, while keeping the original concept intact. In doing so, the impact of inner workings of a calorimeter can be assessed in more detail, and their representation in the equations can be improved.

It has become clear that physics of the room, i.e. its climate aspects, may be as important as the gas analysis itself. This is thought to be the next future improvement: resolving more details on physics level in combination with resolving more details in the gas-fractions, improving precision of data while removing assumptions.

\section{THIS THESIS}

\section{A fundamental approach}

Over the past 3-4 decades technical innovations have enabled researchers to speed up the analytical process with more sophisticated methods and reveal more details than ever before, measuring the smallest EE of low-birth-weight infants [88-90], through measuring resting metabolic rate [54, 91-93] up to very fast response $\mathrm{VO}_{2}$ max exercise testing $[94,95]$. I.e. with increasing details regarding resolution, response time, environment and interval. However, does modern day equipment, less obvious in manner of working, really performs its task as supposed $[76,96]$ ? There are abundant validation studies that perform both subject tests and technical validation tests, yet nowadays, results are often less favorable when comparing the former to the latter [78].

In individual instances the question will arise if a subject's 'technical' data from a machine can be trusted when showing values outside of the expected 'biological' range. Here the historical context becomes important, as classic research involved known rules of physics and chemistry, capturing and measuring the total of all parameters involved $[5,9,32,33,79,97]$. The term "gold standard" was indeed applicable [98] as all parameters could be, and were, validated.

In Maastricht, from the start in 1982, the approach has been to design and validate both equipment and methods. Starting with the historical and laborious chemical analy- 
sis [79], and continuing the search for fundamental validity of results, both technical and biological, through the years (figure 12).

This fundamental approach, measuring the total of all parameters involved in combination with full range on-site technical and biological validation methods, resulted in this thesis.

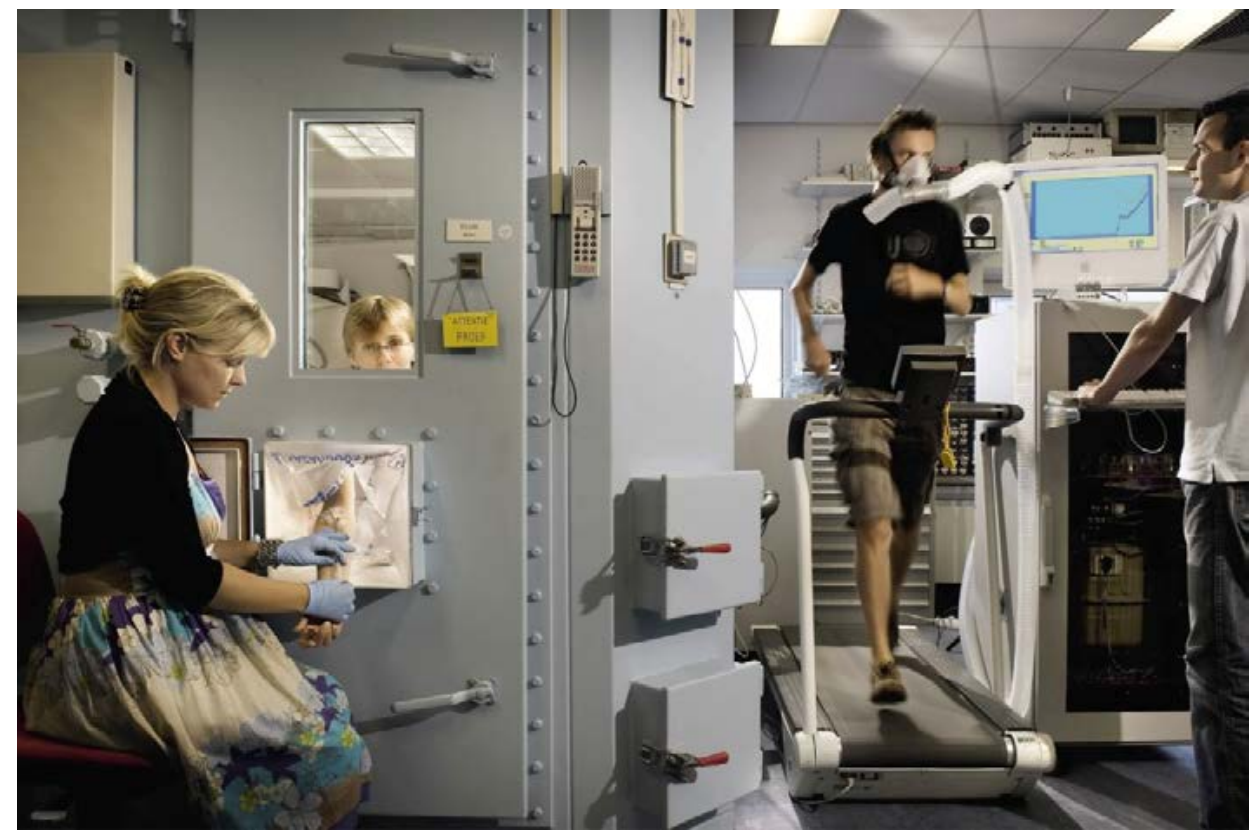

Figure 12. Whole room calorimetry and $\mathrm{VO}_{2}$ max equipment in Maastricht

\section{Objective}

Variability in human EE measurements by means of indirect calorimetry has been shown to have both technical and biological causes, ranging from biased- or unstable technical equipment, to biological variation in human metabolism. Although historical methods may be limited in application, cost, or practical use, a lesson to be learned was to adhere to the unchanging truth of physics where possible. From a "gold standard" perspective this might be deemed the "capture all" concept.

This thesis has the objective to show that biological variation in normal healthy subjects and technical validity can be in agreement regarding magnitude of variability, and that this can be achieved by following the capture all concept with modern day equipment and methods.

A second objective was to emphasize that technical validation methods should be readily available on site, and these should be able to realistically mimic subject responses. A final goal was to build up awareness for some of the pitfalls in indirect calorimetry. 


\section{Thesis outline}

The following chapters define key elements in the measurement of human EE, typically consisting of four stages; theory, implementation, validation and application. These four stages apply to Man- and Machine in a similar fashion for their respective technical and biological background (Table 5).

Table 5, technical and biological pathways and their four typical stages defined for and indirect calorimeter.

\begin{tabular}{lll}
\hline Stage & Machine (technical) & Man (biological) \\
\hline Theory & Physics of measuring gas exchange & Substrate gas exchange \\
Implementation & Indirect calorimeter & Protocol \\
Validation & Independent true-physics tests & Repeated tests \\
Application & Suitability for research target & Research target \\
\hline
\end{tabular}

The two pathways, technical and biological, have typically been followed through these four stages, providing a platform of technical and biological know-how.

This straightforward projection is a simplification as these aspects are interconnected at various levels and will change in description and order over time. For this thesis the projected stages are applicable as a fundamental chain of events to start measuring biological data with validated equipment.

Starting with basics of calorimetry, Chapter 2 focuses on a calorimetric study on the work of walking. Applying a combined direct- and indirect calorimeter; both constructed in Maastricht. The combination of direct- and indirect calorimetry with independent validation showed the ability to measure with near identical results for both classic methods. For indirect calorimetry and its interpretation of chemical substrate gas exchange values, the simultaneous direct measurement of heat validated the interpretative part. Furthermore, an understanding of the concept of internal- and external work was gained.

The validity of interpretative substrate formulae was further investigated in chapter 3, "Utilization of different formulae to calculate substrate oxidation in whole room calorimeters; an updated equation for indirect calorimetry". Historical formulae for converting gas exchange into EE were updated to provide a new formula, and to provide correction factors for variation in protein EE estimates. In addition, the new formula as well as the historical formulae were validated using modern day subject data, appraising the formulae regarding validity. The "Brouwer" equation as used in Chapter 3 with its proven agreement with direct calorimetry was used as the baseline.

In Chapter 4 the technical implementation and validity of two whole room calorimeters is described, comparing validation results with those found in literature. The technical and methodological aspects of this calorimeter system can be considered to be both the foundation and the backbone of indirect calorimetry in Maastricht. Its design was 
used for indirect calorimeters ranging from BMR to VO2max, while applying accurate whole-room gas analysis techniques for full capture calorimeters.

Fulfilling and validating technical requirements, and having evaluated biological theory, proved the whole room calorimeters suitable for research in the field of human EE. In Chapter 5 the lowest EE for a biological "protocol" i.e. overnight- and sleeping metabolic rate was investigated. Providing results on intra-individual variability of SMR in Man. Probably the most commonly used EE level, BMR, was investigated in Chapter 6 . This study showed technical validity, included effects of on-site validation, and described an outpatient protocol for measuring BMR. Results for subjects biological intra-individual variability earned the description "of outstanding interest" [60]. This study was of interest as measurements of BMR using a small calorimeter, i.e. metabolic cart, are nowadays measured in institutions all over the world. In most instances, human variability will be influenced by the fact that subjects slept at home and had to be transported to the laboratory, thereby introducing variability due to activity levels before the measurement can take place. The study provided a realistic target for achievable results. Chapter 7 describes the measurement of the maximum oxygen uptake in humans using indirect calorimetry, following the same four stages as defined above in both a technical and biological sense.

Finally, in chapter 8, "Measurement of respiratory gas exchange: derivation of equations for- and comments on true molar balance in whole room calorimetry" the latest developments in formulae for gas exchange measurements are presented, explicitly adhering to known rules of physics and conforming to SI standards. These new "machine" formulae have recently been adopted for use with whole room indirect calorimeters in Maastricht, Warwick and Singapore, resulting in both practical results and a better understanding of technical processes in indirect calorimetry.

In Chapter 9, the general discussion, variability and validity is discussed for commonly published levels of Human EE. Including aspects of accuracy and precision, both relative and absolute. A few more or less futuristic suggestions for progress in the field of human calorimetry are proposed. 


\section{REFERENCES}

1. Lavoisier, A., Laplace, P.S. de, Memoire sur la chaleur, in Histoire de I'Academie Royale des Sciences (Paris), Annee 1780, avec les Memoires de Mathematique et Physique, . 1780. p. 355-408.

2. Lavoisier, M., Experiences sur la respiration des animaux, et sur les changemens qui arrivent a l'air en passant par leur poumon. Memoires de l'Academie des Sciences de Paris; 1777, 185-194. 1777. 10.

3. Santorio, S., Ars ... de statica medicina, aphorismorum sectionibus septem comprehensa. 1614, Venetiis Italy: Apud Nicolaum Polum. 12 leaves, $84 ; 14 \mathrm{~cm}$.

4. Lehmann, C., et al., Untersuchungen an zwei hungernden Menschen. Von C. Lehmann, F. Mueller, I. Munk, H. Senator, N. Zuntz. 1893. vi, 228.

5. Zuntz, N. and W.A.E.F.D. Schumburg, Studien zu einer Physiologie des Marsches. Bibliothek von Coler Bd. 6. 1901, Berlin: August Hirschwald. viii, 361 pages, 1 unnumbered folded leaf of plates : illustrations ; $22 \mathrm{~cm}$.

6. Atwater, W.O. and F.G. Benedict, A respiration calorimeter with appliances for the direct determination of oxygen. Publication no. 42. 1905, Washington, D.C: Carnegie Institution of Washington. ix, 193 pages, 16 unnumbered leaves of plates : illustrations; $26 \mathrm{~cm}$.

7. Hill, A.V. and A.M. Hill, A self-recording calorimeter for large animals. 1914.

8. Hagemann, O., Das Respirations-Calorimeter in Bonn und einige Untersuchungen mit demeselben bei zwei Rindern und einem Pferde. Landw. Jahrb. Bd. 41, Erg. Bd. 1. 1911, Berlin. 438 : illus., 8 pl. ; 26 cm.

9. Haldane, J., A new form of Apparatus for measuring the Respiratory Exchange of Animals. J Physiol, 1892. 13(5): p. 419-30.

10. Zuntz, N. and C. Lehmann, Remarks on the Chemistry of respiration in the Horse during Rest and Work. J Physiol, 1890. 11(4-5): p. 396-8.

11. Taylor, B.N. and A. Thompson, NIST SPECIAL PUBLICATION 3302008 EDITION. 2008: National Institute of Standards and Technology Gaithersburg, MD 20899.

12. Energy and protein requirements: report of a joint FAO-WHO ad hoc expert committee. Rome, 22 March 2 April 1971. World Health Organ Tech Rep Ser, 1973. 522: p. 1-118.

13. Webb, P., Human Calorimeters. 1985: Greenwood Publishing Group.

14. West, J.B., The collaboration of Antoine and Marie-Anne Lavoisier and the first measurements of human oxygen consumption. Am J Physiol Lung Cell Mol Physiol, 2013. 305(11): p. L775-85.

15. Lavoisier, A.L., Traite elementaire de chimie. 1789, Paris: Cuchet. 2 v. : ill. ; $21 \mathrm{~cm}$.

16. Celsius, A., [Observationer om twänne beständiga grader på en thermometer.] Beobachtungen von zween beständigen Graden auf einem Thermometer. 1742.

17. Pettenkofer, M.^., Ueber einen neuen Respirations-Apparat. Abhandlungen der Bayerischen Akademie der Wissenschaften, Mathematisch-Physikalische Klasse. 1862, München: Verl. der k. Akad. S. 232 - 276, 3 Taf.

18. Ott, I. and M.S. Foster, An improved calorimeter. Contributions to the physiology and pathology of the nervous system Part XI. 1891, Easton: s. n. 4 : ill. ; $22 \mathrm{~cm}$.

19. Atwater, W.O., et al., A respiration calorimeter and experiments on the conservation of energy in the human body. 1897 , s. I.: s. n. 32 : ill. ; $23 \mathrm{~cm}$

20. Marcet, W., et al., A calorimeter for the human body. 1898, London: s. n. 11 : ill. ; $22 \mathrm{~cm}$.

21. Atwater, W.O. and F.G. Benedict, The respiration calorimeter: with the appliances for the direct determination of oxygem. Carnegie Institution of Washington publication no. 42. 1905, Washington, D.C: Carnegie Institution of Washington. 193, 16 leaves of plates : ill. ; $23 \mathrm{~cm}$.

22. Langworthy, C.F. and R.D. Milner, The respiration calorimeter and the results of experiments with it, by C.F. Langworthy and R.D. Milner. From Yearbook, Dept. of agric. 1911, Wash. cm.23.

23. Magnus-Levy, A., Ueber die Grösse des respiratorischen Gaswechsels unter dem Einfluss der Nahrungsaufnahme. Archiv für die gesamte Physiologie des Menschen und der Tiere, 1893. 55(1): p. 1-126.

24. Lusk, G., The elements of the science of nutrition. Ed. 4. ed. 1928, Philadelphia: W. B. Saunders Co.

25. Weir, J.B., New methods for calculating metabolic rate with special reference to protein metabolism. J Physiol, 1949. 109(1-2): p. 1-9. 
26. Cathcart, E.P. and D.P. Cuthbertson, The composition and distribution of the fatty substances of the human subject. J Physiol, 1931. 72(3): p. 349-60.

27. Livesey, G. and M. Elia, Estimation of energy expenditure, net carbohydrate utilization, and net fat oxidation and synthesis by indirect calorimetry: evaluation of errors with special reference to the detailed composition of fuels. Am J Clin Nutr, 1988. 47(4): p. 608-28.

28. Consolazio, C.F., R.E. Johnson, and L.J. Pecora, Physiological Measurements of Metabolic Functions in Man. [By] C. F. Consolazio ... Robert E. Johnson ... Louis J. Pecora. [With illustrations and charts.]. 1963, New York: McGraw-Hill Book Co. ix, 505 ; 8‥

29. Brouwer, E., On simple formulae for calculating the heat expenditure and the quantities of carbohydrate and fat oxidized in metabolism of men and animals, from gaseous exchange (Oxygen intake and carbonic acid output) and urine-N. Acta Physiol Pharmacol Neerl, 1957. 6: p. 795-802.

30. Westerterp, K.R., Energy Expenditure and Intake Methods, in Nutrition Research Methodologies, L.H. Julie A. Lovegrove, Sangita Sharma, Susan A. Lanham-New, Editor. 2015, Wiley-Blackwell.

31. Scholander, P.F., Accurate analysis of respiratory gases in 0.5 cubic centimeter samples. Fed Proc, 1947. 6(1 Pt 2): p. 198.

32. Haldane, J., Some Improved Methods of Gas Analysis. J Physiol, 1898. 22(6): p. 465-80.

33. Atwater, W.O. and F.G. Benedict, A respiration calorimeter. 1905, Washington.

34. Harris, J.A., et al., A biometric study of basal metabolism in man. Carnegie Institution of Washington publication no. 279. 1919, Washington: Carnegie Institution of Washington. vi, 266 : ill. ; $26 \mathrm{~cm}$.

35. Lusk, G., Food Values. Science, 1917. 45(1163): p. 345-50.

36. Webb, P., et al., The work of walking: a calorimetric study. Med Sci Sports Exerc, 1988. 20(4): p. 331-7.

37. Dauncey, M.J., P.R. Murgatroyd, and T.J. Cole, A human calorimeter for the direct and indirect measurement of 24 h energy expenditure. Br J Nutr, 1978. 39(3): p. 557-66.

38. Atwater, W.O., F.G. Benedict, and M.S. Foster, A respiration calorimeter with appliances for the direct determination of oxygen. 1904, S.I: s.n. 24 , with 6 tables : ill. ; $23 \mathrm{~cm}$.

39. Carpenter, T.M., Tables, factors, and formulas for computing respiratory exchange and biological transformations of energy : prepared by Thorne M. Carpenter. Carnegie Institution of Washington publication 303C. 1948, Washington, D.C: Carnegie Institution of Washington.

40. Frayn, K.N., Calculation of substrate oxidation rates in vivo from gaseous exchange. J Appl Physiol Respir Environ Exerc Physiol, 1983. 55(2): p. 628-34.

41. Webb, P., The measurement of energy exchange in man: an analysis. Am J Clin Nutr, 1980. 33(6): p. 1299-310.

42. Webb, P., J.F. Annis, and S.J. Troutman, Jr., Energy balance in man measured by direct and indirect calorimetry. Am J Clin Nutr, 1980. 33(6): p. 1287-98.

43. Kenny, G.P., et al., Calorimetric measurement of postexercise net heat loss and residual body heat storage. Med Sci Sports Exerc, 2008. 40(9): p. 1629-36.

44. Kenny, G.P., et al., Heat balance and cumulative heat storage during intermittent bouts of exercise. Med Sci Sports Exerc, 2009. 41(3): p. 588-96.

45. Speakman, J.R. and C. Hambly, Using doubly-labelled water to measure free-living energy expenditure: Some old things to remember and some new things to consider. Comp Biochem Physiol A Mol Integr Physiol, 2016.

46. Westerterp, K.R., et al., Energy expenditure climbing Mt. Everest. J Appl Physiol (1985), 1992. 73(5): p. 1815-9.

47. Speakman, J.R., Principles, problems and a paradox with the measurement of energy expenditure of freeliving subjects using doubly-labelled water. Stat Med, 1990. 9(11): p. 1365-80.

48. Westerterp, K.R., et al., Comparison of doubly labeled water with respirometry at low-and high-activity levels. J Appl Physiol (1985), 1988. 65(1): p. 53-6.

49. Speakman, J.R., Calculation of CO2 production in doubly-labelled water studies. J Theor Biol, 1987. 126(1): p. 101-4.

50. Schoeller, D.A. and P.B. Taylor, Precision of the doubly labelled water method using the two-point calculation. Hum Nutr Clin Nutr, 1987. 41(3): p. 215-23. 
51. Westerterp, K.R., Physical activity and physical activity induced energy expenditure in humans: measurement, determinants, and effects. Front Physiol, 2013. 4: p. 90.

52. Westerterp, K.R. and A.D. Kester, Physical activity in confined conditions as an indicator of free-living physical activity. Obes Res, 2003. 11(7): p. 865-8.

53. Claessens-van Ooijen, A.M., et al., Heat production and body temperature during cooling and rewarming in overweight and lean men. Obesity (Silver Spring), 2006. 14(11): p. 1914-20.

54. Schols, A.M., et al., Measurement of resting energy expenditure in patients with chronic obstructive pulmonary disease in a clinical setting. JPEN J Parenter Enteral Nutr, 1992. 16(4): p. 364-8.

55. Plasqui, G. and K.R. Westerterp, Seasonal variation in total energy expenditure and physical activity in Dutch young adults. Obes Res, 2004. 12(4): p. 688-94.

56. Plasqui, G., A.D. Kester, and K.R. Westerterp, Seasonal variation in sleeping metabolic rate, thyroid activity, and leptin. Am J Physiol Endocrinol Metab, 2003. 285(2): p. E338-43.

57. Dugas, L.R., et al., Total daily energy expenditure in black and white, lean and obese South African women. Eur J Clin Nutr, 2009. 63(5): p. 667-73.

58. van Dale, D., et al., Effects of addition of exercise to energy restriction on 24-hour energy expenditure, sleeping metabolic rate and daily physical activity. Eur J Clin Nutr, 1989. 43(7): p. 441-51.

59. Van Dale, D., et al., Does exercise give an additional effect in weight reduction regimens? Int J Obes, 1987. 11(4): p. 367-75.

60. Donahoo, W.T., J.A. Levine, and E.L. Melanson, Variability in energy expenditure and its components. Curr Opin Clin Nutr Metab Care, 2004. 7(6): p. 599-605.

61. Blaak, E.E. and W.H. Saris, Postprandial thermogenesis and substrate utilization after ingestion of different dietary carbohydrates. Metabolism, 1996. 45(10): p. 1235-42.

62. Webb, P., Daily activity and body temperature. Eur J Appl Physiol Occup Physiol, 1993. 66(2): p. 174-7.

63. Fredrix, E.W., et al., Resting energy expenditure in patients with non-small cell lung cancer. Cancer, 1991. 68(7): p. 1616-21.

64. Fredrix, E.W., et al., Effect of different tumor types on resting energy expenditure. Cancer Res, 1991. 51(22): p. 6138-41.

65. Fredrix, E.W., et al., Resting energy expenditure in cancer patients before and after gastrointestinal surgery. JPEN J Parenter Enteral Nutr, 1991. 15(6): p. 604-7.

66. Fredrix, E.W., et al., Resting and sleeping energy expenditure in the elderly. Eur J Clin Nutr, 1990. 44(10): p. 741-7.

67. Brouns, F., et al., Eating, drinking, and cycling. A controlled Tour de France simulation study, Part I. Int J Sports Med, 1989. 10 Suppl 1: p. S32-40.

68. Westerterp-Plantenga, M.S., et al., Sex differences in energy homeostatis following a diet relatively high in protein exchanged with carbohydrate, assessed in a respiration chamber in humans. Physiol Behav, 2009. 97(3-4): p. 414-9.

69. Smeets, A.J. and M.S. Westerterp-Plantenga, Acute effects on metabolism and appetite profile of one meal difference in the lower range of meal frequency. Br J Nutr, 2008. 99(6): p. 1316-21.

70. Westerterp-Plantenga, M.S., et al., High protein intake sustains weight maintenance after body weight loss in humans. Int J Obes Relat Metab Disord, 2004. 28(1): p. 57-64.

71. Lejeune, M.P., E.M. Kovacs, and M.S. Westerterp-Plantenga, Effect of capsaicin on substrate oxidation and weight maintenance after modest body-weight loss in human subjects. Br J Nutr, 2003. 90(3): p. 651-59.

72. Proctor, D.N. and K.C. Beck, Delay time adjustments to minimize errors in breath-by-breath measurement of Vo2 during exercise. J Appl Physiol (1985), 1996. 81(6): p. 2495-9.

73. Yamamoto, Y., et al., Breath-by-breath measurement of alveolar gas exchange with a slow-response gas analyser. Med Biol Eng Comput, 1987. 25(2): p. 141-6.

74. Noguchi, H., et al., Breath-by-breath VCO2 and VO2 required compensation for transport delay and dynamic response. J Appl Physiol Respir Environ Exerc Physiol, 1982. 52(1): p. 79-84.

75. Wessel, H.U., et al., Breath-by-breath variation of FRC: effect on VO2 and VCO2 measured at the mouth. J Appl Physiol Respir Environ Exerc Physiol, 1979. 46(6): p. 1122-6. 


\section{Chapter 1}

76. Perret, C. and G. Mueller, Validation of a new portable ergospirometric device (Oxycon Mobile) during exercise. Int J Sports Med, 2006. 27(5): p. 363-7.

77. Larsson, P.U., et al., Validation of the MetaMax I/ portable metabolic measurement system. Int J Sports Med, 2004. 25(2): p. 115-23.

78. Prieur, F., J. Castells, and C. Denis, A methodology to assess the accuracy of a portable metabolic system (VmaxST). Med Sci Sports Exerc, 2003. 35(5): p. 879-85.

79. Schoffelen, P.F.M., Evaluation of an automatic indirect calorimeter for measurement of energy balance in man, in European Nutrition Report No 5., A.J.H. van Es Editor. 1985: The Hague, The Netherlands: Koninklijke Bibliotheek. p. 51-54.

80. Nguyen, T., et al., Chamber for indirect calorimetry with accurate measurement and time discrimination of metabolic plateaus of over 20 min. Med Biol Eng Comput, 2003. 41(5): p. 572-8.

81. Schoffelen, P.F., et al., A dual-respiration chamber system with automated calibration. J Appl Physiol (1985), 1997. 83(6): p. 2064-72.

82. Seale, J.L., W.V. Rumpler, and P.W. Moe, Description of a direct-indirect room-sized calorimeter. Am J Physiol, 1991. 260(2 Pt 1): p. E306-20.

83. Minghelli, G., et al., Twenty-four-hour energy expenditure and basal metabolic rate measured in a wholebody indirect calorimeter in Gambian men. Am J Clin Nutr, 1990. 51(4): p. 563-70.

84. Charbonnier, A., et al., A whole body transportable indirect calorimeter for human use in the tropics. Eur J Clin Nutr, 1990. 44(10): p. 725-31.

85. Ravussin, E., et al., Determinants of 24-hour energy expenditure in man. Methods and results using a respiratory chamber. J Clin Invest, 1986. 78(6): p. 1568-78.

86. Jequier, E. and Y. Schutz, Long-term measurements of energy expenditure in humans using a respiration chamber. Am J Clin Nutr, 1983. 38(6): p. 989-98.

87. Dauncey, M.J. and P.R. Murgatroyd, A direct and indirect calorimeter for studies on energy expenditure in man over $24 \mathrm{~h}$ periods [proceedings]. J Physiol, 1978. 284: p. 7P-8P.

88. Sauer, P.J., H.J. Dane, and H.K. Visser, Longitudinal studies on metabolic rate, heat loss, and energy cost of growth in low birth weight infants. Pediatr Res, 1984. 18(3): p. 254-9.

89. Meis, S.J., et al., A gradient-layer calorimeter for measurement of energy expenditure of infants. Am J Physiol, 1994. 266(3 Pt 2): p. R1052-60.

90. Moon, J.K., C.L. Jensen, and N.F. Butte, Fast-response whole body indirect calorimeters for infants. J Appl Physiol (1985), 1993. 74(1): p. 476-84.

91. Adriaens, M.P., P.F. Schoffelen, and K.R. Westerterp, Intra-individual variation of basal metabolic rate and the influence of daily habitual physical activity before testing. Br J Nutr, 2003. 90(2): p. 419-23.

92. Visser, M., et al., Resting metabolic rate and diet-induced thermogenesis in young and elderly subjects: relationship with body composition, fat distribution, and physical activity level. Am J Clin Nutr, 1995. 61(4): p. 772-8

93. Weststrate, J.A., Resting metabolic rate and diet-induced thermogenesis: a methodological reappraisal. Am J Clin Nutr, 1993. 58(5): p. 592-601.

94. Rietjens, G.J., et al., Validation of a computerized metabolic measurement system (Oxycon-Pro) during low and high intensity exercise. Int I Sports Med, 2001. 22(4): p. 291-4.

95. Prieur, F., et al., Validity of oxygen uptake measurements during exercise under moderate hyperoxia. Med Sci Sports Exerc, 1998. 30(6): p. 958-62.

96. Littlewood, R.A., et al., Comparison of the Cosmed $K 4 \mathrm{~b}(2)$ and the Deltatrac II metabolic cart in measuring resting energy expenditure in adults. Clin Nutr, 2002. 21(6): p. 491-7.

97. McLean, J.A. and P.R. Watts, Analytical refinements in animal calorimetry. J Appl Physiol, 1976. 40(5): p. 827-31.

98. Versi, E., "Gold standard" is an appropriate term. BMJ, 1992. 305(6846): p. 187. 




\section{Chapter}

\section{The work of walking: a calorimetric study}

WEBB, P., W. H. M. SARIS, P. F. M. SCHOFFELEN, G. J. VAN INGEN SCHENAU, and F. TEN HOOR. The work of walking: a calorimetric study. Med. Sci. Sports Exerc., Vol. 20, No. 4, pp. 331-337, 1988. 


\section{ABSTRACT}

Experiments were designed to test the traditional assumption that during level walking all of the energy from oxidation of fuel appears as heat and no work is done. Work is force expressed through distance, or energy transferred from a man to the environment, but not as heat. While wearing a suit calorimeter in a respiration chamber, five women and five men walked for 70 to 90 min on a level treadmill at 2.5, 4.6, and 6.7 $\mathrm{km} \bullet \mathrm{h}^{-1}$ and pedaled a cycle ergometer for 70 to 90 min against 53 and $92 \mathrm{~W}$ loads, they also walked with a weighted backpack and against a horizontal load. During cycling, energy from fuel matched heat loss plus the power measured by the ergometer. During walking, however, energy from fuel exceeded that which appeared as heat, meaning that work was done. The power increased with walking speed; values were 14, 29, and $63 \mathrm{~W}$, which represented 11,12 , and $13 \%$ of the incremental cost of fuel above the resting level. Vertical and horizontal loads increased the fuel cost and heat loss of walking but did not alter the power output. This work energy did not re-appear as thermal energy during $18 \mathrm{~h}$ of recovery. The most likely explanation of the work done is in the inter-action between the foot and the ground, such as compressing the heel of the shoe and bending the sole. We conclude that work is done in level walking. 


\section{INTRODUCTION}

Work, heat, and fuel are the energy terms of interest in exercise, heat and fuel being measurable by calorimetric techniques. In walking, man's most common exercise, the traditional analysis is biomechanical (e.g., 5, 8-10, 12, 25) and assumes that the work done in level walking is all internal, and that therefore all of the energy from the oxidation of fuel will appear as heat. Using the strict definition of work, force applied over distance, and considering a person as a system with boundaries at the skin, it is not obvious that during level walking on a hard surface any work is done. Snellen (19) showed that energy from fuel during treadmill walking appeared as evaporative heat loss when other avenues of heat loss were blocked. But as far as we can discover, the assumption of zero work output has never been tested with a direct calorimeter. Despite an early promise by Benedict and Carpenter (4), who wrote in 1910 that a special calorimeter was being constructed around a treadmill, neither they nor subsequent calorimetrists (22) have directly measured the heat produced by people walking. Perhaps the reason is that the heat produced by a treadmill is large and interferes with the measurement of heat produced by the subject. This difficulty is circumvented by a calorimeter made as a suit of clothing (24), which keeps any exercise equipment external to the heat measuring apparatus.

Early studies with water-cooled suits $(21,23)$, which were largely aimed at developing methods of controlling their potent cooling power, mentioned that heat loss during walking on a treadmill was usually less than the energy from oxidation of fuel, but that during cycle ergometer exercise, energy in fuel was essentially equal to heat loss plus work done. This observation of energy balance during cycling repeated what has been consistently demonstrated with human calorimeters, since the studies of Atwater and Benedict (2) at the turn of the century. But the extra energy which would be needed to add to heat loss during walking in order to match energy from fuel, if verified in more rigorous settings, raised the possibility that there might be classical work done in level walking.

Water-cooled suits were developed into suit calorimeters $(13,24)$. In the present study, using the suit calorimeter with recently improved instrumentation and a newly built metabolic chamber for measuring respiratory gas exchange, we returned to the matter of the energetics of walking on a level treadmill. Experiments designed to establish whether or not there is work in level walking were as follows: (i) walking on a motordriven treadmill at three different speeds while measuring metabolic expenditure (oxidation of fuel), heat loss, and heat storage; ii) as a control, the same measurements were taken while subjects exercised on a cycle ergometer with measured power output, during which they maintained about the same level of metabolic expenditure as in the two higher walking speeds; iii) since much of the energy from fuel during walking is spent for repeatedly raising the body mass against gravity (net power zero), subjects walked with added weight to see if this would change the possible work of walking; and 
iv) subjects also walked against a load in the horizontal direction, a measured power output, to see how this affected the possible work of walking.

\section{Terminology}

The movements powered by the oxidation of fuel are used for external and internal work. External work is work done on the environment. Internal work is used, for example, to change the kinetic energy of body segments; it appears as heat to be dissipated. We here limit the use of the word work to external work, considering man as a system bounded by his skin. Work is force expressed through distance; another definition of work (6) is the transfer of energy from the body to an external system (not as heat). Using this strict definition of work, a man who does work over time delivers power, as is true for any engine. From the law of conservation of energy, energy from the oxidation of fuel equals the sum of heat loss, work, and body heat storage:

$$
\dot{Q} M=\dot{Q} H L+\dot{Q} W+\dot{Q} \Delta H
$$

where $\dot{Q}$ is power (the rate of change of energy) in watts and the subsequent letters are: $\mathrm{M}$ for metabolic expenditure; $\mathrm{HL}$ for heat loss; $\mathrm{W}$ for work (external work, useful work, positive and negative work); and $\Delta \mathrm{H}$ for change in body heat content.

In the experiments reported here, equation 1 is solved for $\dot{Q} W$, since all of the other terms are measured. The measured power in cycling exercise $\left(\dot{Q} W_{c y}\right)$ and that of pulling a horizontal load $\left(\dot{Q} W_{\text {hld }}\right)$ are distinguished from the possible power of walking $\left(\dot{Q} W_{w l k}\right)$. When a given exercise has continued long enough for body temperatures to stabilize, heat storage becomes negligibly small and power is found by:

$$
\dot{Q} W_{c y}=\dot{Q} M-\dot{Q} H L
$$

and

$$
\dot{Q} W_{w l k}=\dot{Q} M-\dot{Q} H L-\dot{Q} W_{h l d}
$$

\section{METHODS}

To measure the terms of equation 1, subjects wore a suit calorimeter in a respiration chamber while walking and cycling and during recovery from exercise.

\section{The respiration chamber}

The chamber (17) is a sealed space for measuring oxygen uptake and carbon dioxide output. It was equipped with a motor-driven treadmill, a cycle ergometer, a platform scale, air locks for transferring food and waste, and items needed to make long stays 
possible, such as a bed, table, television set, radio, telephone, intercom, and selfcontained toilet.

A stream of fresh outdoor air was drawn through the chamber by maintaining an underpressure of $0.2 \mathrm{kPa}$ inside; the air volume was measured downstream from the chamber by calibrated dry gas meters accurate to $0.5 \%$. The air was sampled upstream and downstream of the chamber and the samples analyzed in a paramagnetic oxygen analyzer (Taylor Servomex) and an infrared carbon dioxide analyzer (Hartmann and Braun). The analyzers were checked every 30 min with zero gas, span gas, and air. The throughflow of air was constant at about $701 \cdot \mathrm{min}^{-1}$ while the subjects rested and about $1501 \cdot \mathrm{min}^{-1}$ during exercise. This flow through the $14 \mathrm{~m}^{3}$ volume of the chamber kept the carbon dioxide level between 0.5 and 1.0\%. Oxygen uptake and carbon dioxide output were calculated from the gas analyzer and air flow data, then converted to energy units by the method of Brouwer (7). Oxygen uptake and carbon dioxide output were calculated every $10 \mathrm{~min}$, using mathematical procedures similar to those proposed by McLean and Watts (14) to quicken measurements despite a large chamber volume. There was a second, independent system for gas analysis consisting of a separate sampling system and chemical analysis. In columnar glass tubes with mercury-sealed pistons, samples were taken of chamber gas at the beginning and end of experimental periods of interest, and during such periods small incremental samples were drawn into other glass columns. The gases were analyzed in a modified Haldane (Sonden) apparatus. Agreement between the chemical system and the one based on electronic gas analyzers was generally within $1 \%$ (range 0 to $3 \%$ ).

Temperature in the chamber was regulated at $25^{\circ} \pm 2^{\circ} \mathrm{C}$, vapor pressure at $1.6 \pm 0.3$ $\mathrm{kPa}$, and air speed below $0.1 \mathrm{~m} \bullet \mathrm{sec}^{-1}$. However, the subject experienced a different microenvironment, that imposed by the suit calorimeter.

\section{The suit calorimeter}

The subject wears a close-fitting elastic undergarment which carries a network of small plastic tubing over the entire body surface, except for the face, fingers, and soles of the feet (22). Water circulated through the tubing carries heat from the skin, which is measured as the product of mass flow of water and the change in water temperature across the suit. Three layers of insulating garments limit the exchange of heat with the environment to a small and known quantity. Any heat flow through the shoes was small because subjects in the present study wore thick socks and rubber-soled jogging shoes; cooling tubes were laid over the shoe tops and insulated with an overlying thick woolen sock.

The suit calorimeter was improved in two ways for the present experiments. First, extra cooling tubes were added to the thigh and calf areas to increase cooling capacity over the major muscles of the leg. Second, the accuracy of measuring the change in water temperature across the suit was improved from the previous level of $0.02^{\circ}$ to $0.002^{\circ} \mathrm{C}$, 
through the use of individually characterized thermistors (Yellow Springs Instrument Co.), which were pre-aged and glass-coated for stability.

Transducers were read with a microprocessor-based 6.5 digit voltohmeter with sequencing and A/D conversion (TAC-CAT, CompuDas) connected to a computer (IBM PC). The accuracy of measuring heat in the water stream was calculated to be $0.1 \%$ of reading, Water temperatures and flow were measured once per minute, then averaged and recorded every 5 min.

In addition to heat taken up by the suit, other avenues of heat loss included evaporative loss from skin and from respiration, convective losses from the face and from respiration, and heat transfer through the insulated clothing layers. Evaporative water loss was known from body weight change, corrected for intake and output of solids and liquids, and for the mass difference between oxygen intake and carbon dioxide output. An electronic platform scale (Sauter) with a capacity of $150 \mathrm{~kg}$ and an accuracy of $5 \mathrm{~g}$ allowed periodic weighing of the clothed subject. Food and waste in containers were either kept on the platform or were weighed separately on a laboratory scale accurate to $0.1 \mathrm{~g}$. Convective heat loss from the face was calculated from the skin area exposed, the gradient between skin and air temperature, and the heat transfer coefficient for free convection. Respiratory convective heat loss was calculated from the relationship between inspired and expired air temperatures and the respiratory minute volume, which had been determined for each subject at several levels of $\dot{Q} M$. Heat transfer through the heavy clothing insulation ( $3,8 \mathrm{clo}$ ) was calculated from equations derived from testing with an electrically heated mannequin and based on skin and air temperatures.

\section{Body heat content}

Change in body heat content was calculated, from changes in rectal and mean skin temperatures, using weighting coefficients of 0.67 and 0.33 , respectively (6). Skin temperatures were measured with five thermistors sewn into the water-cooled undergarment, and located over the biceps, kidney, abdomen, thigh, and calf. Rectal temperature was measured by a thermistor inserted $10 \mathrm{~cm}$ past the anal sphincter. Body temperatures were read and recorded every $5 \mathrm{~min}$.

\section{Procedures}

The procedure for an experiment with alternating walking and cycling started with the subject coming to the laboratory after supper and donning the suit calorimeter in the respiration chamber. The chamber was sealed and data collection began at 21:00. The subject stayed quiet, then slept in bed from 23:30 to 07:00, Following breakfast, a 6-h exercise session began at 09:00, Half the subjects walked at $4.6 \mathrm{~km} \bullet \mathrm{h}^{-1}$ for 90 min on a motor-driven treadmill (Quinton Instrument Co.), then pedaled an electrically braked cycle ergometer (Lode) at about $70 \mathrm{rpm}$ against a $53 \mathrm{~W}$ load for $90 \mathrm{~min}$, then repeated 
the walking and cycling. Zero grade for the treadmill was checked with an accurate level. The other half of the subjects followed the same routine but cycled first, then walked. Metabolic energy expenditure for these two exercises had been established previously as being about $400 \mathrm{~W}$. During the $6 \mathrm{~h}$ of exercise, subjects ate freely from snack foods, such as fruit, candy bars, orange juice, grain bars, and a flavored water drink containing carbohydrate at $3 \mathrm{~kJ} \mathrm{ml}^{-1}$ (Perform, Wander). They were urged to keep fluid and energy intakes high, to roughly match the losses produced by the exercise. Following the exercise, subjects remained in the suit in the chamber for the rest of the afternoon and evening, and slept for a second night. After being awakened at 07:00, they had breakfast and stayed quiet until 09:00. A second exercise period lasting 5 to 6 $\mathrm{h}$ followed. It included walking at 2.5 and $4.7 \mathrm{~km} \bullet \mathrm{h}^{-1}$ against a horizontal load, walking $4.6 \mathrm{~km} \bullet \mathrm{h}^{-1}$ with a weighted backpack, and cycling at about $70 \mathrm{rpm}$ against a $92 \mathrm{~W}$ load. Total time in the suit and chamber was $42 \mathrm{~h}$.

For vertical loading, subjects wore a hiker's backpack filled with enough weight to increase clothed body weight by $10 \%$ for the women and $20 \%$ for the men. For loading of the horizontal component of walking, subjects were pulled backwards as they walked by means of a torso harness with a rope leading back to a pulley and a hanging weight (Fig. 1). Walking with the backward pull force was done at two velocities, 2.5 and $4.7 \mathrm{~km} \bullet \mathrm{h}^{-1}$; a larger weight was used at the slower speed, such that at both speeds the pulling force caused a power output between 75 and $83 \mathrm{~W}$, with a mean of $80 \mathrm{~W}$. These weights were individually determined for each subject in preliminary testing so as to cause a metabolic expenditure of about $600 \mathrm{~W}$. Walking against the backward pull is working similar to that of pulling a weight across the ground.

In a second procedure, which examined the energetics of walking at three speeds, subjects came to the laboratory after breakfast. After donning the suit in the chamber, they rested quietly for 1 to $1.5 \mathrm{~h}$. At 10:00, a 6-h exercise period began. First there was a 2-h walk at a slow $2.5 \mathrm{~km} \bullet \mathrm{h}^{-1}$ (1.55 mph). After $15 \mathrm{~min}$ of rest, there was $105 \mathrm{~min}$ of walking at $4.6 \mathrm{~km} \bullet \mathrm{h}^{-1}$ (2.86 $\mathrm{mph}$ ), then another $15 \mathrm{~min}$ of rest. 


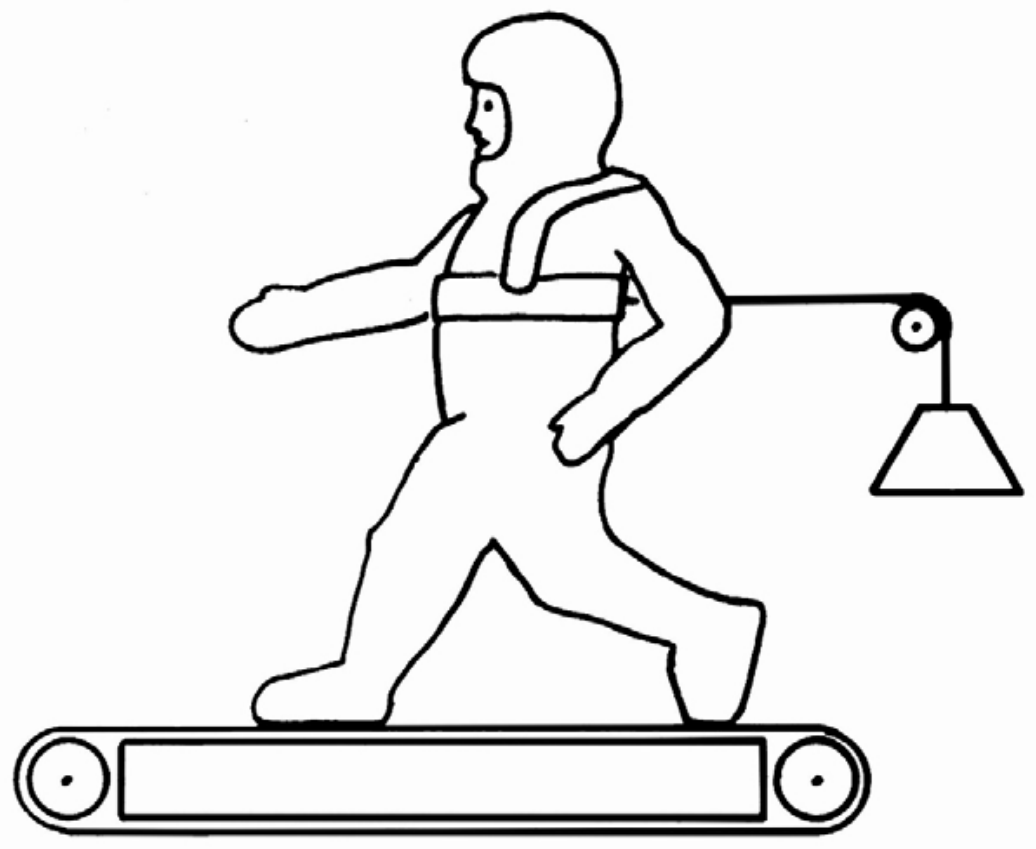

Figure 1 Subject in the suit calorimeter walking on the treadmill against the horizontal load imposed by a weight.

The final exercise was 90 min of walking at a brisk $6.7 \mathrm{~km} \bullet \mathrm{h}^{-1}$ (4.16 mph). Subjects ate frequently from snack foods and the high carbohydrate drink. The schedule of the two procedures is displayed in Figure 2, along with a typical heat loss curve.

\section{Steady-state values of expenditure and heat loss}

Plateaus appeared in the computer display of $\dot{Q} H L$, starting 25 to $40 \mathrm{~min}$ after the onset of a new exercise, except that the first exercise of a series took 40 to 60 min for the plateau to begin. At the same time, body temperatures became stable. Plateaus in $\dot{Q} M$ occurred much earlier than those of $\dot{Q} H L$ and body temperatures. During these plateaus, steady-state data for $\dot{Q} M$ and $\dot{Q} H L$ were computed by averaging the 10- and 5min data points. The criteria for determining the plateau when an average could be computed were: i) rectal temperature which varied no more than $0.1^{\circ} \mathrm{C}$ and mean skin temperature. which varied no more than $0.2^{\circ} \mathrm{C}$; and ii) values for $\dot{Q} M$ and $\dot{Q} H L$ which varied by no more than $5 \%$. 


\section{Subjects}

Five women and five men volunteered to participate in response to an advertisement in the university newspaper. Those selected were the larger and more athletic individuals. Mean characteristics for the women were: age, $23 \mathrm{y}$; height, $177 \mathrm{~cm}$; weight, $65 \mathrm{~kg}$; clothed weight, $73 \mathrm{~kg}$; and body fat, $24 \%$ of weight. Mean characteristics for the men were: age, 22 y; height, $179 \mathrm{~cm}$; weight, $70 \mathrm{~kg}$; clothed weight, $78 \mathrm{~kg}$; and body fat, 13\% of weight. One woman was a well-conditioned distance runner currently in training. The other subjects enjoyed bicycling, hiking, soccer, and similar activities. All were able to complete the assigned exercise schedules.

Subjects were fully informed of the procedures and measurements to be taken, and they freely consented to undertake the experiments. The procedures had been approved by the university's ethical committee.

\section{RESULTS}

The principal data are the steady-state values for metabolic expenditure and heat loss for the 10 subjects, as given in Table 1. Also listed are the work rates imposed by the horizontal load and the cycle ergometer. The fourth column, $\dot{Q} W_{w l k}$, lists values found by solving equation 3 and the next column to the right shows that all of these were significantly different from zero except for the value $\dot{Q} W_{w l k}=1$ during walking at 2,5 $\mathrm{km} \cdot \mathrm{h}^{-1}$ with the horizontal load.

Putting the energy terms measured during cycling into equation 2 showed that energy balance was realized with only small errors of 6 and $-6 \mathrm{~W}$ for the 53 and $92 \mathrm{~W}$ loads, respectively.

Figures 3 and 4 illustrate energy balance with pairs of bars, in which the left-hand bar is metabolic expenditure, and the right-hand bar is the sum of the heat loss and power terms. Figure 3 shows that metabolic expenditure is matched by heat loss plus power during rest and cycling, but during walking, to account for the difference between metabolic expenditure and heat loss there must be increasing power at increasing speed. This is shown by the clear areas at the tops of the right-hand bars for the three walking exercises. Figure 4 compares loaded and unloaded walking at two speeds. In 4 of 5 cases, power terms similar to those in Figure 3 complete the energy balance, as shown by the clear areas atop the right-hand bars, and these are not influenced by either vertical or horizontal loads. 

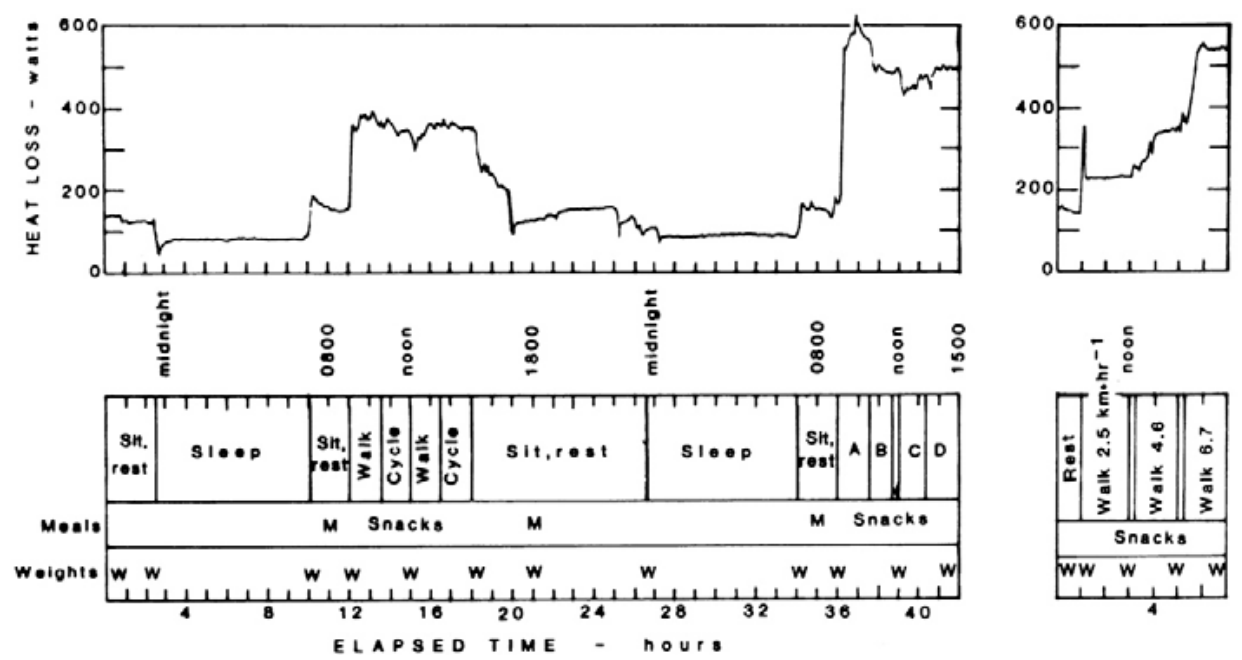

Figure $2 \mathrm{~A}$ recording of heat loss measured by the suit calorimeter from subject $\mathrm{M}-21$ during the $42 \mathrm{~h}$ of the first procedure and the $7 \mathrm{~h}$ of the second, showing also: his major activities; when he ate meals (M); and when he was weighed (W). Walking in the first exercise session was at $4.6 \mathrm{~km} \bullet \mathrm{h}^{-1}$, level and cycling was at $53 \mathrm{~W}$. At the end of the first procedure, the letters $A, B, C$, and D stand for walking $4.7 \mathrm{~km} \bullet \mathrm{h}^{-1}$ with an $80 \mathrm{~W}$ horizontal load, cycling with a $92 \mathrm{~W}$ load, walking $4.6 \mathrm{~km} \bullet \mathrm{h}^{-1}$ with a vertical load, and walking at $2.5 \mathrm{~km} \bullet \mathrm{h}^{-1}$ with an $80 \mathrm{~W}$ horizontal load.

Table 1 Steady-state values for energy terms during walking and cycling exercises.

\begin{tabular}{|c|c|c|c|c|c|c|}
\hline & $\dot{Q M}$ & $\dot{Q} H L$ & $\dot{Q} W_{\text {hld }}$ & $\dot{Q} W_{w l k}$ & $P^{*}$ & $\dot{Q} W_{c y}$ \\
\hline Walk $2.5 \mathrm{~km} \bullet \mathrm{h}^{-1}$ & $239 \pm 8$ & $225 \pm 9$ & & $14 \pm 6$ & 0.02 & \\
\hline Walk $2.5 \mathrm{~km} \bullet \mathrm{h}^{-1}$ with horizontal load & $535 \pm 8$ & $455 \pm 12$ & 80 & $1 \pm 11$ & NS & \\
\hline Walk $4.6 \mathrm{~km} \bullet \mathrm{h}^{-1}$ & $364 \pm 8$ & $335 \pm 9$ & & $29 \pm 3$ & 0.00001 & \\
\hline Walk $4.6 \mathrm{~km} \bullet \mathrm{h}^{-1}$ with vertical load & $435 \pm 13$ & $407 \pm 11$ & & $28 \pm 7$ & 0.001 & \\
\hline Walk $4.7 \mathrm{~km} \bullet \mathrm{h}^{-1}$ with horizontal load & $610 \pm 13$ & $491 \pm 13$ & 80 & $39 \pm 12$ & 0.006 & \\
\hline Walk $6.7 \mathrm{~km} \bullet \mathrm{h}^{-1}$ & $601 \pm 22$ & $538 \pm 19$ & & $63 \pm 8$ & 0.0005 & \\
\hline Cycle with $53 \mathrm{~W}$ load & $399 \pm 11$ & $340 \pm 11$ & & & & 53 \\
\hline Cycle with 92 W load & $548 \pm 27$ & $462 \pm 14$ & & & & 92 \\
\hline
\end{tabular}

Means $\pm S E$, in watts.

*Probability that the value differs from zero (NS = non-significant difference). 


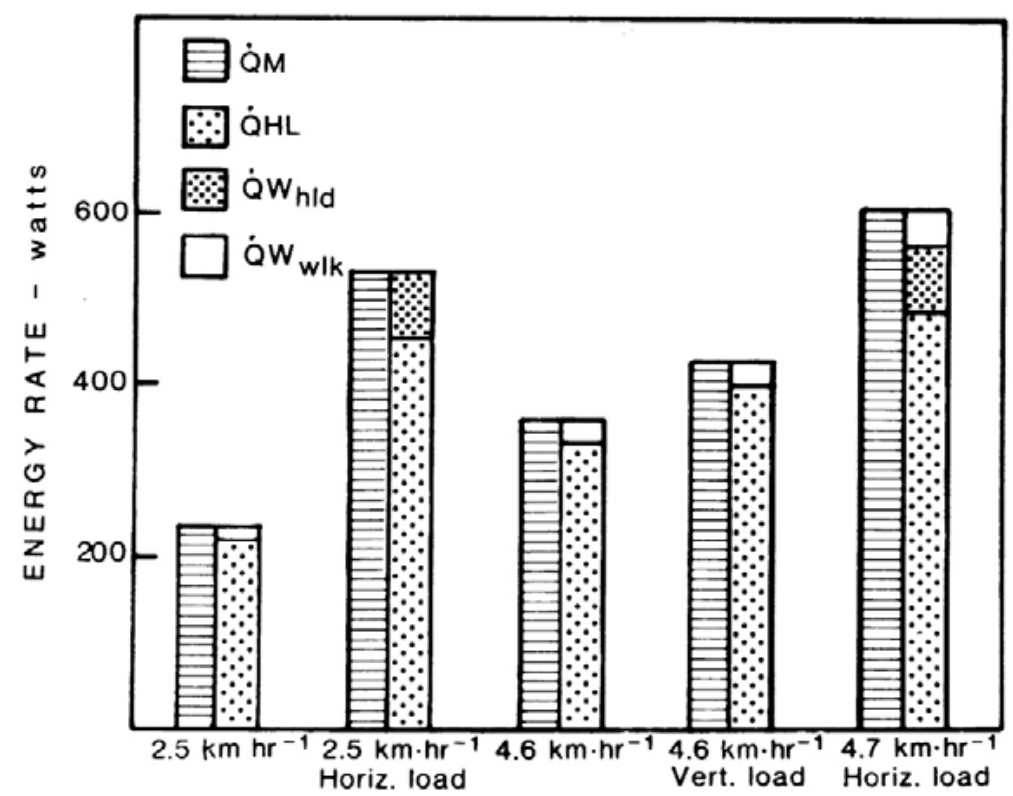

Figure 3 Bar graph of energy balance during various activities. The left-hand bar of each pair is metabolic expenditure rate, $\dot{Q} M$. The right-hand bar shows the sums of heat loss, $\dot{Q} H L$, and power. The clear areas atop the right-hand bars in the three walking exercises demonstrate the power term that completes the energy balance.

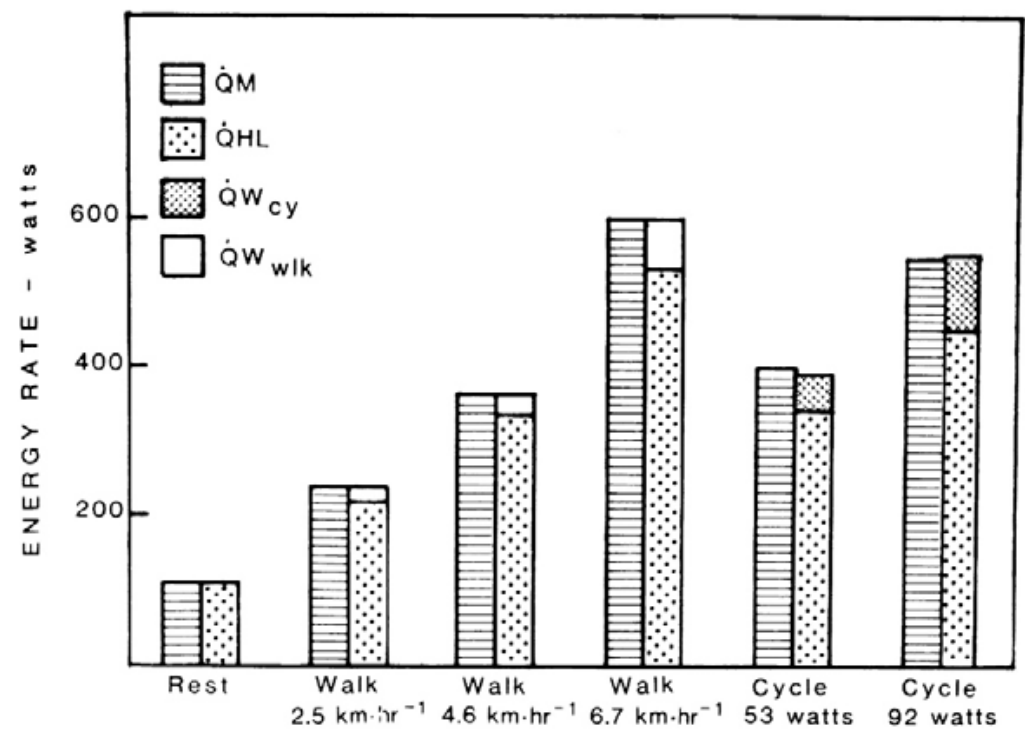

Figure 4 Bar graph of energy balance during loaded and unloaded walking. As in Fig. 3, the clear areas atop the right-hand bars demonstrate the power expended in level walking. 
The proportion of fuel which was used for power in walking was found by subtracting the daytime resting energy expenditure of $115 \mathrm{~W}$ from the total expenditure at the three walking speeds. Thus, the 14,29 , and $63 \mathrm{~W}$ represent 11,12 , and $13 \%$ of the increment of fuel needed for unloaded walking at the three speeds.

\section{DISCUSSION}

The values for $\dot{Q} W_{w l k}$ shown in Table 1, and in Figures 3 and 4, are clear calorimetric evidence that there is work done in walking, that is, that there is energy leaving the system not as heat. At the same time, energy balance appeared with only small error ( $\pm 6 \mathrm{~W}$ ) during cycling exercise, which demonstrates the validity of the calorimetric methods used.

It might be argued that $\dot{Q} W_{w l k}$ represents energy which is somehow stored in the body, to reappear as extra heat during recovery. This possibility was examined by a study of the recovery data following the first exercise session with alternate walking and cycling. The following are total energies in $\mathrm{kJ}$, means \pm SE for 10 subjects, after corrections for changes in heat storage had been made: in $6 \mathrm{~h}$ of exercise, $\dot{Q} M=8,568 \pm 220$ and $\dot{Q} H L=7,684$ \pm 111 ; in $18 \mathrm{~h}$ of recovery, $\dot{Q} M=7,535 \pm 300$ and. $\dot{Q} H L=7,608 \pm 309$. The difference between $\dot{Q} M$ and $\dot{Q} H L$ over the $18 \mathrm{~h}$ of recovery was - $73 \mathrm{~kJ}$. The difference between $\dot{Q} M$ and $\dot{Q} H L$ during exercise was $884 \mathrm{~kJ}$; subtracting the total work done on the cycle ergometer, $555 \mathrm{~kJ}$, leaves a difference of $329 \mathrm{~kJ}$, Had these values been of the same magnitude, one could say the missing energy had re-appeared as heat.

The addition of loads in two major axes of motion in walking caused increases in metabolic expenditure rate and heat loss. Vertical loading did not increase the power of walking, which supports the concept that the positive work of raising the body mass against gravity is matched by the negative work of lowering it again. The power required for the horizontal load fitted into equation 3 as expected. But $\dot{Q} W_{w l k}$ was significant while walking under these loads, just as it was when walking level without load. The one exception to this was the slow walk with a horizontal load; in this case, perhaps the increased rate of heat loss helped to mask what was expected to be only a small value for $\dot{Q} W_{w l k}$, like the $14 \mathrm{~W}$ in unloaded walking at that speed.

It seems reasonable to conclude that $\dot{Q} W_{w l k}$ is mainly dependent on walking speed and not on other forces which influence the intensity of the exercise. This suggests that $\dot{Q} W_{w l k}$ represents work which is done in the contact between the shoe and the ground. In bending the sole of the shoe, in compressing its heel, and in rotating the sole against the surface, work is done, which is at least partly converted into heat that then flows to the ground. For running it has been shown (18) that, during heel strike, a considerable amount of energy is absorbed in the heel and sole of the shoe, accounting for $40 \mathrm{~W}$ if no re-utilization of the energy occurs. To a lesser extent this might apply to walking. The 
power $\dot{Q} W_{w l k}$ will thus depend on the force responsible for the shoe deformations and the number of deformations per unit time. Since the latter is equal to the step frequency of the subject, and since step frequency is highly dependent on walking speed, the dependency of $\dot{Q} W_{w l k}$ on walking speed is explained.

Previous studies of loaded walking have measured energy cost primarily. When the energy costs reported here were compared with predicted values for walking level with and without loads (15), and for cycle work (1), our energy costs were some 15 to $20 \%$ higher. This was, we assume, the result of exercising in the bulky suit assembly. However, since the increase occurred in cycling as well as walking, it does not explain $\dot{Q} W_{w l k}$. In walking, there are three forces acting between the subject and the environment: gravitational force; air friction; and the force exerted by the feet, In level walking, the mean power against the gravitational force is zero. The power lost to air friction, which is proportional to the cube of the subject's velocity with respect to the air, is estimated to be less than $3 \mathrm{~W}$ when walking across the ground at the speeds of interest (10). During treadmill walking, this power is approximately zero. So the destination of the power involves the inter-action of the feet with the surface walked upon.

In walking, the subject pushes against the earth. This force on the earth can only explain a flow of energy to the earth if the point of application of the force is displaced, as in the case of walking on soft surfaces, like sand. On a hard surface, any acceleration of the earth due to this force can be neglected on the basis of the difference between the mass of the subject and that of the earth.

To be complete, we must consider to what extent walking on the treadmill can be compared to over-ground walking on a level, hard surface. It has been shown that the mechanics of treadmill walking are equal to over-ground walking as long as the surface of the treadmill (its belt) is not influenced by the walking subject $(3,20)$. There is essentially no vertical displacement of the surface. But to test the influence of walking in the horizontal direction, we measured the instantaneous belt speed when the subjects walked. During both deceleration and propulsion phases of the walking cycle, the belt speed showed small fluctuations, up to a maximum of $4 \%$ of the highest speed of 6.7 $\mathrm{km} \bullet \mathrm{h}^{-1}$. However, the energy flow equations from a previous study (20) show that this effect is small with respect to the power revealed in the present study. At mean deceleration and propulsion forces of approximately $10 \%$ of body weight at a walking speed of $7.2 \mathrm{~km} \mathrm{~h}^{-1}(16)$, and given the measured fluctuations in belt speed, a maximum possible energy flow of only $6 \mathrm{~W}$ can be calculated.

The power spent in walking has about the same magnitude as the power necessary to overcome the rolling resistance during cycling at comparable levels of energy expenditure (11). In modelling the energetics of walking and running, this power should be accounted for.

We conclude that there is work done during level walking, which is unaffected by vertical and horizontal loads, and which probably results from the inter-action between the foot and the ground. 


\section{REFERENCES}

1. ÅSTRAND, P.-O. and K. RODAHL. Textbook of Work Physiology. NY: McGraw Hill, 1970.

2. ATWATER, W. G. and F. G. BENEDICT. Experiments on the Metabolism of Matter and Energy in the Human Body, 1900-1902. U.S. Department of Agriculture, Office of Experiment Stations, Bulletin No. 136. Washington, D.C.: Government Printing Office, 1903.

3. BASSET, D. R., JR., M. D. GIESE, F. J. NAGLE, A. WARD, D. M. RAAB, and B. BALKE. Aerobic requirements of overground versus treadmill running. Med. Sci. Sports Exerc. 17:477-481, 1985.

4. BENEDICT, F. G. and T. M. CARPENTER. Respiration Calorimeters for Studying the Respiratory Exchange and Energy Transformations of Man. Publication No. 123. Washington, D.C.: Carnegie Institution of Washington, 1910,

5. BENEDICT, F. G. and H. MURSCHHAUSER. Energy Transformations during Horizontal Walking. Publication No. 231. Washington D.C.: Carnegie Institution of Washington, 1915.

6. BLIGH, J. and K. G. JOHNSON. Glossary of terms for thermal physiology. J. Appl. Physiol. 35:941-961, 1973.

7. BROUWER, E. Report of subcommittee on constants and factors in energy metabolism. In: Proceedings of Third Symposium on Energy Metabolism, EAAP Publication ii, K.L. Blaxter (Ed.). London, England: Academic Press, 1965, pp. 441-443.

8. CAVAgnA, G. A., F. P. SAIBEnE, and R. MARGARIA. External work in walking. J. Appl. Physiol, 18:1-9, 1963.

9. COTES, J. E. and F. MEADE The energy expenditure and mechanical energy demand in walking. Ergonomics 3:97-119, 1960.

10. DEAN, G. A. An analysis of the energy expenditure in level and grade walking. Ergonomics 8:31-47, 1965.

11. Di PRAMPERO, P. E., G. CORTILI, P. MOGNONI, and F. SAIBENE. Equation of motion of a cyclist. J. Appl. Physiol.: Respirat. Environ. Exerc. Physiol. 47:201-206, 1979.

12. GERSTEN, J. W., W. ORR, A. W. SEXTON, and D. OKIN. External work in level walking. J. Appl. Physiol. 26:286-289, 1969.

13. GORODINSKII, S. M., A. A. GLUSHKO and B. V. OREKHOV. Human Calorimetry in Protective Garments. Moscow, USSR: Mashinostroyeniye, 1976.

14. McCLEAN, J. A. and P. R. WATTS. Analytical refinements in animal calorimetry. J. Appl. Physiol. 40:827831, 1976.

15. PANDOLF, K. B., B. GIVONI, and R. F. GOLDMAN. Predicting energy expenditure with loads while standing or walking very slowly. J. Appl. Physiol.: Respirat. Environ. Exerc. Physiol., 43:577-581, 1977.

16. ROZENDAL, R. H., Y. F. HEERKENS, G. J. VAN INGEN SCHENAU, C. D. VAN RAVENSBERG, and L. H. V. VAN DER WOUDE. Vector diagrams in the evaluation of human gait. Arch. Phys. Med. Rehab. 66:682-686, 1985.

17. SCHOFFELEN, P. F. M., W. H. M. SARIS, K. R. WESTERTERP, and F. TEN HOOR. Evaluation of an automated indirect calorimeter for measurement of energy balance in man. In: Human Energy Metabolism: Physical Activity and Energy Expenditure Measurements in Epidemiological Research Based upon Direct and Indirect Calorimetry, European Nutrition Report No. 5., A.J.H. van Es (Ed.). The Hague, The Netherlands: Koninklijke Bibliotheek, 1985, pp. 51-54.

18. SNEL, J. G., N. J. DELLEMAN, Y. F. HEERKENS, and G. J. VAN INGEN SCHENAU. Shock absorbing characteristics of running shoes during actual running. In: Biomechanics IX, D.A. Winter, R.W. Norman, P. Wells, K.C. Hayes, and A.E. Patla (Eds.). Champaign, IL: Human Kinetics Publishers, 1985, pp. 133-138.

19. SNELLEN, J. W. External work in level and grade walking on a motor-driven treadmill. J. Appl. Physiol. 15:759-763, 1960.

20. VAN INGEN SCHENAU, G. J. Some fundamental aspects of the biomechanics of overground versus treadmill walking. Med. Sci. Sports Exerc. 12:257-261, 1980. 
21. WEBB, P. Thermoregulation in actively cooled working men. In: Physiological and Behavioral Temperature Regulation, Chapter 52, J.W. Hardy, A.P. Gagge, and J.A.J. Stolwijk (Eds.). Springfield, IL: Charles C Thomas, 1970, pp. 756-774.

22. WEBB, P. Human Calorimeters. NY: Praeger, 1985.

23. WEBB, P, and J. F. ANNIS. Cooling required to suppress sweating during work. J. Appl. Physiol. 25:489493, 1968.

24. WEBB, P., J. F. ANNIS, and S. J. TROUTMAN, Jr. Human calorimetry with a water-cooled garment. J. Appl. Physiol. 32:412-418, 1972,

25. WINTER, D. A. A new definition of mechanical work done in human movement. J. Appl. Physiol.: Respirat. Environ. Exerc, Physiol. 46:79-83, 1979. 

Chapter

Utilization of different formulae to calculate energy expenditure from gas exchange and substrate oxidation; an updated equation for indirect calorimetry 


\section{ABSTRACT}

The calculation of energy-expenditure (EE) from measurement of $\mathrm{O}_{2}, \mathrm{CO}_{2}$ and $\mathrm{N}_{\text {urin }}$ $\left(\mathrm{EE}_{\text {protein }}\right)$ in indirect calorimetry is traditionally done with formulae that where developed 40-100 years ago. Differences in formulae, or in accounting for protein, may affect EE upwards of $3 \%$.

In 1949 Weir provided a formula allowing calculation of $E E$ with an $E_{\text {protein }}$ fraction estimated at $0.123 \cdot E E$, i.e ' $p$ ' $=0.123$. In this paper we followed Weir's approach with updated values for substrates and an $E_{\text {protein }}$ fraction of $0.15 \bullet E E$, resulting in the formula $E E[K J]=15.78 \bullet O 2[L]+5.19 \bullet C O 2[L]$. Both this formula and Weir's where provided with correction factors for variation in $E_{\text {protein }}$ fraction ' $p$ ', of specific interest to metabolic carts with Weir "build in".

Indirect calorimeter 24 hour data including measured $\mathrm{N}_{\text {urin }}$ provided a data-set (7.8-17.6 $\mathrm{MJ} \bullet \mathrm{day}^{-1}, \mathrm{n}=164$ ) for comparing formulae. The Brouwer formula results were used for baseline, as Brouwer has been applied during side-by-side direct-and indirect calorimetry. The Weir formula showed a mean difference of $-0.38 \%$ for $E E$, while the largest deviation found was $-3.33 \%$ for Consolazio versus Brouwer. The updated formula decreased mean difference to $-0.16 \%$.

Applied to a human EEprotein fraction range of $0.05<p<0.3$, the updated formula halved the error over the range from $2.1 \%$ (Weir) to $1 \%$ (updated).

We conclude that the equation presented here is suitable for nowadays nutritional research, providing close agreement to the Brouwer formula in the presence of measured urinary nitrogen and halving the impact of estimated EEprotein fraction mismatch. 


\section{INTRODUCTION}

Measuring Energy Expenditure (EE) in man has found many applications, resulting in a variety of methods ranging from simple activity measurements from step counts and heart rate up to complex equipment like whole room calorimeters. For over a century, laboratories provided data on human and animal calorimetry, extensively using both direct- and indirect calorimeters. Direct calorimetry measures heat produced and if done well, it is considered to provide a direct link for EE from values measured on a direct physics level, i.e. heat. In contrast, indirect calorimetry measures the gasexchange required for oxidizing food, where measured values are $\mathrm{O}_{2}$ uptake, $\mathrm{CO}_{2}$ production, urinary nitrogen production and in some animals Methane production. The route to obtain EE values requires energetic values for burning food as obtained from chemistry, which is why it is considered to be an indirect method; not heat but its gasexchange is determined. A simplification would be to state that direct calorimetry measures heat while indirect calorimetry converts gas-exchange into EE by means of a set of chemical tables and derived formulae. The term "simplification" is truly applicable, as direct calorimetry has proven to be a complex method with its own set of problems, while indirect calorimetry has proven to be a more easily implemented method with conversion and measurement errors of the same magnitude as errors in direct calorimetry. Moreover, indirect calorimetry measures total energy expenditure, i.e. not only heat but also the energy required for external work, and additionally it provides information on substrate use.

Here we focus on the conversion of gas exchange values towards EE values as applied to measured participant data, and more specifically how to execute this conversion in the absence of urinary nitrogen values. Typically, urinary nitrogen values are useful in studies over $24 \mathrm{hr}$ or more, as urine is not a momentary value but is collected in the bladder over time. However, a plethora of short-interval indirect calorimeters exists, be it ventilated hood systems for measuring resting metabolic rate (RMR), sports calorimeters for measuring sub-maximal or maximum exertion, or even short interval whole-room calorimetry. In these instances, representative urinary nitrogen values are often unachievable for the interval of interest.

In the late 1800's the chemical know-how for converting gas-exchange into EE and substrate use was derived, and these values where augmented in the past century ${ }^{(1 ; 2 ; 3}$; $4 ; 5 ; 6)$. A well-known pioneer in this field was J.B. de V. Weir ${ }^{(3)}$, who recognized the possibility to link human nitrogen production to the level of EE and in this way eliminated the need for measuring urinary nitrogen unless required for other purposes then $E E$ alone. In fact, his original values are still in use today even though they have been calculated almost 70 years ago and based on chemical values from the early 1900 's ${ }^{(2 ; 7)}$. It seems reasonable to state that the method used by Weir to obtain correct EE values without requiring urinary nitrogen values is one of elegance, and this method will keep its value in the foreseeable future and specifically in short-interval indirect calorimetry. 
The aim of this paper was 1 ) to follow the Weir method using modern chemical values (8) to arrive at a contemporary conversion formula, and 2) to compare the resulting formula to the one of Brouwer ${ }^{(4)}$ who used a different set of chemical values ${ }^{(6)}$. The reason for this choice of comparison is that the Brouwer formula has been the one of choice in our laboratory for experiments where urinary nitrogen was measured, and importantly it has been applied in parallel with direct calorimetry ${ }^{(9)}$.

For comparison we applied all formulae to meta-data from two experiments that consisted of $24 \mathrm{hr}$ EE measurements using whole room indirect calorimetry, with measured $24 \mathrm{hr}$ urinary Nitrogen and without protein intervention.

\section{METHODS}

\section{SI units}

The original papers by Weir, Zuntz and Brouwer ${ }^{(1 ; 3 ; 4)}$ used the kcal instead of kJ as the unit for EE. For traceability to the original papers and formulae here the calorie unit was used, with the updated formula also presented using the SI unit kJ. Note that in Weir's paper the notation 'kg.cal' or ' $\mathrm{K}$ ' was used for 'kcal'.

\section{Statistics}

Formulae themselves do not show variability in output when given an unchanging input. The impact of a single variable parameter can therefore be calculated without statistical analysis, revealing a repeatable difference of output with repeated changes of input. For the formulae found in this paper such a difference will mostly be co-linear, allowing the calculation of impact for a single parameter, for instance the impact of protein $E E$ fraction ' $p$ '.

To introduce biological variability in evaluating these formulae, a modern day subject data set was used. Testing the continued validity of historical formulae, and allowing inter-formula comparison when used with actual subject data. In this instance, variability of multiple input parameters is a biological reality, and statistics were applied. Nine formulae where used to calculate 9 EE results with each subject's individual measurements as input parameters. One formula, Brouwer, was chosen to provide a baseline $\mathrm{EE}$, and individual differences for the other 8 formulae versus baseline where calculated. The standard deviation and mean of results for each of the 8 formulae where used to calculate the point bi-serial correlation value $|r|$ as effect size ${ }^{(11)}$. The smallest effect size from baseline was found to be 0.395 , range $0.395-0.997$. Using the smallest effect value of 0.395 a post-hoc two-tailed power calculation showed a power $>0.999$ for the 164 intra-individual mean results. Software used was Excel (Microsoft, Redmond, USA) and $\mathrm{G}^{*}$ Power ${ }^{(12)}$ (Heinrich Heine Universität, Düsseldorf, Germany). 
Bland Altman plots ${ }^{(10)}$ were prepared to illustrate differences in historical formulae when applied with the subject data.

\section{Substrate formulae}

In his paper, Weir solves a three unknown's equation, choosing $x, y$ and $z$ for carbohydrate, protein and fat respectively. Normally the required input for solving this equation would be three results, i.e. Oxygen consumption, Carbon Dioxide production and urinary Nitrogen production for calculating protein. Having only two results, Oxygen consumption and Carbon Dioxide production, Weir estimated the third from common food protein energy fraction of the era; $p=0.123$. In a weight-stable person the energy uptake must be in balance with the energy expenditure, i.e. the amount of food energy will be linear with energy expenditure at a 1:1 ratio. Given a common food protein energy fraction of 0.123 it follows that the amount of protein will also be linear with energy expenditure yet at a ratio of 1:0.123.

Weir solved the three unknown's equation, using the estimated $p=0.123$ for protein by way of setting up an equation for 1 liter of oxygen, i.e. formula nr 1 in Weir's original paper:

$$
\mathrm{O}_{2} \text { consumed }=\mathrm{x}+\mathrm{y}+\mathrm{z}=1
$$

Where $x, y$, and $z$ are allotted the energy equivalent for the substrate per 1 liter of oxygen consumed (Table 1 ).

Table 1. This is table 1 from Weir's original paper with $x, y$ and $z$ as chosen denomination for variables, Carbohydrate values from Zuntz (1897), Protein values from Loewy modified by Lusk (1928), Fat values from Cathcart \& Cuthbertson (1931).

\begin{tabular}{lccc}
\hline & Carbohydrate & Protein & Fat \\
\hline R.Q. & 1 & 0.802 & 0.718 \\
Kg.cal. per liter of $\mathrm{O}_{2}$ & 5.047 & 4.463 & 4.735 \\
Vol. of $\mathrm{O}_{2}$ metabolizing & $\mathrm{x}$ & $\mathrm{y}$ & $\mathrm{z}$ \\
\hline
\end{tabular}

This is solved into Weir's formula nr 6, where for 1 liter of oxygen the amount of Carbon Dioxide must be given as ' $R$ ' and the resulting energy in kcal ' $K$ ' is:

$$
K=3.941+1.106 R-0.365 y
$$

The factor $-0.365 y$ was resolved to -2.17 kcal per gram of urinary nitrogen, which allowed Weir's formula nr 6 to be written as:

$$
\mathrm{EE}[\mathrm{kcal}]=3.941 \bullet \mathrm{O}_{2}[\mathrm{~L}]+1.106 \bullet \mathrm{CO}_{2}[\mathrm{~L}]-2.17 \bullet \mathrm{N}[\mathrm{g}]
$$

Next Weir introduced the fixed fraction ' $p$ ' which represents the fraction of calories from the total calories that are attributed to protein metabolism per liter of Oxygen. 


\section{Chapter 3}

This fraction was defined at ' $p$ ' $=0.123$ and, together with a chemical value ${ }^{(2)}$ which states that 1 gram of urinary $N$ is equivalent to 5.941 liter of oxygen used, Weir's formula nr 6 for 1 liter of oxygen was resolved into Weir's formula nr 9 :

$$
K=3.9+1.1 R
$$

(Weir, nr 9)

This important intermediary formula was then derived into Weir's final formula $\mathrm{nr} 20$ based on the expired $\mathrm{O}_{2}$ fraction 'Oe':

$$
K^{\prime}=1.046-0.05 \mathrm{Oe}
$$

(Weir, nr 20)

The latter formula is less useful in today's application in contrast to Weir's intermediary formula $\mathrm{nr} 9$, which is used commonly and was emphasized by Weir in his summary point $\mathrm{nr} 2$ and expressed in the form of the classical Weir equation we use today, i.e.:

$$
\left.\mathrm{EE}[\mathrm{kcal}]=3.9 \bullet \mathrm{O}_{2}[\mathrm{~L}]+1.1 \cdot \mathrm{CO}_{2}[\mathrm{~L}] \quad \text { (Weir's summary, } \mathrm{nr} 2\right)
$$

The derived formula above is based on substrate values from Loewy-Lusk ${ }^{(2)}$, Cathcart \& Cuthbertson ${ }^{(13)}$ and Zuntz $1897^{(7)}$. Here we follow the same steps using values from Livesey \& Elia $1988^{(8)}$, and table 1 is replaced by table 2 (Table 2 ).

Table 2. Following Weir $\mathrm{x}, \mathrm{y}$ and $\mathrm{z}$ are chosen as variables; substrate values are from table 6 Livesey \& Elia (1988).

\begin{tabular}{lccc}
\hline & Carbohydrate & Protein & Fat \\
\hline R.Q. & 1 & 0.835 & 0.71 \\
Kg.cal. per liter of $\mathrm{O}_{2}$ & 5.047 & 4.656 & 4.685 \\
Vol. of $\mathrm{O}_{2}$ metabolizing & $\mathrm{x}$ & $\mathrm{y}$ & $\mathrm{z}$ \\
\hline
\end{tabular}

Now for 1 liter of oxygen the amount of calories found becomes:

$$
K=3.799+1.248 R-0.185 y
$$

Next an updated fraction $p=0.15$ based on 44 participants in 164 calorimetric experiments from our database was introduced, which yet again represents the fraction ' $p$ ' of calories from the total calories that are attributed to protein metabolism per liter of oxygen consumed. Together with a chemical value ${ }^{(2)}$, which states that 1 gram of urinary $\mathrm{N}$ is equivalent to 5.941 liter of oxygen used, the formula can be resolved into $\mathrm{K}=$ $3.77655+1.2412 \mathrm{R}$ resulting in the proposed updated equation, i.e.:

$$
\mathrm{EE}[\mathrm{kcal}]=3.78 \cdot \mathrm{O}_{2}[\mathrm{~L}]+1.24 \cdot \mathrm{CO}_{2}[\mathrm{~L}]
$$

Or in joule (chemical, $4.184 \mathrm{kcal})$ :

$$
\mathrm{EE}[\mathrm{kJ}]=15.78 \cdot \mathrm{O}_{2}[\mathrm{~L}]+5.19 \cdot \mathrm{CO}_{2}[\mathrm{~L}]
$$

The updated equation can be adapted for a known protein EE fraction ' $p$ ' with factor $A$ :

$$
A=1.006-0.04 \cdot p
$$


In a similar way Weir can be adapted for a known protein EE fraction ' $p$ ' with factor B:

$$
B=1.0102-0.0828 \cdot p
$$

The updated equation and the ones from literature where tested using values from 44 participants in 2 studies with 164 calorimetric experiments. No participants were excluded and the original studies conformed to the University of Maastricht protocols for ethics and informed consent, in agreement with the Declaration of Helsinki.

In our lab whole room indirect calorimeter experiments with measured urinary nitrogen used the Brouwer formula ${ }^{(4)}$ as the conversion of choice, of which the chemical values were based on Carpenter ${ }^{(6)}$. Following Weir's method the newly proposed equation does not require urinary $\mathrm{N}$ values, as this part is estimated from $\mathrm{EE}$. Its chemical values are based on modern chemical values by Livesey \& Elia ${ }^{(8)}$.

Table 3 presents formulae that where applied to the participant's data for comparison. Here, for historical reference, the original Zuntz formula ${ }^{(1)}$ was adapted to include Zuntz's correction for nitrogen:

$$
\mathrm{EE}[\mathrm{kcal}]=3.816 \bullet \mathrm{O}_{2}[\mathrm{~L}]+1.23 \bullet \mathrm{CO}_{2}[\mathrm{~L}]-1.9153 \bullet \mathrm{N}[\mathrm{g}]
$$

Table 3. A selection of gas exchange to energy expenditure formulae as found in literature and as applied to each participant's individual gas exchange and nitrogen values.

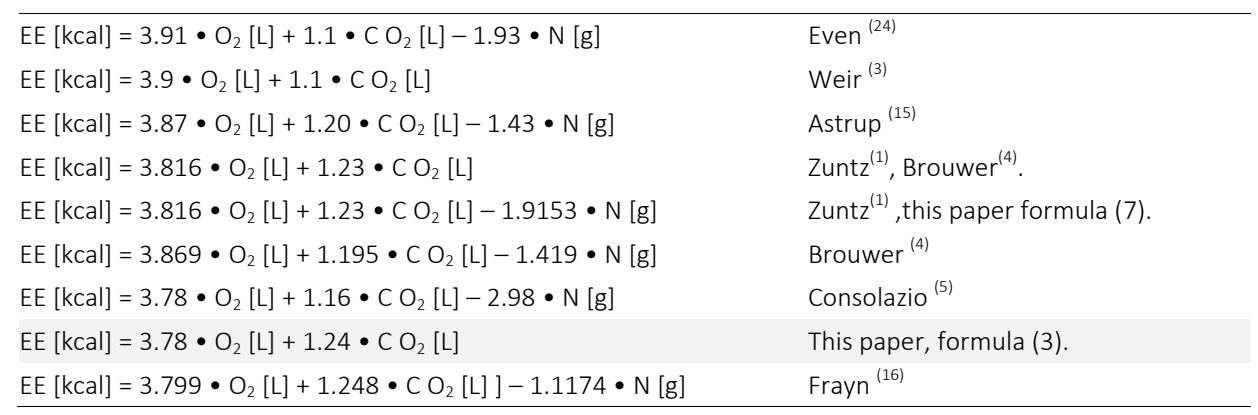

Using the available experiment data as input the deviation from Brouwer ${ }^{(4)}$ was calculated for each of the 164 individual gas exchange and nitrogen values, as well as mean differences versus Brouwer. We chose the Brouwer formula as the baseline for comparison because it is the standard equation used in our lab, and as such it was used in a study with simultaneous direct- and indirect calorimetry ${ }^{(9)}$, showing significant agreement of heat and Energy Expenditure ( \pm 6 Watt).

The results are graphically presented in a Blant-Altman plot, allowing analysis of the differences of the various formulae versus Brouwer. 


\section{RESULTS}

The results presented here were for 44 healthy male participants; age $18-40$ years, BMI 20-32 kg/m2; There where 164 individual measurements for $24 \mathrm{hr}$ Oxygen consumption [L], Carbon Dioxide production [L] and $24 \mathrm{hr}$ urinary Nitrogen [g]. For each measurement nine EE [kcal] derivation formulae as presented in table 3 where applied, and individual values for each participant where compared with the participants value found with the Brouwer formulae. Note that Brouwer values thus form the X-axis, i.e. difference for Brouwer to Brouwer is zero.

The range for $\mathrm{EE}_{24 \mathrm{hr}}$ was 1857 to $4200 \mathrm{kcal}\left(7.8-17.6 \mathrm{MJ} \bullet \mathrm{day}^{-1}\right)$ using the Brouwer formula (Table 4).

\section{Deviation $\Delta \mathrm{kcal}$ from Brouwer for 8 alternative formulae}

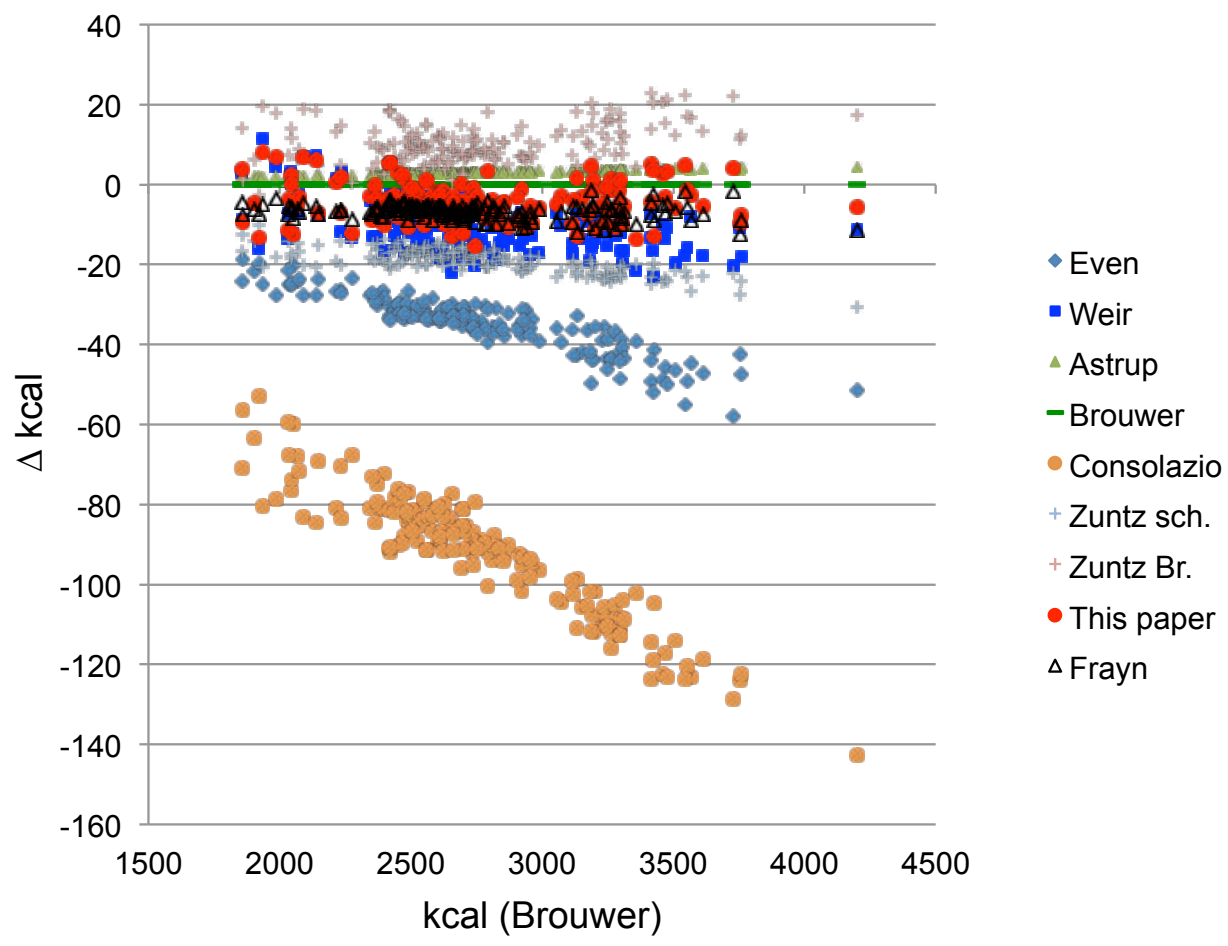

Figure 1. Deviation in kcal for 8 formulae versus the Brouwer formulae, calculated for 164 experiments in 24 $\mathrm{hr}$ whole room calorimetry with $24 \mathrm{hr}$ urinary nitrogen determined. Data points for Weir and this paper applied an EE-related correction instead of using $N$ urinary. Zuntz $(1897,1901)$ displayed with and without protein as a classic reference. Zuntz Br. Is the equation from Zuntz 1897 without N, while Zuntz Sch. is the equation with $\mathrm{N}$ added as a parameter (this paper). 
Table 4. Mean EE values calculated for 164 individual experiments using nine derivation formulae. Values comprise of absolute EE [kcal], delta EE [kcal,\%] compared to Brouwer, maximum deviation [\%] found compared to Brouwer, and show the use of Nitrogen where applicable.

\begin{tabular}{llcccc}
\hline & Mean EE kcal & AVG $\Delta$ EE kcal & AVG $\Delta E E \%$ & Max $\Delta E E \%$ & N Urine. \\
\hline Brouwer & 2756.60 & 0.00 & 0.00 & 0.00 & yes \\
Astrup & 2759.60 & 2.99 & 0.11 & 0.12 & yes \\
This paper & 2752.16 & -4.44 & -0.16 & -0.69 & \\
Frayn & 2749.86 & -6.75 & -0.25 & -0.42 & yes \\
Weir & 2745.98 & -10.62 & -0.38 & -0.84 & \\
Zuntz acc.to Brouwer & 2767.00 & 10.39 & 0.38 & 1.01 & yes \\
Zuntz acc.to this paper & 2737.76 & -18.85 & -0.69 & -1.07 & yes \\
Even & 2722.09 & -34.51 & -1.25 & -1.55 & yes \\
Consolazio & 2664.94 & -91.66 & -3.33 & -4.15 & \\
\hline
\end{tabular}

\section{Deviation $\Delta \%$ from Brouwer for 8 alternative formulae}

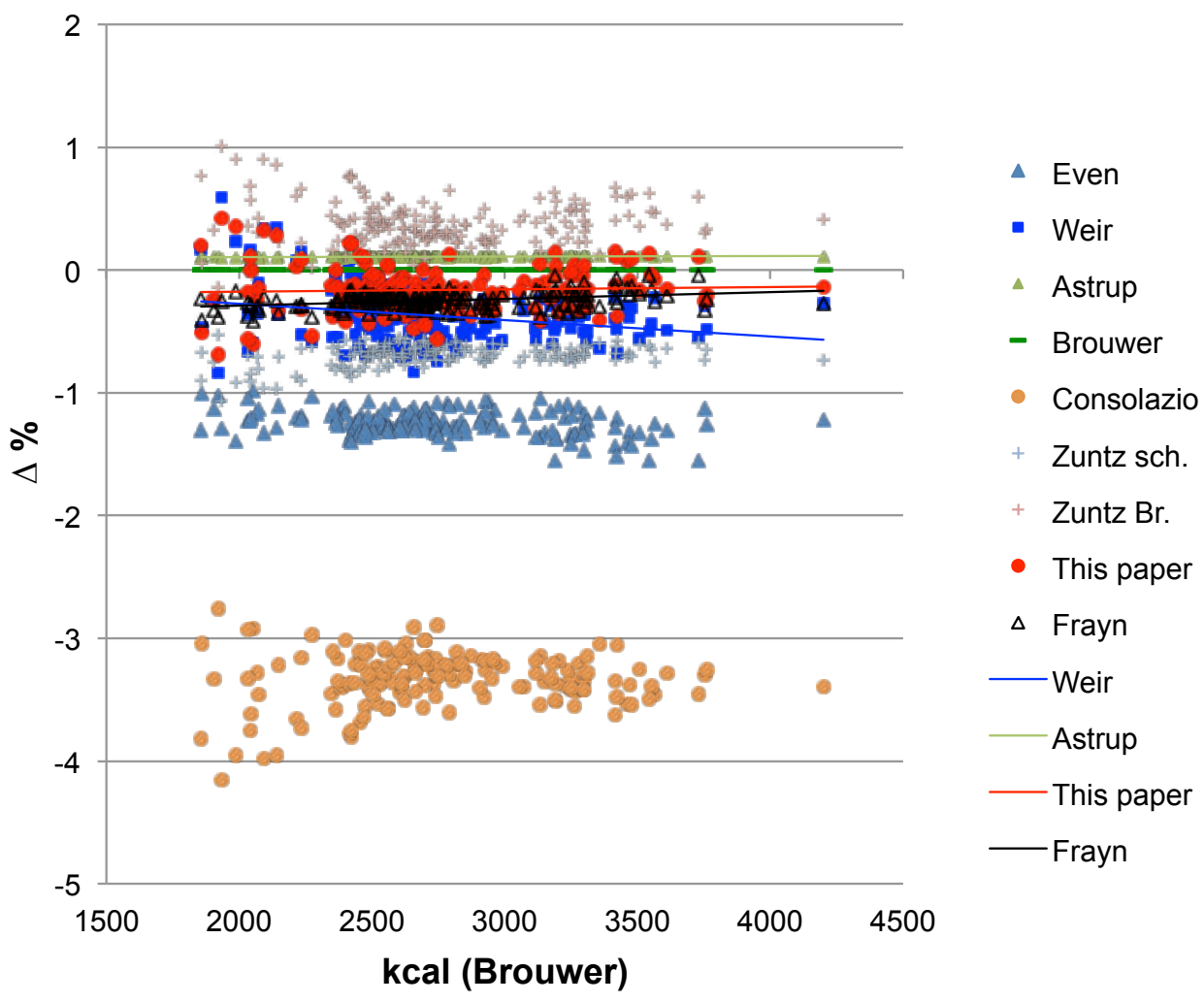

Figure 2. Deviation in \% for 8 alternative formulae versus the Brouwer formulae, calculated for 164 measurements in $24 \mathrm{hr}$ whole room calorimetry with $24 \mathrm{hr}$ urinary nitrogen determined. Data points for Weir and this paper applied an EE-related correction instead of using measured $\mathrm{N}$ urinary. Zuntz $(1897,1901)$ displayed with (Sch.) and without (Br.) protein as a classic reference. 
The individual curves are presented in Figures 1 and 2, showing kcal and percentage differences for each formula versus the baseline calculated using the Brouwer formula. The Weir formula showed a mean difference of $-0.38 \%$ for $E E$, while the largest deviation found was $-3.33 \%$ for Consolazio versus Brouwer. The updated formula decreased mean difference to $-0.16 \%$.

A result from calculation instead of measurement is the effect of protein EE \% consumed on the estimated formula presented here and the classic Weir formula. In methods, factor A (5) and B (6) for respective adaptation of EE where presented. The impact of ' $p$ ' was 0.04 and 0.0828 respectively, i.e. for a change in protein fraction of 0.25 (human range $0.05-0.3$ ) the impacts are 0.01 and 0.0207 respectively, i.e. an $1 \%$ and $2 \%$ error in EE respectively.

\section{The 5 most closely resembling formulae}

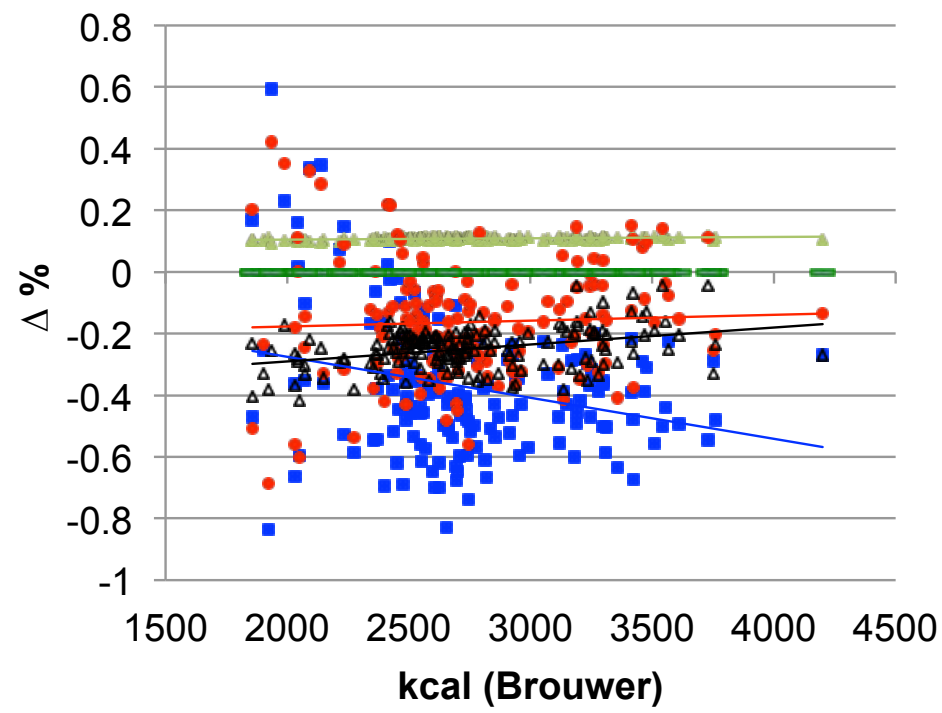

- Weir

$\triangle$ Astrup

- This paper

- Brouwer

$\triangle$ Frayn

Weir

Astrup

- This paper

- Frayn

Figure 3. Deviation in \% for the most closely resembling formulae; three with urinary nitrogen i.e. Astrup, Brouwer and Frayn, two with EE-related protein estimate i.e. this paper and Weir.

\section{DISCUSSION}

Results presented above show the relationship and its uncertainty for energy expenditure converted from gas exchange in $164 \mathrm{EE}_{24 \mathrm{~h}}$ measurements, directly related to today's population and equipment. The Brouwer formula was chosen for baseline having successfully been applied in a study with synchronous direct- and indirect calorimetry, and specifically for experiments including gas exchange and nitrogen measures over $24 \mathrm{hr}$. 
Using the term "indirect" in indirect calorimetry is a technically correct description of the calorimetric method applied, and this method has become the method of choice for measuring Energy Expenditure in man and animal. As such the denominator "indirect" might shed doubt on the accuracy obtained, specifically as not heat but Oxygen consumptions and Carbon Dioxide production are the measured parameters, and these measurements must be converted to Energy by means of an interpretive formula. Authors like Zuntz, Weir, Brouwer ${ }^{(1 ; 3 ; 4)}$ and many others did excellent work on this topic in the distant- or not so distant past, resulting in formulae that closely resemble each other (Figure 3).

Given the fact that from the early 80's on, gas-analysers, computers and a plethora of sensors showed significant improvement, the field of human calorimetry co-currently improved its accuracy (Table 5).

Table 5. The accuracy of Oxygen and Carbon Dioxide measurements in whole room calorimeters in the $80^{\prime} \mathrm{s}$ and 90 's, on average are well within 1\%. Values where derived using burning of gas or alcohols as well as gasinfusions (single values). Absolute levels for these percent values are mostly not available. Source: A dualrespiration chamber system with automated calibration ${ }^{(14)}$ Table 1.

\begin{tabular}{lcc}
\hline & $\Delta \mathrm{O}_{2}, \%$ & $\Delta \mathrm{CO}_{2}, \%$ \\
\hline Charbonier A. et al, 1990 & $-1 \pm 2.2$ & $0 \pm 2.1$ \\
Henning B. et al, 1996 & $0.06 \pm 1.21$ & $-0.49 \pm 1.12$ \\
Jéquier E. et al, 1983 & $0.44 \pm 0.34$ & $-0.36 \pm 0.5$ \\
Moon J.K. et al, 1995 & $-0.22 \pm 1.51$ & $0.21 \pm 0.68$ \\
Moon J.K. et al, 1995 & $-0.53 \pm 0.66$ & $-0.05 \pm 1.36$ \\
Moon J.K. et al, 1995 & $2.3-5.8$ & $1.9-4.9$ \\
Murgatroyd P.R. et al, 1987 & \pm \pm 1.2 & \pm 0.5 \\
Ravussin E. et al, 1986 & $-2.8 \pm 2.8$ & $-2.1 \pm 2.8$ \\
Rumpler W.V. et al, 1990 & $1.5 \pm 1.4$ & $1.5 \pm 1.4$ \\
Seale J.L. et al, 1991 & $0.3 \pm 1.54$ & $0.4 \pm 1.34$ \\
Seale J.L. et al, 1991 & & $0.4 \pm 0.85$ \\
Shetty P.S. et al, 1987 & \pm 0.43 & \\
Treuth M.S. et al, 1996 & $-0.5 \pm 2.1$ & $0.2 \pm 2.3$ \\
Schoffelen et al, 1997 & $0.5 \pm 2.0$ & $-0.3 \pm 1.6$ \\
Schoffelen et al, 1997 & & $-0.6 \pm 2.3$ \\
Summary & $0.13 \pm 1.26$ & $0.09 \pm 0.95$
\end{tabular}

The mean error for the parameters measured, i.e. gas quantities Oxygen and Carbon dioxide is of the same order of magnitude as found when comparing formulae for the derivation of EE from gas quantities as can be seen in Figures 1, 2 and 3. The main difference is that the error in choosing a conversion formula from gas values $[\mathrm{L}]$ to $\mathrm{EE}$ [kcal] will not add noise to results but will shift all individual values in a predictable fashion, i.e. shift intercept (offset) and slope (deviation related to EE magnitude). Consequently, there is little or no impact on revealing intervention effects using repeated 
measures. With the exception where substrates in nutrition with abnormal heat of combustion ${ }^{(8)}$ are applied, or where protein EE was estimated at a fixed value ${ }^{(3)}$ while protein EE itself was part of the intervention.

Livesey and Elia ${ }^{(8)}$ did an in-depth analysis of common and less common substrates energy equivalents and this paper follows their advised values (Table 2).

In the past direct and indirect calorimetry have simultaneously been applied with humans and animals, proving that the heat measured directly and the heat measured indirectly are nearly identical. This has also been the case for our whole room calorimeter system ${ }^{(9)}$ when we applied indirect calorimetry ${ }^{(9 ; 14)}$ using the Brouwer formula ${ }^{(4)}$ and compared it with the direct calorimeter system ${ }^{(9)}$. Ten participants where measured in 10 differing stages of protocol resulting in an agreement within $1 \%$ for indirectcompared to direct calorimetry ${ }^{(9)}$. The calorimetry involved consisted of the third revision of Paul Webb's direct suit calorimeter specifically integrated in our second revision indirect whole room calorimeter. The indirect whole room calorimeter was separately described later on ${ }^{(14)}$ and has now been in use for over 3 decades. Due to the agreement between direct calorimetry and indirect calorimetry using the Brouwer formula, here, we have chosen the Brouwer formula as our base-line in comparing other formulae. The Brouwer formula will provide conversion from measured gas values [L] to heat [kcal] within a $1 \%$ error margin, or for sub-maximal exercise \pm 6 watt. However, we cannot determine if other formulae within $1 \%$ of agreement with Brouwer are more accurate in conversion or in contrast less accurate.

In figure 1 and 2 we also included the conversion used by Zuntz (Zuntz and Schumburg 1901) as referenced by Brouwer (Brouwer 1957), and for historical correctness derived the urinary nitrogen correction as applied by Zuntz (Zuntz and Schumburg 1901) at page 261 (6.064 cc $\mathrm{O}_{2}$ and $4.809 \mathrm{cc} \mathrm{CO}_{2}$ per mg N urine, producing 17.14 calorie of heat per $\mathrm{mg} \mathrm{N}$ urine) resulting in the formula $\mathrm{EE}[\mathrm{kcal}]=3.816 \bullet \mathrm{O}_{2}[\mathrm{~L}]+1.23 \bullet \mathrm{CO}_{2}[\mathrm{~L}]-1.9153 \bullet$ $\mathrm{N}$ [g]. Interestingly these two Zuntz references as illustrated in Figures 1 and 2 starts at the $+1 \%$ and $-1 \%$ border compared to Brouwer, and become more comparable for elevated EE values' This illustrates why Zuntz and his contemporaries have remained valued references for over a century. As we focus on formulae that are within $1 \%$ of agreement with the Brouwer formula Figure 3 presents conversion results for 164 measurements using the formulae by Astrup, Brouwer, Frayn, this paper and Weir ${ }^{3 ;} 4$; $15 ; 16)$

Mansell ${ }^{(17)}$ in re-appraising Weir ${ }^{(3)}$ at first followed the same path as found in this paper. He proceeded to derive a formula based on percentage of expired Oxygen "Oe" like Weir's formula $\mathrm{nr}$ 20. The commonly used Weir's formula (9) as emphasized in Weir's summary 2 most probably has been considered as an intermediary formula by Mansell. Yet this intermediary formula by Weir has become the one of choice for calorimetry equipment where urinary nitrogen is not measured, specifically as ventilated hood measurements do not provide Oe measurements due to dilution of exhaled air. 
As a result, we compared 5 selected formulae, 3 that require urinary nitrogen and 2 that use Weir's method to circumvent measured urinary $\mathrm{N}$.

It has already become clear that the errors between the formulae are small, and we ask ourselves what other confounding properties there are in choosing a formula?

Choosing a conversion with a large offset in comparison to formulae that can be related to heat measured by direct calorimetry have been eliminated by choosing a $1 \%$ maximum difference to EE calculated using the Brouwer formula. For example, the formula by Consolazio, with its 3-4 \% lower result in comparison to all others seems the least appropriate equation for general calorimetric use. It may have specific applications that were not recognized here.

The effect of non-linearity with EE [kcal], causing results of conversion to vary with different rates of $E E$, is near absent in all formulae. Weir's formula does show a small negative trend, yet it is still insignificant in relation to today's accuracy of gas exchange measurements. The trend showed a decrease by updating the formula (this paper). However, a non-linear effect up to $1 \%$ of EE can be caused by changing the food protein EE fraction ' $p$ ' as an intervention during an experiment; in this case factor $A$ (5) should be used with the relevant food protein EE fraction ' $p$ '. The same holds true when using Weir's formula, with a non-linear effect up to $2 \%$ of EE. In a similar fashion Weir's formula should then be corrected for fraction ' $p$ ' using factor B (6).

A further confounder would be to mix formulae in an experiment; though effects will be small this might degrade significance in analysis of results. Typically, this may be the case when using multiple types of equipment with differing internal formulae, and it can be remedied by re-converting all the measured gas-values to EE with a single formula of choice.

Another confounding effect, applicable to all these formulae, is the consumption of substrates with a large deviation from the assumed energy equivalent ${ }^{\left({ }^{(8)}\right.}$. A common way to handle these substrates (including alcohol) is to determine the amount consumed and calculate $\mathrm{O}_{2}[\mathrm{~L}]$ uptake and $\mathrm{CO}_{2}[\mathrm{~L}]$ production for the amount consumed, as well as heat $(\mathrm{kcal}, \mathrm{kJ})$ produced. Once determined, subtract the amount of gas exchange from measured quantity, convert the remainder to $E E$ using the conversion formula of choice, and then add the heat provided by the amount of substrate oxidized ${ }^{(3 ; 4 ; 7 ; 18)}$. Also note that pathways and conversion cycles for abnormal substrates may pose yet another challenge $\left({ }^{(8 ; 16 ; 19 ; 20)}\right.$.

Finally, there is one confounding effect that has less to do with the formulae applied; the difference in measuring inside a whole room calorimeter versus measuring with a hood or facemask. The former includes diffusion of $\mathrm{CO}_{2}$ through the skin, while the latter disregards diffusion of $\mathrm{CO}_{2}$ through the skin and it is lost to the environment. The effect of diffusion is ignorable for $\mathrm{O}_{2}$ yet for $\mathrm{CO}_{2}$ it is in the order of $1-2 \%{ }^{(8 ; 21 ; 22 ; 23)}$. The effect on $\mathrm{EE}$ is in the order of $-0.2 \%$ to $-0.4 \%$, while $\mathrm{RQ}$ will be affected in the order of 0.01 to 0.02 absolute. 


\section{Chapter 3}

The difference in values for our participant data illustrated that it is possible to choose a formula that introduces a significant error, yet there are sufficient formulae that are accurately converting gas exchange in to EE within a 1\% margin (figure 3). As concluded before ${ }^{(17)}$ the Weir formula is still a valid choice, which may be improved upon by using the formula presented in this paper. As expected the best results are obtained by including measured urinary nitrogen, where it must be remarked that for short interval (hr versus 24hr) this may actually be detrimental to the result due to inaccuracy imposed by the short collection interval. Using the presented formula or Weir's formula with protein intervention or extreme values necessitates a correction as presented in methods (5) and (6).

Care should be taken when comparing results in multi-centre studies or when mixing equipment with various internal conversion formulae. A problem that can be solved by using the same formula throughout.

\section{CONCLUSIONS.}

We conclude that several converging formulae (figure 3) are well suited to convert gasexchange values to EE within 1\% of accuracy. Improper use of formulae based on a fixed estimate of protein EE \% can result in errors of twice that magnitude if not corrected for.

We also conclude that the new formula presented here is well suited to nowadaysnutritional research, and advise the use of the new formula also in the presence of measured urinary nitrogen.

Furthermore, it is advised to use the correction factor provided here in cases where $E E_{\text {protein }}$ fraction deviates from estimated $p=0.15$. Such a factor is now also provided for the classical Weir formula with $p=0.123$ and may be retrospectively applied to results of existing equipment. 


\section{REFERENCES.}

1. Zuntz N, Schumburg WAEFD (1901) Studien zu einer Physiologie des Marsches, Bibliothek von Coler Bd 6. Berlin: August Hirschwald.

2. Lusk G (1928) The elements of the science of nutrition. Ed. 4. ed. Philadelphia: W. B. Saunders Co.

3. Weir JB (1949) New methods for calculating metabolic rate with special reference to protein metabolism. J Physiol 109, 1-9.

4. Brouwer E (1957) On simple formulae for calculating the heat expenditure and the quantities of carbohydrate and fat oxidized in metabolism of men and animals, from gaseous exchange (Oxygen intake and carbonic acid output) and urine-N. Acta Physiol Pharmacol Neerl 6, 795-802.

5. Consolazio CF, Johnson RE, Pecora LJ (1963) Physiological Measurements of Metabolic Functions in Man. [By] C. F. Consolazio ... Robert E. Johnson ... Louis J. Pecora. [With illustrations and charts.]. New York: McGraw-Hill Book Co.

6. Carpenter TM (1948) Tables, factors, and formulas for computing respiratory exchange and biological transformations of energy : prepared by Thorne M. Carpenter, Carnegie Institution of Washington publication 303C. Washington, D.C: Carnegie Institution of Washington.

7. Zuntz N, Schumburg W (1901) Studien zu einer Physiologie des Marsches, Bibliothek von Coler. Berlin: Hirschwald.

8. Livesey G, Elia M (1988) Estimation of energy expenditure, net carbohydrate utilization, and net fat oxidation and synthesis by indirect calorimetry: evaluation of errors with special reference to the detailed composition of fuels. Am J Clin Nutr 47, 608-628.

9. Webb P, Saris WH, Schoffelen PF et al. (1988) The work of walking: a calorimetric study. Med Sci Sports Exerc 20, 331-337.

10. Bland JM, Altman DG (1986) Statistical methods for assessing agreement between two methods of clinical measurement. Lancet 1, 307-310.

11. Cooper H, Cooper HM, Hedges LV et al. (1994) The handbook of research synthesis. New York: Russell Sage Foundation.

12. Faul F, Erdfelder E, Lang AG et al. (2007) G*Power 3: a flexible statistical power analysis program for the social, behavioral, and biomedical sciences. Behav Res Methods 39, 175-191.

13. Cathcart EP, Cuthbertson DP (1931) The composition and distribution of the fatty substances of the human subject. J Physiol 72, 349-360.

14. Schoffelen PF, Westerterp KR, Saris WH et al. (1997) A dual-respiration chamber system with automated calibration. J Appl Physiol (1985) 83, 2064-2072.

15. Astrup A, Thorbek G, Lind J et al. (1990) Prediction of 24-h energy expenditure and its components from physical characteristics and body composition in normal-weight humans. Am J Clin Nutr 52, 777-783.

16. Frayn KN (1988) Indirect calorimetry. Metabolism 37, 1185.

17. Mansell PI, Macdonald IA (1990) Reappraisal of the Weir equation for calculation of metabolic rate. Am J Physiol 258, R1347-1354.

18. Joosen AM, Bakker AH, Kersten S et al. (2008) The PPARgamma ligand rosiglitazone influences triacylglycerol metabolism in non-obese males, without increasing the transcriptional activity of PPARgamma in the subcutaneous adipose tissue. Br J Nutr 99, 487-493.

19. Akanji AO, Bruce MA, Frayn KN (1989) Effect of acetate infusion on energy expenditure and substrate oxidation rates in non-diabetic and diabetic subjects. Eur J Clin Nutr 43, 107-115.

20. Frayn KN (1983) Calculation of substrate oxidation rates in vivo from gaseous exchange. J Appl Physiol Respir Environ Exerc Physiol 55, 628-634.

21. Fitzgerald LR (1957) Cutaneous respiration in man. Physiol Rev 37, 325-336.

22. Klocke RA, Gurtner GH, Farhi LE (1963) Gas transfer across the skin in man. J Appl Physiol 18, 311-316.

23. Alkalay I, Suetsugu S, Constantine H et al. (1971) Carbon dioxide elimination across human skin. Am J Physiol 220, 1434-1436.

24. Even PC, Mokhtarian A, Pele A (1994) Practical aspects of indirect calorimetry in laboratory animals. Neurosci Biobehav Rev 18, 435-447. 



\section{Chapter}

\section{4}

\section{A dual-respiration chamber system with automated calibration}

Paul F. M. Schoffelen, Klaas R. Westerterp, Wim H. M. Saris, and Foppe ten Hoor. 


\section{ABSTRACT}

This study characterizes respiration chambers with fully automated calibration. The system consists of two $14-\mathrm{m}^{3}$ pull-type chambers. Care was taken to provide a friendly environment for the subjects, with the possibility of social contact during the experiment. Gas analysis was automated to correct for analyzer drift and barometric pressure variations and to provide ease of use. Methods used for checking the system's performance are described. The gas-analysis repeatability was within $0.002 \%$. Results of alcohol combustion (50-350 ml/min $\mathrm{CO}_{2}$ ) show an accuracy of $0.5 \pm 2.0$ (SD) \% for $\mathrm{O}_{2}$ consumption and $-0.3 \pm 1.6 \%$ for $\mathrm{CO}_{2}$ production for 2 - to 24 -h experiments. It is concluded that response time is not the main factor with respect to the smallest practical measurement interval (duration); volume, mixing, gas-analysis accuracy, and levels of $\mathrm{O}_{2}$ consumption and $\mathrm{CO}_{2}$ production are at least equally important. The smallest practical interval was 15-25 min, as also found with most chamber systems described in the literature. We chose to standardize $0.5 \mathrm{~h}$ as the minimum measurement interval. 


\section{INTRODUCTION}

Energy expenditure in humans can be determined by direct measurement of heat loss (direct calorimetry) or by calculation of heat production from $\mathrm{O}_{2}$ consumption $\left(\dot{V} \mathrm{O}_{2}\right.$; $\mathrm{ml} / \mathrm{min}), \mathrm{CO}_{2}$ production $\left(\dot{V} \mathrm{CO}_{2} ; \mathrm{ml} / \mathrm{min}\right)$, and nitrogen loss in urine. $\dot{\mathrm{V}} \mathrm{O}_{2}$ and $\dot{V} \mathrm{CO}_{2}$ may be deter- mined with a variety of methods usually involving a mouthpiece, face mask, or ventilated hood $(2,9,20)$, limiting the duration of the measurement to a few hours. For the determination of $\dot{V} O_{2}$ and $\dot{V} C_{2}$ during a longer time interval (up to several days), a respiration chamber may be the method of choice $(1,3-6,8,11-19)$. During the measurement, the subject stays in an airtight room through which a stream of fresh air is directed. Composition and volume of the inlet and outlet airstream are measured. The respiration chambers described below feature a double set of gas analyzers with continuous automated calibration and automated data collection. This approach circumvents most problems due to ambient variations in gas composition and pressure and due to operator errors. Independent checks of the automated calibration procedure are performed regularly by using alcohol combustion or injection of gas with known composition. The chambers have been operational for over 10 years and provide an easy-to-use and labor-saving service with minimum downtime.

\section{METHODS}

\section{Subject Environment}

Two equally sized $\left(14 \mathrm{~m}^{3}\right)$ and furnished chambers were placed next to each other (Fig. 1). They give the impression of a normal room, with windows positioned in the door for contact with researchers, in the wall (outside view), and between the chambers for visual contact between subjects. Curtains ensure privacy when needed. Each chamber has a full-sized foldaway bed, a bureau with built-in sink, a folding chair, a color television set, an audiocassette player, an alarm clock, a telephone, an automated intercom, and a computer- network connection. Confined spaces were avoided because of the adverse effect on the air-mixing process (Appendix A). Both chambers are occupied simultaneously, preventing subjects from feeling isolated and stimulating normal domestic behavior.

The chambers are equipped with a deep-freeze toilet (Special Product, Mulders) for collecting feces; urine is collected separately in bottles. Three air locks provide passage for the exchange of food, collection of feces and urine, and for sampling of blood. Safety precautions include a fire alarm and extinguisher, emergency lighting, and panic buttons. The door can be opened from both sides without hindrance. The chambers are checked once a year for electrical safety (S1 standard), and the climate is constantly 
regulated and monitored by an automated information system. Physical activity can be performed by using a cycle ergometer (Lode) or a treadmill (Quinton). The height of the chamber also allows the use of a stepping platform. Activity of the subject is measured by an analog ultrasound system (Advisor DU160).

\section{Ventilation}

For airtightness, each room was constructed of six prefabricated welded steel parts, bolted together with a sealing mass in between. Door and air locks have a flexible seal. The air in the surrounding laboratory is ventilated with fresh air at a rate of five times its volume per hour $\left(1,200 \mathrm{~m}^{3} / \mathrm{h}\right)$. Fresh air from outside the building is drawn through the chambers by a ventilator with a capacity of 30-250 I/min at a negative pressure of 600$50 \mathrm{~Pa}$, respectively (pull type). The flow is adjusted with a valve at the output. Negative pressure is adjusted to $250 \pm 125 \mathrm{~Pa}$ with a valve at the input and is measured by using a U-type oil gauge against barometric pressure. Flow is measured with dry bellows meters (G4, Meterfabriek Schlumberger) calibrated by mass-flow $\left(\mathrm{CO}_{2}\right.$ weight) from a gas bottle to $0.2 \%$. [This calibration method was periodically verified by sending a calibrated gas meter to the national standards laboratory (Nederlands Meet Instituut)] The flowmeters are equipped with a digital pulse output for continuous flow measurement. The air-conditioning has a capacity of 3,700 W, which is mainly needed for dehumidification of the air during exercise. The air in the chambers is mixed with a radial ventilator, forcing the air through a draft-reducing perforated ceiling at a controllable rate of 3,300$10,000 \mathrm{l} / \mathrm{min}$.

The fresh-air supply is routed directly into the air-conditioning for mixing and temperature control. The temperature variation is $\pm 0.1^{\circ} \mathrm{C}$ during rest and $\pm 0.4^{\circ} \mathrm{C}$ during exercise. The air leaves the chamber diagonally opposite the input at two levels. Volume and flow measurements are corrected to STPD by using data obtained from temperature (AD590, National Semiconductor), humidity (SA100c, Rotronic), and barometric pressure (4801-1124, Bell \& How- ell) sensors that are calibrated on a yearly basis. 


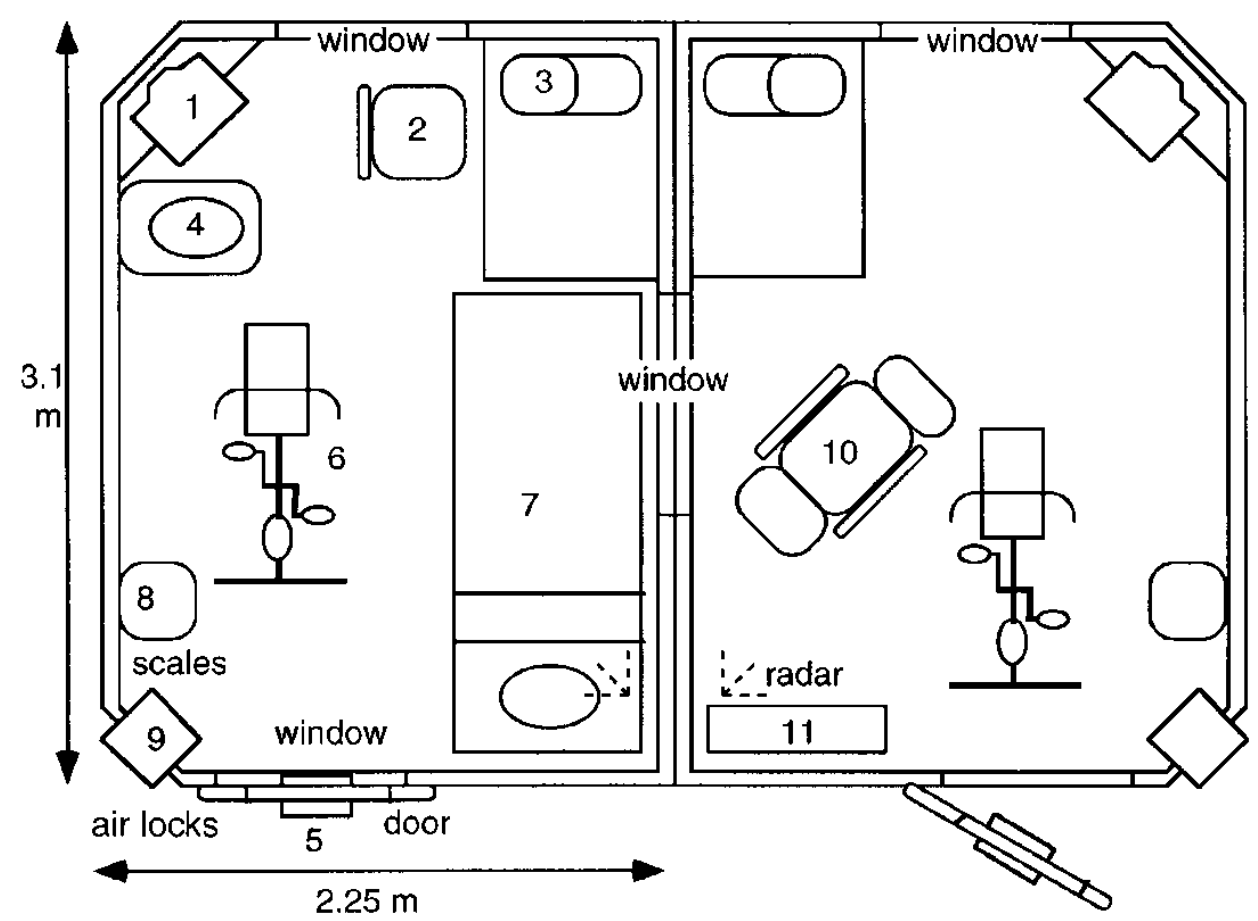

Figure 1. Layout of dual respiration chamber. 1, Television set; 2 , chair; 3, sink with hot and cold running water; 4, deep-freeze toilet; 5, air lock for blood samples; 6, cycle ergometer; 7, bed (folded down for sleeping or sitting); 8 , body-weight balance; 9 , air locks, one for food, one for feces; 10 , folding chair, which may be stored under bed; 11, bed (folded up for more floor space).

\section{$\mathrm{O}_{2}$ - and $\mathrm{CO}_{2}$-Measurement Systems}

$\mathrm{O}_{2}$ is measured by using paramagnetic 0-22\% oxygen analyzers (Magnos 6G, Hartmann \& Braun; OA184A, Servomex), and $\mathrm{CO}_{2}$ is measured by using infrared $0-1 \%$ analyzers (Uras 3G, Hartmann \& Braun). To improve the reliability of the measurement, each gas sample is analyzed in duplicate, reducing the risk of losing data because of hard-todetect failures.

Samples from the input and the output of the chamber are drawn into a sample preparation unit by using membrane pumps (model 300 , Wisa). When a sample is not selected, the sample line is still flushed to reduce dead time. Pressure and humidity variations are reduced through utilization of needle valves and oil-filled overflow bubblers (constant pressure to ambient) and by using membrane dryers (ME050-24-MFL, Perma Pure). The membrane dryers have an enhanced drying capacity obtained from using an outer hull with a counterflowing dry purge gas at $50 \mathrm{KPa}$ negative pressure; this provides a steady drying capacity. The combination of fully flushed sample routes with identical delays and a membrane-drying tube resulted in a $90 \%$ response of the $\mathrm{CO}_{2}$ analyzers of $5 \mathrm{~s}$ after the switch from $\mathrm{N}_{2}$ to calibration gas. The system ensures that all 
samples are clean (1- $\mu \mathrm{m}$ filter) and are of equal pressure (610 $\mathrm{Pa})$, temperature $\left( \pm 0.1^{\circ} \mathrm{C}\right)$, and humidity $\left(215^{\circ} \mathrm{C}\right.$ dew point). The linearity error of each $\mathrm{CO}_{2}$ analyzer was reduced by constructing a linearization curve for each apparatus. The range of the linearized curve is $0-0.8 \%$; the $\mathrm{CO}_{2}$ concentration inside the chambers normally never exceeds $0.8 \%$.

The difference in gas composition (dg) between incoming and outgoing air and the ratio of $d g$ to the difference in time $(d t)$ in the chamber (derived from measurement of the outgoing air) have to be known for the calculation of $\dot{V} \mathrm{O}_{2}$ and $\dot{V} \mathrm{CO}_{2}$ (Appendix B). Air samples are measured in sequence (10) and alternated with samples of calibration and zero gases, thus eliminating errors because of differences in analyzers or sample preparation. The measurement of each sample requires $1 \mathrm{~min}$. During each interval of $15 \mathrm{~min}$, samples of fresh air and zero and calibration gas are measured in addition to the 12 chamber samples (Fig. 2). In this way, effects due to baseline drift, barometric pressure $(3,18)$, and temperature variation, factors that vary more slowly than in $15 \mathrm{~min}$, are minimized. Because of the full automatization, no operator action is required, eliminating this source of error.

full calibration
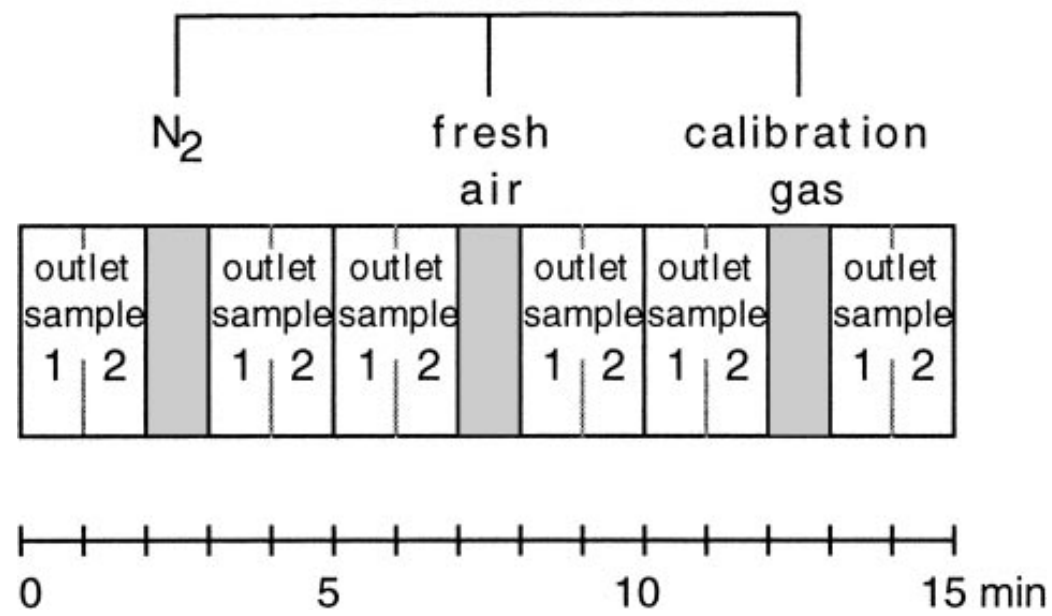

Figure 2. Sample sequence. Inlet and outlet samples from chambers 1 and 2 are alternated with $\mathrm{N}_{2}$ (zero control), fresh air, and calibration gas, thus obtaining zero control and calibration every 15 min.

Calibration and fresh-air measurements account for 12 min every hour. The remaining 48 min during the hour provide time for two concentration measurements for both chambers during each of twelve 5-min intervals. $\dot{V} O_{2}$ and $\dot{V} \mathrm{CO}_{2}$ are calculated for each 5-min interval, and the 5-min results are integrated to 0.5 -h values in the standard output file. Although it is possible to calculate 5 -min values for $\dot{V} O_{2}$ and $\dot{V} C O_{2}$, the accuracy of these values will be low because the standard deviation (SD) in the measurement 
of the minute concentration changes is multiplied with the large volume of the chamber (13). The standard procedure is the calculation of $\dot{V} \mathrm{O}_{2}$ and $\dot{V} C \mathrm{O}_{2}$ over $0.5 \mathrm{~h}$ or longer time intervals.

The calibration gas contains $0.8 \% \mathrm{CO}_{2}-18 \% \mathrm{O}_{2}$ - remainder $\mathrm{N}_{2}$. The $\mathrm{CO}_{2}$ concentration of this gas can be obtained with a certified accuracy of $0.008 \%$. The $\mathrm{O}_{2}$ concentration, however, has a certified accuracy of only $0.18 \%$. For the $\mathrm{O}_{2}$ analysis, we therefore rely on the accuracy of the overall $\mathrm{O}_{2}$ concentration of the fresh air $(4,10,14,15)$ during a whole day, while using the $18 \% \mathrm{O}_{2}$ content of the calibration gas as a stable, but at first unknown, $\mathrm{O}_{2}$ reference. The unknown $\mathrm{O}_{2}$ concentration of the calibration gas is calculated on the basis of measurement of fresh air, $\mathrm{N}_{2}$, and calibration gas $\mathrm{O}_{2}$ concentration by using mean values over the whole experiment. The calculated calibration gas $\mathrm{O}_{2}$ value is then used to determine momentary $\mathrm{O}_{2}$ concentrations during the experiment. Because the $\mathrm{O}_{2}$ concentration of the calibration gas is calculated during each experiment, monitoring the obtained calibration gas values over a 3-mo interval (lifespan of a single calibration gas bottle) provides data on the accuracy of the $\mathrm{O}_{2}$ measurement, including any drift in fresh-air $\mathrm{O}_{2}$ concentration over the 3-mo interval.

A microcomputer (Macintosh, Apple) is used to monitor the parameters for determining $\dot{V} \mathrm{O}_{2}$ and $\dot{V} \mathrm{CO}_{2}$. Each analyzer and sensor has its own analog-to-digital converter (ADC; voltage- to-frequency, VFC62, Burr-Brown) and is optically isolated from the microcomputer, enabling optimal conversion of electrical signals by reducing electrical noise from long cabling and earth loops. Calibration of sensors is done in the software; the analog range of the converters was individually chosen to handle any long-term drift. Parameters used in the calculation of $\dot{V} \mathrm{O}_{2}$ and $\dot{\mathrm{V}} \mathrm{CO}_{2}$ are temperature, humidity, flow, barometric pressure, and a digital reading of $\mathrm{O}_{2}$ and $\mathrm{CO}_{2}$ concentrations in sample and calibration gases.

On-line calculation enables continuous monitoring of the progress of the experiment. Final calculation is done after the experiment is completed, allowing the use of all data for calculation of calibration constants (12), specifically the $\mathrm{O}_{2}$ concentration in the calibration gas bottle. The equations used in the calculation of gas exchange are based on the assumption of $\mathrm{N}_{2}$ conservation ["haldane" correction $(3,5,7,10-12,15-17)$ ] with incorporation of differentiated changes in the chamber volume for the $\mathrm{N}_{2}$ equation $\left[\mathrm{dFN}_{2} / \mathrm{d} t\right.$; determined at the outlet $\left.(3,7,12,17)\right]$. Water vapor is taken into account $(3$, 10) by first calculating all flow and volumes [including differentiated changes in the chamber volume $\left.\left(\mathrm{dH}_{2} \mathrm{O} / \mathrm{d} t\right)\right]$ to STPD. Energy expenditure is calculated from $\dot{V} \mathrm{O}_{2}$ and $\dot{V} \mathrm{CO}_{2}$ with the Weir formula (21).

To achieve flexibility, the software for the system is modular; data acquisition is based on a graphical engineering program (Labview, National Instruments), and calculation is performed with a spreadsheet macro program (Excel, Microsoft). Additional parameters can be incorporated by using the flexibility of the software and the network capability of the computer (network-connected ADCs and serial ports). The audio capability of the com- 
puter (speech) was used to synchronize the subject's behavior to a protocol by providing an audio signal to the subject when it was time for a certain activity.

\section{Validation}

Each month, an independent check of the whole system is obtained by combusting alcohol inside the chamber or, in some instances, by injecting gas with a known composition into the chamber. The alcohol ( $99.8 \%$ methanol pro analyse; Merck) is combusted by using a gas burner (Fig. 3A). The burner is placed on a calibrated balance connected to a computer to measure the rate of combustion during the experiment. When alcohol is combusted, $\mathrm{O}_{2}$ is consumed and $\mathrm{CO}_{2}$ is produced, mimicking normal measurement. With the use of gas injection with $\mathrm{CO}_{2}, \mathrm{~N}_{2}$, or a combination of both (Fig. 3B; Refs. 4, 11-14, 17, 18), the accuracy of $\mathrm{CO}_{2}$ and $\mathrm{O}_{2}$ measurement can be checked. Calculating produced $\mathrm{CO}_{2}$ from weight should take into account that at barometric pressure the $\mathrm{CO}_{2}$ compressibility ( $3 a$ ) accounts for a $-0.6 \%$ deviation between molar and volume fraction, valid for both alcohol combustion and $\mathrm{CO}_{2}$ injection. In this context, it should be pointed out that calibration gas certificates can therefore be obtained on the basis of molar or volume fraction. In our setting, all calculations were done by using volume (fractions) at STPD.

The duration of validation experiments is 24 or $2 \mathrm{~h}$; both time intervals are relevant to actual experiments.

\section{RESULTS}

During operation of the system for $10 \mathrm{yr}$, only 2 of 2,000 subjects felt isolated and finished the experiment prematurely. No safety hazards have occurred.

\section{Ventilation}

The perforated ceiling reduced the noise at ear level to $45 \mathrm{dbA}$ at the lowest recirculation flow of $3,300 \mathrm{l} / \mathrm{min}$. At the highest recirculation of $10,000 \mathrm{l} / \mathrm{min}$, the noise increased to $54 \mathrm{dbA}$. At the lowest recirculation flow of $3,300 \mathrm{l} / \mathrm{min}$ and a flow through the chamber of $50 \mathrm{l} / \mathrm{min}, 99 \%$ of a 5 -min continuous injection was measured within 15 $\min$, and $63 \%$ was measured in 5 min. 

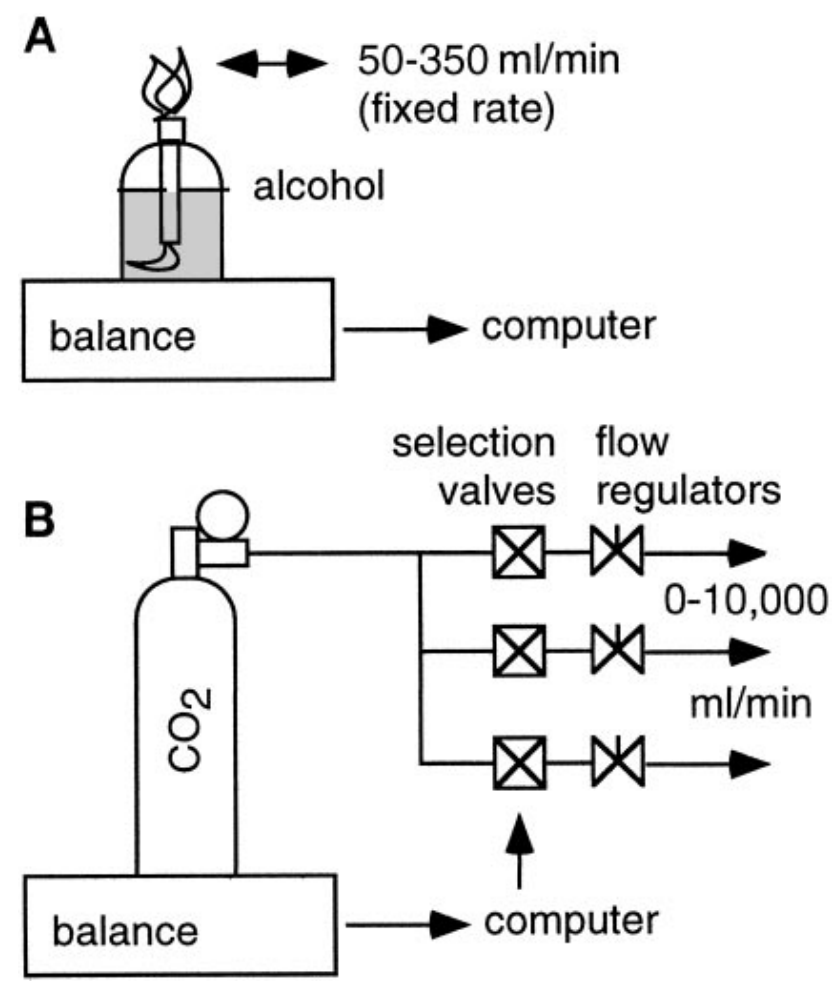

Figure 3. Chambers are checked by combustion of alcohol $(A)$ or infusion of $\mathrm{CO}_{2}(B)$. Amount of combusted alcohol or injected gas is calculated from weight change of containers; connecting balance to a computer allows continuous measurement of rate of combustion or infusion. Computer can change this rate during experiment if computer-controlled valves $(B)$ are used.

\section{$\mathrm{O}_{2}$ - and $\mathrm{CO}_{2}$-Measurement System}

Key elements in the gas-analysis system are the sampling system and the reproducibility of the gas analyzers. The time needed to flush the sampling system after a change of sample was measured to be $\leq 5 \mathrm{~s}$, leaving $55 \mathrm{~s}$ for stabilization; at least 10-fold analyzer response time [response time to $90 \%\left(t_{90}\right) \leq 3.5 \mathrm{~s}$ ] and measurement. The drying capacity of the sampling system, particularly important for measuring $\mathrm{O}_{2}$, showed a steady sample dew point lower than $-15^{\circ} \mathrm{C}$. To check the reproducibility of the $\mathrm{O}_{2}$ analyzers, the difference between two analyzers was measured over the $0-18 \% \mathrm{O}_{2}$ concentration range (Fig. 4) when identical gas samples were measured. The signal-to-noise levels had an SD $<0.002 \%(n=75)$, illustrating the reproducibility of the $\mathrm{O}_{2}$ gas analysis. 


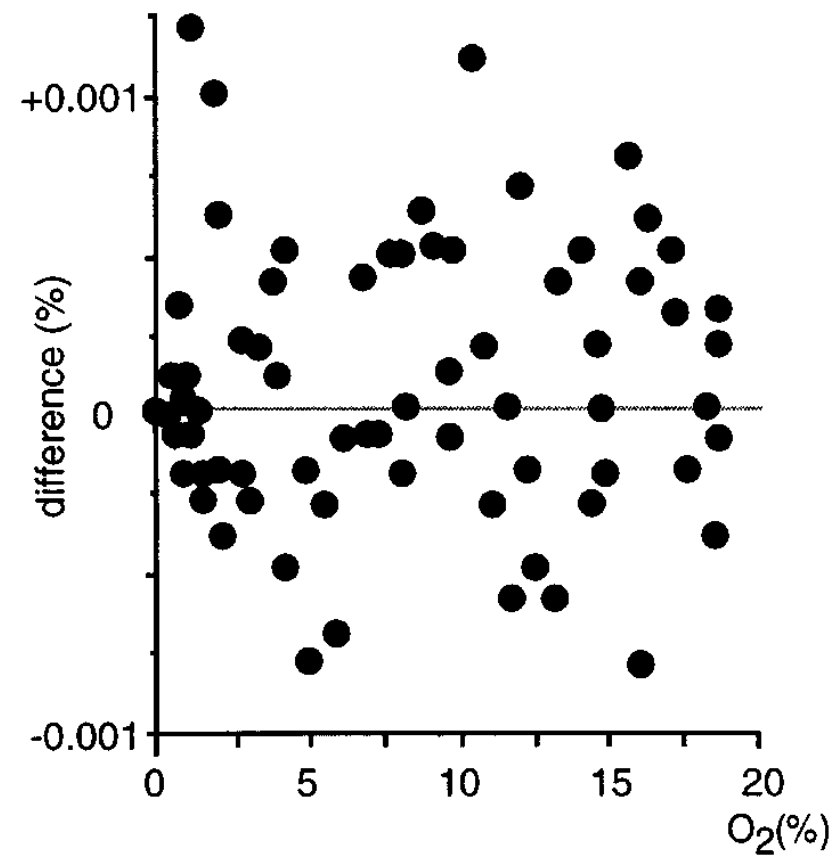

Figure 4. Difference between 2 analyzer cells ( $y$-axis, \%) when identical samples are measured as a function of $\mathrm{O}_{2}$ concentration in measured gas $(x$-axis, \%).

\section{Validation}

Alcohol-combustion experiments over the present year $(n=44)$ resulted in differences between "alcohol combustion" values and "chamber system" values of $-0.3 \pm 1.6 \%$ for $\mathrm{CO}_{2}, 0.5 \pm 2.0 \%$ for $\mathrm{O}_{2}$ (Fig. 5 ) and a respiratory quotient of $0.663 \pm 0.012$. No difference was found between 2 - and 24-h tests. The results of calibration experiments using $\mathrm{CO}_{2}$ injection over the past years were comparable with those found for alcohol combustion $(-0.6 \pm 2.3 \%, n=20)$.

The system compares the stable $\mathrm{O}_{2}$ concentration of the calibration gas with the mean 24-h fresh-air $\mathrm{O}_{2}$ concentration; the variation in these 24- $\mathrm{h} \mathrm{O}_{2}$ concentration measurements can be determined. Maximum difference in 24-h measurements over the 3-mo lifespan of a calibration gas bottle was found to vary from $0.003 \pm 0.002$ to $0.006 \pm$ $0.004 \% \mathrm{O}_{2}$. This variation can be attributed to both variation in fresh air $\% \mathrm{O}_{2}$ and variation in the measurement system; these factors cannot be separated. 


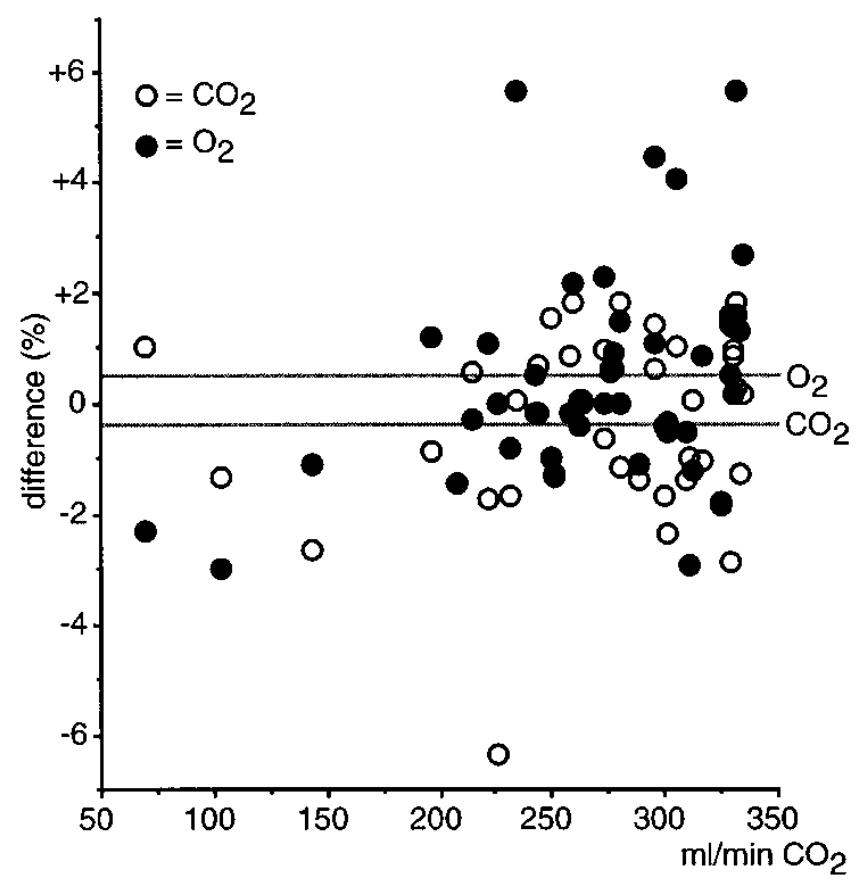

Figure 5. Results of alcohol-combustion experiments. Difference between amount calculated from alcohol combustion and amount measured by system ( $y$-axis, \%) as a function of $\mathrm{CO}_{2}$ production by alcohol combustion ( $x$-axis, $\mathrm{ml} / \mathrm{min}$ ) is shown.

Because these variations are also both present in normal experiments, the maximum difference found is an indication of the performance and stability of the system with respect to calibration based on fresh air $\mathrm{O}_{2} \%$. If calculated $\mathrm{O}_{2}$ concentration in the calibration gas was compared by using data of two $\mathrm{O}_{2}$ analyzers, the maximum difference and SD increased by $50 \%$, showing the advantage of measuring input and output concentrations sequentially $(10,14)$ with one analyzer compared with measurement of input and output concentrations with separate analyzers.

Registration of energy expenditure and physical activity of a subject is shown in Fig. 6 . Energy expenditure data are given for 0.5-h intervals. Physical activity was synchronized with these 0.5 -h intervals by using computer audio. 

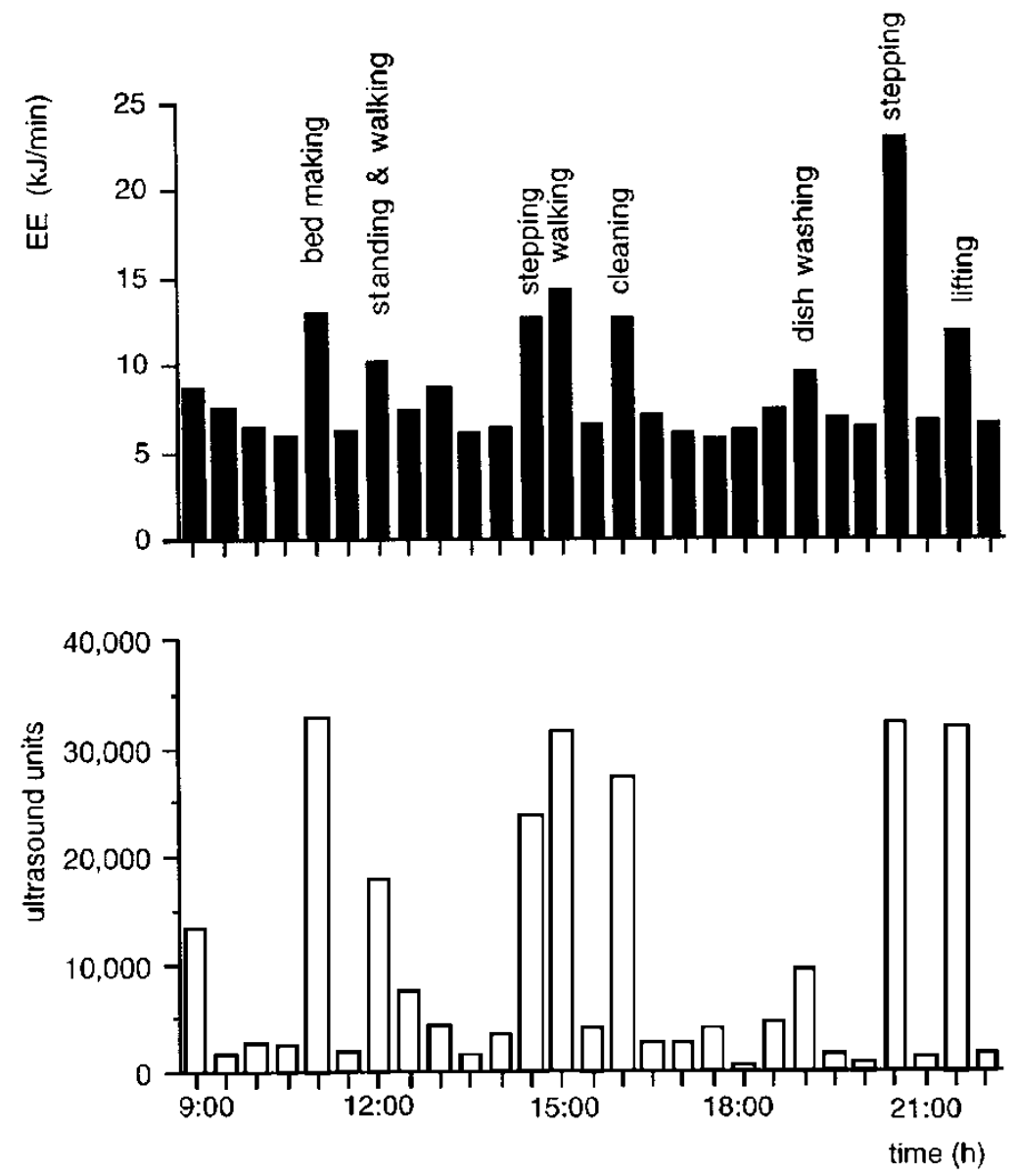

Figure 6. Energy expenditure (EE) and physical activity of a subject (male, aged $32 \mathrm{yr}$, body weight $68 \mathrm{~kg}$ ) as measured over 0.5 -h intervals.

\section{DISCUSSION}

\section{Subject Environment}

After the creation of a friendly environment, only noise and draft due to air conditioning remain as the major factors compromising comfort. The rate of recirculation flow is therefore limited (12) and, because of its cooling effect, the room temperature is normally set a few degrees higher $\left(\leq 3^{\circ} \mathrm{C}\right)$ than at home. 


\section{Ventilation}

The recirculation flow range of ventilating the $14-\mathrm{m}^{3}$ volume at a rate of $15-42$ times per hour calculates to a mixing time constant (12) of 1.4-4.2 min, which is comparable to those calculated from the literature $(4-6,12,14-16)$, ranging from 0.4 to $4 \mathrm{~min}$. The result of observing $99 \%$ of a 5 -min continuous injection within $15 \mathrm{~min}$ is slightly better than expected from the calculated 4.2-min time constant at the lowest recirculation rate. Extending the recirculation flow range will either compromise the mixing time constant ( $\geq 4 \mathrm{~min}$ ) or the comfort of the subject. The negative pressure [pull type $(5,8$, $13,15)$ ] ensures that airflow through leaks will only be from outside to inside the chamber. If the room around the chamber is well ventilated, this will have a negligible effect on the measurements. In some settings, factors like environment (4) or control of inlet air $(11,12)$ can necessitate the use of a positive pressure system. Such a system [push type $(4,6,11,12,14,16-18)]$ requires better sealing $(12,16)$ because it cannot be guaranteed that leaked air was already completely mixed and sampled.

Wherever possible, care was taken to avoid confined spaces, which would act as buffer volumes. A confined space behaves as a volume in which gas concentrations will slowly follow the concentration in the chamber. If a subject's expired air is directed to a confined space, the mixing time will increase. For this reason, no closed cabinets were provided inside the chambers and the cabinets around equipment like the deep-freeze toilets and television sets were perforated.

\section{$\mathrm{O}_{2}$ - and $\mathrm{CO}_{2}-$ Measurement System}

The automated system operates continuously, and thus the system is calibrated 96 times $/ 24 \mathrm{~h}$. The $\mathrm{SD}<0.004 \%$ in the daily calculated $\mathrm{O}_{2}$ concentration of the calibration gas over 3 mo shows the capability of the system for handling environmental variation and drift. As far as we know from the literature, this frequent automated calibration is a unique feature of the system, making it easy to use; to start an experiment, one has only to close the door of the chamber. Multiplexing samples in time on one analyzer $(10,14)$, rather than using multiple analyzers, combined with interleaved (frequent) calibration, eliminates the need for temperature and pressure correction $(3,18)$ when momentary concentration values are calculated, because the time of calibration is almost identical to the measurement time ( $\leq 15 \mathrm{~min})$.

\section{Validation}

The results of the alcohol-combustion tests were $-0.3 \pm 1.6 \%$ for $\mathrm{CO}_{2}$. One factor determining the accuracy is the $\mathrm{CO}_{2}$ concentration in the calibration gas, which in our case was determined to be $0.8 \pm 0.008 \%$. Elimination of this possible source of deviation would require a certificate with an accuracy of $0.8 \pm 0.0008 \%$ for the $\mathrm{CO}_{2}$ component 
and possibly further improved linearization of the analyzers. However, neither was available.

The $0.5 \pm 2.0 \%$ result for $\mathrm{O}_{2}$ is only achievable with analyzers that perform well within the factory specification and requires meticulous sample preparation and stable laboratory conditions. The reason for this is the $\sim 20 \% \mathrm{O}_{2}$ background in all measured air because every type of analyzer has to deal with a $20 \%$ background in relation to a $1 \%$ measurement span, requiring a $21 \%$ physical measurement range for a $1 \%$ differential physiological range. This is easily understood for massspectrometer (17) and paramagnetic optical analyzers that measure one gas stream; they can only be differential in time $(10,14)$. However, it is also valid for dual-gas stream differential analyzers because these use dual compartments (magnetic wind principle) for comparison, and in each of these compartments the $20 \%$ background again largely determines the signal-to- noise ratio. Because the result of subtracting the background in differential analyzers is instantaneous, it is often erroneously assumed that the $20 \%$ background is eliminated from the physical measurement.

Alcohol combustion is normally used for checking experiments because it tests $\dot{V} \mathrm{O}_{2}$ and $\dot{V} \mathrm{CO}_{2}$ simultaneously and experiments are easy to perform. However, for troubleshooting, $\mathrm{CO}_{2}$ and $\mathrm{N}_{2}$ infusion is the method of choice because it is independent of a chemical reaction. The slightly larger error margin in the $\mathrm{CO}_{2}$ - infusion experiments (over several years) compared with the regular alcohol-combustion experiments (over $1 \mathrm{yr}$ ) is attributable to the fact that gas infusion was mostly used for troubleshooting when a problem was detected.

\section{Response Time and Measurement Interval}

In the literature, two types of system responses are given. One is actually the time constant (therefore, not referred to as response time in this study) of the mixing process (8, $12,15)$, and the other is the (90-99\%) response time of the complete system to a change in energy expenditure $(4,6,11,12,14)$. The response time incorporates the mixing time constant (because all air should first be well mixed) and will therefore be larger than the mixing time constant. The response time is only important, in part, when measurement protocol is decided on, i.e., rate of change of energy expenditure to be measured. The volume of the chamber, the rate of gas flow through the chamber, and the accuracy of the gas measurement determine the interval (duration) needed to reach $95 \%$ of accuracy. Normally, this interval is at least $1 \mathrm{~h}$, as can be seen from calibration experiments (Table 1, Refs. 4, 6, 8, 11, 12, 15-17, 19), even if the response time is much smaller $(4,6,11,12,14,15,17)$. Furthermore, it is not proven that subjects will behave in the same way as the testing methods, specifically with respect to the mixing and leaking (push-type chamber) of the subject's expired air, because the subject can direct his breath and move in any direction inside the chamber in an unpredictable 
manner. This may be the reason that virtually all publications refer to a minimum measurement interval (duration) of 15-30 min, as illustrated in Table 1.

Today's line of research is often a combination of long-term observations with shortterm changes in energy expenditure. If, for example, the $\mathrm{O}_{2}$ concentration SD of $0.002 \%$, which is the SD we found for our calibration gas $\mathrm{O}_{2}$ concentration check over 3 mo, is applied to a subject with a $\dot{V} O_{2}$ of $350 \mathrm{ml} / \mathrm{min}$ for a 0.5 -h interval, the resulting SD in $\dot{V} O_{2}$ will be $\sim 3 \%$. In reality, the shorter intervals have a slightly lower SD because the short-term stability of the $\mathrm{O}_{2}$ measurement is better than $0.002 \%$. In addition, the change in concentration of the chamber volume is smaller, which de- creases eventual errors due to nonlinearity of $\mathrm{CO}_{2}$ analyzers.

Table 1. Overview of achieved accuracy of chambers in the literature in relation to test duration

\begin{tabular}{|c|c|c|c|c|c|c|c|c|}
\hline & $\Delta \mathrm{O}_{2}$, 要 & $\Delta \mathrm{CO}_{2}, \%$ & $n$ & $\begin{array}{c}\text { Tested } \\
\text { Duration, h }\end{array}$ & $\begin{array}{c}\text { Suggested } \\
\text { Minimum } \\
\text { Duration, min }\end{array}$ & $\begin{array}{l}\text { Size, } \\
\mathrm{m}^{3}\end{array}$ & $\begin{array}{l}\text { Reference } \\
\text { No. }\end{array}$ & Checking Method \\
\hline & $-1 \pm 2.2(\mathrm{CV})^{2}$ & $0 \pm 2.1(\mathrm{CV})^{*}$ & 5 & $3-24$ & 60 & 27 & 4 & Butane, $\mathrm{N}_{2}+\mathrm{CO}_{2}$ inf \\
\hline & $0.06 \pm 1.21$ & $-0.49 \pm 1.12$ & 5 & $4-6$ & 20 & 30 & 6 & Butane \\
\hline & $+0.44 \pm 0.34$ & $-0.36 \pm 0.5$ & 14 & 1 & $15-30$ & 31 & 8 & Butane \\
\hline & $-0.22 \pm 1.51$ & $0.21 \pm 0.68$ & 14 & 24 & 30 & 34 & 12 & $\mathrm{~N}_{2}, \mathrm{CO}_{2}$ inf \\
\hline & $-0.53 \pm 0.66$ & $-0.05 \pm 1.36$ & 9 & 24 & & 19 & 12 & $\mathrm{~N}_{2}, \mathrm{CO}_{2}$ inf \\
\hline & $2.3-5.8$ & $1.9-4.9$ & 2 & 0.5 & & & 12 & $\mathrm{~N}_{2}, \mathrm{CO}_{2}$ inf \\
\hline & \pm 1.2 & \pm 0.5 & & & & 30 & 13 & $\mathrm{~N}_{2}, \mathrm{CO}_{2}$ inf \\
\hline & $-2.8 \pm 2.8^{*}$ & $-2.1 \pm 2.8^{*}$ & 18 & $3-6$ & & 19 & 15 & Propane \\
\hline & $1.5 \pm 1.4(\mathrm{CV})$ & $1.5 \pm 1.4(\mathrm{CV})$ & 9 & $18-22$ & & 20 & 16 & Alcohol \\
\hline & $0.3 \pm 1.54$ & $0.4 \pm 1.34$ & 30 & $>2-24$ & 30 & 20 & 17 & Alcohol \\
\hline & & $0.4 \pm 0.85$ & 10 & $>2-24$ & & 20 & 17 & $\mathrm{CO}_{2}$ inf \\
\hline & \pm 0.43 & & & & & 15 & 18 & $\mathrm{~N}_{2}$ inf \\
\hline & $-0.5 \pm 2.1$ & $0.2 \pm 2.3$ & 3 & 24 & & 16 & 19 & Propane \\
\hline & $0.5 \pm 2.0$ & $-0.3 \pm 1.6$ & 44 & $2-24$ & 30 & 14 & Present study & Alcohol \\
\hline & & $-0.6 \pm 2.3$ & 20 & $2-24$ & & 14 & Present study & $\mathrm{CO}_{2}$ inf \\
\hline Summary & $+0.13 \pm 1.26$ & $+0.09 \pm 0.95$ & & & & & & \\
\hline
\end{tabular}

Summary mean $\pm \mathrm{SD}$ is average deviation from $0 . \Delta$, Change; $n$, No. of experiments; CV, coefficient of variation; inf, infusion. ${ }^{*}$ Values calculated from literature.

Although the results of "ideal" injection experiments (good mixing, predictable injection flow) show that shorter interval measurements are feasible, we chose the standard of 0.5-h results as the smallest practical time interval with subjects. The smallest experiment duration allowed (limited in software) is $2 \mathrm{~h}$, to provide at least eight automatic calibrations for the off-line calculation, although a minimum of $12 \mathrm{~h}$ is preferred (for instance, one night). The 2-h interval is also used in our standard checking experiments because it illustrates the accuracy for measuring sleeping metabolic rate, which is done over a 2- to 3-h interval (mostly over $3 \mathrm{~h}$ ). Whenever possible, the experiment duration with subjects was chosen to be at least $24 \mathrm{~h}$.

\section{CONCLUSIONS}

The automated system with its intermittent calibration showed stable performance and can effectively be used on a 24-h/day, 7-day/wk basis. The system has a low risk of operating errors. Variations in ambient temperature and pressure have little effect because of the intermittent-calibration method. 


\section{Chapter 4}

The accuracy of the respiration chambers is dependent on the measurement interval (duration) and the level of $\dot{V} O_{2}$ and $\dot{V} \mathrm{CO}_{2}$ to be measured. In our setting, the accuracy, described as a mean error $\pm \mathrm{SD}$, is $2.1 \pm 7.4$ and $1.3 \pm 3.7 \mathrm{ml} / \mathrm{min}$ for $\mathrm{O}_{2}$ and $\mathrm{CO}_{2}$, respectively, for intervals $\geq 2 \mathrm{~h}$. Calculated energy expenditure has an accuracy of $0.7 \pm 2.3 \%$ for an adult consuming $300 \mathrm{ml} / \mathrm{min} \mathrm{O}_{2}$.

On the basis of our experiments, the smallest time interval needed to measure a subject was 15-25 min. When measuring plateau values (constant metabolic rate), one should wait a few minutes ( $\geq 5 \mathrm{~min}$ ) after changing the plateau to accommodate the mixing time constant. The smallest time constant possible was determined, for the most part, by the mixing properties of the chamber, but the smallest practical measurement interval (duration $0.5 \mathrm{~h}$ ) was determined by volume and gas-analysis accuracy.

\section{APPENDIX A}

\section{Glossary}

$\begin{array}{ll}\text { A } & \text { Analyzer-output uncalibrated value } \\ \mathrm{c} & \text { Chamber } \\ \text { cal } & \text { Calibration } \\ \mathrm{F} & \text { Volumetric fraction of gas (STPD) } \\ \mathrm{g} & \text { Any gas } \\ \mathrm{i} & \text { Incoming } \\ \mathrm{o} & \text { Outgoing } \\ \mathrm{P} & \text { Pressure } \\ \mathrm{r} & \text { Recirculation } \\ \mathrm{Rh} & \text { Relative humidity } \\ \mathrm{s} & \text { Time-derivative operator, d/dt } \\ \mathrm{sat} & \text { Saturated with water vapor } \\ \mathrm{T} & \text { Temperature } \\ \mathrm{t} & \text { Time } \\ t_{90} & \text { Response time to 90\% } \\ \tau & \text { Time constant } \\ \tau_{d} & \text { Delay time } \\ \mathrm{V} & \text { Volume (STPD) } \\ \dot{V} & \text { Volumetric flow rate (STPD) } \\ \mathrm{w} & \text { Water vapor }\end{array}$




\section{Mixing Process}

Response time is understood, in general, to be the time needed for the outlet of a process to reach at least $90 \%$ of final value after a step change at the inlet. Percentages used to define the response time vary: $90 \%\left(t_{90}\right), 95 \%\left(t_{95}\right)$, and $99 \%\left(t_{99}\right)$ are often used. A response time may be the result of complex higher-order terms. In contrast, the time constant $(\tau)$ associated with a first-order process of type

$Y(t)=X \cdot\left(1-e^{(-t / \tau)}\right)$ or, better, in process notation $H=1 /(\tau s+1)$

is well defined; e.g., it takes $3 \tau$ to reach $95 \%$ and $10 \tau$ to reach $99.995 \%$ (14.5-bit resolution) of final value.

The first-order system $1 /\left(\tau_{c 1} s+1\right)$ normally associated with a respiration chamber is only valid for a completely mixed volume; in reality, there will always be a small initial mixing interval before a subject's air is well mixed. With the use of recent fast-response respiration chambers, the measurement interval approaches the mixing interval, raising the question of how the mixing interval fits into the equation and which factors affect it.

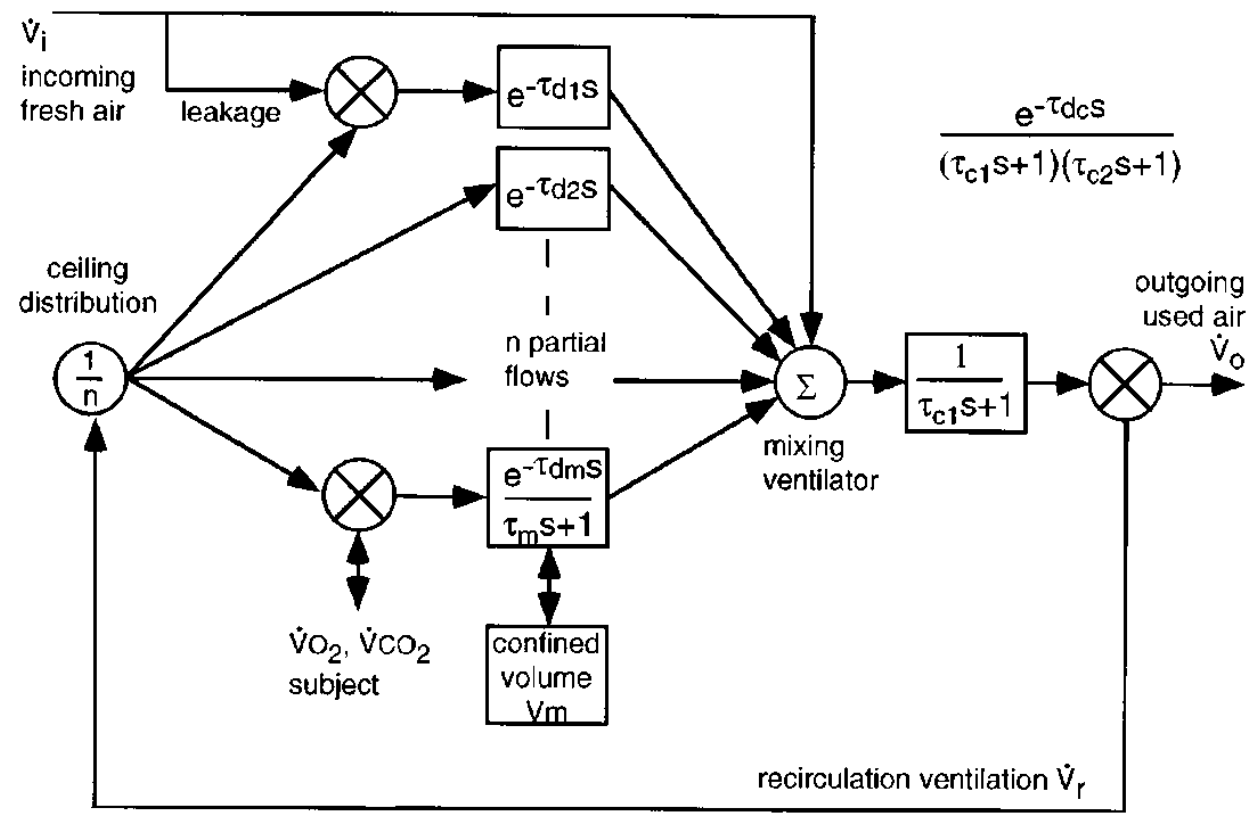

Figure 7. Diagram of 1 st-order system $1 /\left(\tau_{c 1} s+1\right)$ normally associated with a respiration chamber augmented with higher-order terms $\left(\tau_{c 2}\right.$ and $\left.\tau_{d c}\right)$ for mixing. Recirculation flow through chamber can be thought to be sum of several $(n)$ partial pathways, each of which has its own delay time $\tau_{d n}$ and, where confined space is present, a time constant $\tau_{n}\left(\tau_{d c}\right.$ and $\tau_{c 2}$ are a complex composite of values $\tau_{d 1 \sim n}$ and $\left.\tau_{1 \sim n}\right)$. Subject's respiration and possibly leakage take place in some of pathways, depending on subject's position in chamber. For clarity, subject's respiration and confined volume influence have been drawn only in a single pathway; $\dot{V} \mathrm{O}_{2}$ and $\dot{V} \mathrm{CO}_{2}, \mathrm{O}_{2}$ uptake and $\mathrm{CO}_{2}$ production, respectively. 
The recirculation flow through the chamber (if evenly distributed) can be thought to be the sum of several ( $n$ ) partial flows or pathways (Fig. 7), each behaving as a tube reactor. Because diffusion in a tube reactor (backward or axial mixing) is beneficial to mixing and we are interested only in the problematic dominant factors, we chose to consider each flow as an ideal tube reactor with a delay time $\left(e^{-\tau_{d} s}\right)$. If a partial flow $m$ passes a confined space, an additional time constant $1 /\left(\tau_{m} s+1\right)$ is added for that pathway. The subject's expired air enters one or more of the pathways. Leakage will also affect one or more of the pathways, and possibly where the subject respires. In a negativepressure chamber, the direction of the leakage flow prevents loss of subject air and has the same effect as fresh air normally entering the chamber.

Determination of each parameter involved (including position and level of energy expenditure) is difficult; however, most higher-order natural processes can be simplified to the form $K e^{-\tau_{d} s} /\left[\left(\tau_{1} s+1\right) \cdot\left(\tau_{2} s+1\right)\right]$. This is usually also the maximum number of parameters that can be determined from measurement of standard input signals (pulse and step). When the simplified higher-order system $K e^{-\tau_{d c} s} /\left[\left(\tau_{c 1} s+1\right) \bullet\right.$ $\left(\tau_{c 2} s+1\right)$ ] with a respiration chamber $K=1$ (response at $t=\infty$ ) is used, $\tau_{d c}$ and $\tau_{c 2}$ are a complex composite of values $\tau_{d 1 \sim n}$ and $\tau_{1 \sim n}$ from the $n$ partial flows, and the dominant time constant $\tau_{c 1}$ is determined by volume and flow $\left(\dot{V}_{o} / V c\right)$. In the case of evenly distributed flow, $\tau_{d c}$ will be mostly determined by volume and recirculation flow $(V c / \dot{V} r)$ and by the position of the subject in the chamber (i.e., at midpoint $0.5 \cdot V c$ / $\dot{V} r) . \tau_{c 2}$ is the result of backward and axial mixing and exchange with confined spaces. If confined spaces are avoided, $\tau_{c 2}$ will be very small. Determining chamber characteristics from standard input signals (pulse and step) should take into account possible variation of $\tau_{d c}$ and $\tau_{c 2}$.

\section{APPENDIX B}

\section{Calculation of $\dot{\mathrm{V}} \mathrm{O}_{2}$ and $\dot{\mathrm{V}} \mathrm{CO}_{2}$}

We define two moments in time: $t_{1}$ is the start time of a single measurement, and $t_{2}$ is the end time of the measurement, i.e., in our case, $t_{2}-t_{1} \geq 5 \mathrm{~min}$, the smallest usable interval with our sample sequence. A value at $t_{1}, t_{2}$, or $t_{1+2}$ (average over interval $t_{1}$ to $t_{2}$ ) represents the best value calculated from multiple samples for that point in time. Algorithms used ensure that summing values calculated over small intervals are mathematically identical to calculation over one long interval.

The frequent calibration technique allows pressure- and temperature-independent calculations of momentary gas concentration

$$
F_{g}(t)=F_{\text {cal }} \cdot\left[A_{g}(t)-A_{0}(t)\right] /\left[A_{c a l}(t)-A_{0}(t)\right]
$$

For calculation of $\dot{V} \mathrm{O}_{2}$ and $\dot{V} \mathrm{CO}_{2}$, the following parameters can be derived directly 


$$
\begin{gathered}
\mathrm{F}_{\mathrm{iN} 2}(t)=100-\mathrm{F}_{\mathrm{OO} 2}(t)-\mathrm{F}_{\mathrm{iCO} 2}(t) \\
\mathrm{F}_{\mathrm{ON} 2}(t)=100-\mathrm{F}_{\mathrm{OCO} 2}(t)-\mathrm{F}_{\mathrm{OcCO} 2}(t)
\end{gathered}
$$

$\mathrm{P}_{\text {wsat }}(t)$ is derived from $\mathrm{T}_{c}(t)$ by means of a lookup table.

$$
\begin{gathered}
\mathrm{P}_{\mathrm{w}}(t)=\mathrm{Rh}_{\mathrm{c}}(t) \bullet \mathrm{P}_{\mathrm{wsat}}(t) / 100 \\
\dot{V}_{o}(t)=\dot{V}_{O \mathrm{ATP}}(t) \bullet\left[\mathrm{P}_{\mathrm{o}}(t)-\mathrm{P}_{\mathrm{w}}(t)\right] /\left[1013.25 \bullet\left(1+0.00367 \bullet \mathrm{T}_{\mathrm{o}}(t)\right]\right. \\
\mathrm{V}_{\mathrm{c}}(t)=\mathrm{V}_{\mathrm{cATP}} \bullet\left[\mathrm{P}_{\mathrm{c}}(t)-\mathrm{P}_{\mathrm{w}}(t)\right] /\left[1013.25 \bullet\left(1+0.00367 \bullet \mathrm{T}_{\mathrm{c}}(t)\right]\right. \\
\dot{V}_{o \mathrm{OO} 2}(t)=\dot{V}_{o}(t) \bullet \mathrm{F}_{\mathrm{OCO} 2}(t) / 100 \\
\dot{V}_{o \mathrm{CO} 2}(t)=\dot{V}_{o}(t) \bullet \mathrm{F}_{\mathrm{ocCO} 2}(t) / 100 \\
\dot{V}_{o \mathrm{~N} 2}(\mathrm{t})=\dot{V}_{o}(\mathrm{t}) \bullet \mathrm{F}_{\mathrm{ON} 2}(\mathrm{t}) / 100=\dot{V}_{o}(\mathrm{t})-\dot{V}_{o} \mathrm{O}_{2}(\mathrm{t})-\dot{V}_{o} \mathrm{CO}_{2}(\mathrm{t})
\end{gathered}
$$

Next, parameters have to be derived that involve $\dot{V}_{i}(t)$, the flow of the input in STPD. $\dot{V}_{i}(t)$ may be calculated by using the "haldane" correction. The formula used must incorporate changing $\mathrm{N}_{2}$ fractions and STPD correction of the chamber volume as a function of time

$$
\dot{V}_{i}\left(t_{1+2}\right)=\left[\dot{V}_{o}\left(t_{1+2}\right) \bullet \mathrm{F}_{\mathrm{oN} 2}\left(t_{1+2}\right)+\mathrm{V}_{\mathrm{c}}\left(t_{2}\right) \bullet \mathrm{F}_{\mathrm{oN} 2}\left(t_{2}\right)-\mathrm{V}_{\mathrm{c}}\left(t_{1}\right) \cdot \mathrm{F}_{\mathrm{oN} 2}\left(t_{1}\right)\right] / \mathrm{F}_{\mathrm{iN} 2}\left(t_{1+2}\right)
$$

Now that $\dot{V}_{i}(t)$ is known, the following parameters are derived

$$
\begin{gathered}
\dot{V}_{i \mathrm{O} 2}\left(\mathrm{t}_{1+2}\right)=\dot{V}_{i}\left(\mathrm{t}_{1+2}\right) \bullet \mathrm{F}_{\mathrm{iO} 2}\left(\mathrm{t}_{1+2}\right) / 100 \\
\dot{V}_{i \mathrm{CO} 2}\left(\mathrm{t}_{1+2}\right)=\dot{V}_{i}\left(\mathrm{t}_{1+2}\right) \bullet \mathrm{F}_{\mathrm{iCO} 2}\left(\mathrm{t}_{1+2}\right) / 100 \\
\dot{V}_{c \mathrm{O} 2}\left(t_{1+2}\right)=\left[V_{c}\left(t_{2}\right) \bullet \mathrm{F}_{\mathrm{ocO} 2}\left(t_{2}\right)-V_{c}\left(t_{1}\right) \bullet \mathrm{F}_{\mathrm{OCO} 2}\left(t_{1}\right)\right] /\left[100 \bullet\left(t_{2}-t_{1)}\right]\right. \\
\dot{V}_{c \mathrm{CO} 2}\left(t_{1+2}\right)=\left[V_{c}\left(t_{2}\right) \bullet \mathrm{F}_{\mathrm{ocCO} 2}\left(t_{2}\right)-V_{c}\left(t_{1}\right) \bullet \mathrm{F}_{\mathrm{ocCO} 2}\left(t_{1}\right)\right] /\left[100 \bullet\left(t_{2}-t_{1)}\right]\right.
\end{gathered}
$$

This leaves only $\dot{V} \mathrm{O}_{2}$ and $\dot{V} \mathrm{CO}_{2}$ to be calculated

$$
\begin{gathered}
\dot{V}_{\mathrm{O} 2}\left(\mathrm{t}_{1+2}\right)=\dot{V}_{i \mathrm{O} 2}\left(\mathrm{t}_{1+2}\right)-\dot{V}_{c \mathrm{O} 2}\left(\mathrm{t}_{1+2}\right)-\dot{V}_{\mathrm{O} \mathrm{O} 2}\left(\mathrm{t}_{1+2}\right) \\
\dot{V}_{\mathrm{CO} 2}\left(\mathrm{t}_{1+2}\right)=\dot{V}_{\mathrm{OCO} 2}\left(\mathrm{t}_{1+2}\right)+\dot{V}_{c \mathrm{CO} 2}\left(\mathrm{t}_{1+2}\right)-\dot{V}_{i \mathrm{CO} 2}\left(\mathrm{t}_{1+2}\right)
\end{gathered}
$$

\section{AKNOWLEDGEMENT}

The authors acknowledge Dr. P. Webb ${ }^{\dagger}$ for many valuable comments in the field of calorimetry during the past. 


\section{REFERENCES}

1. Atwater, W. O., and F. G. Benedict. Experiments on the Metabolism of Matter and Energy in the Hum an Body. Washing- ton, DC: US Government Printing Office, 1903. (USDA Office of Experiment Stations Bull. No. 136)

2. Benedict, F. G. A helmet for use in clinical studies of gaseous metabolism. N. Engl. J. Med. 203: 150-158, 1930.

3. Brown, D., T. J. Cole, M. J. Dauncey, R. W. Marrs, and P. R. Murgatroyd. Analysis of gaseous exchange in open-circuit indirect calorimetry. Med. Biol. Eng. Com put. 22: 333-338, 1984.

3a. Centre de Recherche Claud-Delorme de L'Air Liquid. Encyclopedie des Gaz. Amsterdam: Elsevier, 1976.

4. Charbonnier, A., C. D. R. Jones, Y. Schutz, P. R. Mur- gatroyd, R. G. Whitehead, E. Je' quier, and G. Spinnler. A whole body transportable indirect calorimeter for human use in the tropics. Eur. J. Clin. Nutr. 44: 725731, 1990.

5. Dauncey, M. J., P. R. Murgatroyd, and T. J. Cole. A human calorimeter for the direct and indirect measurement of 24 h energyexpenditure.Br.J.Nutr.39:557-566,1978.

6. Henning, B., R. Löfgren, and L. Sjöström. Chamber for indirect calorimetry with improved transient response. Med. Biol. Eng. Com put. 34: 207-212, 1996.

7. Heymsfield, S. B., D. B. Allison, F. X. Pi-Sunyer, and Y. Sun. Columbia respiratory-chamber indirect calorimeter: a new ap- proach to air-flow modelling. Med. Biol. Eng. Comput. 32: 406-410, 1994.

8. Je' quier, E., and Y. Schutz. Long-term measurements of energy expenditure in humans using a respiration chamber. Am . J. Clin. Nutr. 38: 989-998, 1983.

9. Kinney, J. M., A. P. Morgan, F. J. Domingues, and K. J. Gildner. A method for the continuous measurement of gas exchange and expired radioactivity in acutely ill patients. Metabo- lism 13: $205-211,1964$.

10. McLean, J. A., and P. R. Watts. Analytical refinements in animal calorimetry. J . Appl. Physiol. 40: 827-831, 1976.

11. Moon, J. K., C. L. Jensen, and N. F. Butte. Fast-response whole body indirect calorimeter for infants. J. Appl. Physiol. 74: 476-484, 1993.

12. Moon, J.K., F.A. Vohra, O.S. Valerio Jimenez, M.R. Puyau, and N. F. Butte. Closed-loop control of carbon dioxide concentra- tion and pressure improves response of room respiration calorim- eters. J . Appl. Physiol. 125: 220-228, 1995.

13. Murgatroyd, P. R., H. L. Davies, and A. M. Prentice. Intra-individual variability and measurement noise in estimates of energy expenditure by whole body indirect calorimetry. Br. J. Nutr. 58: 347-356, 1987.

14. Prentice, A. M., G. R. Goldberg, H. L. Davies, P. R. Mur- gatroyd, and W. Scott. Energy-sparing adaptations in human pregnancy assessed by whole-body calorimetry. Br. J. Nutr. 62: 5-22, 1989

15. Ravussin, E., S. Lillioja, T. Anderson, L. Christin, and C. Bogardus. Determinants of 24-hour energy expenditure in man: methods and results using a respiratory chamber. J. Clin. Invest. 78: 1568 - 1578, 1986.

16. Rumpler, W. V., J. L. Seale, J. M. Conway, and P. W. Moe. Repeatability of 24-h energy expenditure measurements in hu- mans by indirect calorimetry. Am. J. Clin. Nutr. 51: 147-152, 1990.

17. Seale, J. L., W. V. Rumpler, and P. W. Moe. Description of a direct-indirect room-sized calorimeter. Am . J . Physiol. 260 (Endo- crinol. Metab. 23): E306-E320, 1991.

18. Shetty, P. S., M. L. Sheela, P. R. Murgatroyd, and A. V. Kurpad. An open-circuit indirect whole body calorimeter for the continuous measurement of energy expenditure of man in the tropics. Indian J. Med. Res. 85: 453-460, 1987.

19. Treuth, S. M., G. R. Hunter, R. L. Weinsier, and S. H. Kell. Energy expenditure and substrate utilization in older women after strength training: 24-h calorimeter results. J. Appl. Physiol. 78: 2140 - 2146, 1995.

20. Webb, P., and S. J. Troutman, Jr. An instrument for continu- ous measurement of oxygen consumption. J. Appl. Physiol. 28: $867-871,1970$.

21. Weir, J. B. New methods for calculating metabolic rate with special reference to predicting protein metabolism. J. Physiol. (Lond.) 109: 1-9, 1949. 




\section{Chapter}

\section{Intra-individual variability and adaptation of overnight- and sleeping metabolic rate}




\section{ABSTRACT}

The largest component of daily energy expenditure is resting energy expenditure as reflected in overnight metabolic rate (OMR) and sleeping metabolic rate (SMR). Here, we determined the variation in OMR (24:00-6:00 h) and SMR values ( $3 \mathrm{~h}$ intervals) as affected by physical activity (PA) during the day and the night. Subjects were 32 females and 17 males, age 18-52 years. Energy expenditure (EE) was measured for $36 \mathrm{~h}$ in a whole room calorimeter $\left(14 \mathrm{~m}^{3}\right)$, starting in the evening, providing values before and after behavioral limitation. The mean intra-individual coefficient of variation was $1.8 \pm 1.4 \%$ for $\mathrm{SMR}_{\min }$ (minimum EE), $2.8 \pm 2.0 \%$ for $\mathrm{SMR}_{\text {act }}$ (minimum PA), $2.4 \pm 2.5 \%$ for $\mathrm{SMR}_{\text {res }}$ (minimum residual EE, residual calculated from $24 \mathrm{~h}$ relationship between $\mathrm{EE}$ and $P A)$ and $2.8 \pm 2.2 \%$ for OMR ( $n=49)$. Mean clock time for SMR ranged from 3:15 till $4: 13$ h. EE and PA increased in the hour before awakening. Surprisingly, OMR showed a significant $2.7 \%$ increase $(P<0.05)$ during the second night of the 36 h measurement, but only for a second visit, and was related to increased physical activity during night period ( $R 2=0.50, P<0.001$ ). OMR measurements following unrestricted daily activity showed identical results for first and second (repeat) visits: $6.82 \pm 0.86 \mathrm{MJ} /$ day and 6.79 $\pm 0.93 \mathrm{MJ} /$ day $(\mathrm{n}=49$ ), respectively. It is advised to measure SMR based on minimum residual EE during nights following free-living conditions, and to exclude EE measures 1 $\mathrm{h}$ before awakening from SMR and OMR calculations to prevent influences of habitual wake-up time. 


\section{INTRODUCTION}

The largest component of 24-h energy expenditure (24hEE) is resting energy expenditure as reflected in overnight metabolic rate (OMR) and its derivative sleeping metabolic rate (SMR). The other two components of $24 \mathrm{hEE}$ are activity-induced energy expenditure (AEE) and diet-induced energy expenditure (DEE) [1-5]. In this study OMR and SMR using three different methods were measured. Based on variability, and by reviewing modulating factors, an advice is formulated for measuring this major component of daily energy expenditure.

The measurement of OMR and SMR is usually performed inside a whole room calorimeter [3,5-20], effectively limiting the subject's activity due to the confined space. Westerterp and Kester [3] showed a decrease in physical activity level (PAL=24hEE/SMR) from 1.76 to 1.40 for subjects when confined to a $14 \mathrm{~m}^{3}$ whole room calorimeter. Garby et al. [13] found no effect of an activity program (PAL range 1.30 to 1.53 ) on SMR once inside a whole room calorimeter, neither did Goldberg et al. [5]. The reported variability in SMR of about $2 \%$ as observed in whole room calorimeter measurements is generally ascribed to this lower level of AEE $[8,9,11,15]$. However, in contrast to other SMR studies [21-24] a whole room calorimeter will allow normal sleep without facemask, hood or probes $[5,17]$ and is generally considered the instrument of choice for studying night time metabolism.

Several other factors have been shown to modulate overnight metabolic rate and sleeping metabolic rate, including sleep stages, menstrual and seasonal cycles, temperature, diet-induced energy expenditure, daily physical activity and body movement during the night [12-16,18-20]. Unexpected, sleep stages play only a minor role in SMR variability $[3,9,12]$. In women, SMR shows an increase in the range of $8 \%$ to $16 \%$ during the post ovulation phase of the menstrual cycle $[14,23,25]$. Season affects SMR with $4.5 \%$ difference when comparing the summer-low with the winter-high [10]. When subjects stayed in a whole room calorimeter for $60 \mathrm{~h}$ at a temperature of $16{ }^{\circ} \mathrm{C}$ in comparison to $22^{\circ} \mathrm{C}$, SMR increased 5.6\% [26]. The effect of DEE was demonstrated by overfeeding in a late night meal, causing a $6.7 \%$ increase in OMR [5]. Twelve weeks of energy restriction to 2.9-3.5 MJ/day in obese women caused a decline in SMR of 29.9\% [27]. Here we focus on short-term variability of overnight metabolic rate and sleeping metabolic rate.

A steady decrease pattern for SMR, with a low just before wakening of subjects, has been reported [20]. Others found that SMR was at its lowest between 4:00 and 6:00 h $[6,12,28]$. The latter corresponds with the moment of the lowest residual EE [18], calculated as the residual of the individual relationship between energy expenditure and physical activity (PA) over $24 \mathrm{~h}$ [4], and the time of lowest heat production [13]. A decline in OMR, only for subjects that were fed a late night meal, while other subjects were found to have a relatively constant and lower overnight metabolic rate, was also reported [5]. The measurement of OMR and SMR will thus be dependent on the interval chosen. 
The activity component during the night has either been measured $[9,20,26,27]$, discarded [16] or ignored by way of selecting minimum measured energy expenditure $[5,19]$. Systems for measurement of body movement were accelerometry [19], forceplatform [20], level-detection [1,16] and analog doppler [9,17]. In contrast with the latter analog system, both force- platform and level-detection require a minimum activity $[1,16]$, thus exhibiting a "decrease to nearly zero" [20] during the lowest activity period in the night. An advice with regard to the method of choice for incorporating activity measurements as well as regarding the impact of activity during the day has not yet been postulated.

The consistent message in the aforementioned publications was that the significant causes for variation in SMR measurements, if conducted in a whole room calorimeter with a thermoneutral setting, are body movement during the night and diet-induced energy expenditure. Yet, in contrast to the impact of diet-induced energy expenditure the impact of physical activity, both during the day and the night, has been relatively ignored. Here, two mechanisms can be postulated, the impact of the transition from free-living conditions to the confined space of a whole room calorimeter and the impact of activity during the night. Additionally, studies have been hampered by the lack of definition of time-interval. Fixed interval measurements like OMR are generally welldefined, with the exception of intervals being excluded due to subject activity [16]. In contrast SMR measures over a variable interval, for instance the lowest continuous 60 min EE value [5,19], the continuous average over $3 \mathrm{~h}$ with most stable EE value [19] and the continuous average over $3 \mathrm{~h}$ with lowest activity measure $[10,27]$, have in general not provided defined intervals.

In this study, a subject group typical for whole room calorimeter studies was observed, originating from $36 \mathrm{~h}$ experiments where intervention between visits was limited to dietary effects on ad-lib energy requirements. Potential confounders as de- scribed above were kept to a minimum and all experiments used the same protocol. The analysis can thus be considered a best choices meta-analysis.

The application context here was concerned with diminishing the role of activity and time as confounders for OMR and SMR, resulting in advice for choosing the most reproducible method and moment in time as well as for incorporating activity measurements into a less confounded SMR measure. The study thus aimed to answer two questions. Firstly, how does SMR progress during the night in relation to body movement and the residual energy expenditure with attention to time-interval? Secondly, is there an impact on OMR and SMR stemming from the transition from free-living conditions to the behavioral limitation inside the confined space of a whole room calorimeter? 


\section{METHODS}

Data on whole room calorimeter experiments originated from unpublished and published studies from the Maastricht respiration chambers over the period 2004-2007. The selection included low impact diet intervention experiments with healthy adult subjects, measured over $36 \mathrm{~h}$ intervals and starting at 19:00 h. Furthermore, subjects were measured on a first and second visit $(n=49$, Table 1$)$, where the first visit was the subject's first experience in a whole room calorimeter. Inter-visit interval was $32 \pm 18$ days, range 5-91 days. Female subjects were studied in the same phase of the menstrual cycle on both visits. The $36 \mathrm{~h}$ protocol provided for a designated sleeping period from 23:00 h till 7:30 h, furthermore subjects were asked to refrain from unusual or heavy exercise on the day preceding measurements. Subjects provided written informed consent and were assessed by medical history. The Medical Ethical Committee of Maastricht University approved experiments.

Whole room calorimeter measures were taken in a dual respiration chamber system with automated calibration [17]. The analysis system consisted of dual pairs of infra-red CO2 (ABB/Hartmann\&Braun Uras, Frankfurt a.M., Germany) and paramagnetic O2 analysers (Servomex 4100, Crowborough, England and ABB/Hartmann\&Braun Magnos, Frankfurt a.M., Germany). Flow was measured using electronically modified dry gasmeters (G6, gasmeterfabriek Schlumberger, Dordrecht, The Netherlands). Data-acquisition was performed using custom build interfaces (IDEE, University of Maastricht, the Netherlands), a computer (Apple Macintosh, Cupertino, United states) and graphical programming environment (Labview, National Instruments, Austin, United states).

\section{Table 1}

Subject characteristics (mean $\pm \mathrm{SD})$

\begin{tabular}{lllll}
\hline & Age (years) & Height $(\mathrm{m})$ & Weight $(\mathrm{kg})$ & Body fat $(\%)$ \\
\hline Women $(n=32)$ & $23 \pm 6$ & $1.70 \pm 0.06$ & $66.5 \pm 8.8$ & $27.7 \pm 6.8$ \\
Men $(n=17)$ & $26 \pm 8$ & $1.81 \pm 0.11$ & $75.0 \pm 9.7$ & $14.4 \pm 6.5$ \\
\hline
\end{tabular}

Each room had a volume of $14 \mathrm{~m}^{3}$ with $6.4 \mathrm{~m}^{2}$ floorspace and was furnished with a bed, chair, radio and television, computer, laptop network connection, telephone, handsfree intercom, deepfreeze toilet, hot and cold running water and a desk with built in sink. The rooms had a controlled climate and could be operated from 16 to $28^{\circ} \mathrm{C}$. Subjects were allowed to select their own thermal comfort zone, resulting in a setting $0-3^{\circ}$ higher than at home, in order to compensate for the effects of draught inside the room. The temperature measured was $21.9 \pm 0.9{ }^{\circ} \mathrm{C}$, range $19.8-25.3{ }^{\circ} \mathrm{C}, \mathrm{n}=49$. Humidity was $51 \pm 5 \%$, range $11-18 \mathrm{mBar} \mathrm{H} 2 \mathrm{O}$. Ambient pressure was $1009 \pm 8 \mathrm{mBar}$, range 979-1025 
mBar. Recirculation flow inside the room was at its lowest setting of $1100 \mathrm{l} / \mathrm{min}$ and flow through the rooms was set at 100 I/min STPD. Safety measures included fire alert and on-line gas analysis with cellular phone alert. The calorimeter was validated on a monthly interval with methanol burning. Oxygen and carbon dioxide measures were converted to energy expenditure in joules using the Weir formula [29], values are presented in MJ/day by extrapolating the measured energy expenditure to $24 \mathrm{~h}$. Physical activity was measured with an analog ultrasound doppler system, directly processing the analog Doppler signal from inside the sensor (Advisor DU160, Aritech BV, Roermond, Netherlands).

OMR was calculated over the 24:00 till 6:00 h interval. For SMR measurements, data from the 23:00 till 7:00 h interval was evaluated, providing compatibility with broader intervals found in literature $[2,5,15]$ and providing for SMR results to be found outside the here defined OMR interval if present. SMR measures were calculated for continuous intervals. $\mathrm{SMR}_{\min }$ was defined as the lowest EE value over a $3 \mathrm{~h}$ interval. SMR res was defined as the EE value over a $3 \mathrm{~h}$ interval with the lowest residual energy expenditure $\left(E E_{r e s}\right)$, calculated as the residual of the individual relationship between energy expenditure and physical activity over $24 \mathrm{~h}$ [4] as a measure of diet-induced energy expenditure and diurnal variation of energy expenditure required for maintaining body temperature: For each experiment linear regression of activity $(\mathrm{ACT}(\mathrm{t}))$ and energy expenditure $(\mathrm{EE}(\mathrm{t}))$ over exactly $24 \mathrm{~h}$, calculated from 48 individual $30 \mathrm{~min}$ values, yielded slope (a) and intercept (b) values. The residual energy values were then calculated as EEres $(t)=E E(t)$ - $a \cdot A C T(t)-b$. For this method an analog movement detection system, with continuous values from zero movement upward, was deemed a requirement.

$\mathrm{SMR}_{\text {act }}$ was defined as the EE value over a $3 \mathrm{~h}$ interval with lowest physical activity as measured by the ultrasound system.

OMR and SMR values for the subsequent nights, one after normal daily behavior in freeliving conditions (night 1 ) and one after spending a night and day inside the whole room calorimeter (night 2), were calculated for each visit.

The intra-individual variability was assessed for subsequent nights, providing a shortterm measurement of variability without influence of seasonal [10] and hormone cycle $[14,23,25]$ variation. Subjects were measured in their thermoneutral comfort zone and were not provided with food after dinner, i.e. after 20:00 h, eliminating the impact of ambient temperature variation [26,9] and restricting the impact of diet-induced energy expenditure as described before [5] as well as decreasing the impact of body temperature variation $[13,21]$. 

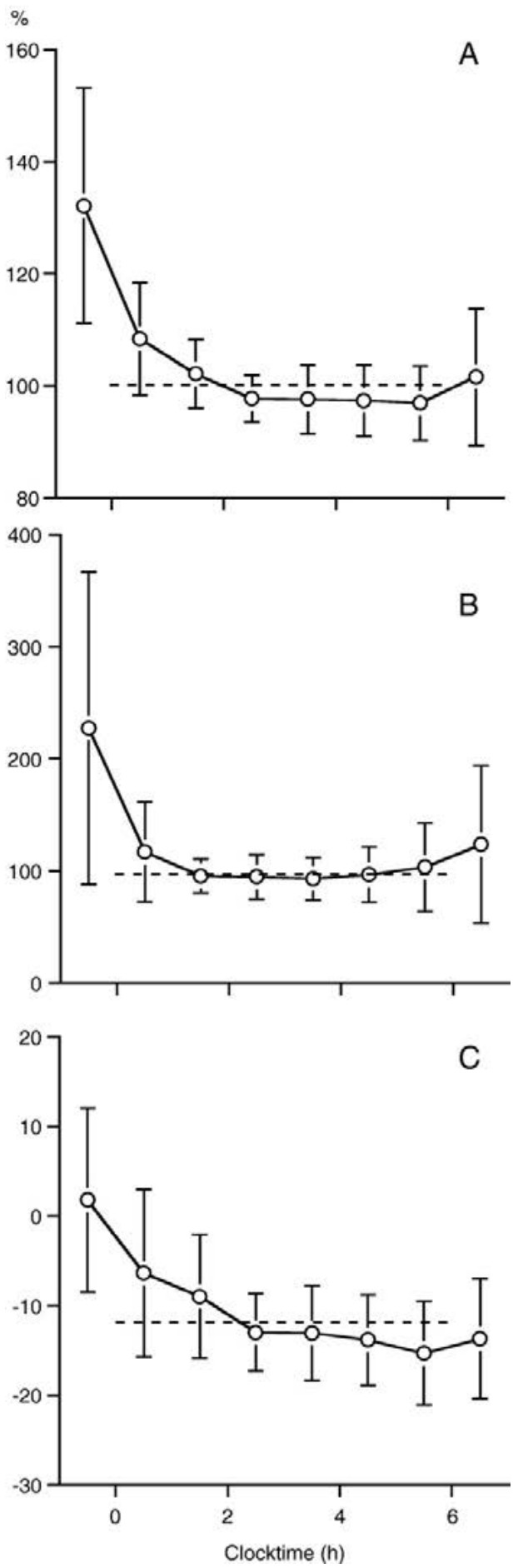

Figure 1. Energy expenditure (A), physical activity (B), and residual energy expenditure $(C)$. Hourly values from 23:00 to 7:00 h expressed as percentage of the mean value of the overnight values from 24:00 to 6:00 h (dotted line). 
Table 2

Overnight metabolic rate (OMR, 0:00-6:00 h) measures, sleeping metabolic rate (SMR) measures with mean time value, respiratory quotient (RQ) and estimated basal metabolic rate (BMRea) for the same subjects on two separate visits

\begin{tabular}{|c|c|c|c|c|c|c|c|}
\hline & Night 1 (MJ/day) & Mean time (hh:mm) & RQ & Night 2 (MJ/day) & Mean time (hh:mm) & RQ & $\mathrm{Cv}(\%)$ \\
\hline \multicolumn{8}{|l|}{ Visit I } \\
\hline OMR & $6.82 \pm 0.86$ & 03:00 & 0.85 & $6.87 \pm 0.80$ & 03:00 & 0.85 & $2.8 \pm 2,2$ \\
\hline $\mathrm{SMR}_{\text {min }}$ & $6.48 \pm 0.77$ & $04: 14$ & 0.86 & $6.49 \pm 0.75$ & $04: 28$ & 0.86 & $1.8 \pm 1.4$ \\
\hline $\mathrm{SMR}_{\text {mat }}$ & $6.63 \pm 0.87$ & $03: 15$ & 0.85 & $6.68 \pm 0.77$ & $02: 56$ & 0.84 & $2.8 \pm 2.0$ \\
\hline $\mathrm{SMR}_{\text {res }}$ & $6.60 \pm 0.83$ & 04:07 & 0.87 & $6.60 \pm 0.87$ & $04: 16$ & 0.86 & $2.4 \pm 2.5$ \\
\hline \multicolumn{8}{|l|}{ Visit 2} \\
\hline OMR & $6.79 \pm 0.93$ & 03:00 & 0.85 & $6.97 \pm 0.90^{*}$ & 03:00 & 0.85 & $3.9 \pm 4.4$ \\
\hline $\mathrm{SMR}_{\min }$ & $6.44 \pm 0.81$ & $04: 10$ & 0.86 & $6.49 \pm 0.75$ & $04: 30$ & 0.86 & $2.8 \pm 2.9$ \\
\hline $\mathrm{SMR}_{\mathrm{mt}}$ & $6.60 \pm 0.84$ & $02: 54$ & 0.85 & $6.67 \pm 0.78$ & $03: 43^{* \bullet}$ & 0.84 & $3.6 \pm 3.0$ \\
\hline $\mathrm{SMR}_{\mathrm{res}}$ & $6.48 \pm 0.82$ & $04: 12$ & 0.86 & $6.57 \pm 0.77$ & $04: 33$ & 0.86 & $2.9 \pm 3.1$ \\
\hline $\mathrm{BMR}_{\mathrm{et}}$ & $6.67 \pm 0.98$ & & & & & & \\
\hline
\end{tabular}

For OMR, calculated over the 0:00 $\mathrm{h}$ till 6:00 h period, the mean time equals $3: 00 \mathrm{~h}$. SMR values are presented for $3 \mathrm{~h}$ minimum energy expenditure (SMR $\mathrm{min}_{\text {) }}$, minimum physical activity $\left(\mathrm{SMR}_{\mathrm{ace}}\right)$ and minimum residual energy expenditure ( $\mathrm{SMR}_{\mathrm{es}}$ ). The intra-individual coefficient of variation and mean time of interval used in this article were from the first visits nights, as these were not significantly different for OMR, SMR and mean time values. A significant increase in OMR for the second night of the second visit was observed, as well as a significant shift in mean time for SMR in comparison to visit 1 .

$* P<0.05$

$* P<0.001$.

Basal metabolic rate $\left(B_{\text {M }}\right.$ est $)$ was estimated from subject characteristics height, weight, age and gender [30]. Body composition was determined by underwater weighing in the morning upon leaving the chamber.

Statistical analysis was performed using Statview software (Abacus concepts inc, Berkeley, United States), significance was based on two-sided paired T-tests and individual CV $\%$ values were calculated as $100 \times$ the unbiased standard deviation of the difference divided by the mean value. Furthermore Cv \% values were not corrected for measurement noise, responsible here for $0.4 \%$ of reported Cv \% [15].

\section{RESULTS}

There were no significant or trend-like changes in ambient factors between visits and nights, temperatures were statistically identical.

Energy expenditure showed a rapid decline after 23:00 h, the time subjects prepared for the night, until 2:00 $\mathrm{h}$ followed by a steady decrease till the 5:00-6:00 $\mathrm{h}$ interval and a rise during the 6:00-7:00 h interval before wakening (Fig. 1A). Physical activity showed a similar decrease between 23:00 $\mathrm{h}$ and 2:00 $\mathrm{h}$, followed by a plateau until approximately 5:00 $\mathrm{h}$ and then a rise in activity before wakening (Fig. 1B). The residual of the individual relationship between energy expenditure and physical activity, as a measure for diet-induced energy expenditure and the variation in energy expenditure required for maintaining body temperature, showed a decrease over the night until a minimum was reached between 5:00 $\mathrm{h}$ and 6:00 $\mathrm{h}$ (Fig. 1C).

On the first visit, there was no significant difference between expenditure measures for night 1 and night 2 . The mean intra-individual variation for these nights was the smallest for $S M R_{\min }$ and $S M R_{\text {res }}$ with a value of $1.8 \pm 1.4$ and $2.4 \pm 2.5 \%$, respectively (Table 2 ). The mean clock time for measured $3 \mathrm{~h}$ intervals varied from 3:15 $\mathrm{h}$ till 4:13 $\mathrm{h}$, indicating 
that the $3 \mathrm{~h}$ minima for $\mathrm{EE}_{\min }, \mathrm{EE}_{\mathrm{act}}$ and $\mathrm{EE}_{\mathrm{res}}$ were on average all found within the 1:45 $\mathrm{h}$ till 5:43 h time frame.

Expenditure values of a second night showed a tendency to be higher, this difference was found to be larger at a second visit to the whole room calorimeter. On a first visit there was no significant difference between night 1 and night 2, whereas on a second visit the OMR for the second night increased $2.7 \%(P<0.05, n=49)$.

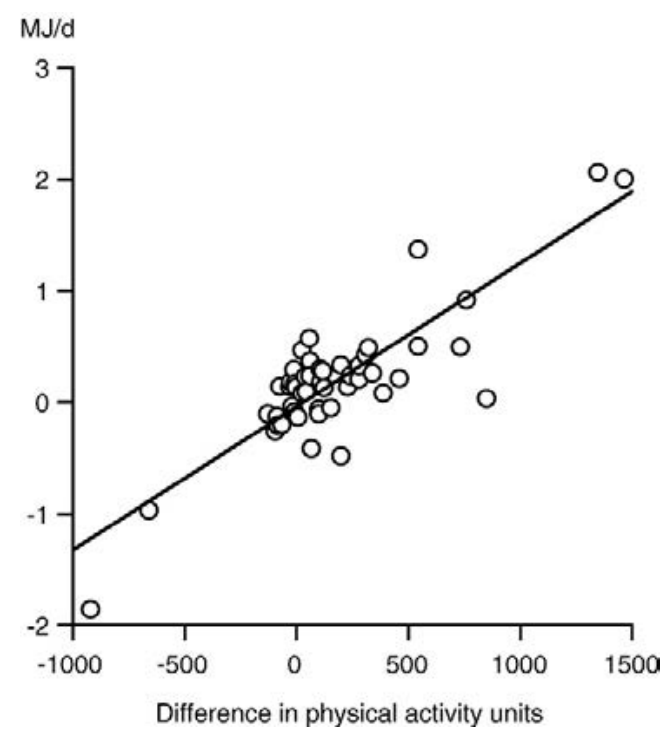

Figure 2. Difference in energy expenditure between night 1 and night 2 (24:00- 6:00 h) for a second visit to the respiration chamber, in relation to the difference in physical activity for the same interval.

The increase in OMR on the second night of a second visit was related to physical activity (Fig. 2). The mean intra-individual variation values for the second visit were deemed confounded in light of the simultaneous increase in OMR during these nights.

The clock time for $S M R_{\text {act }}$ showed a shift of $50 \mathrm{~min}(P<0.001)$ on the second visit, which was the only significant shift in clock times found.

There was no significant difference in SMR and OMR measures when comparing night 1 of the first and second visit. There was no significant difference in respiratory quotient $(R Q)$ values between nights and visits, except for a small difference in $R Q$ values between residual and activity methods $(P<0.01)$.

\section{DISCUSSION AND CONCLUSIONS}

The shape of the energy expenditure curve during the night (Fig. 1A) was similar to earlier observations by Fontvieile et al. [12], Garby et al. [13] and others [6,28], with a 
minimum in the 4:00 $\mathrm{h}$ to 6:00 $\mathrm{h}$ interval. Zhang et al. [20] also found a steady decline in energy expenditure during the night, but with the minimum just before wakening the subjects. The change in overnight energy expenditure curve can be seen to be the combination of physical activity (Fig. 1B) and residual energy expenditure (Fig. 1C), both of which show a rapid decline till approximately 2:00 $\mathrm{h}$. The phase relation of the figures indicates that the combined decline is for the greater part initially driven by the decline in activity, while the decline of the residual is of a smaller percentage but progressing longer into the night. The Y-axis of Fig. 1 is expressed in relative percentages, and although activity (Fig. 1B) might seem to decline in advance of measured energy expenditure (Fig. 1A) this is not the case but merely illustrates this larger initial decline of activity. Garby et al. [13] and Webb [31] showed that subjects are not in heat balance during the night, where subjects heat-loss is different from subjects heat production, i.e. subjects are losing heat to the ambient resulting in a lowering of body temperature. During the interval from 2:00 till 6:00 h diet-induced energy expenditure together with subjects decline in body temperature is thought to be the main cause for the remaining slow decline in energy expenditure, while the effect of activity remained at an almost constant plateau value from 2:00 h till 5:00 h. After 5:00 h physical activity started to increase.

In contrast to the energy expenditure curve found here, Goldberg et al. [5] reported a relatively constant overnight metabolic rate, unless a late night meal was provided. The effect of diet-induced energy expenditure thus must have had a faster rate of decline than in our setting, possibly related to the size of the last meal. The absence of an increase in energy expenditure before awakening, as found in research by both Goldberg et al. [5] and Zhang et al. [20], was speculated on by Zhang et al. [20] as being caused by not allowing subjects to wake naturally, i.e. due to staff awakening the subjects. The data presented here agreed with this speculation and it is suggested that depending on subject group characteristics the effect of circadian pattern may cause subjects to wake naturally at a different time due to differences in habitual sleep time. Fraser et al. [22] concluded that the circadian cycle was a main factor controlling sleeping metabolic rate, and though Fraser et al.'s [22] conclusion that the rapid decrease of energy expenditure at the onset of sleep was not related to diet-induced energy expenditure did not agree with the data presented here, the subjects habitual circadian pattern may indeed have resulted in differences in activity and restoration of body temperature between subject groups as observed in the hours before awakening. The observed intra-individual variability for OMR of $2.8 \%$ (Table 2 ) was comparable to OMR variability found in literature $[5,8,15]$ of 1.4 to $2.7 \%$. The variability found here can be ascribed in part to the smaller OMR interval used, causing a decrease in variability due to the lesser impact of physical activity in the selected interval, and in part to the effect of natural awakening as observed in the subject group causing an increase in variability. During the night, the intraindividual variability decreased to $1.8 \%$ for $\mathrm{SMR}_{\min }$ and $2.4 \%$ for $\mathrm{SMR}_{\text {res }}$ as effects of residual energy expenditure and activity decreased. 
The different definitions of the time-interval chosen for OMR and SMR will yield different values. Wouters-Adriaens and Westerterp [19] defined SMR as the $3 \mathrm{~h}$ interval with most stable energy expenditure, which was $4.6 \%$ below BMR. Here, the $\mathrm{SMR}_{\min }$ and $\mathrm{SMR}_{\text {res }}$ were $5.0 \%$ and $3.3 \%$ lower respectively in comparison to overnight metabolic rate $(P<0.001, P<0.0001)$. The results acquired from minimal residual energy expenditure in our view provide the best measure for selecting sleeping metabolic rate intervals when incorporating physical activity measurements, furthermore it is deemed advisable to restrict OMR and SMR measurement intervals to at least $1 \mathrm{~h}$ before wakening the subjects or alternatively to before 6:00 h.

One surprising aspect of this study was the fact that on the second night of the $36 \mathrm{~h}$ protocol, after the relative calm of confined behavior, the overnight metabolic rate increased significantly. An early indication of this effect was found when 160 experiments with a $36 \mathrm{~h}$ protocol as used in this study were evaluated, and an increase in OMR for the second night of 1.4\% ( $P=0.01)$ was found. The smaller dataset presented here results in lower significance $(P<0.05)$ but also offers an explanation for the found effect; subjects' first experience in a whole room calorimeter is different from repeat experiments when subjects have already become accustomed to the laboratory setting. This is illustrated by the fact that on a first visit no significant differences between OMR and SMR values for the two nights in the $36 \mathrm{~h}$ experiments are found (Table 2), however, on the second visit a significantly elevated OMR as well as a trend towards an increase in SMR for the second night of the $36 \mathrm{~h}$ experiment was observed. Since there was no significant difference in OMR, SMR and temperature for night 1 of the first and second visit it seems unlikely that any form of intervention other then behavioral adaptation causes this increase in metabolism. For energy expenditure measurements following a $36 \mathrm{~h}$ protocol, and possibly longer protocols, it is advisable to use the night following free-living conditions for OMR and SMR evaluation.

\section{ACKNOWLEDGEMENTS}

Authors would like to thank M.P. Lejeune, A. Smeets and A. Hochstenbach-Waelen for the contribution of data from their experiments. 


\section{REFERENCES}

[1] Jequier E, Schutz Y. Long-term measurements of energy expenditure in humans using a respiration chamber. Am J Clin Nutr 1983;38(6): 989-98.

[2] Rumpler WV, Seale JL, Conway JM, Moe PW. Repeatability of 24-h energy expenditure measurements in humans by indirect calorimetry. Am J Clin Nutr 1990;51(2):147-52.

[3] Westerterp KR, Kester AD. Physical activity in confined conditions as an indicator of free-living physical activity. Obes Res 2003;11(7):865-8.

[4] Westerterp KR, Wilson SA, Rolland V. Diet induced thermogenesis measured over $24 \mathrm{~h}$ in a respiration chamber: effect of diet composition. Int J Obes Relat Metab Disord 1999;23(3):287-92.

[5] Goldberg GR, Prentice AM, Davies HL, Murgatroyd PR. Overnight and basal metabolic rates in men and women. Eur J Clin Nutr 1988;42(2):137-44.

[6] Ravussin E, Burnand B, Schutz Y, Jequier E. Twenty-four-hour energy expenditure and resting metabolic rate in obese, moderately obese, and control subjects. Am J Clin Nutr 1982;35(3):566-73.

[7] Westerterp KR, Meijer GA, Schoffelen P, Janssen EM. Body mass, body composition and sleeping metabolic rate before, during and after endurance training. Eur J Appl Physiol Occup Physiol 1994;69(3):203-8.

[8] Astrup A, Thorbek G, Lind J, Isaksson B. Prediction of 24-h energy expenditure and its components from physical characteristics and body composition in normal-weight humans. Am J Clin Nutr 1990;52(5):777-83.

[9] Buemann B, Astrup A, Christensen NJ, Madsen J. Effect of moderate cold exposure on 24-h energy expenditure: similar response in postobese and nonobese women. Am J Physiol 1992;263(6 Pt 1):E1040-5.

[10] Plasqui G, Kester AD, Westerterp KR. Seasonal variation in sleeping metabolic rate, thyroid activity, and leptin. Am J Physiol 2003;285(2): E338-43.

[11] De Boer JO, Van Es AJ, Vogt JE, Van Raaij JM, Hautvast JG. Reproducibility of 24 h energy expenditure measurements using a human whole body indirect calorimeter. Br J Nutr 1987;57(2):201-9.

[12] Fontvieille AM, Rising R, Spraul M, Larson DE, Ravussin E. Relation- ship between sleep stages and metabolic rate in humans. Am J Physiol 1994;267(5 Pt 1):E732-7.

[13] Garby L, Kurzer MS, Lammert O, Nielsen E. Energy expenditure during sleep in men and women: evaporative and sensible heat losses. Hum Nutr 1987;41(3):225-33.

[14] Meijer GA, Westerterp KR, Saris WH, ten Hoor F. Sleeping metabolic rate in relation to body composition and the menstrual cycle. Am J Clin Nutr 1992;55(3):637-40.

[15] Murgatroyd PR, Davies HL, Prentice AM. Intra-individual variability and measurement noise in estimates of energy expenditure by whole body indirect calorimetry. Br J Nutr 1987;58(3):347-56.

[16] Ravussin E, Lillioja S, Anderson TE, Christin L, Bogardus C. Determinants of 24-hour energy expenditure in man. Methods and results using a respiratory chamber. J Clin Invest 1986;78(6):1568-78.

[17] Schoffelen PF, Westerterp KR, Saris WH, Ten Hoor F. A dual-respiration chamber system with automated calibration. J Appl Physiol 1997;83(6): 2064-72.

[18] Westerterp KR. Diet induced thermogenesis. Nutr Metab 2004;1(1):5 [electronic resource].

[19] Wouters-Adriaens MP, Westerterp KR. Basal metabolic rate as a proxy for overnight energy expenditure: the effect of age. Br J Nutr 2006;95(6): 1166-70.

[20] Zhang K, Sun M, Werner P, Kovera AJ, Albu J, Pi-Sunyer FX, et al. Sleeping metabolic rate in relation to body mass index and body composition. Int J Obes Relat Metab Disord 2002;26(3):376-83.

[21] Webb P, Hiestand M. Sleep metabolism and age. J Appl Physiol 1975;38(2): 257-62.

[22] Fraser G, Trinder J, Colrain IM, Montgomery I. Effect of sleep and circadian cycle on sleep period energy expenditure. J Appl Physiol 1989;66(2):830-6.

[23] Henry CJ, Lightowler HJ, Marchini J. Intra-individual variation in resting metabolic rate during the menstrual cycle. Br J Nutr 2003;89(6):811-7.

[24] Mortola JP. Breathing around the clock: an overview of the circadian pattern of respiration. Eur J Appl Physiol Occup Physiol 2004;91(2-3):119-29.

[25] Webb P. 24-hour energy expenditure and the menstrual cycle. Am J Clin Nutr 1986;44(5):614-9. 
[26] Westerterp-Plantenga MS, van Marken Lichtenbelt WD, Strobbe H, Schrauwen P. Energy metabolism in humans at a lowered ambient temperature. Eur J Clin Nutr 2002;56(4):288-96.

[27] van Dale D, Schoffelen PF, ten Hoor F, Saris WH. Effects of addition of exercise to energy restriction on 24-hour energy expenditure, sleeping metabolic rate and daily physical activity. Eur J Clin Nutr 1989;43(7):441-51.

[28] White DP, Weil JV, Zwillich CW. Metabolic rate and breathing during sleep. J Appl Physiol 1985;59(2):384-91.

[29] Weir JBV de. New methods for calculating metabolic rate with special reference to protein metabolism. J Appl Physiol 1949;109(1-2):1-9.

[30] Westerterp KR, Donkers JH, Fredrix EW, Boekhoudt P. Energy intake, physical activity and body weight: a simulation model. Br J Nutr 1995;73(3):337-47. [31] Webb P. The physiology of heat regulation. Am J Physiol 1995;268(4 Pt 2): R838-50. 



\section{Chapter}

\section{Intra-individual variation of basal metabolic rate and the influence of daily habitual physical activity before testing}




\section{ABSTRACT}

The present study determined the intra-individual variation of BMR measurements, using a standard out-patient protocol, with the subjects transporting themselves to the laboratory for the BMR measurements after spending the night at home. The effect of a non-fasting state and variation in daily habitual physical activity the day before testing was evaluated. Eight male and eleven female subjects participated in three BMR measurements with 2-week intervals. Physical activity was estimated with a tri-axial accelerometer for movement registration, during the $3 \mathrm{~d}$ before each BMR measurement. There were no significant differences in estimated BMR (ANOVA repeated measures, $\mathrm{P}=0.88$ ) and in physical activity (ANOVA repeated measures, $\mathrm{P}=0.21$ ). Mean withinsubject CV in BMR was found to be 3.3 (SD 2.1) \%, ranging from 0.4 to $7.2 \%$. Differences between BMR measurements could not be explained by differences in physical activity the day before; however, the mean within-subject CV in BMR changed from 5.7 to $5.2 \%$ after correcting for within-machine variability and from 5.2 to $3.3 \%$ after excluding five measurements because of non-compliance to the protocol including fasting. In conclusion, BMR values measured with a standard out-patient protocol are sufficiently reproducible for most practical purposes despite the within-subject variability in physical activity the day before the measurement. For this purpose, however, nonfasting subjects must be excluded and a regular function check of the ventilated-hood system is recommendable. 


\section{INTRODUCTION}

BMR is the main component of average daily metabolic rate. It is defined as the daily rate of energy metabolism an individual needs to maintain and preserve the integrity of vital functions. A measurement of BMR must meet certain conditions. The subject must be awake and the measurement must be performed in a thermo-neutral environment to avoid heat production or heat loss for maintenance of body temperature. Furthermore, the subject must be in a fasted state (absence of diet-induced thermogenesis) and in rest (absence of activity-induced energy expenditure).

Diet-induced thermogenesis is an increase in energy expenditure (EE) above BMR after eating. A 10-12h fast before BMR measurements is the accepted procedure followed by investigators to eliminate the thermic effect of food on basal EE. However, the time interval required to eliminate any residual effect of physical activity on BMR has not yet been described in a similar way. Some studies have observed that moderate-intensity physical activity elevates metabolic rate for only a few minutes to a few hours (Bahr et al. 1992; Melby et al. 1993; Smith \& McNaughton, 1993; Quinn \& Vroman, 1994; Almuzaini et al. 1998); others observed an elevated BMR for a period of up to $24 \mathrm{~h}$ (Maehlum et al. 1986; Weststrate \& Hautvast, 1990; Herring et al. 1992; Williamson \& Kirwan, 1997; Borsheim et al. 1998; Osterberg \& Melby, 2000; Melanson et al. 2002). Finally, some studies did not observe any effect of physical activity including high-intensity exercise (Freedman-Akabas et al. 1985; Weststrate et al. 1990).

To perform an accurate measurement of BMR, subjects usually stay overnight in a hospital or research centre while nutritional intake and physical activity are strictly controlled, therefore assuring the absence of diet- and activity-induced thermogenesis. However, this method is expensive, time-consuming and inconvenient for both subjects and researchers. Additionally, the aim of most studies is not just an accurate estimation of BMR but rather to detect changes in BMR due to an intervention. Therefore many studies use an out-patient protocol, which means that the subjects transport themselves to the laboratory for the BMR measurement after spending the night at home. Turley et al. (1993), Goran \& Nagy (1996) and Figueroa-Colon et al. (1996) compared the results of the out-patient protocol with the in-patient protocol. Goran \& Nagy (1996) found higher BMR values with the out-patient protocol (Goran \& Nagy, 1996), while Turley et al. (1993) and Figueroa-Colon et al. (1996) did not find significant differences. Turley et al. (1993) and Goran \& Nagy (1996) concluded that an in-patient proto$\mathrm{col}$ is the best for an accurate measurement of BMR. However, the change in BMR due to an intervention can be detected by using either an in-patient or an out-patient protocol (Turley et al. 1993; Goran \& Nagy, 1996). For this application a high reproducibility is especially important.

The aim of the present study was to determine the reproducibility or intra-individual variability of BMR after three repeated measurements, using an out-patient protocol. The disadvantage of an out-patient protocol is the impossibility to supervise the fasting 
state and the physical activity before the measurement. Therefore the present study planned to estimate the influence of variability in daily habitual physical activity and of non-compliance to the protocol including fasting on the reproducibility of BMR measurements. To a lesser degree, the reproducibility of BMR measurements is, for both an in-patient and an out-patient protocol, influenced by the within-machine variability of the ventilated-hood system. Consequently, the present study also focuses on the effect of the within-machine variability. Additionally, the goal of the study was to assess the inter-individual variability of BMR and to explain differences between subjects by differences in physical characteristics.

\section{METHODS}

\section{Subjects}

Nineteen volunteers (eleven females and eight males, mean age 23.6 (SD 7.5) years) participated in the study. Criteria for subject selection were good health (with special attention given to the absence of metabolic diseases), and the absence of any use of medication that could have affected metabolic rate and weight stability during the last 6 months $( \pm 3 \mathrm{~kg})$. Also, the subjects were not consuming special diets or participating in exercise programs. Subjects were informed of the procedures before they gave their consent to participate, and the Medical Ethical Committee of the Maastricht University approved the protocol of the study.

Physical characteristics of the subjects are presented in Table 1.

Table 1. Physical characteristics of the subjects

\begin{tabular}{lcclll}
\hline & \multicolumn{2}{c}{ Male $(n$ 8) } & & \multicolumn{2}{c}{ Female $(n$ 11) } \\
\cline { 2 - 3 } & Mean & SD & & Mean & SD \\
\hline Age (years) & 23 & 5 & & 24 & 9 \\
Body mass $(\mathrm{kg})$ & 78.6 & 14.3 & & 61.7 & 7.2 \\
Height $(\mathrm{m})$ & 1.86 & 0.1 & & 1.73 & 0.1 \\
Fat mass $(\mathrm{kg})$ & 14.4 & 5.9 & & 18.2 & 5.9 \\
Fat-free mass $(\mathrm{kg})$ & 64.3 & 10.3 & & 43.6 & 3.7 \\
\hline
\end{tabular}

\section{Experimental design}

At 1 week before the first BMR measurement a single assessment of body mass was performed. BMR was measured three times at 2-week intervals using a ventilated-hood system. The measurements were repeated at the same time and day of the week for each subject. During the $3 \mathrm{~d}$ before each measurement physical activity was estimated. 
The day of the measurement started with the BMR assessment, followed by an estimation of body weight. An underwater weighing for measuring body density took place at the end of the first and the second day of testing.

The function of the ventilated-hood system was checked with methanol burning, alternately before or after each BMR measurement.

\section{Basal metabolic rate}

Subjects were instructed to fast after 22.00 hours the night before the BMR measurement, and to transport themselves to the research centre in a vehicle or by bus. They were also asked to avoid exercise the day before testing. Using a ventilated-hood system (Omnical, Maastricht University, the Netherlands), BMR was measured for $45 \mathrm{~min}$ at an environmental temperature of $22-24^{\circ} \mathrm{C}$. To eliminate effects of subject habituation to the testing procedure, the respiratory measurements during the first 10 min were discarded, and the following 20min were used to calculate BMR. The criterion for this chosen time interval was the reproducibility of the calculated BMR values, resulting in the last $15 \mathrm{~min}$ of the $45 \mathrm{~min}$ during measurement being excluded because the subjects became more restless at the end of the measurement.

Gas analyses were performed by dual paramagnetic $\mathrm{O}_{2}$ analysers and dual infrared $\mathrm{CO}_{2}$ analysers (type 1156, 1507, 1520; Servomex, Crowborough, Sussex, UK), similar to the analysis system described by Schoffelen et al. (1997). Respiratory gas measurements were corrected for standard temperature, pressure and dry conditions. The Weir equation (Weir, 1949) was used to convert $\mathrm{VO}_{2}$ and $\mathrm{VCO}_{2}$ values to $\mathrm{EE}$ values.

Alternately before or after each BMR measurement, the function of the ventilated-hood system was checked with methanol burning during $20 \mathrm{~min}$. The methanol burner has been set to burn $0.2 \mathrm{~g} / \mathrm{min}$, which is equivalent to the production of $150 \mathrm{ml} / \mathrm{min} \mathrm{CO}_{2}$ and the consumption of $225 \mathrm{ml} / \mathrm{min} \mathrm{O}_{2}$. Since an error percentage is dependent on burn-rate the expression of the error limit in absolute $\mathrm{ml} / \mathrm{min}$ is preferred, hence the limit values of 7.5 and $11 \mathrm{ml} / \mathrm{min}$ for $\mathrm{CO}_{2}$ and $\mathrm{O}_{2}$ respectively $(5 \%$ of $150 \mathrm{ml} \mathrm{CO}$ and $5 \%$ of $225 \mathrm{ml} \mathrm{O}_{2}$ ).

\section{Physical activity}

Habitual physical activity was registered during $3 \mathrm{~d}$ before each BMR measurement with a tri-axial accelerometer for movement registration (Tracmor; Philips Research, Eindhoven, the Netherlands). The accelerometer was an improved version (same principle, but smaller) of the accelerometer used in previous studies (Bouten et al. 1996). It measures accelerations in the anteroposterior, medio-lateral and vertical directions. The dimensions of the accelerometer are $72 \times 27 \times 8 \mathrm{~mm}$ and it weighs $22 \mathrm{~g}$. Subjects wore the accelerometer in a waist belt at the lower back during waking hours and recorded the times when they got up, put the Tracmor on and off, and when they went to 
bed. The registered accelerations in counts per min were used as an objective measure for the physical activity level of each subject.

\section{Body mass and body composition}

Body weight was estimated directly after every BMR measurement as well as 1 week before the first BMR measurement. Subjects were weighed in underwear before any food consumption and after emptying the bladder, on a digital balance accurate to $0.01 \mathrm{~kg}$ (KCC 300; Mettler, Greifensee, Switzerland).

Measurements of body composition were performed twice, both after the first and the second BMR measurement. Body composition was estimated from the three- compartment model of Siri (1956). Underwater weighing with simultaneous assessment of residual lung volume was used to assess body density. The lung volume was measured with the He dilution technique using a spirometer (Volugraph 2000; Mijnhardt, Bunnik, the Netherlands). The ${ }^{2} \mathrm{H}$ dilution method was used to determine total body water according to the Maastricht protocol (Westerterp et al. 1995). Subjects had to drink a ${ }^{2} \mathrm{H}$ dilution ( $70 \mathrm{~g}$ with an enrichment of 5 atom $\%$ excess ${ }^{2} \mathrm{H}$ ) in the evening before the measurements after the collection of a baseline urine sample. The next morning after a $10 \mathrm{~h}$ equilibration period a second urine sample was collected.

\section{Statistics}

Data are presented as mean values and standard deviations. A one-way factor ANOVA for repeated measures was used to compare the three measurements of BMR, physical activity and body weight. The factor sex was taken as a between-subject variable. Furthermore the coefficient of variation, the mean differences between the measurements and the coefficient of correlation were used to compare the BMR values between the three visits for each subject.

To assess the contribution of independent variables to the intra- and inter-variability of BMR measurements multiple and simple linear regression analyses were used.

The SPSS program, version 10 (SPSS Inc., Chicago, IL), was used for the statistical analysis.

\section{Results}

Before the statistical analysis was performed eight measurements were corrected for within-machine variability larger than $7.5 \mathrm{ml} / \mathrm{min}$ for $\mathrm{CO}_{2}$ or $11 \mathrm{ml} / \mathrm{min}$ for $\mathrm{O}_{2}$. Furthermore, five measurements were excluded from the analysis because subjects admitted their non-compliance to the protocol in relation to fasting. Mean measurements of BMR are presented in Table 2. 
Table 2. Basal metabolic rate and physical activity measured repeatedly at 2-week intervals in nineteen adults* (Mean values and standard deviations)

\begin{tabular}{|c|c|c|c|c|c|c|}
\hline & \multicolumn{2}{|c|}{ Measurement 1} & \multicolumn{2}{|c|}{ Measurement 2} & \multicolumn{2}{|c|}{ Measurement 3} \\
\hline & Mean & SD & Mean & SD & Mean & SD \\
\hline BMR (MJ/24h) & $6 \cdot 59$ & $1 \cdot 16$ & $6 \cdot 86$ & $1 \cdot 36$ & $6 \cdot 87$ & $1 \cdot 15$ \\
\hline Body weight (kg) & $68 \cdot 6$ & $13 \cdot 2$ & 68.9 & $13 \cdot 3$ & 69.5 & $12 \cdot 9$ \\
\hline Physical activity day 1 (kcounts/min) & 10288 & 6790 & 9346 & 3587 & 9565 & 2714 \\
\hline Physical activity day 2 (kcounts/min) & 10469 & 5539 & 9706 & 2676 & 9285 & 3137 \\
\hline Physical activity day 3 (kcounts/min) & 9599 & 4695 & 8406 & 3308 & 9204 & 4091 \\
\hline
\end{tabular}

*For details of subjects and procedures, see Table 1

There was no evidence of significant differences in BMR between the three measurements and the variation was not different for men and women (ANOVA repeated measures, $\mathrm{P}=0.88$ ). The mean intra-individual $\mathrm{CV}$ was 3.3 (SD 2.1) \%. The CV of BMR ranged from 0.4 to $7.2 \%$. The mean difference between the three measurements was 0.3 (SD 0.3) MJ/24h (between measurement 1 and 2), 0.2 (SD 0.2) MJ/24h (between measurement 2 and 3) and 0.3 (SD 0.2) MJ/24h (between measurement 1 and 3) (Table 3). The coefficient of correlation was 0.939 between measurement 1 and 2, 0.918 between measurement 1 and 3 and 0.980 between measurement 2 and 3 .

Physical activity tended to be lower the last day before measurement 2 (8406 (SD 3308) kcounts/min) in comparison with the last day before measurement 1 (9599 (SD 4695) kcounts/min) and measurement 3 (9204 (SD 4091) kcounts/min) (Table 2) but the differences were not significant and the variation was the same for men and women (ANOVA repeated measures, $\mathrm{P}=0.21$ ). The physical activity on day 3 and day 2 before the BMR measurement is presented in Table 2 and is similar to the results of the last day before testing (Table 2). The mean intra-individual CV for physical activity was 21 (SD 18) \% and it ranged from 0 to $65 \%$. Differences in body weight between the measurements seemed small (Table 2), but were significant. The variation in body weight did not depend on the factor sex (ANOVA repeated measures, $\mathrm{P}<0.01$ ).

Differences between BMR could not be explained by differences in physical activity the day before testing (simple regression analysis) or by changes in body mass (simple regression analysis). 
Table 3. Coefficient of variation of intra-individual variance in basal metabolic rate and the mean differences between the basal metabolic rate measurements*

(Mean values and standard deviations)

\begin{tabular}{lll}
\hline & Mean & SD \\
\hline $\begin{array}{l}\mathrm{CV}(\%) \\
\text { Difference between measurement 1 and 2 } \\
(\mathrm{MJ} / 24 \mathrm{~h})\end{array}$ & 3.3 & 2.1 \\
$\begin{array}{c}\text { Difference between measurement 2 and 3 } \\
(\mathrm{MJ} / 24 \mathrm{~h})\end{array}$ & 0.3 & 0.3 \\
$\begin{array}{l}\text { Difference between measurement 1 and 3 } \\
(\mathrm{MJ} / 24 \mathrm{~h})\end{array}$ & 0.2 & 0.2 \\
$\begin{array}{l}\text { Coefficient of correlation between measurement 1 } \\
\text { and 2 }\end{array}$ & 0.939 & 0.2 \\
$\begin{array}{l}\text { Coefficient of correlation between measurement 2 } \\
\text { and 3 }\end{array}$ & 0.918 & \\
$\begin{array}{c}\text { Coefficient of correlation between measurement 1 } \\
\text { and 3 }\end{array}$ & 0.980 & \\
\hline
\end{tabular}

*For details of subjects and procedures, see Table 1

The mean inter-individual CV of BMR measurements was 18.0 (SD 1.6) \% and thus much larger than the intra-individual CV of BMR measurements. Most of this variation was explained by fat-free mass differences between the subjects $\left(r^{2} 0.76, \mathrm{P}<0.001\right.$; simple regression analysis). Other variables, including physical activity the day before testing, did not explain any additional variation in BMR after adjustment for fat-free mass.

\section{DISCUSSION}

The intra-individual CV in the present study was 3.3 (SD 2.1) \% with a range from 0.4 to 7.2\%. Similar results were observed by others (Table 4; Murgatroyd et al. 1987; Fredrix et al. 1990; Rieper et al. 1993; Figueroa-Colon et al. 1996; Ventham \& Reilly, 1999). Discrepancies could be due to differences in protocol, methodology and study population. The present study quantified potential factors affecting the reproducibility of BMR values, including the habitual physical activity the day before the measurement and non-compliance to fasting.

The measured BMR values were corrected when the subjects appeared not to be in a fasting state and when the within-machine variability was larger than $7.5 \mathrm{ml} / \mathrm{min}$ for $\mathrm{CO}_{2}$ or $11 \mathrm{ml} / \mathrm{min}$ for $\mathrm{O}_{2}$. The correction for the within-machine variability reduced the $\mathrm{CV}$ from 5.7 to $5.2 \%$. After exclusion of measurements because of non-compliance to the protocol including fasting the CV decreased from 5.2 to $3.3 \%$. 
Table 4. Mean intra-individual coefficients of variation for basal metabolic rate measurements as observed in earlier studies

\begin{tabular}{lc}
\hline & CV (\%) \\
\hline Rieper et al. (1993) & $4 \cdot 3$ \\
Figueroa-Colon et al. (1996) & $5 \cdot 8$ \\
Murgatroyd et al. (1987) & $5 \cdot 9$ \\
Ventham \& Reilly (1999) & $2 \cdot 6$ \\
Fredrix et al. (1990) & $3 \cdot 3$ \\
\hline
\end{tabular}

Other authors do not describe these corrections mentioned and this could therefore partly explain the relatively high reproducibility found in the present study.

Differences between the three BMR measurements could not be explained by differences in physical activity the day before testing and by changes in body mass. Subjects were asked to avoid exercise the day before the measurements, but they were not limited in their habitual non-exercise activity. Physical activity the day before testing tended to be lower the day before measurement 2 (8406 (SD 3308) kcounts/min) in comparison with the day before measurement 1 (9599 (SD 4695) kcounts/min) and measurement 3 (9204 (SD 4091) kcounts/min), but the differences between the periods were not significant despite the high intra-individual variability (mean CV 21.5 (SD 18.7) \%).

Earlier studies were not conclusive about the effect of physical activity on BMR measurements (Freedman- Akabas et al. 1985; Maehlum et al. 1986; Weststrate \& Hautvast, 1990; Weststrate et al. 1990; Bahr et al. 1992; Herring et al. 1992; Melby et al. 1993; Smith \& McNaughton, 1993; Quinn \& Vroman, 1994; Williamson \& Kirwan, 1997; Almuzaini et al. 1998; Osterberg \& Melby, 2000; Melanson et al. 2002). Possible explanations for the discrepant results could be differences in the time interval between exercise and BMR measurement as well as variation in duration and intensity of the exercise. The results of several studies suggest that the magnitude of the elevation of EE above resting values during recovery from exercise primarily depends on the intensity of exercise and to a lesser extent on exercise duration (Sedlock et al. 1989; Gore \& Withers, 1990; Bahr et al. 1992; Smith \& McNaughton, 1993; Quinn \& Vroman, 1994; Borsheim et al. 1998). On the other hand, Melanson et al. (2002) found that EE immediately post exercise was elevated after low- and high-intensity exercise compared with no exercise, but they did not find differences in EE between low- and high-intensity exercise during the remainder of the day (Melanson et al. 2002).

Since, in the present study, only non-exercise physical activity was allowed, while the studies mentioned earlier estimated the effect of exercise, an evident influence of variation in non-exercise physical activity was not expected. Thus, in the present study no evidence is found for an important influence of the intra-individual variability of nonexercise activity on the reproducibility of BMR measurements.

The inter-individual CV of BMR in the present study was 18.0 (SD 1.6) \%, much larger than the intra-individual CV of BMR measurements. Most of this variation was explained 
by fat-free mass differences between the subjects $\left(r^{2} 0.76, \mathrm{P}<0.001\right.$; simple regression analysis). Other variables including physical activity did not explain any additional variation in BMR after adjustment for fat-free mass. This is in agreement with studies in which the fat-free mass or the active cell mass was shown to be the best predictor of BMR (Cunningham, 1980, 1991; Welle \& Nair, 1990; Goran \& Nagy, 1996; Lührmann et al. 2001).

In conclusion, the present study showed that BMR measurements as performed with a standard out-patient protocol result in highly reproducible BMR values; specifically, if corrected for non-compliance to the protocol including fasting and for within-machine variability larger than $7.5 \mathrm{ml} / \mathrm{min}$ for $\mathrm{CO}_{2}$ or $11 \mathrm{ml} / \mathrm{min}$ for $\mathrm{O}_{2}$. The lack of supervision of the fasting state is proven to be an evident disadvantage, while in the present study five measurements were excluded because of non-compliance to the fasting state. To assume that subjects will behave according to the rules of a protocol can therefore result in errors. Consequently, it is important to exclude the measurement when subjects admit their non-compliance or in the case of an elevated respiratory quotient. The actual recommendation to refrain from exercise is sufficient to ensure accurate measurements of BMR in a repeated-measures design, while the BMR measurements in the present study were highly reproducible despite the within-subject variability in habitual physical activity. Finally, the correction for the within-machine variability improved the reproducibility and therefore a regular function check is recommendable. The present study proved that it is practically possible to check the function of the ventilated-hood system on a daily basis. On the other hand, this method is somewhat inconvenient and only required if the highest degree of resolution is needed. A weekly methanol calibration seems therefore a reasonable recommendation. 


\section{REFERENCES}

Almuzaini KS, Potteiger JA \& Gree SB (1998) Effects of split exercise sessions on excess postexercise oxygen consumption and resting metabolic rate. Can J Appl Physiol 23, 433-443.

Bahr R, Gronnerod O \& Sejersted OM (1992) Effect of supramaximal exercise on excess postexercise 02 consumption. Med Sci Sports Exerc 24, 66-71.

Borsheim E, Knardahl S, Hostmark AT \& Bahr R (1998) Adrenergic control of post-exercise metabolism. Acta Physiol Scand 162, 313-323.

Bouten C, Verboeket-van de Venne W, Westerterp K, Verduin M \& Janssen J (1996) Daily physical activity assessment: comparison between movement registration and doubly labelled water. J Appl Physiol 81, 1019-1026.

Cunningham JJ (1980) A reanalysis of the factors influencing basal metabolic rate in normal adults. Am J Clin Nutr 33, $2372-2374$

Cunningham JJ (1991) Body composition as a determinant of energy expenditure: a synthetic review and a proposed general prediction equation. Am J Clin Nutr 54, 963-969.

Figueroa-Colon R, Franklin FA, Goran MI, Lee JY \& Weinsier RL (1996) Reproducibility of measurement of resting energy expenditure in prepubertal girls. Am J Clin Nutr 64, 533-536.

Fredrix EWHM, Soeters PB, von Meyenfeldt MF \& Saris WHM (1990) Measurement of resting energy expenditure in a clinical setting. Clin Nutr 9, 299-340.

Freedman-Akabas S, Colt E, Kissilef HR \& Pi-Sunyer FX (1985)

Lack of sustained increase in VO2 following exercise in fit and unfit subjects. Am J Clin Nutr 41, 545-549. Goran MI \& Nagy TR (1996) Effect of the pre-testing environment on measurement of metabolic rate in children.

Int J Obes Relat Metab Disord 20, 83-87. Gore CJ \& Withers RT (1990) Effect of exercise intensity and duration on postexercise metabolism. J Appl Physiol 68, 2362 - 2368.

Herring JL, Mole PA, Meredith CN \& Stern JS (1992) Effect of suspending exercise training on resting metabolic rate in women. Med Sci Sports Exerc 24, 59-65.

Lührmann PM, Herbert BM \& Neuhä user-Berthold M (2001) Effects of fat mass and body fat distribution on resting metabolic rate in the elderly. Metabolism 50, 972-975.

Maehlum S, Grandmontangne M, Newsholme EA \& Sejersted OM (1986) Magnitude and duration of excess postexercise oxygen consumption in healthy young subjects. Metabolism 35, $425-429$.

Melanson EL, Sharp TA, Seagle HM, et al. (2002) Effect of exercise intensity on 24-h energy expenditure and nutrition oxidation. J Appl Physiol 92, 1045-1052.

Melby C, Scholl C, Edward G \& Bullough R (1993) Effect of acute resistance exercise on postexercise energy expenditure and resting metabolic rate. J Appl Physiol 75, 1847-1853.

Murgatroyd PR, Davies HL \& Prentice AM (1987) Intra-individual variability and measurement noise in estimates of energy expenditure by whole body indirect calorimetry. Br J Nutr 58, $347-356$.

Osterberg KL \& Melby CL (2000) Effect of acute resistance exercise on postexercise oxygen consumption and resting metabolic rate in young women. Int J Sport Nutr Exerc Metab 10, 71-81.

Quinn TJ \& Vroman NB (1994) Postexercise oxygen consumption in trained females: effect of exercise duration. Med Sci Sports Exerc 26, 908-913.

Rieper H, Karst H, Noack R \& Johnsen D (1993) Intra- and inter-individual variations in energy expenditure of 14-15-year-old schoolgirls as determined by indirect calorimetry. Br J Nutr 69, 29-36.

Schoffelen PFM, Westerterp KR, Saris WHM \& ten Hoor F (1997) A dual-respiration chamber system with automated calibration. J Appl Physiol 83, 2064-2072.

Sedlock DA, Fissinger JA \& Melby CL (1989) Effect of exercise intensity and duration on postexercise intensity and duration on postexercise energy expenditure. Med Sci Sports Exerc 21, $662-666$.

Siri WE (1956) The gross composition of the body. In Advances in Biological and Medical Physics, vol. IV, pp. 239-280 [JH Lawrence and CA Tobias, editors]. New York, NY: Academic Press. 


\section{Chapter 6}

Smith J \& McNaughton L (1993) The effects of intensity of exercise on excess postexercise oxygen consumption and energy expenditure in moderately trained men and women. Eur J Appl Physiol 67, 420-425.

Turley KR, McBride PJ \& Wilmore JH (1993) Resting metabolic rate measured after subjects spent the night at home vs. at a clinic. Am J Clin Nutr 58, 141-144.

Ventham JC \& Reilly JJ (1999) Reproducibility of resting metabolic rate measurement in children. Br J Nutr 81, $435-437$.

Weir JB (1949) New methods for calculating metabolic rate with special reference to protein metabolism. J Physiol 109, 1-9.

Welle S \& Nair KS (1990) Relationship of resting metabolic rate to body composition and protein turnover. Am J Physiol 258, E990 - E998.

Westerterp KR, Wouters L \& van Marken Lichtenbelt WD (1995) The Maastricht protocol for the measurements of body composition and energy expenditure with labeled water. Obes Res 3, 49-57.

Weststrate JA \& Hautvast GAJ (1990) The effects of short-term carbohydrate overfeeding and prior exercise on resting metabolic rate ad diet-induced thermogenesis. Metabolism 39, $1232-1239$.

Weststrate JA, Weys P, Poortvliet E, Deurenberg P \& Hautvast JGAJ (1990) Lack of a systematic sustained effect of prolonged exercise bouts on resting metabolic rate in fasting subjects. Eur J Clin Nutr 44, 91-97.

Williamson DL \& Kirwan JP (1997) A single bout of concentric resistance exercise increases basal metabolic rate 48 hours after exercise in healthy 59-77-year-old men. J Gerontol 52A, M352 - M355.

Intra-individual variation of BMR 423 




\section{Chapter}

\section{Test-retest variability of $\mathrm{VO}_{2 \max }$ using total- capture indirect calorimetry reveals linear relationship of $\mathrm{VO}_{2}$ and Power}

Paul F. M. Schoffelen, Marcel den Hoed, Eric van Breda, and Guy Plasqui 


\section{ABSTRACT}

This study aimed to analyze the intra-individual variation in $\mathrm{VO}_{2 \max }$ of human subjects using total-capture and free-flow indirect calorimetry. Twenty-seven men ( $27 \pm 5$ year; $\mathrm{VO}_{2 \max } 49-79 \mathrm{ml} \bullet \mathrm{kg}^{-1} \bullet \mathrm{min}^{-1}$ ) performed two maximal exertion tests (CPETs) on a cycle ergometer, separated by a $7 \pm 2$ day interval. $\mathrm{VO}_{2}$ and $\mathrm{VCO}_{2}$ were assessed using an indirect calorimeter (Omnical) with total capture of exhalation in a free-flow airstream. Thirteen subjects performed a third maximal exertion test using a breath-by-breath calorimeter (Oxycon Pro). On-site validation was deemed a requirement. The mean within-subject $\mathrm{CV}$ for $\mathrm{VO}_{2 \max }$ was $1.2 \pm 0.9 \%$ (0.0-4.4 \%) and for $\mathrm{P}_{\max } 1.3 \pm 1.3 \%(0-4.6 \%)$ for the Omnical, $V_{2} \mathrm{O}_{2 \max }$ values with the Oxycon Pro were significantly lower in comparison to Omnical values (3570 versus 3984 and $4061 \mathrm{ml} \bullet \mathrm{min}^{-1} ; \mathrm{p}<0.001 ; \mathrm{n}=13$ ).

Validation results for the Omnical with methanol combustion were $-0.05 \pm 0.70 \%$ (mean $\pm S D ; n=31$ ) at the $225 \mathrm{ml} \bullet \mathrm{min}^{-1} \mathrm{VO}_{2}$ level and $-0.23 \pm 0.80 \%(n=31)$ at the 150 $\mathrm{ml} \cdot \mathrm{min}^{-1} \mathrm{VCO}_{2}$ level. Results using gas-infusion were $0.04 \pm 0.75 \%(\mathrm{n}=34)$ and $-0.99 \pm 1.05$ $\%(n=24)$ over the respective $500-6000 \mathrm{ml} \cdot \mathrm{min}^{-1} \mathrm{VO}_{2}$ and $\mathrm{VCO}_{2}$ ranges. Validation results for the Oxycon pro in breath-by-breath mode were - $2.2 \pm 1.6 \%(n=12)$ for $\mathrm{VO}_{2}$ and $5.7 \pm 3.3 \%(n=12)$ for $\mathrm{VCO}_{2}$ over the $1000-4000 \mathrm{ml} \bullet \mathrm{min}^{-1}$ range.

On a Visual Analogue Scale participants reported improved breathing using the freeflow (score $7.6 \pm 1.2$ versus $5.1 \pm 2.7, p=0.008$ ).

We conclude that total capturing free-flow indirect calorimetry is suitable for measuring $\mathrm{VO}_{2}$ even with the highest range. $\mathrm{VO}_{2 \max }$ was linear with the incline in $\mathrm{P}_{\max }$ over the full range. 


\section{INTRODUCTION}

Maximal oxygen uptake $\left(\mathrm{VO}_{2 \mathrm{max}}\right)$, i.e. the maximal capacity of the cardiovascular system to provide $\mathrm{O}_{2}$ to the working muscle and the capacity of the muscle to use $\mathrm{O}_{2}$ during sustained exercise, is considered the physiological gold standard of cardiovascular fitness (Poole \& Jones 2017). It is an important health parameter as well, as it has been shown that a high $\mathrm{VO}_{2 \max }$ is inversely related with the risk of developing cardiovascular diseases and mortality (Blair et al. 1989; Wei et al. 1999). $V_{2} O_{2 m a x}$ refers to the highest value of $\mathrm{VO}_{2}$ that a person can obtain despite further increase in load. It has been found that under similar circumstances, using an identical test protocol, differences in $\mathrm{VO}_{2 \max }$ are under influence by physiological and/or psychological factors. In this light, the concept of $\mathrm{VO}_{2 \text { peak }}$ represents the $\mathrm{VO}_{2}$ as the single highest value attained during any particular test and can be regarded as a practical but not physiological $V O_{2 \max }$. Improvements in $V_{2}$ max have been shown to have a significant beneficial effect on the reduction of cardio-metabolic risk factors, i.e. a decrease in blood pressure and an increased sensitivity to insulin (Totsikas et al. 2011). As such highly accurate gas exchange analysis is mandatory for assessing reliable information. In addition to the effect on general health, $\mathrm{VO}_{2 \max }$ is repeatedly used as the key parameter for assessing training status and for monitoring progress in especially endurance athletes.

Cardiopulmonary-exercise-tests (CPETs) are usually performed under laboratory conditions using an incremental exercise protocol and technological advanced gas analysis devices (Keren et al. 1980). Breath-by-breath analysis has been recommended as a reliable and accurate method for $\mathrm{O}_{2}$ and $\mathrm{CO}_{2}$ analysis during exercise testing (Poole \& Jones 2017). In order to accurately analyze gas exchange in an airflow up to and beyond athletic levels of $6000 \mathrm{ml} \cdot \mathrm{min}-1$, it is mandatory to assess concentrations of $\mathrm{O}_{2}$ and $\mathrm{CO}_{2}$ in both the inhaled and exhaled air, synchronously (Lundgren et al. 2015). However, breath-by-breath analysis during maximum exercise testing or even below that (Larsson et al. 2004; Perret \& Mueller 2006) requires fast response analyzers, and the response time of the most rapid $\mathrm{O}_{2}$ analyzers is much lower than the physiological maximum of the athlete (Farmery \& Hahn 2000). In such devices airflow is typically measured using a bi-directional flow sensor at the mouth, calibrated with a 2-3L volume syringe prior to testing. A disadvantage of this method is that abnormal or maximum exertion breathing patterns may differ from that of simulated breathing with a calibration syringe or other validation devices (Prieur et al. 1998). A more physiological concern is that gasexchange in the lungs is a continues process even during exhalation and hence, alveolar gas-concentrations continually change (Farmery \& Hahn 2000). Since gasconcentrations at the start of exhalation overlap with the exhalation peak-flow, it is necessary in breath-by-breath calorimetry to measure airflow and gas-concentrations $\left(\mathrm{O}_{2}\right.$ and $\left.\mathrm{CO}_{2}\right)$ in parallel and with parallel timing. Subsequently, the increased breathing frequency that is related to $\mathrm{VO}_{2}$ during an incremental CPET will cause breath-by-breath systems to become inaccurate at higher breathing frequencies (Yamamoto et al. 1987). 
Furthermore, tidal volumes during breathing is not always constant and therefore requires multiple breaths to accurately determine the average $\mathrm{VO}_{2}$ level (Aliverti et al. 2004; Potter et al. 1999; Wessel et al. 1979). Since most validation/calibration systems are not capable of fully simulating the changes during physiological exhalation, or replicate the effects of extreme breathing frequencies or breathing patterns, it is difficult to interpret the results from participants during different tests (Larsson et al. 2004). Inaccuracies using breath-by-breath indirect calorimetry devices have been shown previously to underestimate $\mathrm{VO}_{2}$ at levels as low as $2800 \mathrm{ml} \bullet \mathrm{min}^{-1}$ (Larsson et al. 2004; Perret \& Mueller 2006). Finally, a parameter that usually receives little attention is the discomfort subjects experience during a CPET. Breathing can be troubled by the relative small tubes that might cause some resistance and hence lower outcome of gas exchange parameters during higher stages of a CPET .

In the present study we aimed to investigate gas exchange parameters during maximal exercise testing using an total-capture indirect calorimeter, with the subject breathing without valves or restrictions in a grander stream of air open to the ambient at the inlet, i.e. free-flow. The diluted exhalation of the subject is fully captured and analysed, thereby bypassing limitations as mentioned above for breath-by-breath analysis. Importantly, a complete validation range by gas-infusion and/or alcohol-combustion can be performed on-site for this type of calorimeter without the need for specialized equipment

Therefore, the main purpose of the present study was: 1) to assess reproducibility of $\mathrm{VO}_{2 \max }$ using a total-capture indirect calorimeter (Omnical, Maastricht Instruments, Maastricht, The Netherlands) over a wide range of $\mathrm{VO}_{2}$ values, and 2) to compare the total-capture indirect calorimeter with breath-by-breath analysis.

Validation was of interest for proving biological results found in this study, it is applicable to the individual calorimeters used. It was illustrated once more (Adriaens et al. 2003) that successful validation of any individual calorimeter, regardless of type and brand, is required to prove suitability for the full range of technical- and biological variability expected.

\section{METHODS}

\section{Subjects and protocol}

Twenty-seven healthy young men (age $27 \pm 5 \mathrm{yrs}$; BMI $23.0 \pm 3.0 \mathrm{~kg} \bullet \mathrm{m}^{-2}$ ) performed two maximal CPETs on a calibrated cycle ergometer (Lode, Groningen, the Netherlands), with simultaneous gas-analysis using an Omnical total-capture indirect calorimeter (Omnical, Maastricht Instruments, The Netherlands). A subset of subjects, limited in number to the first 13 by subsequent unavailability of the Oxycon, performed a third maximal CPET test with simultaneous gas analysis using a breath-by-breath indirect 
calorimeter (Oxycon Pro, Jaeger $\mathrm{GMBH}$, Germany). For one participant, no $\mathrm{VO}_{2}$ values could be obtained during the final 2 minutes of the test and hence no $\mathrm{VO}_{2 \max }$ value could be obtained. The order of the three tests was always Omnical - Oxycon Pro Omnical. All CPETs were separated by a $7 \pm 2$ day interval.

Each participant was instructed to refrain from heavy exercise the day before a test. Participants were also asked to remain fasted from 22:00 hr the evening before a CPET. On the day of the test, participants came to the lab by car or by public transportation. After assessment of basal metabolic rate (BMR), participants were offered a standardized breakfast (tea and buns), followed by a 45-60 min rest before performing the maximum CPET. BMR was measured for all participants on their first visit following a previously described protocol to provide an individual baseline $\mathrm{VO}_{2 \mathrm{BMR}}$ (Adriaens et al. 2003). Ten participants, the first ten that volunteered to do so, where asked to participate in a second BMR measurement on the last visit to check if BMR reproducibility was in agreement with previously reported values (Adriaens et al. 2003). Immediately after the CPET test, participants were asked to mark a visual analogue scale (VAS) on the ease of breathing near maximal exertion. (10 cm line, measured as 0-10 score from "bad" to "excellent").

\section{Indirect calorimetry systems}

A facemask (Hans Rudolph Inc., Shawnee, USA) was connected to a T-piece that was placed in a free airstream (Omnical) or turbine with sample-tubing (Oxycon Pro) and next the facemask was placed over the participants' nose and mouth. Great care was taken to use masks that fit without detectable leakage to the participants' face. No gelsealing of the total facemask was used (Prieur et al. 1998).

\section{Omnical}

The Omnical is the fourth generation Omnical and is based on methods developed for whole room calorimetry (Schoffelen et al. 1997; Webb et al. 1988). Analogous to a whole room-calorimeter, during all VO2max tests the participants could breathe freely into a grand stream of air, for this study preset at $4501 \cdot \mathrm{min}^{-1}$, passing through the tubes. No valves were used and the same analysis technology as have been used in whole room calorimeters, were used (Adriaens et al. 2003; Schoffelen et al. 1997). In brief, the system measures total airflow passing the participant's face, and determines gas-concentrations for inspired and expired air with a representative resolution of $\leq 0.001 \%$ (Schoffelen et al. 1997). Inspired air (environment) samples were taken every 2 minutes (analyzer 1), while expired air was analyzed every other 2 minutes (analyzer 1) as well as continuously (analyzer 2), allowing for a normalization between analysers 1 and 2. Calculation was performed using gas exchange formulae as described previously (Brown et al. 1984; Schoffelen et al. 1997). Volume was set to nearly zero and evalua- 
tion intervals set to seconds instead of multiple minutes or hours as for facemask or whole room calorimetry respectively. A calculation interval of 5 seconds was used, while samples were continuously evaluated by the analyzers and acquisition software at a rate up to 50 samples per second. The dependency on breathing frequency was that slow (supine, resting) breathing can be distinguished as individual peaks and valleys, while there is no upper limit for breathing frequency as this averages out as with fast changes in whole room calorimetry (Henning et al. 1996).

In breath-by-breath systems, measuring inhalation and exhalation in sequence through a single tube limits breathing frequency because of two main reasons; 1 ) the response time of the analyzers applied(Farmery \& Hahn 2000), and 2) the averaging of sample due to sequential transport of inhalation and exhalation through a single tube (Yamamoto et al. 1987).

In our study, the gas analyzers of the free-flow indirect calorimeter were calibrated automatically every $15-30$ minutes. Nitrogen gas ( $\geq 99.999 \%$, Linde, The Netherlands) was used to set the zero and a calibration gas with $18 \% \mathrm{O}_{2}$ and $0.8 \% \mathrm{CO}_{2}$ certified to $1 \%$ volumetric content (i.e. $0.18 \% \mathrm{O}_{2}, 0.008 \% \mathrm{CO}_{2}$ ) was used for calibration ( $\mathrm{HiQ}$ specialty gas, Linde, The Netherlands). The $\mathrm{O}_{2}$ content of the calibration gas was further corrected based on the $\mathrm{O}_{2}$ content of fresh air as described earlier for a whole room calorimeter (Schoffelen et al. 1997). Sensors for flow, pressure, humidity and temperature were pre-calibrated and checked at service intervals. Performance of calorimeters in our labs is checked in situ by methanol combustion and infusion tests before and during periods of use (Adriaens et al. 2003; Schoffelen et al. 1997).

\section{Oxycon Pro}

The Oxycon Pro is an open circuit indirect calorimeter that measures flow at the participant's mouth using a bi-directional turbine (Triple V, Jaeger GMBH, Germany). It was calibrated before each test with a 3 liter syringe (Jaeger GMBH, Germany). Gas concentrations $\mathrm{VO}_{2}$ and $\mathrm{VCO}_{2}$ were derived from undiluted samples taken at the turbine and thus alternate between inhaled and exhaled air, synchronously with breathing frequency. For optimal synchronization, the sample delay from turbine-sample-point into the Oxycon is determined with the help of a secondary tube equal to sample tube, used to infuse calibration gas pulses during calibration. $\mathrm{VO}_{2}$ and $\mathrm{VCO}_{2}$ results were stored every 30 seconds. The Oxycon Pro has been validated to achieve accurate results up to 5000 $\mathrm{ml} \cdot \mathrm{min}^{-1} \mathrm{O}_{2}$ uptake (Rietjens et al. 2001). The Oxycon requires users to calibrate its flow sensor before use and to perform a gas calibration. Gas calibration uses an ambient sample (room air) and a certified span gas (typically $5 \% \mathrm{CO}_{2}$ in $\mathrm{N}_{2}$ ) both for calibration of analyzer output and for determining sample synchronization from turbine-sample-point to analyzers. Sensors for pressure, humidity and temperature were pre-calibrated similarly to the Omnical. 


\section{Instrumental validation}

The Omnical was validated both with methanol combustion (simulating BMR $~ 1$ $\mathrm{kcal} \bullet \mathrm{min}^{-1}$ by setting wick height of burner) in a ventilated hood volume, and with gasinfusions in the facemask-connection up to the highest expected level of $\mathrm{O}_{2}$ consumption and $\mathrm{CO}_{2}$ production, range $225-6000 \mathrm{ml} \cdot \mathrm{min}^{-1} \mathrm{VO}_{2}$. The principle of measuring total diluted gas-flow allows for the use of combustion of known quantities of methanol or other fuels, as well as for straightforward infusion of known quantities of gasses (here: $\mathrm{N}_{2}$ and $\mathrm{CO}_{2}$ ). This allows simulation of the full range of $\mathrm{O}_{2}$ consumption and $\mathrm{CO}_{2}$ production, from resting- to elite athletes' levels. Combustion tests provide for water vapor production similar to human breathing, while gas infusion tests are dry unless water vapor is specifically added. In the present study handling of water vapor was validated with the combustion tests for Omnical, no humidity was added to infusion tests.

For validation in the BMR range, methanol (pro-analyse, 99.8\%, Merck Millipore B.V., Amsterdam, The Netherlands) was burned (Adriaens et al. 2003; Schoffelen et al. 1997) at a target $\mathrm{VO}_{2}$ rate of $225 \mathrm{ml} \bullet \mathrm{min}^{-1}$. Infusions were performed for validation in the higher ranges of $\mathrm{CO}_{2}$ (99.99\%, Linde, The Netherlands) and $\mathrm{N}_{2}$ ( $\geq 99.999 \%$, Linde, The Netherlands) (Schoffelen et al. 1997). All measurements where normalized to Standard Temperature and Pressure Dry (STPD) values by measuring temperature, humidity and pressure.

The Oxycon Pro was serviced prior to the study and tested in 12 infusion tests during service using a proprietary dry gas sinusoidal breath-simulator (Mijnhardt, Bunnik, the Netherlands) in the range of $1000-4000 \mathrm{ml} \bullet \mathrm{min}^{-1}$. There was no available system to measure impact of humidity, or changes in breathing pattern, for the breath-by-breath mode. Gas infusion occurred inside the calibration unit's lung-simulation i.e. on the face-mask side of the flow sensor in a variable volume.

For both devices the gasses infused where $\mathrm{N}_{2}$ and $\mathrm{CO}_{2}$. For $\mathrm{CO}_{2}$ the amount measured must equal the amount infused, for $\mathrm{N} 2$ the simulated $\mathrm{O}_{2}$ uptake is derived from dilution of inlet $\mathrm{O}_{2}$ air fraction $\left(\mathrm{FiO}_{2}\right)$ as: $\mathrm{O}_{2}$ uptake simulated $=\mathrm{N}_{2}$ infused $\bullet \mathrm{FiO}_{2} \bullet\left(1-\mathrm{FiO}_{2}\right)^{-1}$

\section{$\mathrm{VO}_{2 \max }$ tests}

All $\mathrm{VO}_{2 \max }$ tests were performed on a calibrated bicycle ergometer according to the protocol of Kuipers et al. (1985). Subjects performed a 5 min warming-up at 100W, after which the workload was increased by $50 \mathrm{~W}$ every $2.5 \mathrm{~min}$. After the respiratory exchange quotient (RER) exceeded 1.0 or the heart rate exceeded $160 \mathrm{bpm}$, workload was increased by $25 \mathrm{~W}$ every $2.5 \mathrm{~min}$. Subjects were verbally encouraged to continue until exhaustion by the researcher. The time to exhaustion was recorded. The maximal workload achieved $\left(P_{\max }\right)$ was calculated as the workload completed $\left(\mathrm{W}_{\text {completed }}\right)$ plus time ( $t$, in sec) in the last stage divided by 150 (sec i.e. 2.5 min) and multiplied with the 
load increment of the final stage $(\Delta \mathrm{W}): \mathrm{P}_{\max }=\mathrm{W}_{\text {completed }}+\Delta \mathrm{W} \cdot \mathrm{t} \cdot 150^{-1}$ (Kuipers et al. 1985).

For the Omnical, $\mathrm{VO}_{2 \max }$ was calculated as the highest moving average $\mathrm{VO}_{2}$ value obtained over 30 consecutive seconds (i.e. six 5 -second values). Additionally, the $\mathrm{VO}_{2 \text { peak }}$ was calculated as the single highest obtained $\mathrm{VO}_{2}$ value (i.e. one $5 \mathrm{sec}$ value). For the Oxycon the highest registered 30 seconds $\mathrm{VO}_{2}$ value was used as $\mathrm{VO}_{2 \max }$.

\section{Statistics}

Agreement between the two $\mathrm{VO}_{2 \max }$ tests with the Omnical, and between the Omnical system and Oxycon Pro were examined using linear regression analysis to examine if the slope of the regression line was significantly different from 1 and the intercept significantly different from 0 . In addition, Lin's concordance correlation coefficients were calculated. This coefficient is used to test reproducibility by taking into account the variation from the line of identity (i.e. slope 1, intercept 0)(Lin 1989). Bland Altman plots were prepared to quantify systematic and random error and a paired t-test was used to test for differences in mean $\mathrm{VO}_{2 \max }$ between both Omnical tests and between the Omnical and Oxycon Pro tests, as well as for the VAS value marked by participants for ease of breathing (Bland \& Altman 1986).

\section{RESULTS}

\section{Instrumenta/ validation}

Validation data for the Omnical were $-0.05 \pm 0.70 \%(n=31)$ for $\mathrm{VO}_{2}$ at $225 \mathrm{ml} \cdot \mathrm{min}^{-1}$ methanol combustion rate and $0.04 \pm 0.75 \%(n=34)$ over the $500-6000 \mathrm{ml} \cdot \mathrm{min}^{-1}$ for infusion rate. $\mathrm{CO}_{2}$ values were $-0.23 \pm 0.80 \%(\mathrm{n}=31)$ at the $150 \mathrm{ml} \cdot \mathrm{min}^{-1}$ methanol combustion rate and $-0.99 \pm 1.05 \%(n=24)$ over the $500-6000 \mathrm{ml} \bullet \mathrm{min}^{-1}$ infusion range. The difference in levels of $\mathrm{O}_{2}(225)$ and $\mathrm{CO}_{2}$ (150) for alcohol combustion is caused by the respiratory quotient (RQ) of alcohol, i.e. 0.6667. For the Oxycon Pro, results were $-2.2 \pm 1.6 \%$ for $\mathrm{VO}_{2}$ $(n=12)$ and $5.7 \pm 3.3 \%$ for $\mathrm{CO}_{2}(n=12)$ over the $1000-4000 \mathrm{ml} \bullet \mathrm{min}^{-1}$ range of the breathing-simulator. Note that alcohol combustion with the Oxycon is only possible in ventilated hood mode, effectively disabling the breath-by- breath mode. For that reason, no methanol combustion tests were performed with the Oxycon Pro, instead the breathing simulator for validation of breath-by-breath mode was used. 


\section{Basal Metabolic Rate (BMR) analysis}

Results for BMR were $258 \pm 28 \mathrm{ml} \cdot \mathrm{min}^{-1} \mathrm{O}_{2}(\mathrm{n}=27)$ and repeatability for BMR between two visits was $2.9 \pm 3.3 \%$ coefficient of variation (CV) $(n=10)$, when including substrate usage energy expenditure (EE) for BMR expressed in $\mathrm{kJ} \bullet \mathrm{kg}^{-1}$ the CV was $3.5 \pm 3.7 \%$.

\section{Repeatability $\mathrm{VO}_{2}$ max Omnical}

The mean within-subject CV for $\mathrm{VO}_{2 \max }$ was $1.2 \% \pm 0.9 \%$ (range $0.0 \%-4.4 \%, \mathrm{n}=27$ ) and for $P_{\max } 1.3 \% \pm 1.3 \%$ (range $0.0 \%-4.6 \%$ ). Both maximum Power output $\left(P_{\max }\right)\left(R^{2}=0.97\right.$, $p<0.001)$ and maximum $\mathrm{VO}_{2}\left(R^{2}=0.98, p<0.001\right)$ were highly correlated (Figure 1 ).

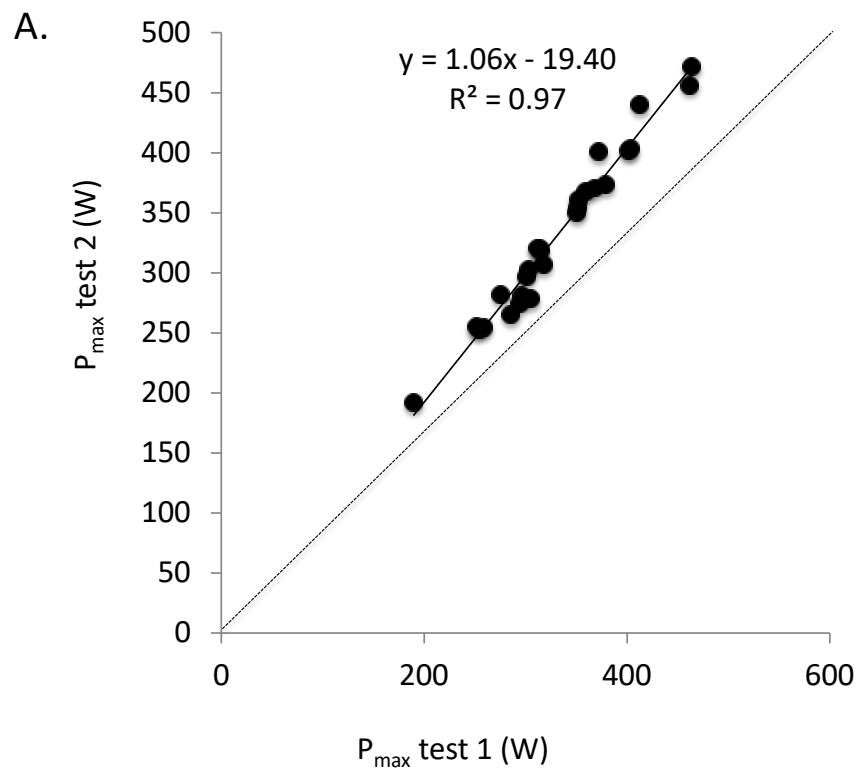



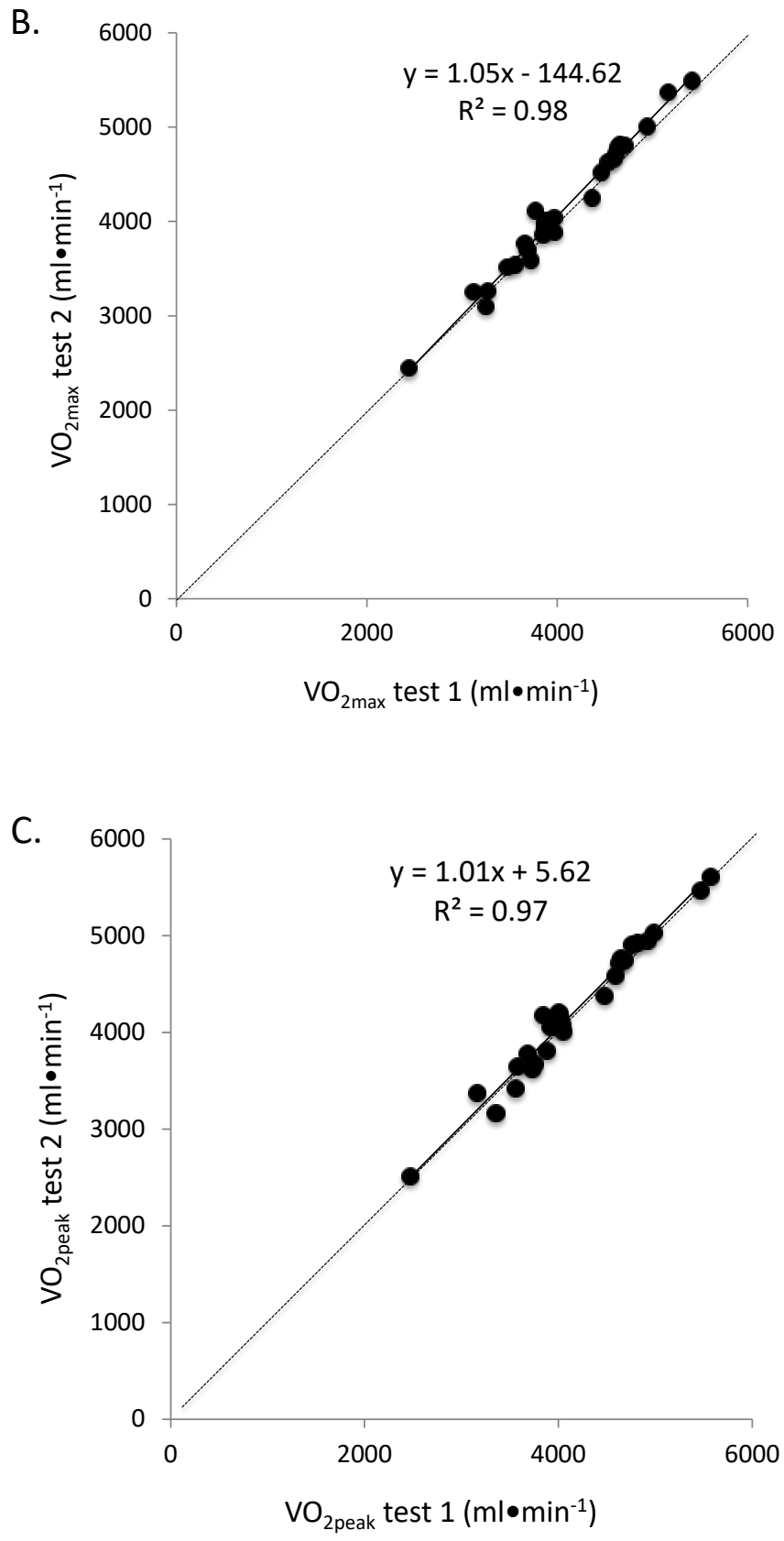

Figure 1. Scatterplot showing the test-retest reproducibility in a) $P_{\max }$, b) $V_{O_{2 m a x}}$ and c) $V_{2} O_{2 p e a k}$ as measured with the Omnical. The full line represents the regression line and the dotted line indicates the line of identity. 
For $\mathrm{VO}_{2 \max }$ the slope of the regression line was not significantly different from 1 (1.05; $95 \% \mathrm{Cl} 0.99$ to 1.11$)$ and the intercept was not significantly different from $0(-145$ $\mathrm{ml} \bullet \mathrm{min}^{-1} ; 95 \% \mathrm{Cl}-396$ to 107$)$. Lin's concordance correlation coefficient was 0.98 . There was a small but significant difference in $\mathrm{VO}_{2 \max }$ between the two Omnical tests $(58 \pm 107$ $\left.\mathrm{ml} \bullet \mathrm{min}^{-1}, \mathrm{p}=0.01\right)$. Bland Altman plots showed a significant and positive correlation between the difference and mean $V_{2 \max }$ of both tests $\left(R^{2}=0.15, p=0.05\right)$ (Figure 2$)$. The same was observed for the $P_{\max }\left(R^{2}=0.15, p=0.04\right)$. When $V_{2} O_{2 \text { peak }}$ was used instead of $\mathrm{VO}_{2 \text { max }}$, the correlation between tests was comparable $\left(R^{2}=0.97, p<0.001\right)$, the slope of the regression line was not significantly different from $1(1.01 ; 95 \% \mathrm{Cl} 0.94$ to 1.08$)$ and the intercept was not significantly different from 0 (6 $\mathrm{ml} \cdot \mathrm{min}^{-1} ; 95 \% \mathrm{Cl}-290$ to 301). The Bland Altman plot for $\mathrm{VO}_{2 \text { peak }}$ did not show a systematic bias proportional to the measured value (Figure 2).

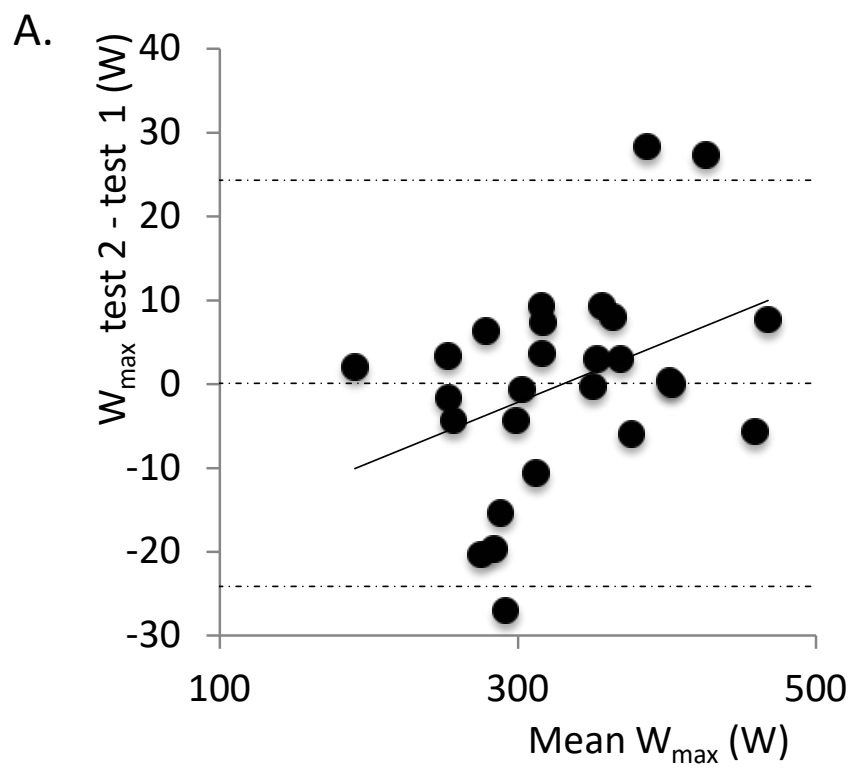


B.
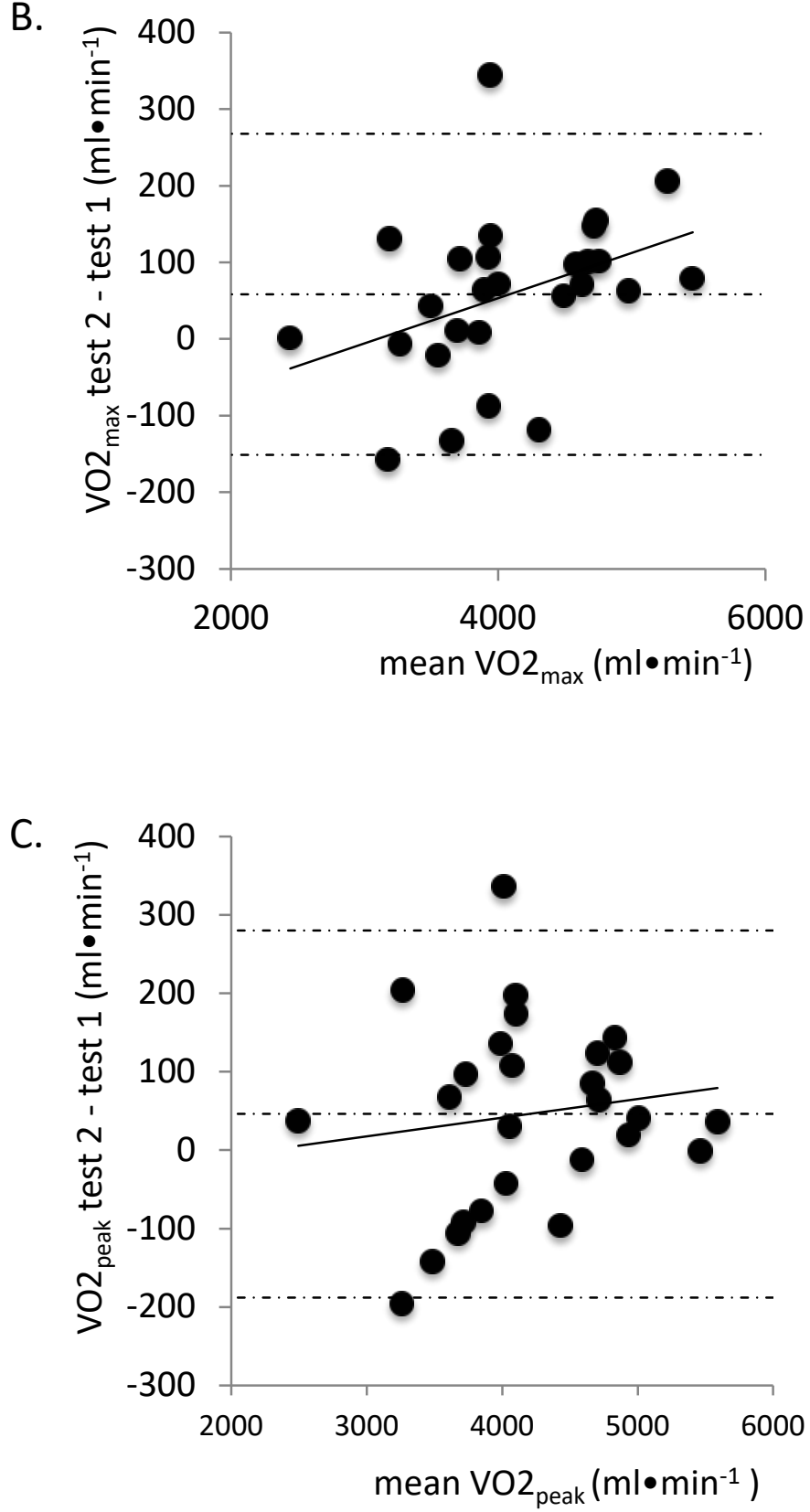

Figure 2. Bland Altman plots showing the mean difference and $95 \%$ limits of agreement between test 1 and 2 on the Omnical. a) $P_{\max }$ (regression line $y=0.07 x-23.9 ; R^{2}=0.15 ; p<0.05$ ), b) $V_{2} O_{\text {max }}$ (regression line $y=0.06 x$ $\left.-183 ; R^{2}=0.15 ; p<0.05\right)$ and $\left.c\right) V_{2 \text { peak }}$ (regression line $y=0.02 x-54 ; R^{2}=0.02 ; p=0.48$ ). 


\section{Comparison Omnical versus Oxycon Pro}

The correlation between the $\mathrm{VO}_{2 \max }$ values as measured by the Oxycon Pro and Omnical was $0.92\left(R^{2}=0.83 ; p<0.001\right)$. The slope $(1.11 ; 95 \% \mathrm{Cl} 0.75$ to 1.41$)$ and intercept (135 $\mathrm{ml} \cdot \mathrm{min}^{-1} ; 95 \% \mathrm{Cl}-1052$ to 1323 ) of the regression line were not significantly different from 1 or 0 , respectively (Figure 3a). Lin's concordance correlation coefficient (Rc) was 0.77 and there was a significant difference in $\mathrm{VO}_{2 \max }$ between the Omnical and Oxycon Pro (3984 and 4061 versus $3570 \mathrm{ml} \bullet \mathrm{min}^{-1}$ respectively; $p<0.001$ ). No difference was observed in $P_{\max }$ or maximal heart rate $\left(P_{\max }\right.$ mean difference $2 \pm 5 \mathrm{~W}, H R_{\max }$ mean difference $2.5 \pm 3.3 \mathrm{BPM} ; \mathrm{p}>0.05)$. The Bland-Altman plot showed a systematic bias that was proportional to the absolute $\mathrm{VO}_{2 \max }$ for the Oxycon Pro (Figure $3 \mathrm{~b}$ ). This is also visualized by plotting $\mathrm{VO}_{2 \max }$ versus $\mathrm{P}_{\max }$ for both the Omnical and Oxycon Pro (Figure 3c).

Visual Analogue Scales (VAS) showed a significant difference in ease of breathing in advantage of the Omnical (7.6 \pm 1.2 vs. $5.1 \pm 2.7, p=0.008)$.

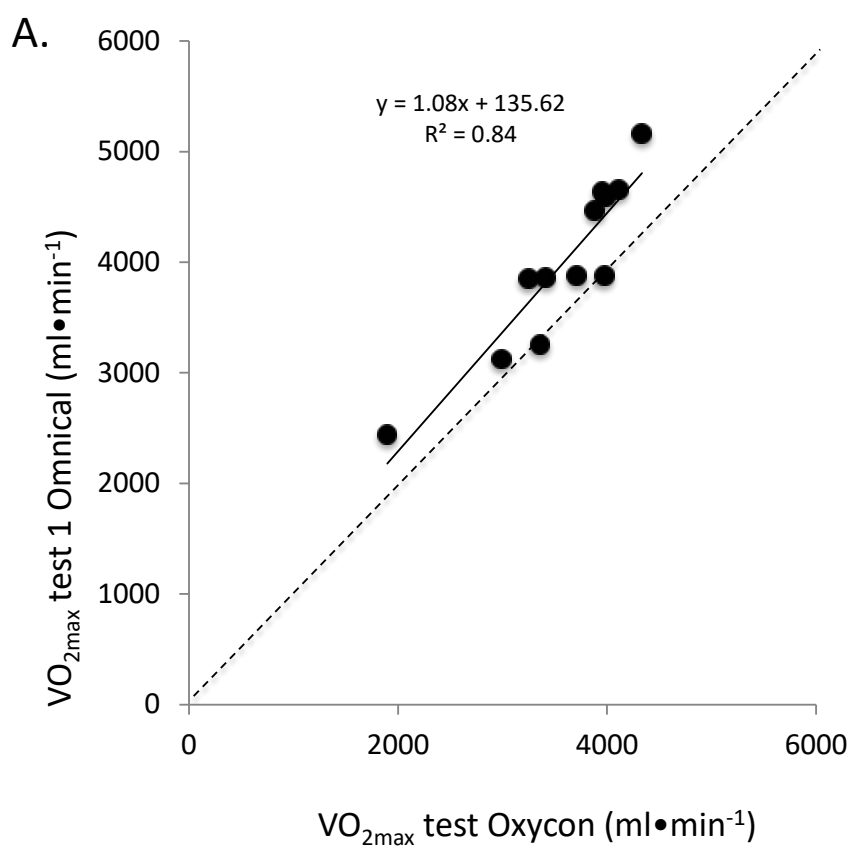



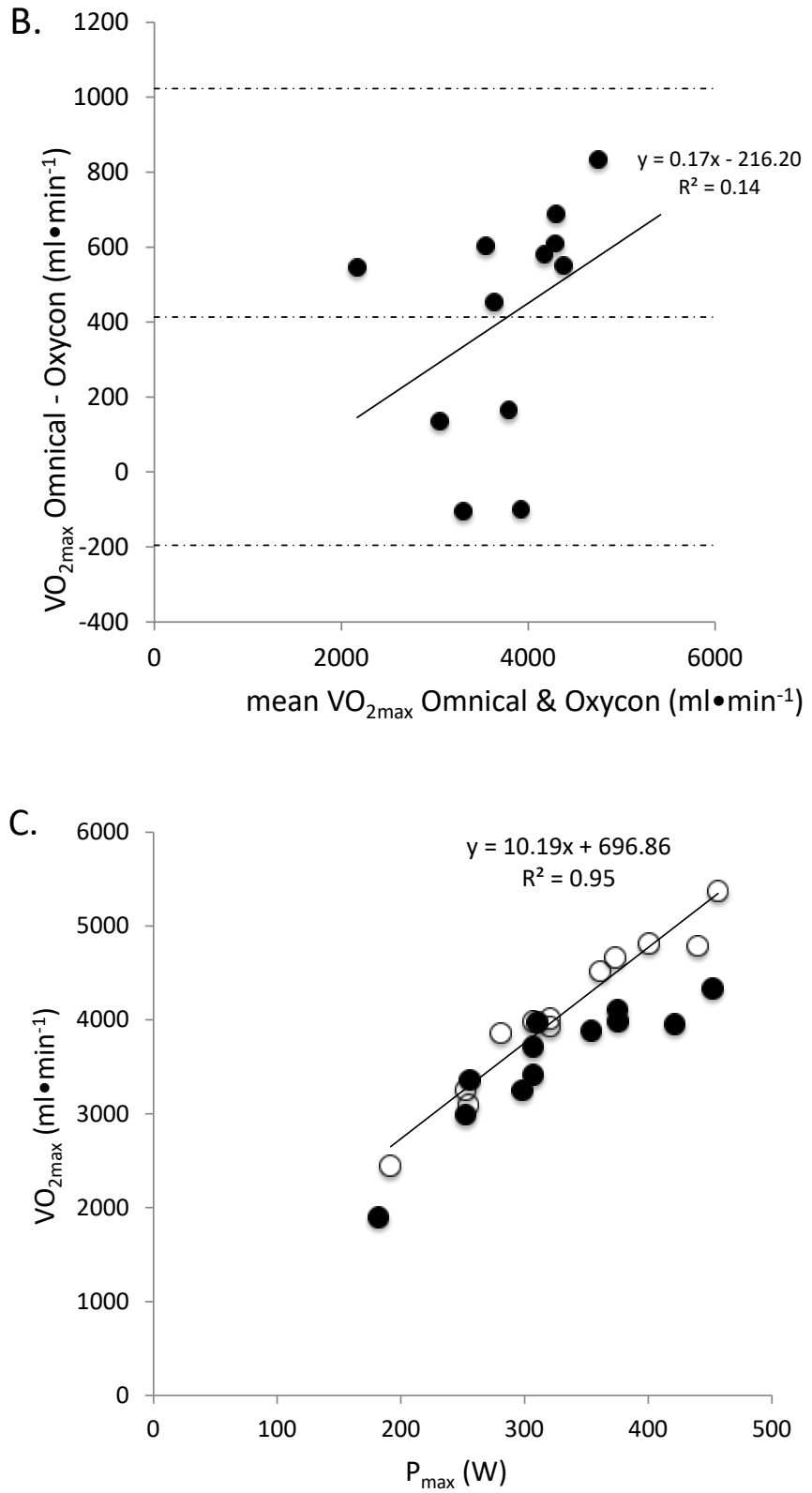

Figure 3. a) Scatterplot showing the test-retest variability in $\mathrm{VO}_{2 \max }$ between the Omnical and Oxycon Pro systems ( $n=12)$. The solid line represents the regression line and the dotted line the line of identity. b) BlandAltman plot for $\mathrm{VO}_{2 \max }$ as measured with the Omnical versus the Oxycon Pro system. Mean bias and $95 \%$ limits of agreement are indicated with dotted lines. The regression line shows there is a systematic bias that is proportional to the measured $\mathrm{VO}_{2 \max }$. c) $\mathrm{VO}_{2 \max }$ plotted against $\mathrm{P}_{\max }$ for both the Omnical (open circles) and Oxycon Pro (closed circles) 


\section{DISCUSSION}

This is, to the best of our knowledge, the first study that shows that total-capture of exhalation diluted into a free-flow indirect calorimeter (Omnical) is capable of accurately measuring $\mathrm{VO}_{2}$ concentrations in athletes. We performed a technical and biological validation of an open circuit diluted flow calorimeter with total capture and analysis of participants' exhaled air until maximal CPETs. The stringent technical validation was deemed a requirement to prove suitability of the individual calorimeter for the full range of technical- and biological variation expected, and this throughout the duration of the study. In contrast, no single application of calorimeter or calorimetric method should be considered a gold standard simply by reference to other units in literature; in that case there is no proof that the application or individual apparatus performed as well. Our results showed consistent values during both validation tests, demonstrating that the Omnical was suitable for gas analysis at rest and during maximal intensity exercise testing in elite athletes and that it is preferable to devices in breath-by-breath mode, and specifically as researchers may validate the unit available on site and fully independent. A suggestion for improvement would be to add water vapor to infusion tests as well (Prieur et al. 2003), though for diluted flow (Omnical) the vapor pressure should be kept below saturation as BTP conditions in reality are only applicable for approximately $50 \%$ of time (exhalation time).

The association between $\mathrm{P}_{\max }$ and $\mathrm{VO}_{2 \max }$ showed a marked linearity across the entire range of $\mathrm{P}$, indicating a low intra-individual variability for both parameters. At the level of basal metabolic rates (BMR), intra-individual variability was similar to previously reported results, acquired using a near-identical outpatient-protocol and BMR measurement equipment (Omnical) (Adriaens et al. 2003). Since the intra-individual BMR variability as reported by Adriaens et al. (2003) was considered low (Donahoo et al. 2004), the results of the present study illustrate strict adherence to the out-patient protocol by participants.

Our results furthermore indicated that the Omnical achieved a high degree of technically validated accuracy over the full range of human energy expenditure. The importance of reliable test and re-test values of $\mathrm{VO}_{2 \max }$ come from a study by Vickers et al., who studied errors in $\mathrm{VO}_{2 \max }$ and proposed a guideline for corrections and some interesting future research recommendations (Vickers 2003). We have been able to address some of the issues and the fact that in our study high accuracies have been achieved using participant generated data confirms the technical validation. More importantly, it implies that human maximal performance is very reproducible and almost perfectly linearly associated with $\mathrm{P}_{\max }$ across the entire range of $\mathrm{P}$ and $\mathrm{VO}_{2}$.

As expected, complete capturing and analysis of exhaled air provides linear and fullrange calorimetric performance. A challenging concern of our hypothesis is if our findings are in line with the current scientific literature, which commonly expresses $P_{\max }-$ $\mathrm{VO}_{2 \max }$ as a single average. We found several studies describing the relationship be- 
tween $\mathrm{P}_{\max }$ and $\mathrm{VO}_{2 \max }$, with $\mathrm{P}_{\max }$ values in the range from 100 to $133 \%$ of that observed in the present study (Angermann et al. 2006; Carita et al. 2014; Gordon et al. 2015; Karlsen et al. 2015; Laursen et al. 2002; Le Meur et al. 2014; Millet et al. 2014; Sousa et al. 2014). Assuming $P$, expressed as Watts, is an independent and calibrated parameter, we used $\mathrm{P}_{\max }$ as a starting point for the comparison. In this study we determined the mean $\mathrm{VO}_{2 \mathrm{BMR}}$ and $\mathrm{P}_{\mathrm{BMR}}$ to be $258 \mathrm{ml} \cdot \mathrm{min}^{-1}$ and $0.0 \mathrm{~W}$ workload, and the mean $\mathrm{VO}_{2 \max }$ and $P_{\max }$ to be $4112 \mathrm{ml} \cdot \mathrm{min}^{-1}$ and $331.4 \mathrm{w}(\mathrm{n}=27)$ workload, respectively. $A$ mean $\mathrm{VO}_{2}$ of $4112-258=3854 \mathrm{ml} \bullet \mathrm{min}^{-1}$ was required for $331.4 \mathrm{w}$, i.e. $11.63 \mathrm{ml} \bullet \mathrm{min}^{-1} \bullet \mathrm{w}^{-1}$. We derived this study's curve for any mean $\mathrm{VO}_{2 \max }$ as a function of mean $\mathrm{P}_{\max }$ as:

$V_{2 \max }\left(P_{\max }\right)\left[\mathrm{ml} \bullet \mathrm{min}^{-1}\right]=258\left[\mathrm{ml} \bullet \mathrm{min}^{-1}\right]+11.63 \cdot \mathrm{P}_{\max }[\mathrm{W}]$. Using this curve with published mean $\mathrm{P}_{\max }$ values from the similar studies (Angermann et al. 2006; Carita et al. 2014; Gordon et al. 2015; Karlsen et al. 2015; Laursen et al. 2002; Le Meur et al. 2014; Millet et al. 2014; Sousa et al. 2014) provides us with predicted $\mathrm{VO}_{2 \max }$ values as if measured in our laboratory. This allows comparison of predicted values with respective published mean $\mathrm{VO}_{2 \max }$ values (Figure 4). Eight out of the nine studies used breath-bybreath analysis, the ninth used separate turbine and exhaled air sampling. None captured total subject exhaled air for analysis. We have to mention, however, that this comparison inherently includes dissimilarities in participants, laboratory conditions, $P_{\max }$-calibration, and other factors. We observed an average deviation of -316 (range -59 to -648$) \mathrm{ml} \cdot \mathrm{min}^{-1}$ between predicted and measured $\mathrm{VO}_{2 \max }$. In view of the successful technical validation over the full range of $\mathrm{P}$, we conclude that $\mathrm{VO}_{2 \max }$ has typically been underestimated in previous studies, and this is in agreement with earlier findings for specific calorimeters (Larsson et al. 2004; Perret \& Mueller 2006; Prieur et al. 2003).

The low intra-individual variability in $\mathrm{P}_{\max }$ and $\mathrm{VO}_{2 \max }$ that we observed, along with their co-linearity, imply that participants can be used to validate calorimetry equipment. In fact, we advocate that calorimetry equipment should not just show good technical validation results, but must also be able to reproduce this in a real-world participantmeasuring setting. This is supported by the fact that results obtained using the Oxycon Pro suggest that this particular device, albeit serviced by the distributor, did not perform as well as the device tested previously by our group (Rietjens et al. 2001). We surmise that not all calorimeters perform to the highest standards each and every day or with each and every unit; it is imperative to check performance of calorimeters on a regular basis (Adriaens et al. 2003). 


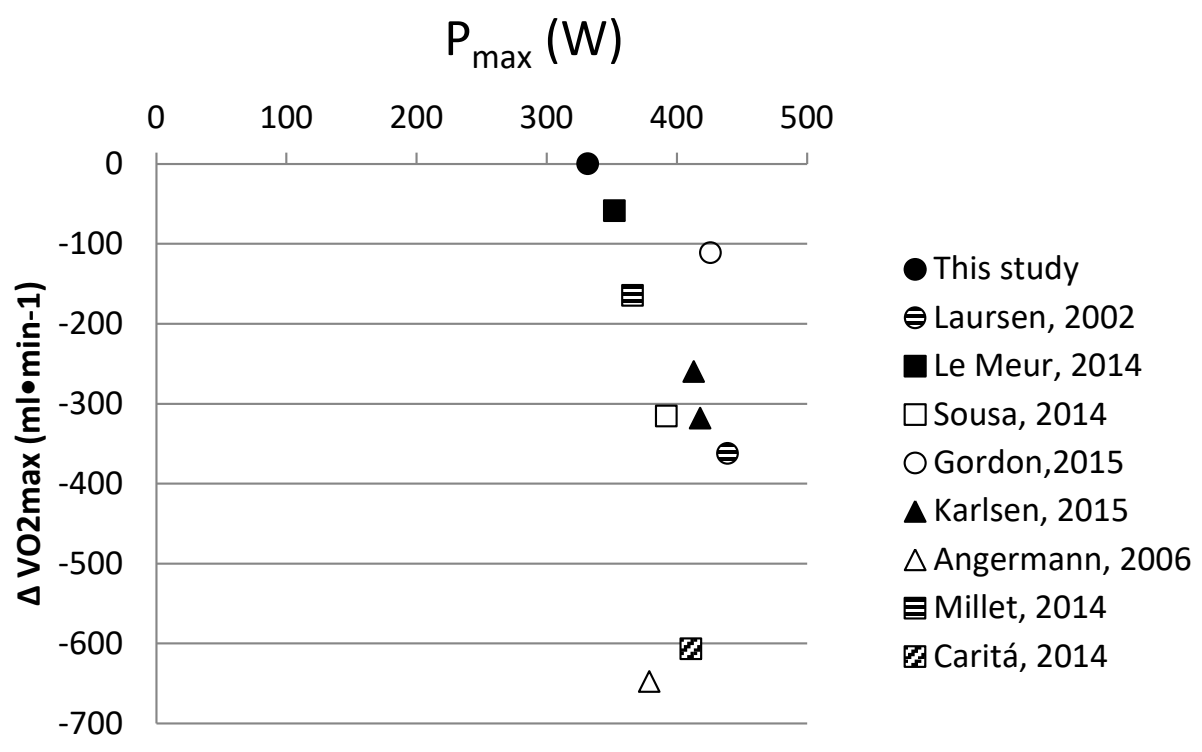

Figure 4. Scatterplot showing relation of average $\mathrm{VO}_{2 \max }$ versus $\mathrm{P}_{\max }$ for 10 separate sources in literature including this article (Omnical) and using BMR for defining intercept (this article, $V_{2} O_{2 \max }=258+11.63 \times P_{\max }$ ). The graph illustrates differences in average $\mathrm{VO}_{2 \max }$ between sources. From literature, no individual values for the relation $\mathrm{VO}_{2 \max }-\mathrm{W}_{\max }$ could be derived, thus averages are compared only to the extend that sources have similar subjects with similar BMR etc.

The Oxycon-Pro and results found in literature (Figure 4) tend to underestimate $\mathrm{VO}_{2}$ in the higher range in comparison to results found by total capturing and analysis of exhaled air. These results are not surprising since at more intense efforts linearity is likely to disappear due to the increasing difficulty for analyzers in breath-by-breath mode to keep up with the increasing minute ventilation.

It is our experience that calorimetric carts are typically tested using alcohol combustion in ventilated hood mode. Alcohol-combustion kits and descriptions for doing this are part of most product lines on offer, as an option. Yet, with respect to breath-by-breath mode this only validates part of the calorimeter, and specifically disregards the important response time of gas analysis in relation to required synchronous operation with participant in- and ex-halation. Performing a validation test in ventilated hood mode will provide basic feedback on operability in the absence of validation equipment for breath-by breath mode. While it is better than no test at all, the presence of trained stable athletes and a calibrated workload (bicycle) proves to be an important asset.

In conclusion, we report that the Omnical as a free airflow calorimeter capturing total exhalation in diluted mode is suitable for measuring human gas exchange $\left(\mathrm{O}_{2}\right.$ and $\left.\mathrm{CO} 2\right)$ and hence energy expenditure over the full range from rest to maximal exertion, and shows a significant increased ease of breathing near maximal exertion. Importantly, such a system can easily be validated by users on site over its full range and in the mode 


\section{Chapter 7}

applicable for subjects. Finally, we conclude that healthy participants with a stable training status have a $\mathrm{VO}_{2 \max }$ that has similar reproducibility as technical validations. $P_{\max }$ and $\mathrm{VO}_{2 \max }$ show a linear relation over the full range of $\mathrm{P}$. The latter challenges previously reported non-linearity between $\mathrm{P}$ and $\mathrm{VO}_{2}$.

\section{PERSPECTIVE}

Cardiopulmonary exercise testing is an important tool to determine exercise capacity in patients with e.g. heart failure and cancer, as well as to determine training status and progress in athletes (De Backer et al. 2007; Le Meur et al. 2014; Rietjens et al. 2005). Since the introduction by Hill et al, accurate assessment of the maximum plateau in $\mathrm{O}_{2}$ concentration has been the focus of many studies (Hill AV 1923). The concept of $\mathrm{VO}_{2 \max }$ originates from the notion that the $\mathrm{VO}_{2}$ curve flattens near exertion. Around $50 \%$ of studies nowadays assess $\mathrm{VO}_{2 \max }$ using breath-by-breath analysis of exhaled air using rapid-response gas analyzers (Robergs et al. 2010). In the present study, we provide evidence that open circuit indirect calorimetry is a valid approach to detect $\mathrm{VO}_{2 \text { max }}$, and is sensitive enough to reveal a linear association between $\mathrm{VO}_{2}$ and $\mathrm{P}$ over the entire range of $P$ in both untrained and endurance trained individuals. Our findings have implications for how results from studies reporting a plateau in $\mathrm{VO}_{2}$ near exhaustion should be interpreted. Finally, frequent validation of individual calorimeters in the modus operandi applied for subjects is deemed a historical and nowadays under-rated requirement. 


\section{REFERENCES}

Adriaens MP, Schoffelen PF, Westerterp KR. Intra-individual variation of basal metabolic rate and the influence of daily habitual physical activity before testing. Br J Nutr. 2003: 90: 419-423.

Aliverti A, Kayser B, Macklem PT. Breath-by-breath assessment of alveolar gas stores and exchange. J App/ Physiol (1985). 2004: 96: 1464-1469.

Angermann M, Hoppeler H, Wittwer M, Dapp C, Howald H, Vogt M. Effect of acute hypoxia on maximal oxygen uptake and maximal performance during leg and upper-body exercise in Nordic combined skiers. Int J Sports Med. 2006: 27: 301-306.

Blair SN, Kohl HW, 3rd, Paffenbarger RS, Jr., Clark DG, Cooper KH, Gibbons LW. Physical fitness and all-cause mortality. A prospective study of healthy men and women. JAMA. 1989: 262: 2395-2401.

Bland JM, Altman DG. Statistical methods for assessing agreement between two methods of clinical measurement. Lancet. 1986: 1: 307-310.

Brown D, Cole TJ, Dauncey MJ, Marrs RW, Murgatroyd PR. Analysis of gaseous exchange in open-circuit indirect calorimetry. Med Biol Eng Comput. 1984: 22: 333-338.

Carita RA, Greco CC, Denadai BS. The positive effects of priming exercise on oxygen uptake kinetics and highintensity exercise performance are not magnified by a fast-start pacing strategy in trained cyclists. PLoS One. 2014: 9: e95202.

De Backer IC, Schep G, Hoogeveen A, Vreugdenhil G, Kester AD, van Breda E. Exercise testing and training in a cancer rehabilitation program: the advantage of the steep ramp test. Arch Phys Med Rehabil. 2007: 88: 610-616.

Donahoo WT, Levine JA, Melanson EL. Variability in energy expenditure and its components. Curr Opin Clin Nutr Metab Care. 2004: 7: 599-605.

Farmery AD, Hahn CE. Response-time enhancement of a clinical gas analyzer facilitates measurement of breath-by-breath gas exchange. J Appl Physiol (1985). 2000: 89: 581-589.

Gordon D, Caddy O, Merzbach V, Gernigon M, Baker J, Scruton A, Keiller D, Barnes R. Prior Knowledge of Trial Number Influences the Incidence of Plateau at VO2max. J Sports Sci Med. 2015: 14: 47-53.

Henning B, Lofgren R, Sjostrom L. Chamber for indirect calorimetry with improved transient response. Med Biol Eng Comput. 1996: 34: 207-212.

Hill AV LH. Muscular exercise, lactic acid, and the supply and utilization of oxygen. Q Q J Med. 1923: 16: 135171.

Karlsen A, Racinais S, Jensen MV, Norgaard SJ, Bonne T, Nybo L. Heat acclimatization does not improve VO2max or cycling performance in a cool climate in trained cyclists. Scand J Med Sci Sports. 2015: 25 Suppl 1: 269-276.

Keren G, Magazanik A, Epstein Y. A comparison of various methods for the determination of VO2max. Eur J Appl Physiol Occup Physiol. 1980: 45: 117-124.

Kuipers H, Verstappen FT, Keizer HA, Geurten P, van Kranenburg G. Variability of aerobic performance in the laboratory and its physiologic correlates. Int J Sports Med. 1985: 6: 197-201.

Larsson PU, Wadell KM, Jakobsson EJ, Burlin LU, Henriksson-Larsen KB. Validation of the MetaMax II portable metabolic measurement system. Int J Sports Med. 2004: 25: 115-123.

Laursen PB, Shing CM, Peake JM, Coombes JS, Jenkins DG. Interval training program optimization in highly trained endurance cyclists. Med Sci Sports Exerc. 2002: 34: 1801-1807.

Le Meur Y, Louis J, Aubry A, Gueneron J, Pichon A, Schaal K, Corcuff JB, Hatem SN, Isnard R, Hausswirth C. Maximal exercise limitation in functionally overreached triathletes: role of cardiac adrenergic stimulation. J Appl Physiol (1985). 2014: 117: 214-222.

Lin LI. A concordance correlation coefficient to evaluate reproducibility. Biometrics. 1989: 45: 255-268.

Lundgren KM, Karlsen T, Sandbakk O, James PE, Tjonna AE. Sport-Specific Physiological Adaptations in Highly Trained Endurance Athletes. Med Sci Sports Exerc. 2015: 47: 2150-2157.

Millet G, Bentley DJ, Roels B, Mc Naughton LR, Mercier J, Cameron-Smith D. Effects of intermittent training on anaerobic performance and MCT transporters in athletes. PLoS One. 2014: 9: e95092. 
Perret C, Mueller G. Validation of a new portable ergospirometric device (Oxycon Mobile) during exercise. Int J Sports Med. 2006: 27: 363-367.

Poole DC, Jones AM. CORP: Measurement of the Maximum Oxygen Uptake (VO2max): VO2peak is no longer acceptable. J Appl Physiol (1985). 2017: jap 0106302016.

Potter CR, Childs DJ, Houghton W, Armstrong N. Breath-to-breath "noise" in the ventilatory and gas exchange responses of children to exercise. Eur J Appl Physiol Occup Physiol. 1999: 80: 118-124.

Prieur F, Busso T, Castells J, Bonnefoy R, Benoit H, Geyssant A, Denis C. A system to simulate gas exchange in humans to control quality of metabolic measurements. Eur J Appl Physiol Occup Physiol. 1998: 78: 549554.

Prieur F, Busso T, Castells J, Bonnefoy R, Benoit H, Geyssant A, Denis C. Validity of oxygen uptake measurements during exercise under moderate hyperoxia. Med Sci Sports Exerc. 1998: 30: 958-962.

Prieur F, Castells J, Denis C. A methodology to assess the accuracy of a 65 portable metabolic system (VmaxST). Med Sci Sports Exerc. 2003: 35: 879-885.

Prieur F, Castells J, Denis C. A methodology to assess the accuracy of a portable metabolic system (VmaxST). Med Sci Sports Exerc. 2003: 35: 879-885.

Rietjens GJ, Kuipers H, Adam JJ, Saris WH, van Breda E, van Hamont D, Keizer HA. Physiological, biochemical and psychological markers of strenuous training-induced fatigue. Int J Sports Med. 2005: 26: 16-26.

Rietjens GJ, Kuipers H, Kester AD, Keizer HA. Validation of a computerized metabolic measurement system (Oxycon-Pro) during low and high intensity exercise. Int J Sports Med. 2001: 22: 291-294.

Robergs RA, Dwyer D, Astorino T. Recommendations for improved data processing from expired gas analysis indirect calorimetry. Sports Med. 2010: 40: 95-111.

Schoffelen PF, Westerterp KR, Saris WH, Ten Hoor F. A dual-respiration chamber system with automated calibration. J Appl Physiol (1985). 1997: 83: 2064-2072.

Sousa A, Ribeiro J, Sousa M, Vilas-Boas JP, Fernandes RJ. Influence of prior exercise on VO2 kinetics subsequent exhaustive rowing performance. PLoS One. 2014: 9: e84208.

Totsikas C, Rohm J, Kantartzis K, Thamer C, Rittig K, Machann J, Schick F, Hansel J, Niess A, Fritsche A, Haring $\mathrm{HU}$, Stefan N. Cardiorespiratory fitness determines the reduction in blood pressure and insulin resistance during lifestyle intervention. J Hypertens. 2011: 29: 1220-1227.

Vickers RR, Jr. Measurmenet error in maximal oxygen uptake tests. Naval health research center. 2003.

Webb P, Saris WH, Schoffelen PF, Van Ingen Schenau GJ, Ten Hoor F. The work of walking: a calorimetric study. Med Sci Sports Exerc. 1988: 20: 331-337.

Wei M, Kampert JB, Barlow CE, Nichaman MZ, Gibbons LW, Paffenbarger RS, Jr., Blair SN. Relationship between low cardiorespiratory fitness and mortality in normal-weight, overweight, and obese men. JAMA. 1999: 282: 1547-1553.

Wessel HU, Stout RL, Bastanier CK, Paul MH. Breath-by-breath variation of FRC: effect on VO2 and VCO2 measured at the mouth. J Appl Physiol Respir Environ Exerc Physiol. 1979: 46: 1122-1126.

Yamamoto Y, Takei Y, Mokushi K, Morita H, Mutoh Y, Miyashita M. Breath-by-breath measurement of alveolar gas exchange with a slow-response gas analyser. Med Biol Eng Comput. 1987: 25: 141-146. 




\section{Chapter}

Measurement of respiratory gas exchange: derivation of equations for- and comments on true molar balance in whole room calorimetry

Paul F.M. Schoffelen, Marc Souren and Guy Plasqui. Submitted 


\section{ABSTRACT}

Two major factors determine accuracy for measuring respiratory gas; the equations used and the equipment applied, nowadays augmented with pre- and post- data filtering and trend analysis techniques. The aim of this study was to focus on the equations, and specifically on the implementation of SI units for real gasses and true molar quantities, allowing the quantification of true mass flux between individual processes. The molar equation derived was:

$\dot{n}_{g s}=-\left(\frac{P_{g i} \dot{V}_{i}}{z_{g}\left(P_{g i}, T_{i}\right) R T_{i}}+\frac{P_{g o} \dot{V}_{o}}{z_{g}\left(P_{g o}, T_{o}\right) R T_{o}}+\frac{d P_{g r}}{d t} \cdot \frac{V_{r}}{z_{g}\left(P_{g r}, T_{r}\right) R T_{r}}\right) \quad \mathrm{mol} \bullet \mathrm{s}^{-1}$

Where: $\mathrm{P}=$ pressure, $\mathrm{V}=$ volume, $\mathrm{T}=$ temperature, $\mathrm{g}=$ selected gas, $\mathrm{s}=$ subject, $\mathrm{i}=$ inlet, $\mathrm{o}=$ outlet, $\mathrm{r}=$ room, $\mathrm{n}=$ number of moles, $\mathrm{z}=$ compressibility, and $\mathrm{R}=$ molar gasconstant.

The compartmentalization of processes in, out and room are yet again recognisable. Deriving the molar equation proved useful in understanding momentary gas properties and fluxes. and the molar formulae have now been applied in whole room calorimetry.

We conclude that a true molar equation using SI notation was achieved, with detailed formal descriptions allowing for strict compartmentalization of sub-processes. For whole room calorimeters and short (dynamic) evaluation interval a specific impact on $\mathrm{O}_{2}$ and RER results was uncovered. Hence, the impact of climate and true molar quantities may prove at least as important as the precision of the applied gas analysis equipment regarding short term dynamic evaluation.

\section{LIST OF SYMBOLS}

$\begin{array}{ll}\mathrm{P}=\text { pressure } & \mathrm{Pa} \\ \mathrm{V}=\text { volume } & \mathrm{m}^{3} \\ \dot{V}=\text { volumetric rate } & \mathrm{m}^{3} \mathrm{~s}^{-1} \\ \mathrm{~T}=\text { temperature } & \mathrm{K} \\ \mathrm{R}=\text { molar gasconstant } 8.3143 & \mathrm{~J} \bullet \mathrm{K}^{-1} \cdot \mathrm{mol}^{-1} \\ \mathrm{t}=\text { time } & \mathrm{S} \\ \mathrm{n}=\text { amount of moles } & \mathrm{mol} \\ \mathrm{X}=\text { molar fraction } & {[\text { dimensionless }]} \\ \dot{n}=\text { rate of change of amount of moles } & \mathrm{mol} \cdot \mathrm{s}^{-1} \\ \mathrm{Z}=\text { compressibility factor } & {[\mathrm{dimensionles}]} \\ \mathrm{mass} \text { density } & \mathrm{kg} \bullet \mathrm{m}^{-3} \\ \mathrm{M}=\text { mass } & \mathrm{kg} \\ \mathrm{F}=\text { fraction } & {[\mathrm{dimensionless}]} \\ \mathrm{C}=\text { molar concentration } & \mathrm{mol} \cdot \mathrm{m}^{-3} \\ \cdot \text { notation denotes rate } & \mathrm{s}^{-1}\end{array}$


stp = standard temperature and pressure, $273.15 \mathrm{~K}, 101325 \mathrm{~Pa}$.

stpd $=$ standard temperature pressure and $d r y$.

atp $=$ ambient temperature and pressure including water vapor

$\mathrm{a}=$ equation of state parameter

$b=$ equation of state parameter

$\mathrm{g}=$ any gas

$\mathrm{m}=$ mix of gasses $\mathrm{g}$

$\mathrm{i}=$ inlet

$\mathrm{o}=$ outlet

$r=$ room

$\mathrm{s}=$ subject or simulation

$\mathrm{d}=$ diffusion

I = leakage

$w=$ water

$\mathrm{c}=$ critical

$\mathrm{O}_{2}=$ oxygen

$\mathrm{CO}_{2}=$ carbon dioxide

$\mathrm{N}_{2}=$ nitrogen

$\mathrm{NI}=$ nitrogen and inert gasses

$\mathrm{CH}_{4}=$ methane 


\section{INTRODUCTION}

Respiratory gas exchange (RGE) measurements can reveal both the source and the extent of the energy expenditure (EE) in human and animal metabolism. Equations for the calculation of respiratory gas exchange (RGE) with fast response can be found in literature $[19,5,29,15,24,34,25,33,22]$, as well as descriptions of equipment $[15,37,29$, $24,8,28,22$ ] Advances in energy regulation science impose ever-increasing demands on the dynamic accuracy and precision of measurements of RGE. To meet these demands, systems must be optimally configured and accuracy must be traceable throughout the system. Improvements in formal descriptions may help researchers to reliably perform comparable multi-center studies and certification procedures.

The aim of this paper is to introduce a practical implementation of SI units in combination with real gasses, opening a pathway towards future improvements on determining RGE fluxes between compartments known- and as yet unknown.

The field of measuring RGE in room sized calorimeters has evolved from measuring total 24 hour energy expenditure ( $\left.T E E_{24 h r}\right)$ and derived parameter respiratory quotient $\left(R_{24 h r}\right)$ to measuring activity-, resting- and sleeping- metabolic rate over shorter intervals $\left(A M R_{t}\right.$, $R M R, S M R_{t}$ and $\left.R Q_{t}\right)$. Often while holding on to assumptions made at the beginning of work in the field. Some commonly $[29,5,6,13,15,19,21,22,26,30,31,35,14,38]$ used assumptions are:

- conservation of $\mathrm{N}_{2}$ and inert gasses for calculating flow

- $\dot{V}_{\mathrm{i}}$ is equal to $\dot{V}_{\text {o }}$

- gasses may be considered ideal gasses

- calculation takes place while the system is in (quasistatic) steady state

- all gasses are well mixed and the model is considered a first order model

- the volume of the chamber is constant

- the mass inside the chamber is constant

- there is no leakage

- dynamic responses can be mathematically resolved by filtering and prediction

Validity of these assumptions will vary depending on context, from acceptable to fully inapplicable.

Further problems may arise when comparing performance of RGE measurements between metabolic research centres. At the moment, there are no standards for defining the accuracy in measuring RGE. Validation tests may be performed over $24 \mathrm{hr}$ steady state, neglecting today's interest in non-steady state shorter intervals, or by neglecting the begin-end change from fresh air concentrations to near steady state used air concentrations typical for measuring a subject in a whole room calorimeter. Moreover, the description of accuracy may be expressed as a percentage of a validation test-level, yet not necessarily identified as an absolute value in relation to the working range. For instance, $1 \%$ accuracy at the $1000 \mathrm{ml} \cdot \mathrm{min}^{-1} \mathrm{RGE}$ level is not equal to $1 \%$ accuracy at 
the $500 \mathrm{ml} \bullet \mathrm{min}^{-1}$ RGE level. In whole room calorimetry there is a base precision limit, a floor level dictated by volume, flow and analysis accuracy. This base precision is more or less independent of EE level and essentially Gaussian in distribution [23]. Finally, EE kJ may be calculated from RGE using different substrate equations with or without taking urinary nitrogen into account $[40,39,4,7,10,17,2,3,18,9]$. This should not pose a problem as long as partners in research identify and use the same equation.

Three suggestions for improvements are:

1) Decrease assumptions

2) Provide validation results including absolute levels of RGE and interval of interest. Do not limit results to percentages without defining the $100 \%$ reference level [29].

3) Include dynamic responses in validation, and in a standardized fashion. Ranging from mimicking the typical begin-end state difference as seen with participants [29], up to step- and impulse responses [13,25].

First of all it was deemed beneficial to derive equations with less assumptions.

Here, a set of true mass based SI equations for whole room calorimetry was derived, intended as building blocks for future improvements and standardisation.

\section{METHODS}

\section{Derivation of the molar equation used.}

\section{Balance equation}

In literature most calculation formulae use gas conservation in a form similar to Brown et al. [5]:

$$
\dot{V}_{g r}=\dot{V}_{g i}+\dot{V}_{g s}-\dot{V}_{g o}
$$

where

$\dot{V}_{\text {gr }}=$ rate of increase of volume of gas g inside the room

$\dot{V}_{\text {gi }}=$ rate of volume flow of gas g into the room

$\dot{V}_{\text {gs }}=$ rate of net volume production of gas g by a subject

$\dot{V}_{\text {go }}=$ rate of volume flow of gas g out of the room

The basis for this equation, known from even before the times of Lomonosov-Lavoisier, can be found in the mass conservation law [32]; "the mass of a body is independent of time" or: 


$$
M=\int \rho d V
$$

In general, the limits of this integration will be the volume occupied by the body as a function of time. Using the postulate of conservation of mass, we derive:

$$
\dot{M} \equiv \frac{d}{d t} \int \rho d V=0
$$

These basic mass conservation rules lead the way to a mass-based formula for gas exchange in the form:

$$
\dot{M}_{g i}+\dot{M}_{g o}+\dot{M}_{g s}+\dot{M}_{g r}=0
$$

In order to prevent problems with gas density for real or ideal gas, volume to mass conversions, and other possible confounders, formula (4) is rewritten for molar quantity:

$$
\dot{n}_{g i}+\dot{n}_{g o}+\dot{n}_{g s}+\dot{n}_{g r}=0
$$

Please note that the sign of a quantity must correctly denote the entry (positive sign) or exit (negative sign) from the control volume. Furthermore, this balance equation may be augmented with additional parameters if they can be assessed, for instance the addition of leakage and diffusion into confined spaces, or the subdivision of central volume in separately flushed- and temperature layered compartments:

$$
\dot{n}_{g i}+\dot{n}_{g o}+\dot{n}_{g s}+\dot{n}_{g r}+\dot{n}_{g l}+\dot{n}_{g d 1}+\dot{n}_{g d 2}+\dot{n}_{g c 1}+\dot{n}_{g c 2}=0
$$

where $\dot{n}_{g l}$ is the rate of molar quantity of gas g leaking, $\dot{n}_{g d}$ is the rate of molar quantity of gas g diffusing into for instance a confined space (1, bed; 2 , trunk), and $\dot{n}_{g c}$ are separately flushed- and temperature layered compartments $(1$, flushed ceiling, walls, and airconditioning-ducts; 2, temperature layering compartments). Note that subdivided compartments share a total sum with the room volume, i.e. a local mass conservation with individual positive or negative sign.

\section{Real versus ideal gas}

Molar quantity is a mass based amount and thus well suited for setting up a true mass conservation model. However, in reality volumes will be measured, and volumes must be converted to molar quantities from measured fractions and volume. Note that this also holds true for mass-flow devices as they are tuned to a specific mass and can't yet discriminate the variation in gas fractions by themselves.

This conversion of a gaseous volume to its mass in general uses the ideal gas assumption, introducing a small error in comparison to using the real gas conversion. Both 
"molar" and "real" indicate true mass i.e. real gas volume, while "ideal" indicates use of the ideal gas assumption.

For a mix of ideal gasses the volume to molar gas laws are:

$$
\begin{gathered}
P V=n R T \text { Bolye Gay Lussac } \\
P_{m}=\sum P_{g} \text { Dalton }
\end{gathered}
$$

For eliminating the ideal-gas assumption, formula (7) for use with a real gas becomes:

$$
P V=Z(P, T) n R T
$$

Where $z$ expresses the deviation of the real gas volume from assumed ideal volume at the (partial) pressure and temperature of the specific gas fraction. The factor $z$ is known as compressibility.

Regarding Daltons law, which effectively states that any gas can be considered to occupy the whole volume as if it were by itself, first, interoperability between gasses in a mixture must be determined. If interoperability is present the effects for any occurring fractional mix must be calculated. The interoperability between gasses can be calculated by means of virial equations for determining the critical temperature $T_{c}$ and pressure $P_{c}$ of a gas mixture. Using the Eykman Molecular Refraction method (EMR) [11], gasses may be divided in two groups:

group 1: $\mathrm{CH}_{4}, \mathrm{CO}_{2}, \mathrm{H}_{2} \mathrm{~S}, \mathrm{~N}_{2}, \mathrm{H}_{2}, \mathrm{O}_{2}$

group 2: $\mathrm{C}_{2} \mathrm{H}_{6}$ and the remaining complex hydrocarbons.

Using average values of $P_{c}$ and $T_{c}$ for each individual group in the gas mixture the interoperability between the groups [11] is determined by the formula:

$$
\left(\frac{T_{c}}{P_{c}}\right)_{m}=X_{1}\left(\frac{T_{c}}{P_{c}}\right)_{1}+X_{2}\left(\frac{T_{c}}{P_{c}}\right)_{2}
$$

Since, favourably, all gasses of interest for RGE fall into group 1 and no gasses from the other group are present $\left(X_{2}=0\right)$ the virial influence is limited to the first factor. For the RGE gasses their individual constants $P_{c}$ and $T_{c}$ can be used to calculate compressibility without interoperability.

Compressibility means that for the same temperature and partial pressure as assumed for an ideal gas, in reality more or less moles of gas will fill the volume i.e. provide the "ideal" partial pressure.

By correcting for the amount in moles the partial pressure remains unaffected and we may apply Daltons law for the real gasses and their partial pressures:

$$
\text { Preal }_{m}=\sum \text { P real }
$$




\section{Calculation of compressibility z}

The compressibility of a gas depends both on pressure and temperature and it can be looked up in tables $[1,16]$. An often used equation to calculate real gas properties is the Van der Waals equation [36]. In comparison to tables for compressibility this equation proved less suitable at- or below atmospheric pressure ( $\leq 101 \mathrm{kPa})$ and applicable temperature range of 200-350 K. A best fit to calculate $z(P, T)$ directly from $P$ and $T$ for RGE gasses was found to be provided by the Redlich Kwong equations of state $[20,27]$ :

$$
P=\frac{R T}{\frac{V}{n}-b}-\frac{a}{T^{0.5} \frac{V}{n}\left(\frac{V}{n}+b\right)}
$$

where

$$
\begin{gathered}
a=\frac{0.42748 R^{2} T_{c}^{2.5}}{P_{c}} \\
b=\frac{0.08664 R T_{c}}{P_{c}}
\end{gathered}
$$

Equation 12 finds partial pressure $P$ from variables temperature $T$, volume $V$ and molar quantity $n$, yet the variable of interest is compressibility $z$. The $z$ value of a fixed volume at constant temperature for a single gas can be written as $z=P_{\text {real }} / P_{\text {ideal }}$, and $1-z$ varies linear proportional with partial pressure $P$. To resolve a particular value of $z$ in the $P, T$ range of interest $(0-100 \mathrm{kPa}, 200-350 \mathrm{~K})$ an assumed volume $\mathrm{V}=0.00548 \mathrm{~m}^{3}$ and assumed quantity $n=1 \mathrm{~mol}$ may be used to calculate $\mathrm{z}$ for $\mathrm{RGE}$ gasses $\mathrm{O}_{2}, \mathrm{CO}_{2}, \mathrm{NH}_{4}$, and $\mathrm{H}_{2} \mathrm{O}$. Other choices for $\mathrm{V}$, $\mathrm{n}$ or tables are possible.

Given the critical temperature and pressure of a gas, $P_{c}$ and $T_{c}$, the $a$ and $b$ factors can be calculated and for $V=0.00548 \mathrm{~m}^{3}$ and $n=1 \mathrm{~mol}$ its real pressure $P_{\text {real }}$ at temperature $T$ may be determined.

Next the identical values for $V, T$ and $n$ may be used to calculate the ideal pressure $P_{\text {ideal, }}$ and used to determine $z\left(P_{\text {real }}, T\right)$ from $P_{\text {real }} / P_{\text {ideal. }}$. This specific instance of $z\left(P_{\text {real }}, T\right)$ was determined for the assumed volume of $0.00548 \mathrm{~m}^{3}$ for a specific gas and temperature. To derive the $z(P, T)$ for this specific gas, dependent on pressure instead of volume, a correction for the change of pressure may be derived:

$$
\mathrm{z}_{g}\left(P_{g}, T_{g}\right)=1-\left(\mathrm{P}_{\mathrm{g}} / \mathrm{P}_{\text {real }}\right) *\left(1-\mathrm{z}\left(\mathrm{P}_{\text {real }}, T_{g}\right)\right)
$$

where 


$$
\mathrm{z}_{g}\left(P_{\text {ideal }}, T_{g}\right)=\frac{\frac{R T_{g}}{0.00548-b_{g}}-\frac{a_{g}}{T_{g}^{0.5} \bullet 0.00548 \bullet\left(0.00548+b_{g}\right)}}{\frac{R T_{g}}{0.00548}}
$$

As a result, the compressibility of the specific gas g may be calculated as a function of ideal partial pressure and temperature.

Alternatively the $z(P, T)$ can be looked up in an accurate table, and $z(P, T)$ must then be interpolated for the exact $\mathrm{P}$ and $\mathrm{T}$ of interest. Working from tables available in literature $[1,16]$ we derive the following interpolation formula for $\mathrm{z}(\mathrm{P}, \mathrm{T})$ when $\mathrm{P}=100 \mathrm{kPa}$ :

$$
\begin{gathered}
\mathrm{z}_{\mathrm{O} 2}\left(100 \mathrm{kPa}, \mathrm{T}_{\mathrm{O} 2}\right)=0.9894647-7.475 \cdot \mathrm{T}_{\mathrm{O} 2}{ }^{2} \cdot 10^{-8}+5.554 \cdot \mathrm{T}_{\mathrm{O} 2} \cdot 10^{-5} \\
\mathrm{z}_{\mathrm{CO} 2}\left(100 \mathrm{kPa}, \mathrm{T}_{\mathrm{CO} 2}\right)=0.9395341-4.1691 \cdot \mathrm{T}_{\mathrm{CO}_{2}}{ }^{2} \cdot 10^{-8}+3.1016 \cdot \mathrm{T}_{\mathrm{CO} 2} \cdot 10^{-5} \\
\mathrm{z}_{\mathrm{N} 2}\left(100 \mathrm{kPa}, \mathrm{T}_{\mathrm{N} 2}\right)=0.99114486-6.5948 \cdot \mathrm{T}_{\mathrm{N} 2}{ }^{2} \cdot 10^{-8}+4.8692 \cdot \mathrm{T}_{\mathrm{N} 2} \cdot 10^{-5}
\end{gathered}
$$

These z's must yet be corrected for the actual partial gas pressures, no values for compressibility of water vapor $\mathrm{H}_{2} \mathrm{O}$ where provided $[1,16]$.

As the Redlich Kwong approach is suitable for any RGE gas with a known $P_{c}$ and $T_{c}$, and may be easily implemented in a computer-algorithm, this equation of state was used as the method of choice.

\section{Remaining assumptions}

Two practical issue with z remain;

Firstly, using $\mathrm{N}_{2}$ for the sum of inert gasses is an assumption. Since air comprises approximately a $1 \%$ rest of inert gasses, mostly Ar and a little $\mathrm{Ne}$, the $\mathrm{z}$ of $\mathrm{N}_{2}$ plus the inert gasses will differ from the $z$ for pure $\mathrm{N}_{2}$. This difference is expressed by using the name $\mathrm{NI}$ for Nitrogen and Inert gasses together. It follows that:

$$
\begin{gathered}
P_{N l}=P_{N_{2}}+P_{\text {inert_rest }} \\
n_{N l}=n_{N_{2}}+n_{\text {inert_rest }} \\
P_{N_{2}}=\frac{z_{N_{2}}\left(P_{N_{2}}, T\right) n_{N_{2}} R T}{V} \\
P_{\text {inert_rest }}=\frac{z_{\text {inert_rest }}\left(P_{\text {inert_rest }}, T\right) n_{\text {inert_rest }} R T}{V}
\end{gathered}
$$

Resulting in: 


$$
P_{N l}=\frac{Z_{N l}\left(P_{N l}, T\right) n_{N l} R T}{V}=\frac{\left(Z_{\text {inert_rest }}\left(P_{\text {inert_rest }}, T\right) n_{\text {inert_rest }}+Z_{N_{2}}\left(P_{N_{2}}, T\right) n_{N_{2}}\right) R T}{V}
$$

Formula 24 illustrates that $z_{n i}$ is the proportional sum of each components $z$.

For $\mathrm{N}_{2}$ and $\mathrm{Ar}$ as the main components of the inert gasses the influence of Ar relative to the $\mathrm{z}$ of pure $\mathrm{N}_{2}$ is in the order of $2 \%$, an impact below the error in the estimate of $\mathrm{z}$ from lookup tables. The next largest inert gas component is $\mathrm{Ne}$, with an impact on the $\mathrm{z}$ of $\mathrm{N}_{2}$ of just $0.002 \%$. Though these fractions can be calculated from the prevalence of said gasses in fresh air, for the moment their impact is small enough to allow consideration of $\mathrm{N}_{2}$ and the rest of the inert gasses as if they were pure $\mathrm{N}_{2}$.

Secondly, the gasses involved are assumed to be in gaseous state, yet water vapor is technically not a gas. As far as we could determine this is of no consequence fulfilling the requirement that its partial pressure remains below saturation pressure.

Finally, using Dalton's law assumes quasi-steady state, ignoring momentary changes in collisions of gas-molecules until mixing- or pressure- variations have stabilized. The speed of the gas molecules is governed by the Maxwell-Bolzmann distribution, otherwise mixing would indeed be almost instantaneous as molecules would travel at extreme speeds without collisions. The effect of Maxwell-Bolzmann distribution on dynamic changes of gas-mixes may be deemed a further refinement, but it is assumed to be of no consequence to the balance equations in quasi-steady state as presented here. Effectively, the speed of distribution may only help to improve the speed of mixing of gasses.

\section{The molar balance equation}

The calorimeter molar balance for any gas g can be written in the form:

$$
\dot{n}_{g s}=-\left(\frac{P_{g i} \dot{V}_{i}}{z_{g}\left(P_{g i}, T_{i}\right) R T_{i}}+\frac{P_{g o} \dot{V}_{o}}{z_{g}\left(P_{g o}, T_{o}\right) R T_{o}}+\frac{d P_{g r}}{d t} \cdot \frac{V_{r}}{z_{g}\left(P_{g r}, T_{r}\right) R T_{r}}\right)
$$

Or for a finite interval t2-t1

$$
n_{g s s_{2-11}}=-\left(\int_{t 1}^{t 2} \frac{P_{g i} \dot{V}_{i}}{z_{g}\left(P_{g i}, T_{i}\right) R T_{i}} d t+\int_{t 1}^{t 2} \frac{P_{g o} \dot{V}_{o}}{z_{g}\left(P_{g o}, T_{o}\right) R T_{0}} d t+\left(\frac{P_{g r_{t}}}{z_{g}\left(P_{g r_{2}}, T_{r_{12}}\right) T_{r_{12}}}-\frac{P_{g r_{11}}}{z_{g}\left(P_{g r_{11}}, T_{r_{1}}\right) T_{r_{11}}}\right) \cdot \frac{V_{r}}{R}\right)
$$

In practice, this continuous time formula must be re-written as computers, analyzers and analog to digital converters do not work with continuous time. Instead, a sampled finite time is used $[22,29]$. 
If $\mathrm{t} 1$ and $\mathrm{t} 2$ are two subsequent samples this leads to the form:

$$
\begin{aligned}
& n_{g s_{t 2-t 1}}=-\left(\frac{P_{g t_{1}} \dot{V}_{i_{t 1}}}{z_{g}\left(P_{g i_{t 1}}, T_{i_{t 1}}\right) T_{i_{t 1}}}+\frac{P_{g t_{2}} \dot{V}_{t_{t 2}}}{z_{g}\left(P_{g i_{t 2}}, T_{i_{t 2}}\right) T_{i_{t 2}}}+\frac{P_{g o_{t 1}} \dot{V}_{a_{1}}}{z_{g}\left(P_{g o_{t 1}}, T_{o_{t 1}}\right) T_{o_{t 1}}}+\frac{P_{g o_{t 2}} \dot{V}_{o_{t 2}}}{z_{g}\left(P_{g o_{t 2}}, T_{o_{t 2}}\right) T_{o_{t 2}}}\right) \cdot \frac{(t 2-t 1)}{2} \\
& +\left(\frac{P_{g r_{12}}}{z_{g}\left(P_{g r_{t 2}}, T_{r_{t 2}}\right) T_{r_{t 2}}}-\frac{P_{g r_{11}}}{z_{g}\left(P_{g r_{t 1}}, T_{r_{t 1}}\right) T_{r_{t 1}}}\right) \bullet \frac{V_{r}}{R}
\end{aligned}
$$

Over a longer measurement interval, the equation can be written as:

$$
\begin{aligned}
& n_{g s_{t m-t 0}}=-\left(\sum_{x=1}^{\frac{t m-t 0}{t^{2-t \mid}}} \frac{P_{g i_{x}} \dot{V}_{i_{x}}}{z_{g}\left(P_{g i_{x}}, T_{i_{x}}\right) T_{i_{x}}}+\sum_{x=1}^{\frac{m-t 0}{t 2-t \mid}} \frac{P_{g o_{x}} \dot{V}_{o_{x}}}{z_{g}\left(P_{g o_{x}}, T_{o_{x}}\right) T_{o_{x}}}\right) \bullet\left(t_{2}-t_{1}\right) \\
& +\left(\frac{P_{g r_{t m}}}{z_{g}\left(P_{g r_{t m}}, T_{r_{t m}}\right) T_{r_{t m}}}-\frac{P_{g r_{t 0}}}{z_{g}\left(P_{g r_{t 0}}, T_{r_{t 0}}\right) T_{r_{t 0}}}\right) \bullet \frac{V_{r}}{R}
\end{aligned}
$$

For the calculation of RGE the following gasses are of interest:

$\mathrm{O}_{2}, \mathrm{CO}_{2}, \mathrm{~N}_{2}, \mathrm{CH}_{4}$ and Water, and each of these will have its own molar equation in the form suggested above.

\section{Effect of water vapor}

For the measured pressures, dry or wet, we may now follow Dalton for the equation:

$$
P_{\text {wet }}=P_{\mathrm{O}_{2}}+P_{\mathrm{CO}_{2}}+P_{\mathrm{N}_{2}}+P_{\mathrm{CH}_{4}}+P_{w}
$$

As gas analysis equipment may require dry gasses the water vapor part can be removed from the sample, physically or mathematically, which will cause the P to decrease. Gasanalysis, in most cases, will take place at ambient pressure and thus the gasses to be analysed are compressed against the outflow to ambient at the following partial pressure:

$$
P_{\text {gdry }}=P_{\text {gwet }} \bullet \frac{z\left(P_{\text {gdry }}, T\right)}{z\left(P_{\text {gwet }}, T\right)} \bullet \frac{P_{\text {wet }}}{P_{\text {wet }}-P_{w}}
$$

Since $\mathbf{Z}\left(P_{\text {gdry }} T\right)$ is dependent on $P_{\text {gdry }}$ an iterative process may be used. At $100 \mathrm{kPa}$, and even for a non-ideal gas like $\mathrm{CO}_{2}$, it only takes 6 iterations to become accurate to $10^{-20}$. For the partial pressures of interest in RGE an accuracy $\leq 10^{-6}$ can be achieved by replacing $\mathbf{Z}\left(P_{\text {gdry }}, T\right)$ with: 


$$
\bar{z}\left(\frac{P_{\text {wet }}}{P_{\text {wet }}-P_{w}} \bullet P_{\text {gwet }}, T\right)
$$

\section{The $\mathrm{N}_{2}$ conservation}

The $\mathrm{N}_{2}$ conservation assumption or Haldane transform [12] is useful to determine $\dot{V}_{i}$ from $\dot{V}_{0}$ for pull system or vice-versa for a push system. The main advantage being that the assumed balance is forced to become $\dot{V}_{1}+\dot{V}_{0}=0$. This effectively eliminates even the smallest, yet cumulative, mismatch of flows in comparison to separately measured in-flow and out-flow, or to a degree the impact of small leakages.

The balance for the N2 conservation approach on a molar basis can be written as:

$$
\dot{n}_{N_{2} s}=-\left(\frac{P_{N_{2} i} \dot{V}_{i}}{z_{N_{2}}\left(P_{N_{2}}, T_{i}\right) R T_{i}}+\frac{P_{N_{2} o} \dot{V}_{o}}{z_{N_{2}}\left(P_{N_{2}}, T_{o}\right) R T_{o}}+\frac{d P_{N_{2} r}}{d t} \bullet \frac{V_{r}}{z_{N_{2}}\left(P_{N_{2} r}, T_{r}\right) R T_{r}}\right)=0
$$

for a pull system this results in:

$$
\dot{V}_{i}=-\frac{z_{N_{2}}\left(P_{N_{2} i}, T_{i}\right) R T_{i}}{P_{N_{2} i}} \bullet\left(\frac{P_{N_{2} \mathrm{O}} \dot{V}_{o}}{z_{N_{2}}\left(P_{N_{2} O}, T_{0}\right) R T_{o}}+\frac{d P_{N_{2} r}}{d t} \bullet \frac{V_{r}}{z_{N_{2}}\left(P_{N_{2} r}, T_{r}\right) R T_{r}}\right)
$$

and for a push system this results in:

$$
\dot{V}_{o}=-\frac{z_{N_{2}}\left(P_{N_{2}}, T_{o}\right) R T_{o}}{P_{N_{2} O}} \bullet\left(\frac{P_{N_{2} i} \dot{V}_{i}}{z_{N_{2}}\left(P_{N_{2}}, T_{i}\right) R T_{i}}+\frac{d P_{N_{2} r}}{d t} \bullet \frac{V_{r}}{z_{N_{2}}\left(P_{N_{2} r}, T_{r}\right) R T_{r}}\right)
$$

$\mathrm{f}_{\mathrm{N} 2}$ for dry gas is normally derived through:

$$
f_{\mathrm{N}_{2}}=1-f_{\mathrm{O}_{2}}-f_{\mathrm{CO}_{2}}-f_{\mathrm{CH}_{4}}
$$

which for real gasses and $\mathrm{P}_{\mathrm{N} 2}$ in a wet environment can be written as:

$$
P_{\mathrm{N}_{2} \text { wet }}=P_{\text {wet }}-P_{\mathrm{O}_{2} \text { wet }}-P_{\mathrm{CO}_{2} \text { wet }}-P_{\mathrm{CH}_{4} \text { wet }}-P_{\mathrm{w}}
$$

or in complete form:

$$
P_{N_{2} \text { wet }}=P_{\text {wet }}-P_{\mathrm{w}}-\frac{P_{\text {wet }}-P_{\mathrm{w}}}{P_{\text {wet }}} \cdot\left(\frac{z\left(P_{\mathrm{O}_{2} \text { wet }}, T\right)}{z\left(P_{\mathrm{O}_{2} \text { dry }}, T\right)} \cdot P_{\mathrm{O}_{2} \text { dry }}+\frac{z\left(P_{\mathrm{CO}_{2} \text { wet }}, T\right)}{z\left(P_{\mathrm{CO}_{2} \text { dry }}, T\right)} \bullet P_{\mathrm{CO}_{2} \text { dry }}+\frac{z\left(P_{\mathrm{CH}_{4} w e t}, T\right)}{z\left(P_{\mathrm{CH}_{4} \text { dry }}, T\right)} \cdot P_{\mathrm{CH}_{4} d r y}\right)
$$

Formula (37) illustrates the link between measurement of $\mathrm{O}_{2}, \mathrm{CO}_{2}$ and $\mathrm{CH}_{4}$ (if present) with the $\mathrm{N}_{2}$ balance, yet also includes water vapor as an important component emphasizing the requirement of accurate equipment for measuring this gas. 
If the assumption that the subject has no part in the $\mathrm{N}_{2}$ gas exchange [12] is invalidated for any reason there are two ways for correctly handling this. First of all one could measure $\dot{n}_{N_{2} s}$ by other means and use the results with (32) to change (33) for a pull system into:

$$
\dot{V}_{i}=-\frac{z_{N_{2}}\left(P_{N_{2} i}, T_{i}\right) R T_{i}}{P_{N_{2} i_{i}}} \bullet\left(\dot{n}_{N_{2} s}+\frac{P_{N_{2} O} \dot{V}_{o}}{z_{N_{2}}\left(P_{N_{2} o}, T_{0}\right) R T_{o}}+\frac{d P_{N_{2} r}}{d t} \bullet \frac{V_{r}}{z_{N_{2}}\left(P_{N_{2} r}, T_{r}\right) R T_{r}}\right)
$$

and similarly for a push system:

$$
\dot{V}_{o}=-\frac{z_{N_{2}}\left(P_{N_{2} o}, T_{o}\right) R T_{o}}{P_{N_{2} \mathrm{O}}} \bullet\left(\dot{n}_{N_{2} s}+\frac{P_{N_{2} i} \dot{V}_{i}}{z_{N_{2}}\left(P_{N_{2} i}, T_{i}\right) R T_{i}}+\frac{d P_{N_{2} r}}{d t} \bullet \frac{V_{r}}{z_{N_{2}}\left(P_{N_{2} r}, T_{r}\right) R T_{r}}\right)
$$

The other option for correctly handling this would be to not use the $\mathrm{N}_{2}$ conservation assumption and measure both $\dot{V}_{l}$ and $\dot{V}_{o}$ with fully identical instruments as well as with complete elimination of leakage.

\section{The model of a room sized calorimeter}

In literature, the common model chosen is the first order model. In reality, there will also be a measurable second order and a delay effect due to the mixing properties in the calorimeter $[29,22]$.

In the case of a first order model the integration in the room is elimated by differentiation in calculation, the room is in fact an integrator for moles of gas $\mathrm{g}$ :

$$
\begin{gathered}
C_{g r}(t)=\frac{1}{V_{r}} \int_{t=0}^{t} \dot{n} d t+C_{t=0} \\
\frac{C_{g r}}{n_{g r}}=\frac{1}{V_{r}}
\end{gathered}
$$

where differentiation resolves back to :

$$
\dot{n}_{g r}=V_{r} \frac{d C_{g r}}{d t}
$$

or:

$$
\dot{n}_{g r}=\frac{d P_{g r}}{d t} \bullet \frac{V_{r}}{z_{g}\left(P_{g r}, T_{r}\right) R T_{r}}
$$


If we assume immediate and complete mixing then the first order system consists only of the integrator $\left(V_{r}\right)$ and the flow through the system. However, in reality we have the mixing flow which together with the integrator forms a second order model and we may calculate the second order or mixing time constant from:

$$
\tau_{2}=\frac{V_{r}}{\dot{V}_{\text {recirculation }}}
$$

This faster mixing time constant is further improved by the particle speed of RGE gasses in the confined volume, governed by the Maxwell-Bolzmann distribution. The latter causes gasses to travel through the enclosed space in the absence of active mixing, not unlike the diffusion front in a tube-reactor or sample-tubing.

Construction of the room-calorimeter regarding mixing will for the greater part define mixing speed obtained, for example by application of laminar- and bypass flows.

In formula 27 and 28 the impact of volume $\mathrm{Vr}$ of a whole room calorimeter is visible, its typically large quantity is multiplied by differences in gas pressure of "any" gas g. Importantly, the difference in gas pressure, i.e. concentration, must be representative of the complete volume in order to prevent momentary over- or under representation of such gas. This is where the assumption "all gasses are well mixed" finds its origin. Part of the construction of a room calorimeter therefore must be the positioning of samplepoint(s) allowing a representative sample for the total of the volume Vr. I.e. not the closest, partially mixed, position to the subject but in contrast the best mixed position of the total volume may provide the optimal input to the differential formulae regarding dynamic precision.

\section{Total balance for a calorimeter system}

The equations derived provide total balance equations for a volume $\mathrm{V}_{\mathrm{r}}$ and the relevant gases for RGE: $\mathrm{O}_{2}, \mathrm{CO}_{2}, \mathrm{~N}_{2}, \mathrm{CH}_{4}$ and Water, and the balance can easily be augmented for additional parameters while using true physics i.e. with less assumptions. This balance can also be derived using classic volumetric equations, yet only the application of correct physics regarding the conversion from mass to volume will yield fully identical results. The latter would in fact be identical to calculating molar quantities as proposed. For this reason, describing the total balance for a calorimeter in absolute molar quantities may ultimately result in the highest precision achievable; a small step towards true molecule counting balance.

The equations where converted to software (Labview, National Instruments, Austin, USA) for two applications. First, in simulation mode, the impact of molar calculation and real- versus ideal gas assumption may be compared for simulated input variables and their expected variation. This allows for the examining the impact of a single variable, for instance single-point (inlet, room, outlet) temperature or pressure variation. 
Secondly the software module can be integrated in production calculation programs for subject and validation experiments.

\section{Measurement system}

The calculation software has been applied in whole room calorimetry. The calorimeter system was described earlier [29] and its measurement system with automatic calibration and dual analyser systems (Servomex, UK and ABB, Hartmann\&Braun Germany) has been kept intact. Based on simulation results, the rooms have been augmented with cross-sectional recirculation flow and flow-division through flushed inner walls and ceiling, proportional climate control, additional continuous gas analysers (Uras, Magnos, ABB, Hartmann\&Braun, Germany) and additional P, Rh, and T sensors. The analog to digital conversion for all parameters has been upgraded to 24 bits resolution, data is stored for each one second interval. Further augmentation is intended based on results and validation of molar equations.

\section{Statistics}

Evaluating the output of a formula will result in repeated identical output for an identical repeated set of input parameters, in this situation the standard deviation is zero and the effect size is 1 . The changing of a single input parameter of interest will therefore reveal an absolute and repeatable impact on result. Hence, for presenting the impact of simulation results no statistics were required or applied.

A power calculation for validation of experiments using molar balance versus volumetric balance projected a minimum sample size of 107 experiments. This is caused by the standard deviation of whole room calorimetry in combination with the small mean difference expected.

\section{RESULTS}

Results for using the molar equation where obtained by changing a single parameter in a set of fixed parameters as input to the calculation software. As no mass may escape calculation the total of molecules has to be accounted for. At first glance this seemed identical to working with volumetric equations and ideal gas assumption, both in creating software and in calculating results. However, differences in the output become visible for dynamic responses as well as for static differences.

To start with, the compressibility of 4 common RGE gasses was calculated using the molar equations (Fig.1). 


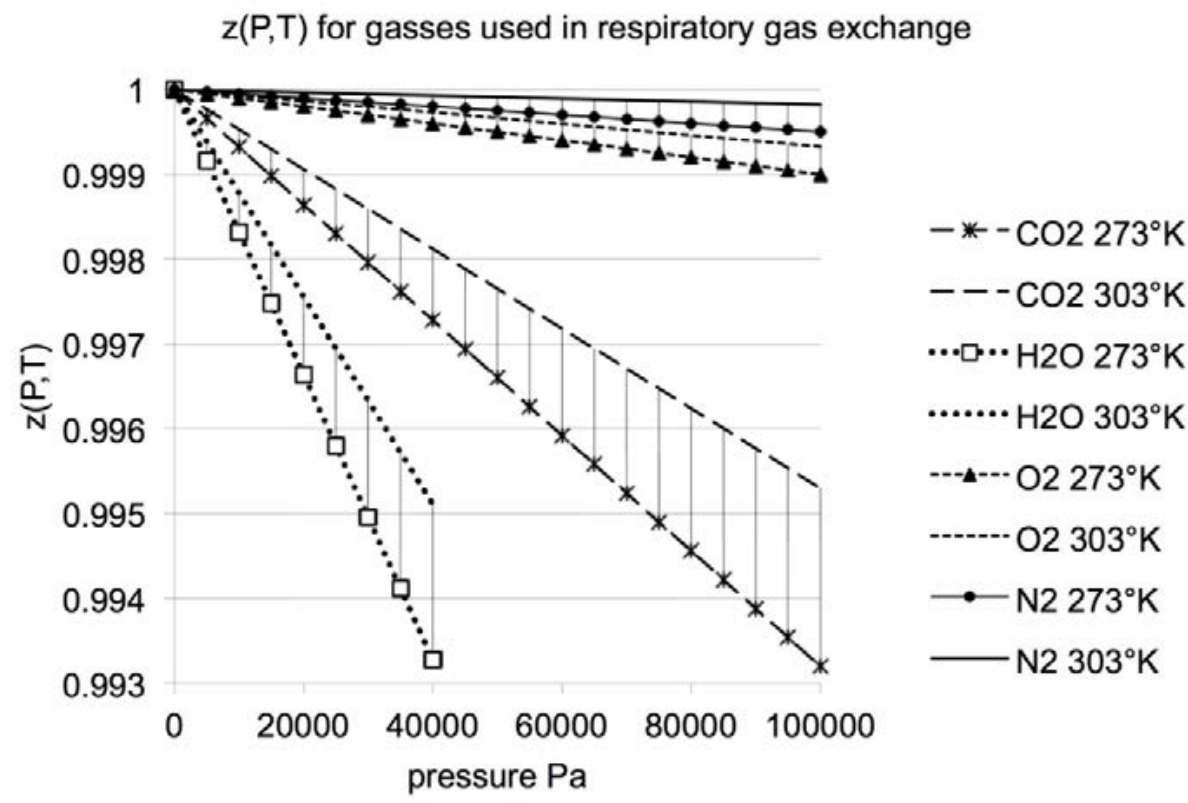

Figure 1. Compressibility $z(P, T)$ for $\mathrm{CO}_{2}, \mathrm{H}_{2} \mathrm{O}, \mathrm{O}_{2}$ and $\mathrm{N}_{2}$. The gasses show a change in compressibility in the normal temperature range, and the effect increases linear with its partial pressure.

Except for $\mathrm{H}_{2} \mathrm{O}$ vapor, $\mathrm{CO}_{2}$ gas is the most compressible. All gasses increase their compressibility linear with partial pressure, i.e. decrease linear with a decrease in partial pressure. Note that $\mathrm{H}_{2} \mathrm{O}$ will condensate at 610-4200 Pascal for the presented temperature range, it was plotted past its saturation pressure for illustrating its non-linear character.

In a closed volume near standard ambient conditions, temperature and pressure will have near-identical impact. In most indirect calorimeters pressure will remain close to the prevalent ambient pressure, with relatively small and slow changes, while temperatures in calorimeter and flows will have a practical range of $\pm 5 \%$ variation ( $\pm 15 \mathrm{~K}$ ) on the Kelvin scale around $293 \mathrm{~K}$. For this reason, a variation in temperature was chosen for illustrating the impact of compressibility (Figure 1 ).

For volume, the impact of $0.5 \mathrm{~K}$ temperature steps around standard temperature and pressure where evaluated with real and ideal calculation. The measured flow at outlet (pull-type) was set to zero, using the Haldane transform to calculate any volumetric error at the inlet caused by the ideal assumption (Fig.2). The impact is identical for a push type calorimeter, setting the inlet to zero. 


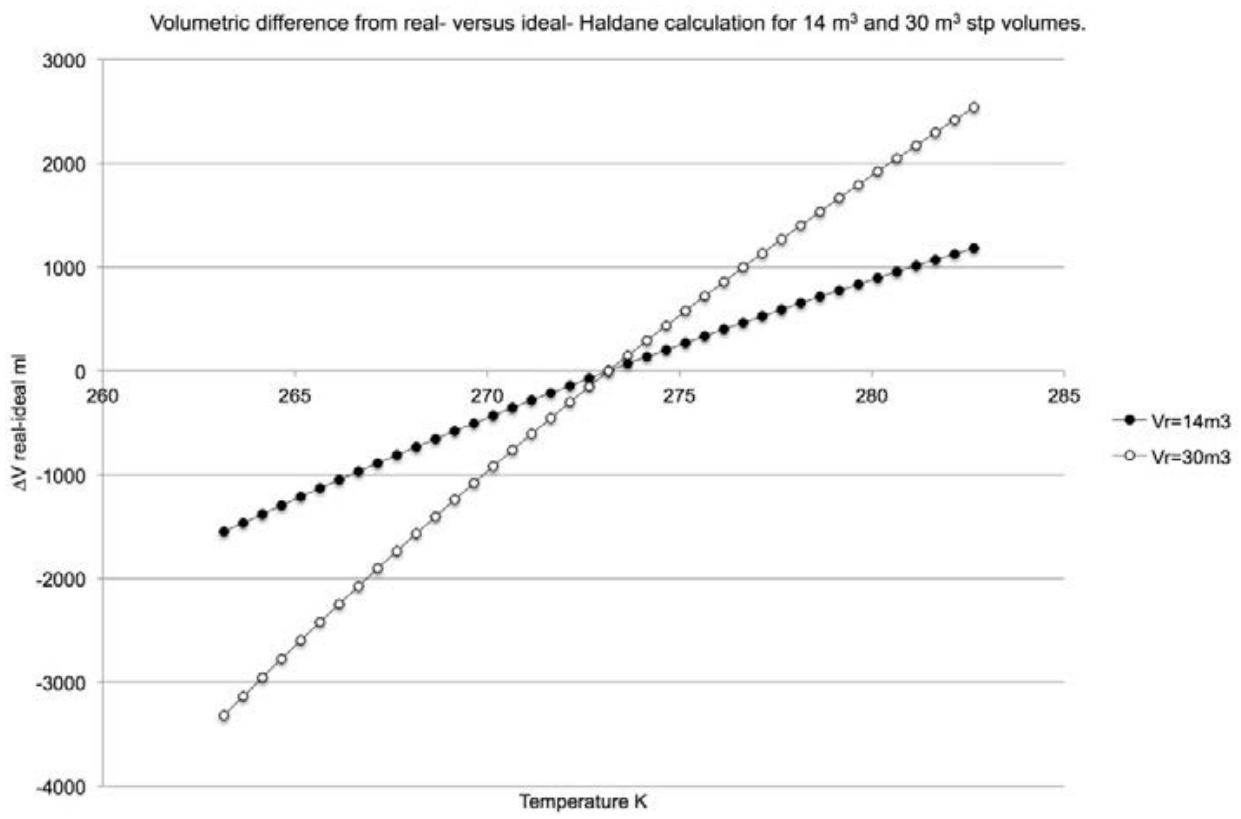

Figure 2. The difference in using real- versus ideal- Haldane calculation for $14 \mathrm{~m}^{3}$ and $30 \mathrm{~m}^{3}$ stp volumes over a \pm 10 degree $K$ range for a single evaluation interval.

Figure 2 shows the difference in volume $\mathrm{ml}$ between real and ideal calculation over a single evaluation interval, plotted for two room volumes of 14 and $30 \mathrm{~m}^{3}$ and for temperature steps over a range of $\pm 10 \mathrm{~K}$. The difference is independent of duration of interval, is linear with room volume, and is not linear with temperature. Typically, the resulting error in measured $\mathrm{O} 2$ consumption for a 1 degree $\mathrm{K}$ change inside a $14 \mathrm{~m}^{3}$ volume is in the order of $\pm 20-25 \mathrm{ml}$ over a single interval.

The cumulative effect of up and down steps will average to zero for any interval with identical start- and end temperature. The difference in $\mathrm{O} 2 \mathrm{ml}$ for Real versus Ideal in a $14 \mathrm{~m}^{3}$ volume, applying a 1 degree $\mathrm{K}$ up and down temperature change, was calculated to illustrate this (Fig.3). 


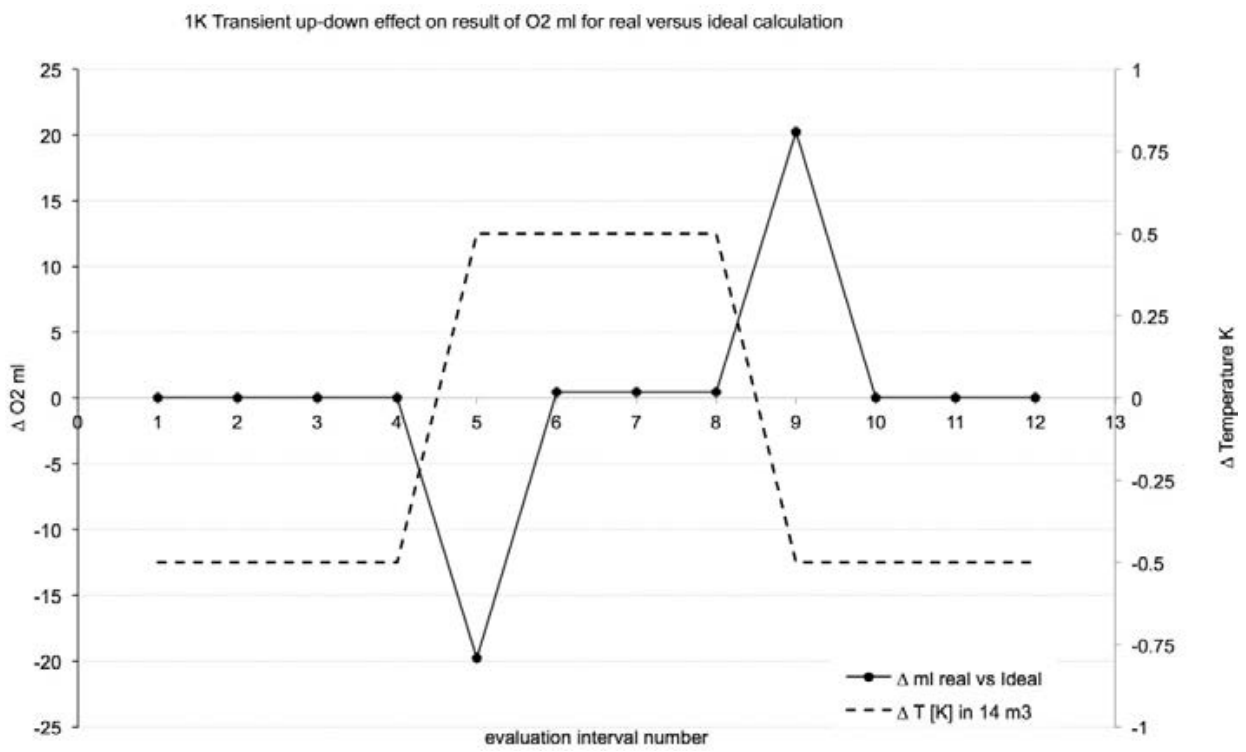

Figure 3. Difference in $\mathrm{O}_{2} \mathrm{ml}$ between Real and Ideal calculation calculated for a $14 \mathrm{~m}^{3}$ volume with a 1 degree $\mathrm{K}$ temperature step applied, negative $\mathrm{O}_{2}$ denotes consumption. Note the slight offset for $\mathrm{O}_{2} \mathrm{ml}$ at points $6-8$, illustrative of the non-linearity with temperature.

A second volume of interest is the flow passing through the calorimeter over time, resulting in totalized ingoing- and outgoing volume. Typically, the temperature difference for flow in- and out- may show a larger and often static temperature difference in comparison to the climatised room-volume with its variation around a setpoint. A temperature difference in the range 10-50 $\mathrm{K}$ may occur depending on season and climate, though such large differences will typically be decreased before reaching the calorimeter or even eliminated completely in sample preparation. A relatively small yet static temperature difference of 2 degrees Kelvin in inlet versus outlet temperature, around standard temperature and pressure, was used to find the difference in $\mathrm{O}_{2}$ consumption resulting from real versus ideal calculation (Fig.4). Note that this difference is assumed to be present in the sample at the point of analysis. 


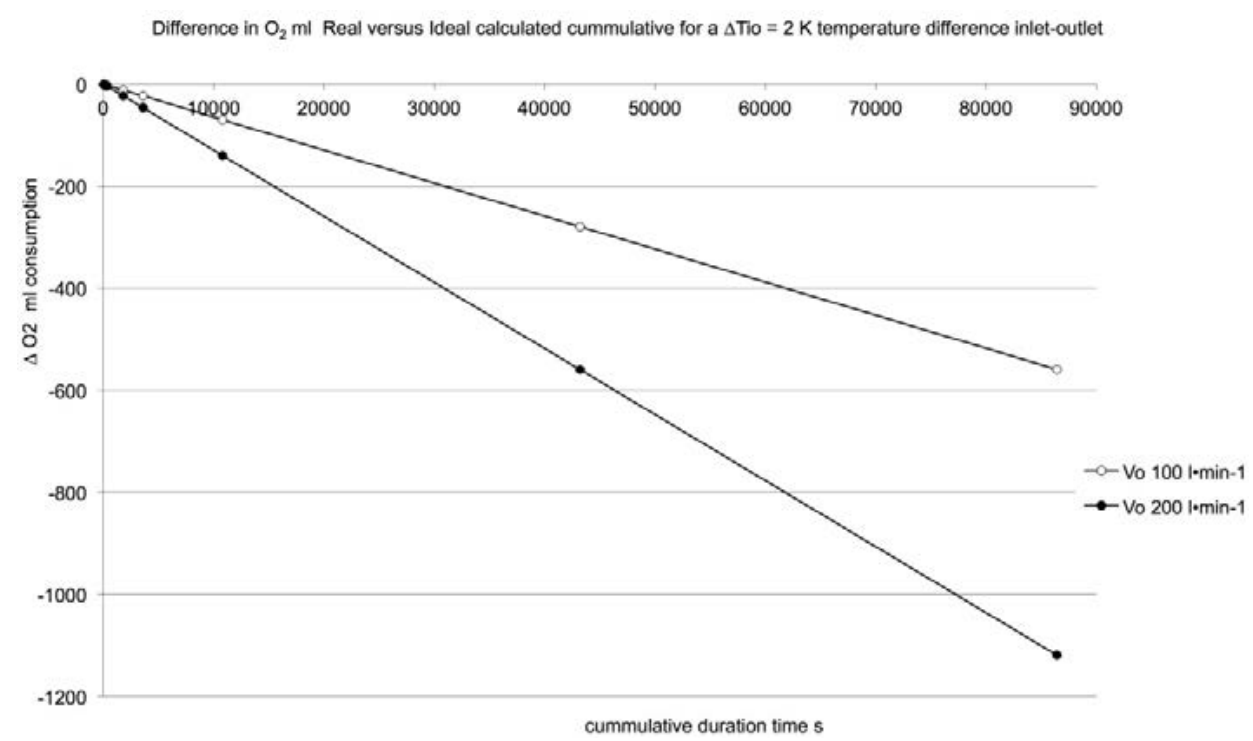

Figure 4. Difference in $\mathrm{O}_{2} \mathrm{ml}$ consumption result between Real and Ideal calculation calculated for two flow rates with a 2 degree $\mathrm{K}$ temperature difference from inlet to outlet.

The effect on $\mathrm{O}_{2}$ measured for a $2 \mathrm{~K}$ difference in inlet and outlet sample temperature at the typical whole room calorimeter flow-through of $100-2001 \cdot \mathrm{min}^{-1}$, was independent of volume, was linear with flow, and was non-linear with temperature. Contrary to volume effects with their 'return-to-zero' impact, this flow effect is cumulative as delta temperatures of inlet and outlet are in general of a static nature and may be in proportional effect at the point of analysis if not stabilized; a difference in sample temperature of $0 \mathrm{~K}$ is perfect, up to $5 \mathrm{~K}$ is thought to be an outer limit for a working calorimeter. The calculation software was used to examine more variations of parameters for their impact (Table 1).

A secondary result of developing and working with molar quantities was an increased understanding of the physics of gas properties, assumptions, and how additional sensors may benefit whole room calorimetry. This was instrumental in applying first improvements to revisions of whole room calorimeters, resulting in subcompartmentalized and flushed inner walls, smooth proportional climate control, crosssectional recirculation flow, repositioned sample points, additional $\mathrm{P}, \mathrm{Rh}$, and $\mathrm{T}$ sensors and near-continuous gas analysis. 
Table 1. The impact of true molar evaluation versus ideal volumetric evaluation on $\mathrm{O}_{2}$ uptake and $\mathrm{CO}_{2}$ production, calculated for a $14 \mathrm{~m}^{3}$ whole room volume at STP conditions, $0.001667 \mathrm{~m}^{3} \cdot \mathrm{s}^{-1}$ flow $\left(100 \mathrm{l} \cdot \mathrm{min}^{-1}\right)$, and without subject. The impact varies with type of parameter change applied, and with length of calculation interval. The $100 \%$ EE reference level was chosen for BMR, i.e. $206 \mathrm{ml} \bullet \mathrm{min}^{-1} \mathrm{O}_{2}$ consumption and 175 $\mathrm{ml} \bullet \mathrm{min}^{-1} \mathrm{CO}_{2}$ production $\left(1 \mathrm{kcal} \bullet \mathrm{min}^{-1}\right), \mathrm{RER}=0.85$. The calculated difference was added to the BMR level to reveal the impact on RER.

\begin{tabular}{|c|c|c|c|c|c|c|c|c|}
\hline Interval s & Parameter & Type of change & $\mathrm{O}_{2} \mathrm{ml}$ & $\mathrm{CO}_{2} \mathrm{ml}$ & RER & $\mathrm{O}_{2} \%$ & $\mathrm{CO}_{2} \%$ & RER \% \\
\hline 60 & Troom & $+0.5 \mathrm{~K}$ step during interval & -91 & -0.3 & 0.589 & 44.2 & -0.1 & -30.7 \\
\hline 300 & Troom & $+0.5 \mathrm{~K}$ step during interval & -91 & -0.3 & 0.781 & 8.8 & 0.0 & -8.1 \\
\hline 300 & $\mathrm{PO} 2$ in & + 10 Pa step during interval & 0.9 & 0.0 & 0.851 & -0.1 & 0.0 & 0.1 \\
\hline 300 & $\mathrm{PCO} 2$ in & + 10 Pa step during interval & -0.3 & 0.0 & 0.850 & 0.0 & 0.0 & 0.0 \\
\hline 60 & P room & + 100 Pa step during interval & 2.7 & 0.0 & 0.861 & -1.3 & 0.0 & 1.3 \\
\hline 300 & P room & +100 Pa step during interval & 2.7 & 0.0 & 0.852 & -0.3 & 0.0 & 0.3 \\
\hline 60 & $T$ inlet & - $5 \mathrm{~K}$ static difference inlet air & -0.7 & 0.0 & 0.847 & 0.3 & 0.0 & -0.3 \\
\hline 300 & $\mathrm{~T}$ inlet & - $5 \mathrm{~K}$ static difference inlet air & -3.6 & 0.0 & 0.847 & 0.3 & 0.0 & -0.3 \\
\hline 86400 & $\mathrm{~T}$ inlet & - $5 \mathrm{~K}$ static difference inlet air & -1040 & -2.9 & 0.847 & 0.4 & 0.0 & -0.4 \\
\hline 3600 & $T$ inlet & $-5 \mathrm{~K}$ step in inlet air in $1 \mathrm{hr}$ & -46.8 & -0.1 & 0.847 & 0.4 & 0.0 & -0.4 \\
\hline 60 & Pw room & - 500 Pa step dehumidification & 12.4 & 0.0 & 0.905 & -6.0 & 0.0 & 6.4 \\
\hline 300 & Pw room & - 500 Pa step dehumidification & 12.4 & 0.0 & 0.860 & -1.2 & 0.0 & 1.2 \\
\hline
\end{tabular}

The impact of both calculus and augmentations are now under investigation, also driving further changes as application of this molar approach becomes a reality.

\section{DISCUSSION}

\section{Molar application}

Using the molar equation and SI units allows true conversion of quantities from volume to mass, this is beneficial for the subdivision of a whole room calorimeter design into compartmentalized processes, as mass transport between sub-processes can be precisely described and quantified. The theoretical model revealed physics of RGE gasses impacted by dynamic changes and static differences of gasses at realisticly occurring ambient temperatures and pressures. The impact of true molar evaluation versus ideal volumetric evaluation is small for $\mathrm{CO}_{2}$ and large for short-interval $\mathrm{O}_{2}$, and hence for RER (Table 1, Figure 4). Related to performance of whole room calorimeters in literature [29] (Table 2), the impact of true molar evaluation on $\mathrm{O} 2$ is comparable in magnitude to published values. For short interval evaluation, the impact may even be high, this will depend on how impact of various parameters adds up or in contrast cancels out. 
Table 2. The impact of using real gas molar equations can be related to typical performance of whole room calorimeters in literature, shown to be well within 1\% [29].

\begin{tabular}{lcc}
\hline & $\Delta \mathrm{O}_{2}, \%$ & $\Delta \mathrm{CO}_{2}, \%$ \\
\hline Charbonier A. et al, 1990 & $-1 \pm 2.2$ & $0 \pm 2.1$ \\
Henning B. et al, 1996 & $0.06 \pm 1.21$ & $-0.49 \pm 1.12$ \\
Jéquier E. et al, 1983 & $0.44 \pm 0.34$ & $-0.36 \pm 0.5$ \\
Moon J.K. et al, 1995 & $-0.22 \pm 1.51$ & $0.21 \pm 0.68$ \\
Moon J.K. et al, 1995 & $-0.53 \pm 0.66$ & $-0.05 \pm 1.36$ \\
Moon J.K. et al, 1995 & $2.3-5.8$ & $1.9-4.9$ \\
Murgatroyd P.R. et al, 1987 & \pm 1.2 & \pm 0.5 \\
Ravussin E. et al, 1986 & $-2.8 \pm 2.8$ & $-2.1 \pm 2.8$ \\
Rumpler W.V. et al, 1990 & $1.5 \pm 1.4$ & $1.5 \pm 1.4$ \\
Seale J.L. et al, 1991 & $0.3 \pm 1.54$ & $0.4 \pm 1.34$ \\
Seale J.L. et al, 1991 & & $0.4 \pm 0.85$ \\
Shetty P.S. et al, 1987 & \pm 0.43 & \\
Treuth M.S. et al, 1996 & $-0.5 \pm 2.1$ & $0.2 \pm 2.3$ \\
Schoffelen et al, 1997 & $0.5 \pm 2.0$ & $-0.3 \pm 1.6$ \\
Schoffelen et al, 1997 & & $-0.6 \pm 2.3$ \\
Summary & $0.13 \pm 1.26$ & $0.09 \pm 0.95$ \\
\hline
\end{tabular}

The molar equation has been made operational in whole room calorimetry. As expected, first results for validation tests fall within the previous specification [29]. Given the mathematical similarity of molar and volumetric calculation, the detection of a possible small shift in mean validation results was not yet possible. For the calorimeter at hand, it would require a sample size estimated at 107. Moreover, this shift will be specific for the calorimeter examined and its environmental parameters, for instance static differences in sample temperatures, possibly impacted by seasonal or even circadian variability.

\section{Non-linearity aspects - gasses}

The nonlinearity of $\mathrm{CO}_{2}$ has been mentioned before [29] and was suspected as a possible confounding factor, yet its low partial pressure in fresh- and room-calorimeter air in the range 40-1000 Pascal decreases its compressibility significantly. At low partial pressures compressibility of $\mathrm{CO}_{2}$ for all practical purposes does not affect measurements using either ideal volumetric or real molar equations, and amounts in this diluted gaseous form may be converted to moles using the ideal gas assumption without measurable error. Moreover, classic formulae for the conversion from gas-exchange to energy expenditure (EE) $[40,39,4,7]$ likely have used ideal volumetric conversion at similar low partial pressures, even though their origins are molar based, and no references to the contrary where found. Effectively, pure $\mathrm{CO}_{2}$ at atmospheric pressure and ambient temperature due to its non-linearity will occupy about - $0.7 \%$ less volume in comparison to 
ideally assumed volume, however, in indirect calorimetry "pure" CO2 is only a product of calculus and the actual liters are in reality diluted as well as measured at lower partial pressure. Since molar equations using real gas volumes will result in moles, the resulting real moles of $\mathrm{CO}_{2}$ must yet be converted back to an ideal gas volume in order to fit the classic EE conversion formulae. This can be envisioned as if the pure CO2 was diluted and thus changed compressibility close to ideal gas but not changed in amount.

Depending on the use of true molar quantities or ideal volumetric quantities, $\mathrm{CO}_{2}$ quantity may therefore require a correction if volumetric measures are used instead of gravimetric measures. This is the case with infusion tests using undiluted gasses [29].

The non-linearity of Oxygen is less than that of $\mathrm{CO}_{2}$, the compressibility of $\mathrm{O}_{2}$ is just 0.02 $\%$ even at the higher partial pressure of around $20.9 \mathrm{kPa}$. For pure Oxygen at standard pressure and temperature the compressibility remains well below $0.1 \%$. Thus, for practical purposes there is little effect $(\leq 0.1 \%)$ of molar versus ideal volumetric expression regarding substrate use and conversion of RGE to EE. However, the measurement of $\mathrm{O}_{2}$ itself will be influenced by non-linearity of the other gasses, specifically $\mathrm{N}_{2}$, as calculated volumes may be affected.

The dynamic impact on both $\mathrm{O}_{2}$ and $\mathrm{CO}_{2}$ for a 5 min evaluation interval was calculated (Table 1). These single-parameter percentages can be cumulative or instead cancel each other out.

Note that the calculated impact on $\mathrm{O}_{2}$ is larger in comparison to impact on $\mathrm{CO}_{2}$. This is attributed to the larger amount of $\mathrm{O}_{2}$ passing through the indirect calorimeter, whereas $\mathrm{CO}_{2}$ is for the greater part limited to the quantity of $\mathrm{CO}_{2}$ produced inside the calorimeter.

The impact on $\mathrm{O}_{2}$ was larger than expected in view of the low compressibility of both $\mathrm{O}_{2}$ and the inert gasses. Surprisingly, the least compressible gas, $\mathrm{N}_{2}$, showed the largest effect and specifically regarding $\mathrm{O}_{2}$ consumption. This was caused by the important role of $\mathrm{N}_{2}$ in the Haldane volume calculation [12]. The high $\mathrm{N}_{2}$ partial pressure in combination with large flow- and room- volumes amplifies the non-linearity impact of $\mathrm{N}_{2}$ for both dynamic and static climate effects.

The impact of dynamic variation in room-climate around a set-point will mostly cancel out over time (Figure 3), the symmetrical $\mathrm{O}_{2}$ peaks observed in whole-room indirect calorimetry[33] may be explained by the combined impact effect of $\mathrm{N}_{2}$ compressibility, the Haldane equation, and climate-control impact on large enclosed volumes. This effect is for the greater part linear with the amplitude of temperature variation within the calculation interval, establishing a direct link between EE-noise and climate-control. Note that $\mathrm{O}_{2}$ consumption (Figure 3, Table 1) accounts for 78\% of EE [39].

In contrast to dynamic variation, the static differences may have a cumulative effect (Figure 4). Please note that Figure 4 does not include dynamic storage inside the calorimeter, though formulae $25-28,32-34,38,39$ and 42 do. 


\section{Non-linearity aspects - the Haldane equation}

Haldane [12] used the elegant method of constant throughput of inert gasses, unused by the calorimetric process, to balance input flow with output flow or vice-versa. This effectively eliminates cumulative errors originating from inequality of separate flow measurement on each side. For instance, two highly accurate flow metering devices with $\leq 0.1 \%$ accuracy at $100 \mathrm{~L} \bullet \mathrm{min}^{-1}$, one on the inlet and one on the outlet, may show a deviation of up to 288 liter over 24 hour. At the $20.9 \mathrm{kPa} \mathrm{O}$ level in air this could result in up to 60 liter deviation of measured $\mathrm{O}_{2}$ consumption, i.e. 10 - $20 \%$ of daily adult $\mathrm{O}_{2}$ consumption. Importantly, most flow-meters are less accurate, in general $0.2-1 \%$ of the full range of the device.

This explains why the Haldane equation, establishing a zero balance for inflow and outflow of inert gasses, is still an important tool for nearly all indirect calorimeters.

For a room-calorimeter, with its large volume, the dynamic changes in fractional amounts of inert gasses, i.e. dynamic storage, must also be taken into account. If we momentarily ignore this storage, the Haldane equation simply states that momentary inflow of inert gasses equals momentary outflow of inert gasses. Historically, this is a volumetric equality using the ideal gas assumption. However, the underlying principle is that no change in quantities of inert gasses will occur; i.e. the same amount of moles moves in and out. Use of molar equations therefore adheres to the underlying principle, while eliminating the impact of the ideal gas assumption.

For eliminating the real gas assumption one more aspect is of importance; determining the above mentioned fractional amounts of inert gasses. The non-linearity impact caused by different temperatures and pressures at inlet- and outlet- of the calorimeter might also be in effect at the point of analysis; creating further deviation from reality. However, in general gas samples from outlet-, inlet- and internal sample points will be measured in an analyser at stabilized temperature and stabilized sample pressure. Therefore, at the point of analysis no or decreased changes in compressibility for the gasses will be co-registered, and differences in fractional composition are determined at near-identical temperature and sample pressure. If this equalisation in sample conditions is absent, calorimetric results will be increasingly affected.

Moreover, the volumetric mix at a sample point, with its individual temperature and pressure, will be compressed or expanded to real gas volumes that differ from the "virtual" volumes calculated at the temperature and pressure of the point of analysis. For true molar quantities, these sort of changes in temperature and pressure must be measured and taken into account; de-virtualized as it were. The sample condition at the point of analysis thus may have to be measured with precision, just as in the other compartments, in and out. 


\section{Future impact}

The derivation of true molar equations was less obvious than expected. From a physics and mathematics viewpoint the molar equation should not differ from existing and validated volumetric equations. However, for exact molar quantities the ideal gas assumption had to be eliminated and this revealed an impact on calorimetric measures, both static and dynamic.

The static impact on EE was estimated to be in the $0 \%-1 \%$ range, within published standard deviation of existing systems. The static impact in part may be responsible for small differences in mean results. To investigate such a difference a large number of validation tests would be required, and results would be specific for the individual calorimeter tested. Differences might even depend on time of day or seasonality.

The dynamic impact can be significant for a limited measurement interval (Table 1). Given the multitude of parameters involved, local Rh, $\mathrm{T}$ and $\mathrm{P}$ measures, it has been speculated that coinciding variation will partly cancel out over a single interval of interest, and specifically for longer intervals. In contrast, a shorter finite sample interval will increase both noise and time resolution [23]. Here it has become clear from (26) that improved dynamic response is dependent on the precision of a larger set of input parameters, i.e. not limited to gas measurement precision. With a growing interest in short-interval dynamic changes, the dynamic impact of climate and molar quantities may ultimately become at least as important as the precision of the applied gas analysis. The validation of a whole room calorimeter using the molar equations was not the aim of this study, that is the next tep. Yet, implementation was realized and hence a few remarks can be made regarding the future impact of a true molar balance on requirements:

- As more parameters impact calorimetric resolution, while sample interval decreases, timing differences between signals need to be eliminated. I.e. out-of-phase problems must be eliminated, and not just for sample transport delays but probably also for speed of molecules of gas, i.e. mixing speed and/or diffusion speed of gasses. In this respect water vapor and its memory effect in tubing and sensors must also be considered.

- More sensors for Rh, T, P and flow will allow for evaluating sub-compartments in greater detail, and this may also be the case for measuring layering of airstreams due to temperature differences.

- Quantification noise from analog to digital conversion, or from digital sensors, must be evaluated for minimum step size. The step-size should be small enough as not to cause digitizing noise, for instance in real gas evaluation (Table 1). A possible exception is gas analysis, being allowed an acceptable step-size in favor of accuracy. Nowadays even "analog" sensors may incorporate digital inner workings, using a digital to analog converter at the output. 
Note that the above remarks will hold true for most dynamic aspects of whole room calorimetry, and may reveal an impact on, or variability in, previously measured impulse transfer characteristics.

\section{CONCLUSIONS}

A practical implementation of true molar balance equations for indirect calorimetry based on SI units in combination with real gasses was achieved. The formal description in molar quantities allows for stricter compartmentalization of sub-processes.

From a physics and mathematics viewpoint the molar equation is not different from existing and validated volumetric equations, except for the impact of eliminating the ideal gas assumption. Using Real gasses instead of Ideal gasses will specifically have an impact on whole room indirect calorimeters and their inherent large volumes, and specifically regarding $\mathrm{O}_{2}$ calculations and RER for dynamic short interval evaluation.

The nonlinearity of pure $\mathrm{CO}_{2}$ with its compressibility of around $0.7 \%$ at atmospheric pressure can be mostly ignored, as historically substrate calculations used ideal gas assumption. In contrast, the non-linearity of $\mathrm{CO}_{2}$ must be accounted for where volumetric quantities of pure $\mathrm{CO}_{2}$ at atmospheric pressure are applied, for instance with infusion techniques by volume instead of by mass (weight).

More theoretical and practical work using real molar gas quantities is expected to improve indirect calorimeters on a physics level. Specifically, for short interval evaluation the dynamic impact of climate and true molar quantities may prove at least as important as the precision of the applied gas analysis. 


\section{REFERENCES}

1. Ahlberg K, Aktiebolag AGA (1985) Aga gas handbook. Aga AB, Lindingö

2. Akanji AO, Bruce MA, Frayn KN (1989) Effect of acetate infusion on energy expenditure and substrate oxidation rates in non-diabetic and diabetic subjects. Eur J Clin Nutr 43:107-115

3. Astrup A, Thorbek G, Lind J, Isaksson B (1990) Prediction of 24-h energy expenditure and its components from physical characteristics and body composition in normal-weight humans. Am J Clin Nutr 52:777-783

4. Brouwer E (1957) On simple formulae for calculating the heat expenditure and the quantities of carbohydrate and fat oxidized in metabolism of men and animals, from gaseous exchange (Oxygen intake and carbonic acid output) and urine-N. Acta Physiol Pharmacol Neerl 6:795-802

5. Brown D, Cole TJ, Dauncey MJ, Marrs RW, Murgatroyd PR (1984) Analysis of gaseous exchange in opencircuit indirect calorimetry. Med Biol Eng Comput 22:333-338

6. Charbonnier A, Jones CD, Schutz Y, Murgatroyd PR, Whitehead RG, Jequier E, Spinnler G (1990) A whole body transportable indirect calorimeter for human use in the tropics. Eur J Clin Nutr 44:725-731

7. Consolazio CF, Johnson RE, Pecora LJ (1963) Physiological Measurements of Metabolic Functions in Man. [By] C. F. Consolazio ... Robert E. Johnson ... Louis J. Pecora. [With illustrations and charts.]. McGraw-Hill Book Co, New York

8. Dugas LR, Cohen R, Carstens MT, Schoffelen PF, Luke A, Durazo-Arvizu RA, Goedecke JH, Levitt NS, Lambert EV (2009) Total daily energy expenditure in black and white, lean and obese South African women. Eur J Clin Nutr 63:667-673. doi:10.1038/ejcn.2008.8

9. Even PC, Mokhtarian A, Pele A (1994) Practical aspects of indirect calorimetry in laboratory animals. Neurosci Biobehav Rev 18:435-447

10. Frayn KN (1983) Calculation of substrate oxidation rates in vivo from gaseous exchange. J Appl Physiol Respir Environ Exerc Physiol 55:628-634

11. Gasunie NVN (1988) Physical Properties of natural gases.

12. Haldane J (1892) A new form of Apparatus for measuring the Respiratory Exchange of Animals. J Physiol 13:419-430

13. Henning B, Lofgren R, Sjostrom L (1996) Chamber for indirect calorimetry with improved transient response. Med Biol Eng Comput 34:207-212

14. Heymsfield SB, Allison DB, Pi-Sunyer FX, Sun Y (1994) Columbia respiratory-chamber indirect calorimeter: a new approach to air-flow modelling. Med Biol Eng Comput 32:406-410

15. Jequier $E$, Schutz $Y(1983)$ Long-term measurements of energy expenditure in humans using a respiration chamber. Am J Clin Nutr 38:989-998

16. L'Air liquide. Division s (1976) Encyclopedie des gaz = : Gas encyclopaedia. Elsevier, Amsterdam; New York

17. Livesey G, Elia M (1988) Estimation of energy expenditure, net carbohydrate utilization, and net fat oxidation and synthesis by indirect calorimetry: evaluation of errors with special reference to the detailed composition of fuels. Am J Clin Nutr 47:608-628

18. Mansell PI, Macdonald IA (1990) Reappraisal of the Weir equation for calculation of metabolic rate. Am J Physiol 258:R1347-1354

19. McLean JA, Watts PR (1976) Analytical refinements in animal calorimetry. J Appl Physiol 40:827-831

20. Modell M, Reid RC (1983) Thermodynamics and its applications. Prentice-Hall international series in the physical and chemical engineering sciences. Prentice-Hall, Englewood Cliffs ; London

21. Moon JK, Jensen CL, Butte NF (1993) Fast-response whole body indirect calorimeters for infants. J Appl Physiol (1985) 74:476-484

22. Moon JK, Vohra FA, Valerio Jimenez OS, Puyau MR, Butte NF (1995) Closed-loop control of carbon dioxide concentration and pressure improves response of room respiration calorimeters. J Nutr 125:220228

23. Murgatroyd PR, Davies HL, Prentice AM (1987) Intra-individual variability and measurement noise in estimates of energy expenditure by whole body indirect calorimetry. Br J Nutr 58:347-356 
24. Nguyen T, de Jonge L, Smith SR, Bray GA (2003) Chamber for indirect calorimetry with accurate measurement and time discrimination of metabolic plateaus of over 20 min. Med Biol Eng Comput 41:572-578

25. Pendar H, Socha JJ (2015) Estimation of Instantaneous Gas Exchange in Flow-Through Respirometry Systems: A Modern Revision of Bartholomew's Z-Transform Method. PLoS One 10:e0139508. doi:10.1371/journal.pone.0139508

26. Ravussin E, Lillioja S, Anderson TE, Christin L, Bogardus C (1986) Determinants of 24-hour energy expenditure in man. Methods and results using a respiratory chamber. J Clin Invest 78:1568-1578. doi:10.1172/JCl112749

27. Redlich O, Kwong JN (1949) On the thermodynamics of solutions; an equation of state; fugacities of gaseous solutions. Chem Rev 44:233-244

28. Rising R, Whyte K, Albu J, Pi-Sunyer X (2015) Evaluation of a new whole room indirect calorimeter specific for measurement of resting metabolic rate. Nutr Metab (Lond) 12:46. doi:10.1186/s12986-0150043-0

29. Schoffelen PF, Westerterp KR, Saris WH, Ten Hoor F (1997) A dual-respiration chamber system with automated calibration. J Appl Physiol (1985) 83:2064-2072

30. Seale JL, Rumpler WV, Moe PW (1991) Description of a direct-indirect room-sized calorimeter. Am J Physiol 260:E306-320

31. Shetty PS, Sheela ML, Murgatroyd PR, Kurpad AV (1987) An open-circuit indirect whole body calorimeter for the continuous measurement of energy expenditure of man in the tropics. Indian J Med Res 85:453460

32. Slattery JC (1978) Momentum, energy, and mass transfer in continua. Reprint. edn. Krieger, Huntington, NY

33. Sun M, Reed GW, Hill JO (1994) Modification of a whole room indirect calorimeter for measurement of rapid changes in energy expenditure. J Appl Physiol (1985) 76:2686-2691

34. Tokuyama K, Ogata H, Katayose Y, Satoh M (2009) Algorithm for transient response of whole body indirect calorimeter: deconvolution with a regularization parameter. J Appl Physiol (1985) 106:640-650. doi:10.1152/japplphysiol.90718.2008

35. Treuth MS, Hunter GR, Weinsier RL, Kell SH (1995) Energy expenditure and substrate utilization in older women after strength training: 24-h calorimeter results. J Appl Physiol (1985) 78:2140-2146

36. Waals JDvd (1873) Over de continuiteit van den gas- en vloeistoftoestand : academisch proefschrift. A. W. Sijthoff, Leiden

37. Webb P, Saris WH, Schoffelen PF, Van Ingen Schenau GJ, Ten Hoor F (1988) The work of walking: a calorimetric study. Med Sci Sports Exerc 20:331-337

38. Webb P, Troutman SJ, Jr. (1970) An instrument for continuous measurement of oxygen consumption. J Appl Physiol 28:867-871

39. Weir JB (1949) New methods for calculating metabolic rate with special reference to protein metabolism. J Physiol 109:1-9

40. Zuntz N, Schumburg WAEFD (1901) Studien zu einer Physiologie des Marsches. Bibliothek von Coler Bd. 6. August Hirschwald, Berlin 

Chapter

\section{General discussion}

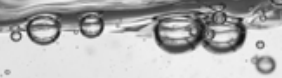

○: ०
- 0

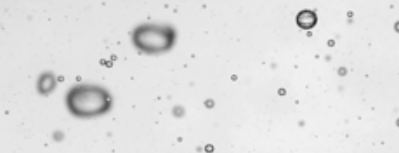



The energy we obtain and expend is the main determinant for life itself [1-27]. It has aptly been called "the fire of life" [28], and measuring this "fire" is the functional description for both direct- and indirect calorimeters.

Aspects of today's nutrition, clinical nutrition, physical activity, obesity, diabetes, exercise, and various extreme environments impact health and lifestyle in a more complex way than ever before. This drives a growing interest in human energy expenditure and its relation to aspects of physiology in man, re-appraising historical findings for modern day aspects and detail.

For measuring human energy expenditure, indirect calorimetry has become the method of choice. Commercial availability and the growing interest have caused a "black box" effect, where application and results may be trusted without check or understanding of inner working. [29]

\section{SUITABILITY OF A CALORIMETER FOR THE INTENDED RESEARCH}

In order to select suitable devices, technical setup, and a viable study protocol, an indepth knowledge of both biological variability and technical validity is required.

It is the primary goal of validation to prove suitability (appropriateness) for the intended research goal, explicitly taking into account the full range of biological variability expected for the type of research.

In this context definitions for biological variability and technical validation are:

\section{Definitions}

1) Biological variability is dependent on the type of research and comprises two aspects; A) the limits of biological parameters that may be achieved but not surpassed by the subjects, for instance level of EE, biological response time, breathing frequencies and breathing abnormalities; and B) limits imposed by physical presence of subjects in a defined environment, for instance duration, ambient conditions, or required freedom of movement.

2) Technical validity is the proof of suitability for the intended research, and specifically while taking into account the expected biological variability. For instance, combustion tests are suitable for systems measuring BMR or $24 \mathrm{~h} \mathrm{EE}$, whereas gas-infusion test are suitable for exercise level calorimeters, in both instances mimicking all relevant biological aspects. A typical example of a mismatch is the validation test of a breath-by-breath calorimeter with a combustion test, i.e. an alcohol-burn in BMR (hood) mode yet without simulated breathing.

The degree of suitability of the combination of biological variability and technical validity determines the required number of experiments for a valid result. While on the other 
hand, there is a definite limit to the number of subjects, funding, and time available to measure energy expenditure.

A combination with lower precision and accuracy will require more experiments for a valid result in comparison to a combination of higher precision and accuracy. Effectively, the combination with lower precision and accuracy may after all not be practical or suitable.

The above introduces precision and accuracy as important aspects for suitability.

\section{Precision and accuracy}

Precision, i.e. repeatability, reproducibility or test-retest reliability, is what can be expressed with a coefficient of variation CV [\%] or standard deviation SD [absolute]; i.e. how precise can an experiment be repeated, what is the distribution and range? Accuracy specifies the mean distance of measured results from reality.

For technical validation accuracy is the mean distance between known true "validation" values and the respective measured values. However, for measured values of subjects there is no known true value. The "true" momentary EE of a subject can only be determined with a parallel and accurate measurement. Thus, accuracy is mostly a technical aspect.

\section{The relation between suitability and aspects of precision and accuracy}

A precise measurement will reveal the true difference in repeated measures if present, it is suitable for finding changes over time in both an individual and in a group. These changes may be detected with significance even when the average values are not accurate, i.e. show an offset from the true value. If this offset is extreme or non-linear or not constant, results may yet be invalid.

An accurate measurement will show a minimal mean distance of measured results from reality. It should be noted that accuracy is defined for mean values, and not for individual values. As a consequence, aspects of distribution and range may need to be considered. For this discussion a normal distribution without abnormal outliers is assumed.

It is the combination of precision and accuracy that determines the error range for an individual assessment, this individual range is the sum of accuracy and precision ranges. A device specified at $\pm 1 \pm 2 \%$ (mean \pm SD) will resolve $95 \%$ of its individual results to within $5 \%$, which is expressed as the $95 \% \mathrm{Cl}$ or the mean $\pm 2 \bullet$ SD (e.g. $\pm 1 \pm 4 \%$ i.e. a range of -5 to $+5 \%$ ).

In literature twelve sites with whole room calorimeters showed a mean technical validation accuracy of $0.0 \pm 1.2 \%$ (range -2.7 to $2.2 \%$ ), based on the mean per site while excluding their variability. Hence a mean accuracy range with $95 \% \mathrm{Cl}$ was within $0.0 \pm$ $2 \cdot 1.2 \%$. (Figure 1 , arrow in the middle) [18]. When including the variability in accuracy 
with $95 \% \mathrm{Cl}$ per site, the inter-site accuracy range increased to -8.5 to $+5.8 \%$, and individual results may be hardly comparable.

For an individual assessment precision (CV\%) and accuracy must both be taken into account.

\section{THE COMBINATION OF TECHNICAL VALIDITY AND BIOLOGICAL VARIABILITY IN REAL LIFE}

\section{The combination according to this thesis}

The first goal of any calorimetric study will be to obtain valid data proving or disproving a hypothesis. This goal can only be achieved by using suitable devices and methods.

The technical and biological pathways and their four typical stages were previously defined for an indirect calorimeter (introduction, Table 5), and consist of theory, implementation, validation and application for both technology and biology. In this thesis the four stages can be recognized for both Man and Machine; providing theoretical background on gas analysis, combined direct- and indirect calorimetry, substrate use, and implementation background for calorimeters and protocols and ultimately providing validation and application results for the combination of technical validity and biological variability. Clarifying this combination was an objective of this thesis, and therefore it is of interest to view the results in comparison to those found in literature[1-27].

\section{The combination according to literature}

Biological variability is related to personal metabolic traits and exogenous factors like diet and physical activity. In literature, an impact of diet and activity on CV\% as high as $30 \%$ were reported $[6,16,30]$.

For this reason, the categories Sleep, OMR, BMR and $24 \mathrm{~h}$ EE are commonly used. Protocols with best standardization of exogenous factors may lead to the lowest biological variability[9]. In turn, such categories with lowest impact of exogenous factors will allow comparative interpretation of data in literature.

This thesis therefore focused on biological variability of SMR, OMR, BMR and 24h EE, augmented with a similarly standardized value for exercise.

For exercise and physical activity, the levels of EE, work or load fail to fit one single category. For example, cycling at a 30 Watt load [20] is completely different from EE at $80 \%$ submaximal or at maximum exertion $[19,26,31]$. 


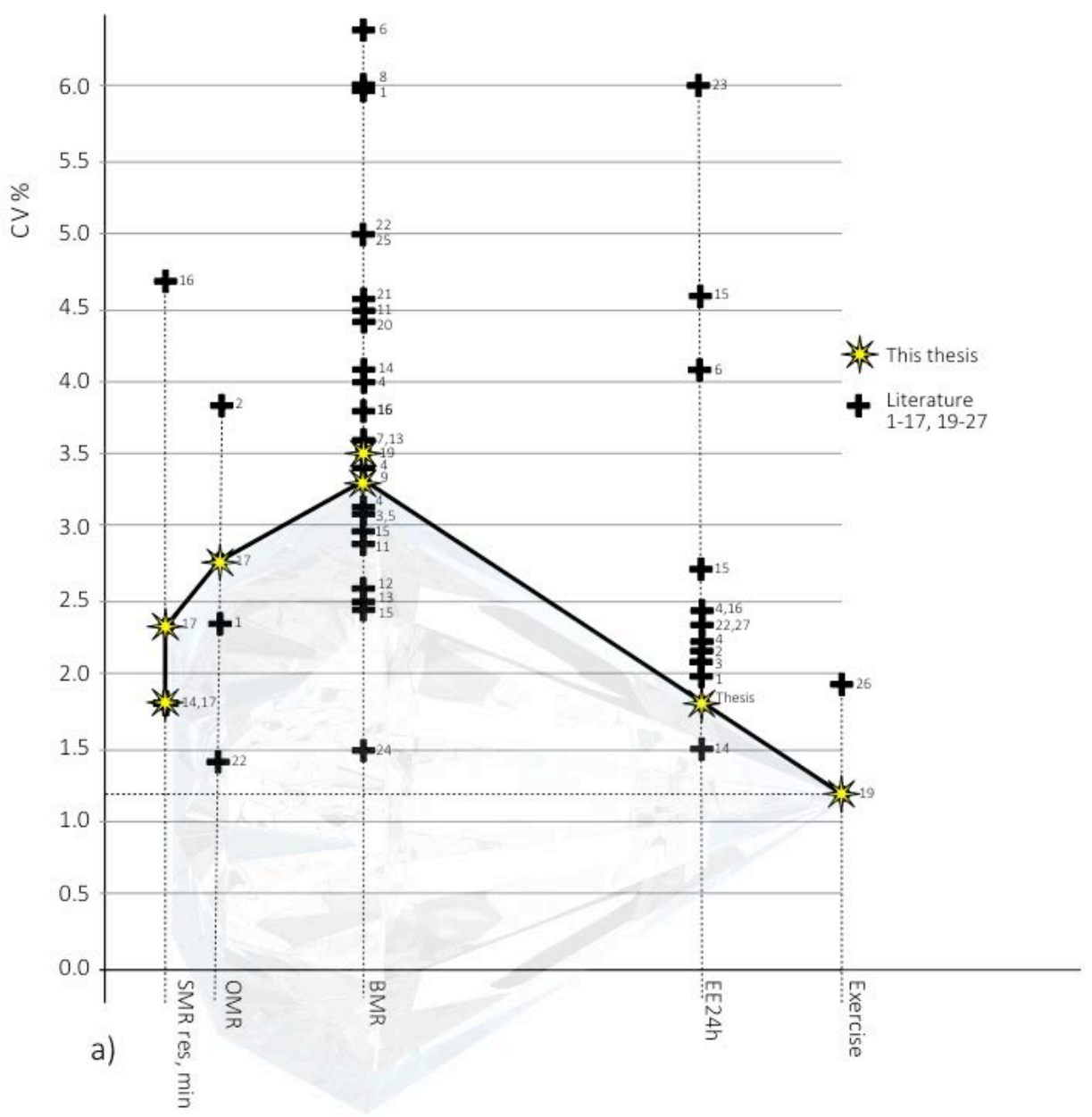

Figure 1. a) The mean intra-individual variability of EE per category is provided as found in literature (+) and in this thesis ( $\bullet$ and solid line). The $X$-axis shows the descriptive categories of 5 typical EE levels ${ }^{*}, T$ the $Y$-axis was limited to 6\% for appropriate scaling.

Since technical CV\% was only revealed in a sub-set of studies, this sub-set was taken over to b).

*) For presentation purposes the categories of EE levels on $\mathrm{X}$-axis are not in proportion. 


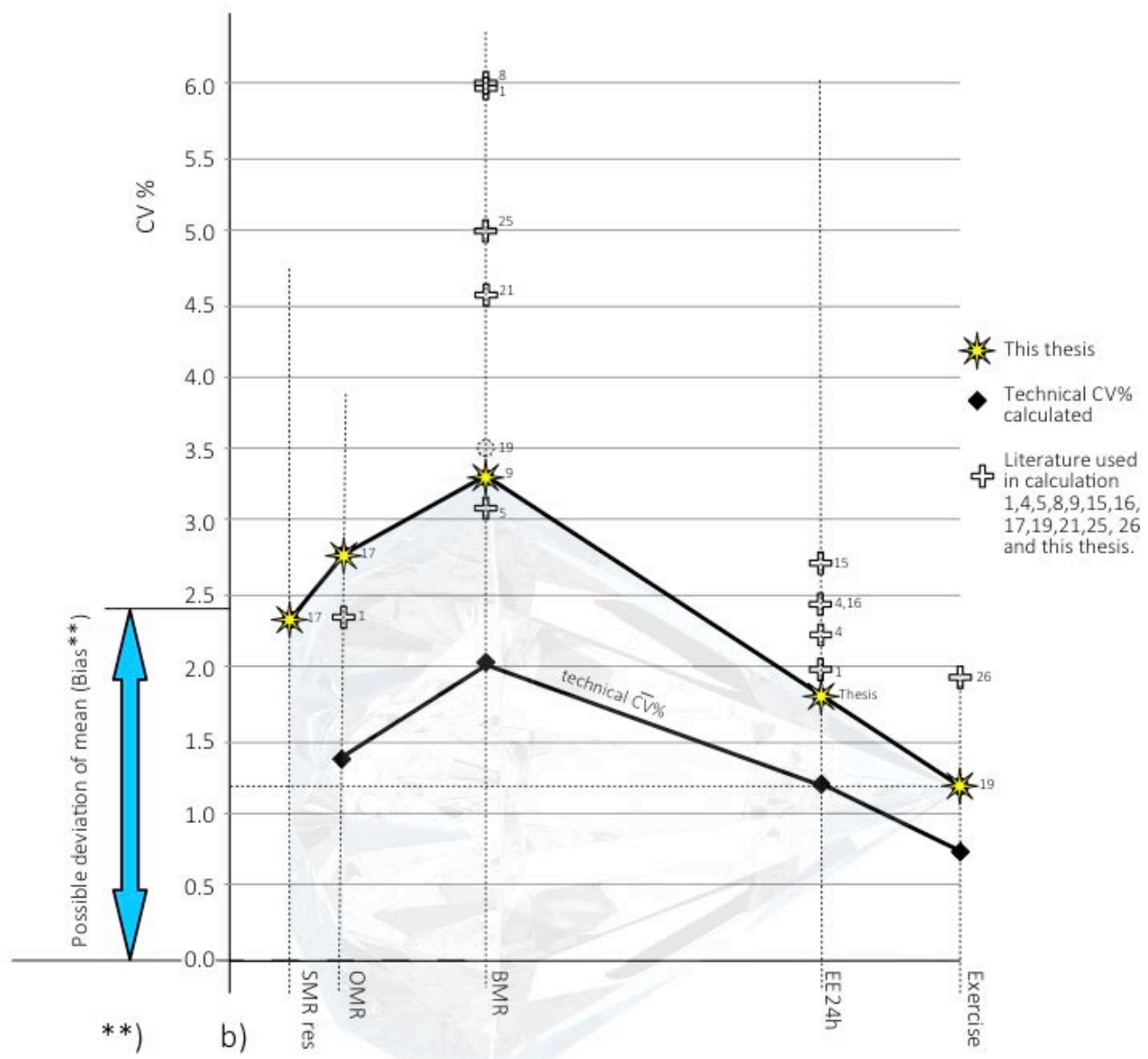

Figure 1. b). For this sub-set the mean technical CV\% for each category could be calculated, represented by the lower solid line in b). Thus, data points in figure a) and b) are identical except for the addition of technical CV\% derived for the sub-set in $b$ ).

**) Note that CV\% expresses reproducibility, not accuracy. A reference of accuracy was taken from literature for whole room indirect calorimeters, calculated as the 2 SD range for mean accuracy of 12 sites. This effectively adds a possible $\pm 2.4 \%$ bias (vertical arrow in the middle, conforming to $y$-axis scale), the size is dependent on the individual site. 
Each activity/exercise level combined with subject selection and equipment specification may have a different CV\% (range $1.2-8.5 \%$ ). The level found for maximum exertion is of special interest as it can be used for selecting subjects based on their physical fitness, i.e. maximal power per kg lean body mass [32, 33], and in turn can be used to preset an individual level of submaximal exercise, i.e. an individual percentage of the subjects maximum performance[34, 35]. It may be considered a standardized value for exercise/activity, revealing the $100 \%$ level of individual performance.

For this reason the reproducibility of physical activity at the maximum of human EE, i.e. maximum exertion, was chosen [19]. This maximum completes the range of Human EE at the top, as opposed to the minimum during sleep. In figure 1 this maximum was used as the category "exercise" at the upper limit of human EE. Based on these considerations five categories SMR, OMR, BMR, 24h EE and exercise are depicted to compare biological and technical variation (Figure 1 a).

In figure 1a the mean intra-individual variability of EE per category is provided as found in literature (Figure 1a). Technical CV\% was only revealed in a sub-set of studies (Figure 1b). For this sub-set the mean technical CV\% for each category could be calculated, represented by the lower solid line (Figure $1 b$ ).

Note that the $Y$-axis was limited to 6\% for appropriate scaling, however, specific values above $6 \%$ exist $[20,21]$.

\section{The combination - aspects of CV\%}

The large differences in the CV\%, even within "common" categories, raise the question how the CV\% was specified. At least three components may be identified, as the subject, the calorimeter, and the validation method each will introduce variability. Consisting of the respective biological, technical and validation method's CV's.

Assuming normal distribution of variability, and assuming components to be uncorrelated [1], the component CV's may be combined:

For a validation test:

$$
C V_{\text {measured }}=\sqrt{C V_{\text {technical }}^{2}+C V_{\text {validation method }}^{2}}
$$

For a subject test:

$$
C V_{\text {measured }}=\sqrt{C V_{\text {technical }}^{2}+C V_{\text {biological }}^{2}}
$$

In concordance with ideal assumptions, the validation method is assumed to have a small CV and may be ignored, in that instance technical CV is measured as the mean result of a validation tests. For this ideal assumption it follows that:

$$
C V_{\text {biological }}=\sqrt{C V_{\text {subject test }}^{2}-\overline{C V}_{\text {validation test }}^{2}}
$$


In practice, this ideal assumption will not hold true, components may or may not be uncorrelated and may or may not have a normal distribution. Also, further subdivision in components can be expected.

Effectively, technical CV as a "component" is an estimate, if it is overestimated the separation of biological CV will be underestimated and vice-versa.

A further specification of CV\% concerns the level of EE involved. As a percentage is not an absolute value, it has a $100 \%$ reference level that varies with selected protocol. A CV of $2.8 \%$ for OMR $(4.8 \mathrm{~kJ} \bullet \mathrm{min}-1)$ has the identical SD of $0.13 \mathrm{~kJ} \bullet \mathrm{min}-1$, as compared to a CV of $1.9 \%$ for EE $24 \mathrm{~h}(6.8 \mathrm{~kJ} \bullet \mathrm{min}-1)$.

Thus, differences in CV\% will be caused by differences in subject group, protocol, equipment, and correction for "estimated" technical CV\%. And these differences for the greater part may explain observed maxima and minima in CV\% (Figure 1a).

\section{MEASURED CV\% FOR THE DIFFERENT COMPONENTS OF EE AND RECOMMENDATIONS FOR GOOD PRACTICE}

\section{Sleeping and overnight metabolic rate.}

Both SMR and OMR are measured during the night. The main difference is the choice of interval, where overnight indicates a 6-8 $\mathrm{h}$ interval in the range 23:00 - 08:00 $\mathrm{h}$, and SMR typically focuses on the EE during a $3 \mathrm{~h}$ interval of sleep in the later hours of the night, for example during 03:00 - 06:00 h.

The CV \% values measured during the night are highly reproducible (Figure 1a, SMR [14, 17], in this thesis the CV for SMRres was $2.4 \%$ including technical CV i.e. $0.11 \mathrm{~kJ} \bullet \mathrm{min}^{-1}$. Yet choice of equipment and method may impact resulting EE and CV\%, up to 4-fold (Figure 1a, OMR [22] versus SMR [16]).

Measuring EE during the night is a typical application for a whole room calorimeter, allowing the subject freedom of movement in bed and undisturbed sleep. Additionally, movement detection systems [18] may independently evaluate activity during bed-time, for instance use of the toilet.

The biological variability is dependent on time of last meal and exercise, bedtime, as well as absence of spontaneous activity and presence of comfortable temperature during the night. For OMR and SMR evaluation it is therefore advised to select a comfortable temperature within the human thermo-neutral zone $[36,37]$, and apply a subjectprotocol with a standardized evening meal without additional food intake or exercise in the evening hours before a standardized bedtime. It is furthermore advised to use the night following free-living conditions [17] and check for activity during the night $[17,18]$. 


\section{Basal metabolic rate}

BMR can be defined as the EE level required for lying on a bed in supine position while awake in a fasted state. The only difference with sleep is arousal (being awake) and a defined position (lying on the back), note that activity or diet previous to measurement will affect BMR [9]. For adult subjects the absolute EE levels for BMR and OMR were near-equal and typically elevated in the order of 5-6\% in comparison to SMR, however, the OMR:BMR ratio proved significantly different from 1.0 for children (0.92) and the elderly (1.06) [38].

In this thesis, the CV \% for BMR was 3.2-3.3\% [17, 19], which was the highest of the 5 categories described (SMR, OMR, BMR, $\mathrm{EE}_{24 \mathrm{~h}}$ and $\mathrm{VO}_{2} \mathrm{max}$ ). In previous studies the $\mathrm{CV} \%$ of BMR also showed the largest variation, with a range 1.5 to $8.5 \%$ (Figure 1a). High CV $\%$ values can be attributed to equipment performance, outpatient protocol or nonadherence of subjects to such protocol [9]. In part, this larger CV \% will be caused by the fact that it is expressed as a percentage of BMR, which is a small absolute value just above sleeping.

Since EE level and equipment accuracy are comparable for BMR measured with a ventilated hood and measuring sleep with a whole room calorimeter, the in general larger CV $\%$ for BMR is caused by a true increase in biological variability.

Once more, separating the biological CV\% from measured CV\% by correcting for technical CV\% may explain some of the lowest CV percentages (Figure 1a), yet only if a similar outpatient protocol was used as in this thesis. The outpatient protocol in this thesis defines a realistic target of 3-4 CV \% for the combination of suitable equipment with a normal healthy subject group and well standardized measurements, while including technical CV\%. Important to this result was the exclusion of subjects that did not adhere to protocol. Results and protocol were deemed "of outstanding interest" [6], and its 3.3 CV\% proved reproducible [19].

Measuring BMR is a typical application for a ventilated hood or whole room calorimeter, with either in- or outpatient protocol. A ventilated hood is more accurate for a short 10 20 minutes interval. A best practice BMR measurement interval of 30 minutes comprises of 10 minutes under the ventilated hood, getting accustomed and restful, followed by a 20 minutes registration of BMR.

In contrast, a whole room calorimeter may provide more comfort yet may require up to 60 minutes presence of the subject.

Biological variability is dependent on time of last meal, time and level of previous exercise, a normal restful night, and temperature (comfort) as well as wakefulness (arousal) during the measurement.

Subjects should refrain from abnormal activities or exercise on the day before a measurement, as well as fast from 22:00 on the evening before a measurement. On the morning of the measurement they should remain fasted, transport themselves by car or public transport to the laboratory, and allowed to rest for 15-30 minutes. During the 
measurement, they must be allowed undisturbed lying on a bed in supine position, in a thermo-neutral environment, awake and without too great distractions.

\section{$24 h E E$}

Human energy expenditure is variable, typically its pattern conforms to a $24 \mathrm{~h}$ cycle i.e. circadian rhythm triggered by light and food [23, 39-41]. With only few exceptions [42] the day-night cycle on average is 24 hours for all people, independent of distribution of night-time versus day-time. Measuring the EE of a subject over $24 \mathrm{~h}$ typically includes all components of EE with their individual proportions intact, and results will be comparable to other $24 \mathrm{~h}$ measurements world-wide. This clarifies why $24 \mathrm{~h}$ is considered a gold standard interval in calorimetry. Expressed as a metabolic rate over time it is called average daily metabolic rate or ADMR.

In this thesis $24 \mathrm{~h}$ EE data for a repeated stay after $10 \pm 5$ days resulted in a CV \% of 1.9 $\%$, when including data up to a longer interval of 2 months the $24 \mathrm{~h}$ EE CV\% increased to $2.8 \%$.

Measuring EE over $24 \mathrm{~h}$ is a typical application for a whole room calorimeter, allowing the subject freedom of movement for meals, toilet, and activities during the long interval, as well as undisturbed sleep during the night.

Biological variability is dependent on diet, activity, bedtime, and climate. These factors depend on study-protocol, for instance regarding energy-balance versus over- and under-eating, regarding impact of thermo-neutral zone versus temperature variation, and regarding impact of time-shift on circadian rhythm.

To assess a normalized $24 \mathrm{~h}$ EE value subjects should refrain from abnormal exercise and follow their normal diet in the days before a measurement, possibly monitored by activity measurement and food-anamnesis. The measurement should take place in energy-balance, in a thermo-neutral environment, and with or without prescribed additional activity to increase PAL in the confined space. The measurement should start during daytime or in the evening, as the sleep interval must not be disturbed. There is an advantage of starting in the evening for measurement of SMR, as explained above. For achieving energy-balance it is advised to measure over $36 \mathrm{~h}$ while starting in the evening, this allows for individual values of the first night to be used for determining energy-requirements (food) for the following 24 h sub-interval.

\section{Exercise}

Exercise is part of the activity EE component. It can be under investigation or it can be used as part of the study protocol, or both. Levels of activity/exercise can vary from low, such as fidgeting [16], to the highest achievable, i.e. $\mathrm{VO}_{2} \max [19,43]$. Measuring the $E \mathrm{E}$ of activity/exercise with a calorimeter is therefore not limited to a single typical setup or type. It depends on level of $E E$, duration, and requirements regarding dynamic response 
time, freedom of movement or climate. In the context of this thesis exercise is considered a higher EE level associated with maximal exertion or a substantial percentage thereof.

In this thesis, the $\mathrm{CV} \%$ for $\mathrm{EE}$ at maximum exertion, calculated for $\mathrm{VO}_{2 \max }$ and including technical variability, was $1.2 \%$. This was measured with a facemask, and the mean $100 \%$ level was $4022 \mathrm{ml} \cdot \mathrm{min}^{-1} \mathrm{O}_{2}$ uptake. The absolute SD was $48.3 \mathrm{ml} \bullet \mathrm{min}^{-1} \mathrm{O}_{2}$, which roughly translates to and $\mathrm{EE}$ value of $\sim 1 \mathrm{~kJ} \bullet \mathrm{min}^{-1}$. The true $\mathrm{EE}$ value cannot be determined at maximum exertion, as flux of VCO2 in exhalation is no longer representative of $E E ;$ i.e. $R Q \neq R E R$. The SD value of $1 \mathrm{~kJ} \bullet \mathrm{min}^{-1}$ was only introduced for comparison with absolute $\mathrm{SD}$ values of EE observed below this maximum.

Measuring maximal exertion EE levels is a typical application for a calorimeter using a facemask or mouthpiece, requiring a fast dynamic response of the calorimeter to capture the short interval of the momentary maximum.

Biological variability is amongst others dependent on time of last meal, time and level of previous exercise, and in this instance fitness or training status.

In general subjects should refrain from abnormal activities, diet and extreme exercise in the days before research. For highly trained athletes their competition schedule should be taken into account, as this may affect their willingness and ability to test at the maximum.

Maximal exercise is not performed fasted, and not directly after a meal, it also requires sufficient cooling of the subject for removal of the excessive body heat.

Recently, maximum exertion tests were performed in a whole room calorimeter, redefining the useable upper limit for whole room calorimetry [43]. Briefly, results for facemask versus room matched with an $R^{2}$ of $0.98(n=29, P<0.001)$, though test-retest reproducibility $R^{2}$ decreased from 0.98 with a facemask to 0.88 . in the room.

Measuring submaximal exercise is a typical application for both a calorimeter using a facemask or mouthpiece, and for a whole room calorimeter. The choice depends mostly on availability of calorimeter and on duration of the exercise, where prolonged exercise is more easily performed inside a whole room calorimeter. A typical example of such prolonged exercise was a tour de France simulation [44].

\section{The relativity of $C V \%$ for the different components of EE}

Calorimeters can be set up specifically for an intended EE range. For the higher exercise levels the calorimeter must cope with the increase in minute-ventilation of the subject i.e. have a higher flow-through, while low-level exercise or short exercise bouts may fit the general setup used, for example when measuring $24 \mathrm{~h} \mathrm{EE}$ in a whole room calorimeter. A ventilated hood calorimeter for BMR may be considered a variant of a whole room calorimeter with a specific setup for low-level EE, having both a lower flow and an insignificant volume. Differences in setup will impact technical SD, i.e. the "absolute" floor noise-level which is co-linear with volume and flow (volume over time) to a large 
degree [1]. In contrast, technical CV\% may remain constant or even show a decrease as CV\% is expressed relative to the $100 \%$ reference, i.e. co-linear with the expected $\mathrm{EE}$ level of the specific setup.

Table 1. Biological variability of sleeping metabolic rate (SMR), overnight metabolic rate (OMR), basal metabolic rate (BMR), average daily metabolic rate (ADMR), and oxygen consumption at maximum exertion $\left(\mathrm{VO}_{2} \mathrm{max}\right)$.

\begin{tabular}{llll}
\hline Parameter & Energy expenditure $(\mathrm{kJ} \bullet \mathrm{min}-1)$ & $\mathrm{SD}(\mathrm{kJ} \bullet \mathrm{min}-1)$ & $\mathrm{CV}(\%)$ \\
\hline $\mathrm{SMR}$ & 4.6 & 0.11 & 2.4 \\
$\mathrm{OMR}$ & 4.8 & 0.13 & 2.8 \\
$\mathrm{BMR}$ & 4.7 & 0.15 & 3.3 \\
$\mathrm{ADMR}$ & 6.8 & 0.13 & 1.9 \\
$\mathrm{VO}_{2} \max$ & $\sim 90$ & $\sim 1$ & 1.2 \\
\hline
\end{tabular}

The categories Sleep, OMR, BMR, 24h EE and Exercise showed a CV\% that was smallest for high-level exercise and largest for outpatient BMR, consistent with literature (Figure 1a, Table 1).

Although exercise has the lowest CV\% of $1.2 \%$, it is the least absolute reproducible. In contrast, SMR with its medium CV\% of $2.4 \%$ showed the best absolute reproducibility, closely followed by OMR, 24h EE and even BMR with an outpatient protocol (Table 1).

In general, co-evaluation of absolute values is advised [18].

\section{IMPLEMENTATION ASPECTS}

Historically the concept for any calorimeter was to fully capture the complete output of the process, collecting total quantities and analyzing these to the highest achievable accuracy. Regarding full-capture there is no conceptual difference in collecting all of the meltwater from an ice-calorimeter, in comparison to collecting all exhaled air. In both instances, the total of heat or gas-exchange from the subject is evaluated. For this "full capture" approach technical capabilities determine the achievable accuracy and precision over an interval of choice. For indirect calorimetry, gas exchange formerly was chemically analyzed [45-51], and nowadays is measured with fully automated electronic analyzers, and includes aspects of dynamic response time [18, 19, 52, 53]. Fundamentally, all exhalation is collected, mixed, measured for quantity of volume or mass, and gas samples are analyzed for mean gas fractions over the interval of interest. Classic examples of open circuit full-capture indirect calorimetry are whole room calorimeters, ventilated hood calorimeters, as well as the historical geppert-zuntz apparatus [49] and the douglas bag method[54].

A typical example of calorimeters that do not fully capture exhaled air are breath-bybreath calorimeters, sampling in- and ex-halation in sequence at the mouth, and com- 
bining rapid gas analysis with bi-directional flow data also measured at the mouth. When applied for exercise and its high minute-ventilation and breathing frequencies, aspects of timing and shape of breathing curves may prove critical and show loss of accuracy, i.e. underestimate reality. Validation of these calorimeters is problematic, as lung simulators are not commonly available. And although breathing frequencies of 60 bpm for an advanced simulator (GESS) are mentioned [55], no measurements above 40 bpm were provided $[55,56]$.

Hence, biological reproducibility can be determined, but accuracy and specifically linearity with level of EE can only be determined by parallel validation against equipment that can be realistically validated, and preferably on-site.

In contrast, indirect calorimetry with full capture of exhaled air is the method of choice for measurements requiring complete, frequent, and on-site validation.

Part of the full-capture concept is the absence $[18,57]$ of requirements for filtering or predictive (feed-forward) algorithms, with the noted exception for whole room calorimeters and methods seeking fast dynamic response by applying such algorithms [58-61]. It can be remarked that such algorithms and assumptions may cause the removal or addition of small changes in results, while for statistical evaluation all changes, even those hidden in noise, should be retained.

\section{TECHNICAL VALIDATION REVISITED - ON SITE AND LONGITUDINAL}

The goal of technical validation was discussed, and in that context the practice of onsite and frequent validation was deemed a requirement. Not all calorimeters will perform to the highest standard each and every day, each individual device must prove its adherence to specifications as found in validation studies. Moreover, validation studies may reveal a momentary status, not taking into account possible decay over time of use. An example is the deposition of particles in exhaled air in analyzers used in breathby-breath calorimetry, caused by the fast transport of exhalation into the analyzers and over time resulting in contamination and decrease of performance (personal observation). A more general example is occurrence of drift or decay of sensors, ranging from a slow and unobtrusive drift to a stepwise change caused by an instantaneous partial defect or even by simply replacing calibration gasses with their certificate uncertainty. Any such correction or replacement may instantly change measurements to a slightly different baseline, i.e. decrease or increase offset, but the proportional step in measurements may affect studies in progress and must be taken into account.

Although specification, or an individual validation, may show results within $2 \%$ including accuracy and CV, a specification used for longitudinal studies must reveal a sustainable performance. This potential problem can be alleviated in the presence of a history of validation tests, allowing the tracking of drift or determining the time of occurrence of a defect or baseline-shift. 
In general, and for the above reasons, a typical $1 \pm 2 \%$ mean \pm SD technical specification should prove achievable, prudent and realistic, both for longitudinal and even for inter-equipment purposes. Yet only by performing periodic and frequent validation tests $[9,18,19]$.

An example would be methanol burns that must stay within $5 \%$ for nearly all individual validation test, i.e. achieve $<5 \%$ individual validation error for a $95 \% \mathrm{Cl}$.

\section{THE NEAR FUTURE}

As technology advances, there will be a proliferation of small and affordable devices, software, and "black boxes". However, in view of the cost and complexity of both validation and variability, results may vary and on occasion fail to meet scientific or clinical standards. Aside from the individual health risk, researchers may be tempted to use such affordable technology without means for validation.

In contrast, this proliferation coincides with a growing awareness amongst groups of researchers that accuracy and reliability need to be more commonly assessed. A growing demand for classical validation, as well as for showing suitability for the applicable range of biological variability, is expected.

Whole room calorimeters targeting a specific application may become more affordable and capable, and able to be validated on-site for the intended biological application and range. This will allow subjects more freedom of movement, comfort, and is expected to decrease biological variability to an as yet unknown extend. A secondary effect may be ease of use, as well as decrease of possible operator errors.

Whole room calorimeters targeting a broad range of applications may show a trend towards compartmentalization, effectively optimizing the momentary active volume and its subject- air dilution mixing.

It is expected that indirect calorimeters of all forms will become capable of live validation, in co-existence with measurements in progress and in the same space where the subject is residing. This may be done by insertion of tracer gasses of known quantity, or by varying physics of climate or volume. 


\section{CONCLUSIONS}

Pertaining to measurement of Human Energy Expenditure.

Validity of an indirect calorimeter for a specific biological application can only be achieved by validation tests that take into account the applicable ranges of biological and technical variability. Technical validation without taking into account the applicable biological variability does not prove suitability for the intended goal.

Technical and biological CV's of energy expenditure measurements are not constant. They are estimated, separated, components of the measured CV. The latter varies with applicable ranges and dynamic responses of calorimeter, subject or validation method.

Human energy expenditure measured by whole room indirect calorimetry was matched by heat loss measured by direct calorimetry plus external work during rest and cycling. Both calorimetric methods used were valid.

The implementation of SI units for real gasses and true molar quantities provides a formal description of gas exchange measured with indirect calorimetry, allowing strict compartmentalization and the quantification of true mass flux between individual processes. The implementation is expected to result in improvements in design, accuracy, precision and dynamic response of whole room calorimeters.

Biological variability in normal healthy adults, originating from formulae for the conversion of gas exchange to energy expenditure using common estimates of substrate composition, was limited to within $1 \%$ for each of 5 selected formulae.

Incorrect estimate of protein consumption, in the absence of measured $\mathrm{EE}_{\text {urin, }}$ can result in errors $>2 \%$ of human EE. The application of an updated formula limits this error to within $1 \%$ for the full range of normal human protein consumption.

Expressed in CV\% maximum exertion tests showed the best reproducibility of $1.2 \%$ (48.3 $\mathrm{ml} \bullet \mathrm{min}^{-1} \mathrm{O}_{2} \sim 1 \mathrm{~kJ} \bullet \mathrm{min}^{-1}$ ) at the highest level of human performance. Sleeping metabolic rate measured on nights following free-living conditions showed the lowest level of human EE with a larger CV of $2.4 \%$ and the best absolute reproducibility $(0.11$ $\left.\mathrm{kJ} \cdot \mathrm{min}^{-1}\right)$.

The Human energy expenditure levels for SMR, OMR, BMR and EE $24 \mathrm{~h}$ are reproducible in the range 0.11 to $0.19 \mathrm{~kJ} \cdot \mathrm{min}^{-1}$ including technical variability.

Basal metabolic rate measured with a standard outpatient protocol is sufficiently reproducible for most practical purposes.

Healthy participants with a stable training status performing a step protocol to Pmax and $\mathrm{VO} 2$ max have a linear relation of $\mathrm{P}$ and $\mathrm{VO} 2$ over the full range of $\mathrm{P}$, This challenges previously reported non-linearity between $\mathrm{P}$ and $\mathrm{VO} 2$. 
Biological variation in normal healthy subjects and technical validity are in agreement regarding magnitude of variability, proving suitability for the intended research. This was achieved by using implementations of the capture-all concept in diluted mode indirect calorimetry.

The capture-all concept in diluted mode indirect calorimetry allows for on-site validation and realistic mimicking of subject responses over the full range of human EE. 


\section{REFERENCES}

1. Murgatroyd, P.R., H.L. Davies, and A.M. Prentice, Intra-individual variability and measurement noise in estimates of energy expenditure by whole body indirect calorimetry. Br J Nutr, 1987. 58(3): p. 347-56.

2. de Boer, J.O., et al., Energy requirements and energy expenditure of lean and overweight women, measured by indirect calorimetry. Am J Clin Nutr, 1987. 46(1): p. 13-21.

3. Dallosso, H.M., P.R. Murgatroyd, and W.P. James, Feeding frequency and energy balance in adult males. Hum Nutr Clin Nutr, 1982. 36C(1): p. 25-39.

4. Garby, L. and O. Lammert, Within-subjects between-days-and-weeks variation in energy expenditure at rest. Hum Nutr Clin Nutr, 1984. 38(5): p. 395-7.

5. Soares, M.J. and P.S. Shetty, Intra-individual variations in resting metabolic rates of human subjects. Hum Nutr Clin Nutr, 1986. 40(5): p. 365-9.

6. Donahoo, W.T., J.A. Levine, and E.L. Melanson, Variability in energy expenditure and its components. Curr Opin Clin Nutr Metab Care, 2004. 7(6): p. 599-605.

7. Gasic, S., B. Schneider, and W. Waldhausl, Indirect calorimetry: variability of consecutive baseline determinations of carbohydrate and fat utilization from gas exchange measurements. Horm Metab Res, 1997. 29(1): p. 12-5.

8. Weststrate, J.A., Resting metabolic rate and diet-induced thermogenesis: a methodological reappraisal. Am J Clin Nutr, 1993. 58(5): p. 592-601.

9. Adriaens, M.P., P.F. Schoffelen, and K.R. Westerterp, Intra-individual variation of basal metabolic rate and the influence of daily habitual physical activity before testing. Br J Nutr, 2003. 90(2): p. 419-23.

10. Henry, C.J., J. Hayter, and D.G. Rees, The constancy of basal metabolic rate in free-living male subjects. Eur J Clin Nutr, 1989. 43(10): p. 727-31.

11. Haugen, H.A., et al., Variability of measured resting metabolic rate. Am J Clin Nutr, 2003. 78(6): p. 1141-5.

12. Ventham, J.C. and J.J. Reilly, Reproducibility of resting metabolic rate measurement in children. Br J Nutr, 1999. 81(6): p. 435-7.

13. Gibbons, M.R., et al., Intra-individual variation in RMR in older people. Br J Nutr, 2004. 91(3): p. 485-9.

14. Toubro, S., N.J. Christensen, and A. Astrup, Reproducibility of 24-h energy expenditure, substrate utilization and spontaneous physical activity in obesity measured in a respiration chamber. Int J Obes Relat Metab Disord, 1995. 19(8): p. 544-9.

15. Rumpler, W.V., et al., Repeatability of 24-h energy expenditure measurements in humans by indirect calorimetry. Am J Clin Nutr, 1990. 51(2): p. 147-52.

16. Ravussin, E., et al., Determinants of 24-hour energy expenditure in man. Methods and results using a respiratory chamber. J Clin Invest, 1986. 78(6): p. 1568-78.

17. Schoffelen, P.F. and K.R. Westerterp, Intra-individual variability and adaptation of overnight-and sleeping metabolic rate. Physiol Behav, 2008. 94(2): p. 158-63.

18. Schoffelen, P.F., et al., A dual-respiration chamber system with automated calibration. J Appl Physiol (1985), 1997. 83(6): p. 2064-72.

19. Schoffelen, P.F.M., et al., Test-retest variability of VO2max using total-capture indirect calorimetry reveals linear relationship of VO2 and Power. Submitted, 2016.

20. Rieper, H., et al., Intra- and inter-individual variations in energy expenditure of 14-15-year-old schoolgirls as determined by indirect calorimetry. Br J Nutr, 1993. 69(1): p. 29-36.

21. Vohra, S.B., et al., Practical limitations of the Deltatrac indirect calorimeter. Clin Nutr, 1995. 14(3): p. 155-61.

22. Astrup, A., et al., Prediction of 24-h energy expenditure and its components from physical characteristics and body composition in normal-weight humans. Am J Clin Nutr, 1990. 52(5): p. 777-83.

23. Muller, H.L., M. Kirchgessner, and G. Wolfram, [Variability and circadian rhythms of maintenance energy expenditure in adult humans]. Ann Nutr Metab, 1989. 33(2): p. 114-24.

24. Soares, M.J., et al., Day-to-day variations in basal metabolic rates and energy intakes of human subjects. Eur J Clin Nutr, 1989. 43(7): p. 465-72. 
25. Bader, N., et al., Intra- and interindividual variability of resting energy expenditure in healthy male subjects -- biological and methodological variability of resting energy expenditure. Br J Nutr, 2005. 94(5): p. 843-9.

26. Pereira, M.A. and P.S. Freedson, Intraindividual variation of running economy in highly trained and moderately trained males. Int J Sports Med, 1997. 18(2): p. 118-24.

27. Webb, P., 24-hour energy expenditure and the menstrual cycle. Am J Clin Nutr, 1986. 44(5): p. 614-9.

28. Kleiber, M., The fire of life : an introduction to animal energetics. 1961, New York ; London: Wiley. xxii, 454 : ill. ; $24 \mathrm{~cm}$.

29. Farre, R., D. Navajas, and J.M. Montserrat, Technology for noninvasive mechanical ventilation: looking into the black box. ERJ Open Res, 2016. 2(1).

30. Westerterp, K.R., S.A. Wilson, and V. Rolland, Diet induced thermogenesis measured over $24 \mathrm{~h}$ in a respiration chamber: effect of diet composition. Int J Obes Relat Metab Disord, 1999. 23(3): p. 287-92.

31. Kuipers, H., et al., Variability of aerobic performance in the laboratory and its physiologic correlates. Int J Sports Med, 1985. 6(4): p. 197-201.

32. Shephard, R.J., et al., The maximum oxygen intake. An international reference standard of cardiorespiratory fitness. Bull World Health Organ, 1968. 38(5): p. 757-64.

33. Bovens, A.M., et al., Physical activity, fitness, and selected risk factors for CHD in active men and women. Med Sci Sports Exerc, 1993. 25(5): p. 572-6.

34. Hawley, J.A., F. Brouns, and A. Jeukendrup, Strategies to enhance fat utilisation during exercise. Sports Med, 1998. 25(4): p. 241-57.

35. van Loon, L.J., et al., Effect of training status on fuel selection during submaximal exercise with glucose ingestion. J Appl Physiol (1985), 1999. 87(4): p. 1413-20.

36. Kingma, B.R., et al., Beyond the classic thermoneutral zone: Including thermal comfort. Temperature (Austin), 2014. 1(2): p. 142-9.

37. Kingma, B., A. Frijns, and W. van Marken Lichtenbelt, The thermoneutral zone: implications for metabolic studies. Front Biosci (Elite Ed), 2012. 4: p. 1975-85.

38. Wouters-Adriaens, M.P. and K.R. Westerterp, Basal metabolic rate as a proxy for overnight energy expenditure: the effect of age. Br J Nutr, 2006. 95(6): p. 1166-70.

39. Scheer, F.A., C.J. Morris, and S.A. Shea, The internal circadian clock increases hunger and appetite in the evening independent of food intake and other behaviors. Obesity (Silver Spring), 2013. 21(3): p. 421-3.

40. Mortola, J.P., Breathing around the clock: an overview of the circadian pattern of respiration. Eur J Appl Physiol, 2004. 91(2-3): p. 119-29.

41. Sulzman, F.M., C.A. Fuller, and M.C. Moore-Ede, Comparison of synchronization of primate circadian rhythms by light and food. Am J Physiol, 1978. 234(3): p. R130-5.

42. Miles, L.E., D.M. Raynal, and M.A. Wilson, Blind man living in normal society has circadian rhythms of 24.9 hours. Science, 1977. 198(4315): p. 421-3.

43. Kleinloog, J.P.D., Validity and reproducibility of VO2max assessment in a respiration chamber., in Human Biology and Movement Sciences, Faculty of Health Medicine and Life-sciences. 2016, Maastricht University: Maastricht: Maastricht University; 2016.

44. Brouns, F., et al., Eating, drinking, and cycling. A controlled Tour de France simulation study, Part I. Int J Sports Med, 1989. 10 Suppl 1: p. S32-40.

45. Atwater, W.O. and F.G. Benedict, A respiration calorimeter. 1905, Washington.

46. Schoffelen, P.F.M., Evaluation of an automatic indirect calorimeter for measurement of energy balance in man, in European Nutrition Report No 5., A.J.H. van Es Editor. 1985: The Hague, The Netherlands: Koninklijke Bibliotheek. p. 51-54.

47. Haldane, J., A new form of Apparatus for measuring the Respiratory Exchange of Animals. J Physiol, 1892. 13(5): p. 419-30.

48. Pettenkofer, M.^., Ueber einen neuen Respirations-Apparat. Abhandlungen der Bayerischen Akademie der Wissenschaften, Mathematisch-Physikalische Klasse. 1862, München: Verl. der k. Akad. S. 232 - 276, 3 Taf. 


\section{Chapter 9}

49. Zuntz, N. and W.A.E.F.D. Schumburg, Studien zu einer Physiologie des Marsches. Bibliothek von Coler Bd. 6. 1901, Berlin: August Hirschwald. viii, 361 pages, 1 unnumbered folded leaf of plates : illustrations; $22 \mathrm{~cm}$.

50. Haldane, J., Some Improved Methods of Gas Analysis. J Physiol, 1898. 22(6): p. 465-80.

51. Scholander, P.F., Accurate analysis of respiratory gases in 0.5 cubic centimeter samples. Fed Proc, 1947. 6(1 Pt 2): p. 198.

52. Webb, P., et al., The work of walking: a calorimetric study. Med Sci Sports Exerc, 1988. 20(4): p. 331-7.

53. Brown, D., et al., Analysis of gaseous exchange in open-circuit indirect calorimetry. Med Biol Eng Comput, 1984. 22(4): p. 333-8.

54. Douglas, C.G., A method for determining the total respiratory exchange in man. J Physiol, 1911. 42: p. 17-18.

55. Prieur, F., et al., A system to simulate gas exchange in humans to control quality of metabolic measurements. Eur J Appl Physiol Occup Physiol, 1998. 78(6): p. 549-54.

56. Prieur, F., J. Castells, and C. Denis, A methodology to assess the accuracy of a portable metabolic system (VmaxST). Med Sci Sports Exerc, 2003. 35(5): p. 879-85.

57. Schoffelen, P.F.M., M. Souren, and G. Plasqui, Measurement of respiratory gas exchange - derivation of equations for-and comments on true molar balance in whole room calorimetry. submitted, 2017.

58. Tokuyama, K., et al., Algorithm for transient response of whole body indirect calorimeter: deconvolution with a regularization parameter. J Appl Physiol (1985), 2009. 106(2): p. 640-50.

59. Granato, L., et al., VO2, VCO2, and RQ in a respiratory chamber: accurate estimation based on a new mathematical model using the Kalman-Bucy method. J Appl Physiol (1985), 2004. 96(3): p. 1045-54.

60. Nguyen, T., et al., Chamber for indirect calorimetry with accurate measurement and time discrimination of metabolic plateaus of over 20 min. Med Biol Eng Comput, 2003. 41(5): p. 572-8.

61. Henning, B., R. Lofgren, and L. Sjostrom, Chamber for indirect calorimetry with improved transient response. Med Biol Eng Comput, 1996. 34(3): p. 207-12. 


Summary

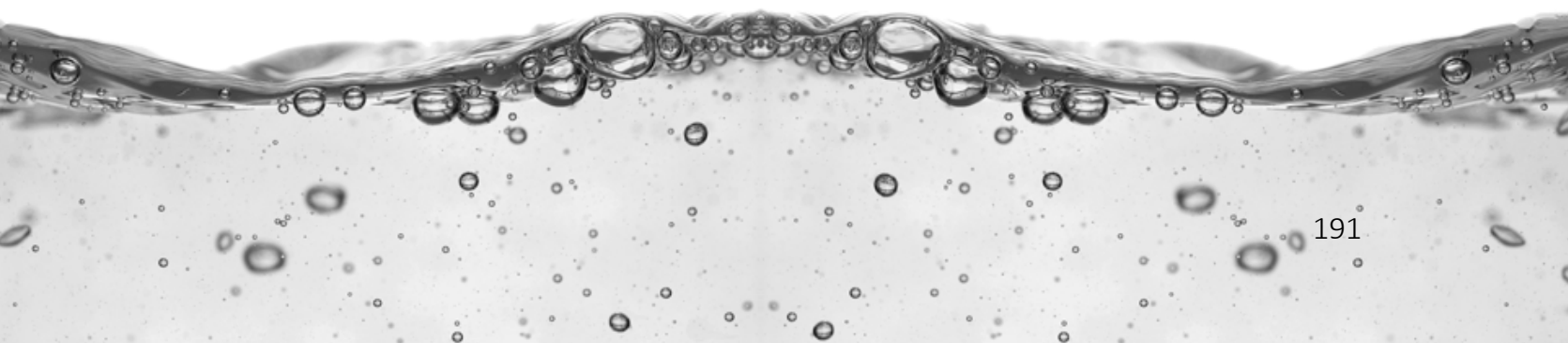





\section{INTRODUCTION}

Energy required for human living results from combustion of food with oxygen; releasing the energy stored in the food by converting it into heat and work.

Measuring energy expenditure in the form of heat became possible in 1780 when A.L. Lavoisier and P.S. Laplace created a direct calorimeter for small animals.

Direct calorimeters for measuring heat (calories), and indirect calorimeters for measuring gas exchange i.e. oxygen uptake and carbon dioxide production were constructed. Indirect calorimeters, estimating energy expenditure by converting measured gas exchange to energy by using data on food composition and its energy content, became most frequently used. Indirect calorimeters have proliferated as basic infrastructure, providing implicitly trusted results often without proper application and validation. This effect becomes visible where biological variability for healthy subjects far exceeds technical validation results.

Indirect calorimetry remains sensitive to sources of error, ranging from ambient- and biological aspects to technical- and operator errors. The availability of specialized knowhow on site should be considered a requirement.

\section{OBJECTIVE}

It was the objective of this thesis to show that biological variability and technical validity should be of similar magnitude, and that this can be achieved by following the 'capture all' (exhalation or heat) concept of the past, with modern day equipment and methods. A second objective was to emphasize that technical validation methods should be readily available on site, and these should be able to realistically mimic subject responses. A final goal was to increase awareness for some of the pitfalls in indirect calorimetry.

\section{METHODS}

Whole room indirect calorimeters were used for average daily metabolic rate (ADMR), overnight metabolic rate (OMR) and sleeping metabolic rate (SMR). Similarly, ventilated hood and face-mask calorimeters were constructed, capturing all exhalation, and were used for determining basal metabolic rate (BMR) and oxygen uptake at maximum exertion $\left(\mathrm{VO}_{2} \mathrm{max}\right)$. A direct "suit" calorimeter was used to allow simultaneous direct- and indirect calorimetric measures as combined with a whole room indirect calorimeter. A typical "breath by breath" exercise calorimeter was also applied for comparison of "capture all" and "breath by breath" measurements of $\mathrm{VO}_{2}$ max.

Technical validity for indirect calorimeters was determined using alcohol combustion and gas infusion, the latter was also used for the simulation of breathing. The direct 
calorimeter was checked using an electric heat-source. In total 101 male and 48 female healthy adults provided data on multiple individual measurements. All studies conformed to the University of Maastricht protocols for ethics and informed consent, in agreement with the Declaration of Helsinki.

\section{RESULTS}

Simultaneous measurement of heat loss and gaseous exchange showed total energy expenditure, calculated from oxygen consumption and carbon dioxide production, matches heat loss at rest. During cycling, total energy expenditure matched heat loss plus the work performed, as measured by the cycle ergometer. Observations during walking showed that work is done in level walking as well.

Application of nine different formulae for the calculation of energy expenditure from oxygen consumption and carbon dioxide production resulted in an updated formula with a minimal effect for variation in protein as energy substrate, the energy substrate that is not fully oxidized to allow excretion of the nitrogen component in urine.

Repeated measurements allowed evaluation of biological variability of the five parameters of energy expenditure mentioned above: SMR; OMR; BMR; ADMR and $\mathrm{VO}_{2}$ max (Table 1). SMR, OMR and ADMR were measured in a room calorimeter over $3 \mathrm{~h}, 5-8 \mathrm{~h}$ and $24 \mathrm{~h}$ intervals, respectively. BMR was measured with a ventilated hood, directly after waking up in the morning over 20-30 min in the fasted state. $\mathrm{VO}_{2}$ max was measured with a facemask during a maximal exertion test on a cycle ergometer

Table 1: Biological variability of sleeping metabolic rate (SMR), overnight metabolic rate (OMR), basal metabolic rate (BMR), average daily metabolic rate (ADMR), and oxygen consumption at maximum exertion $\left(\mathrm{VO}_{2} \mathrm{max}\right)$. These biological measurements are uncorrected and inclusive of technical aspects.

\begin{tabular}{llll}
\hline Parameter & Energy expenditure $(\mathrm{kJ} \bullet \mathrm{min}-1)$ & $\mathrm{SD}(\mathrm{kJ} \bullet \mathrm{min}-1)$ & $\mathrm{CV}(\%)$ \\
\hline SMR & 4.6 & 0.11 & 2.4 \\
OMR & 4.8 & 0.13 & 2.8 \\
$\mathrm{BMR}$ & 4.7 & 0.15 & 3.3 \\
$\mathrm{ADMR}$ & 6.8 & 0.13 & 1.9 \\
$\mathrm{VO}_{2}$ max & $\sim 90$ & $\sim 1$ & 1.2 \\
\hline
\end{tabular}

Technical validity was dependent on the specific calorimeter used. Observed values showed an average accuracy range of $0-1 \%$ and a CV of up to $2 \%$ in agreement with published values.

A final aspect that could yet be deemed "indirect" was the use of assumptions in calculating gas exchange quantities. This aspect was addressed by deriving equations for true molar balance of respiratory gas exchange, eliminating the "ideal gas" assumption and using SI units. Simulations resulted in finding sources of error specifically related to 
temperature differences and transients, drawing attention to effects of internal compartmentalization and climate control in whole room indirect calorimeters.

\section{DISCUSSION AND CONCLUSIONS}

Total energy expenditure as calculated from measured oxygen consumption and carbon dioxide production matched simultaneously measured heat loss plus work performed, as measured by a cycle ergometer. Thus, indirect calorimetry is a valid method for the measurement of energy expenditure. Biological variation of average daily metabolic rate and its components was found to be in agreement with technical validity of measurement over the complete human range. Reduction of technical variability requires regular on-site validation. 

Samenvatting

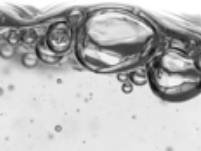

$36=0$

$\circ$

○: :

$0 \therefore 0$

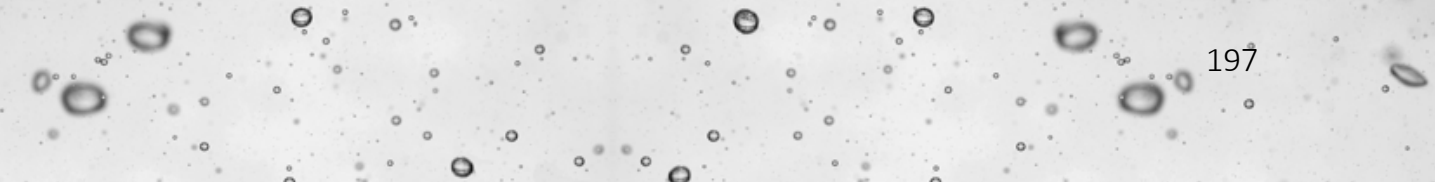





\section{INLEIDING}

De mens gebruikt energie om te leven, afkomstig uit voedsel, door oxidatie van koolhydraat, vet en eiwit. De zo beschikbare energie wordt uiteindelijk omgezet in warmte en uitwendige arbeid. Meting van het energiegebruik werd mogelijk in 1780 met de bouw van een directe calorimeter, geschikt voor kleine dieren, door A.L. Lavoisier en P.S. Laplace. Directe calorimeters voor het meten van warmte (Joules), en indirecte calorimeters voor het meten van gaswisseling werden vervolgens verder ontwikkeld en toegepast. Bij indirecte calorimetrie wordt het energiegebruik berekend uit de gemeten zuurstof opname en koolstof dioxide productie op basis van gegevens over zuurstof opname, koolstof dioxide productie en vrijkomende energie bij oxidatie van de afzonderlijke nutriënten. Meting van het energiegebruik vindt tegenwoordig vrijwel uitsluitend plaats met indirecte calorimetrie. De brede verspreiding van calorimeters als meetapparaat wekt de indruk dat het een eenvoudige standaard meting betreft. Juiste toepassing vereist echter regelmatige controle op validiteit van metingen. Indirecte calorimetrie is tot op heden gevoelig voor fouten in toepassing en gebrek aan deskundigheid, varierend van omgevings- en biologische aspecten tot technische- en bedienings- fouten. De beschikbaarheid van gespecialiseerde kennis en faciliteiten ter plekke dient dan ook als een vereiste te worden beschouwd.

\section{DOELSTELLING}

Het doel van dit proefschrift was aan te tonen dat de biologische variabiliteit en technische validiteit van een vergelijkbare grootte-orde moeten zijn en dat dit kan worden bereikt door het klassieke principe van het compleet opvangen van geproduceerde warmte of uitademingsgassen, met moderne apparatuur en methodes. Een tweede doelstelling was aan te tonen dat technische validatiemethoden ter plekke beschikbaar moeten zijn, met regelmaat worden toegepast, en dat de te verwachten biologische variatie realistisch moet kunnen worden nagebootst. Tenslotte was het doel om kennis over de gevoeligheid voor fouten bij toepassing van indirecte calorimetrie te vergroten.

\section{METHODES}

Respiratiekamers werden toegepast voor het meten van energiegebruik over een etmaal (average daily metabolic rate, ADMR), gedurende de nacht (overnight metabolic rate, OMR) en tijdens slaap (sleeping metabolic rate, SMR). Vergelijkbare apparatuur werd toegepast voor het meten van het basale energiegebruik (basal metabolic rate, $\mathrm{BMR}$ ), waarbij men ontspannen op bed ligt met een geventileerde doorzichtige kap over het hoofd. Zuurstofopname bij maximale inspanning (VO2max) werd gemeten met een 
masker over mond en neus. Een directe calorimeter, lijkend op een ruimtepak, werd toegepast met gelijktijdige meting in een respiratiekamer. De combinatie maakte vergelijking mogelijk van totaal energiegebruik, gemeten met indirecte calorimetrie, met de warmteproductie. Een typische calorimeter voor ademteuganalyse (breath-by-breath methode) werd toegepast voor het vergelijken van metingen van VO2max bemonsterd per adem teug met resultaten verkregen door het compleet opvangen van ademteugen.

Technische validiteit van indirecte calorimeters werd bepaald met behulp van alcoholverbranding en gasinfusie; de gasinfusie methode werd ook gebruikt voor het simuleren van ademteugen. De directe calorimeter werd gevalideerd met behulp van een elektrische warmtebron. In totaal werden gegevens verzameld van 101 mannelijke en 48 vrouwelijke gezonde volwassenen die deelnamen aan meerdere experimenten. Alle studies voldeden aan de medisch-ethische eisen van de Universiteit Maastricht, en waren in overeenstemming met het verdrag van Helsinki.

\section{RESULTATEN}

Bij gelijktijdige toepassing van directe en indirecte calorimetrie bleek dat de gemeten warmte afgifte in rust overeen kwam met het energiegebruik zoals berekend uit gemeten zuurstof opname en koolstof dioxide productie. Tijdens inspanning was het totale energiegebruik in overeenstemming met de warmte afgifte plus de uitwendige arbeid zoals geregistreerd met een fiets ergometer. Waarnemingen tijdens lopen toonden aan dat ook dan sprake is van uitwendige arbeid.

Evaluatie van acht verschillende formules voor de berekening van energiegebruik uit zuurstof opname en koolstof dioxide productie resulteerde in een bijgestelde formule met een minimaal effect van variatie in eiwit als energie substraat, het nutrient dat niet volledig wordt geoxideerd vanwege de uitscheiding van de stikstof component in urine. Herhaalde metingen met proefpersonen resulteerden in waardes voor de biologische variatie van de hierboven genoemde energieparameters: SMR; OMR; BMR; ADMR en VO2max (tabel 1). SMR, OMR en ADMR werden gemeten in een respiratiekamer over een interval van respectievelijk 3 uur, 5-8 uur en 24 uur. BMR werd gemeten met een geventileerde kap, na het ontwaken en voorafgaand aan voedsel inname, over een duur van 20-30 minuten. VO2max werd gemeten met een masker over mond en neus tijdens maximale inspanning op een fiets ergometer. 
Tabel 1. Biologische variatie van het energiegebruik tijdens slaap (SMR), gedurende de nacht (OMR), in rust na ontwaken (BMR), over een etmaal (ADMR) en zuurstofgebruik bij maximale inspanning (VO2max). De metingen zijn niet gecorrigeerd en zijn inclusief de technische aspecten.

\begin{tabular}{llll}
\hline Parameter & Energie gebruik $(\mathrm{k} \bullet \bullet \min -1)$ & $\mathrm{SD}(\mathrm{kJ} \bullet \mathrm{min}-1)$ & $\mathrm{CV}(\%)$ \\
\hline $\mathrm{SMR}$ & 4.6 & 0.11 & 2.4 \\
OMR & 4.8 & 0.13 & 2.8 \\
$\mathrm{BMR}$ & 4.7 & 0.15 & 3.3 \\
$\mathrm{ADMR}$ & 6.8 & 0.13 & 1.9 \\
$\mathrm{VO}_{2}$ max & $\sim 90$ & $\sim 1$ & 1.2 \\
\hline
\end{tabular}

De technische validiteit verschilde per type calorimeter. De gemiddelde waarde varieerde van 0-1\%, met variatie coëfficiënt tot $2 \%$, overeenkomstig gepubliceerde waarden in de literatuur.

Tot slot werden vergelijkingen afgeleid voor een molaire massa balans bij ademgasmetingen, waarbij de aanname dat alle gassen "ideaal" zijn werd geëlimineerd en uitsluitend SI-eenheden werden gebruikt. Simulaties resulteerden in mogelijke fouten bronnen wat betreft temperatuur verschillen en veranderingen, vooral van belang bij gebruik van respiratiekamers met klimaatbeheersing en verdeling van gasvolumina in compartimenten en deel-luchtstromen.

\section{DISCUSSIE EN CONCLUSIES}

Het energiegebruik, bepaald door meting van zuurstof opname en koolstof dioxide productie, komt overeen met gemeten warmte verlies plus uitwendige arbeid, zoals geleverd op een fietsergometer. De biologische variatie van het dagelijks energiegebruik en onderliggende componenten komt overeen met de betrouwbaarheid de gebruikte meetapparatuur over het gehele humane bereik. Betrouwbaarheid van apparatuur voor meting van energiegebruik vereist de aanwezigheid ter plekke van een valide test opstelling alsmede regelmatige toepassing daarvan. 

Valorisation
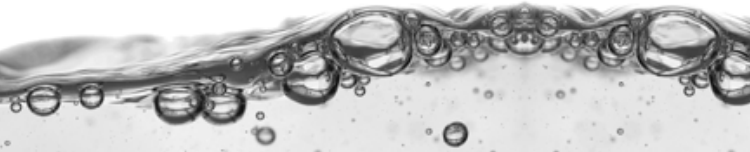

$\circ$ $030-0.0$

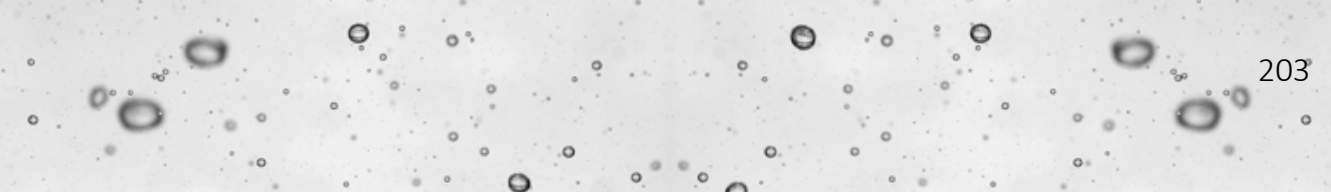





\section{The relevance of human calorimetry and its current status.}

Human Energy Expenditure is the single most important aspect of life, without this energy there is no life. For this reason, interest in the energy of living is as old as recorded science, starting with Plato in 360 B.C. and exponentially growing ever since physics allowed the measurements of this energy as demonstrated for mammals by Lavoisier and Laplace in 1780.

It was at the start of the 20th century that research into Human Energy Expenditure became a well understood science, and during the course of the 20th century a vast and solid body of information on food, food-composition, energy, and gas-exchange was obtained. This information was mostly obtained by combined direct and indirect calorimeters in highly specialized laboratories, measuring both heat and gas exchange as well as performing chemical analysis of food and its substrates.

A solid link between direct and indirect calorimetry was created, still fully valid today, and together with advances in electronics, analysers, and computer sciences this enabled the proliferation of indirect calorimetry in favour of direct calorimetry. Effectively, it appears that the complexity and cost of indirect- and direct calorimetry have switched places. This proliferation of indirect calorimetry was further driven by the appearance of commercial small mobile indirect calorimeters for bed-side and sports-lab applications.

In 1985 Paul Webb predicted that human direct calorimeters will grow in numbers, an expectation that has been superseded by a reality where small indirect calorimeters can now be found in nearly every hospital or food/sports-related institution world-wide. Effectively there are thousands of small, and 30-50 large, indirect calorimeters in operation today; only a single larger direct calorimeter remains. This broad proliferation of what must be considered a method sensitive to methodological and technical errors is problematic; gone are most of the specialized laboratories of the past, replaced by black box technology and/or operated by non-specialized personnel.

The relevance of the Human Energy Expenditure can be understood when viewing it as the counterpart to energy intake; the absorbed food. For a stable weight the expenditure must be matched by the intake, if these two are not in balance we either loose or gain weight.

"Food may be defined as material which, when taken into the body, serves to either form tissue or yield energy, or both" (Wilbur Olin Atwater).

The energy balance of man is one of great importance to the world population; every single person needs sufficient and healthy food. Obviously, this is not the case, whole populations are starving while others become morbidly obese. A problem of the distant past and of even greater interest in future; how do we feed a $10+$ billion world population? How to solve the myriad of health problems traceable to over- and underfeeding? Or sleep, activity and environment? Or even, how do we feed astronauts during their travels to Mars? The scope of questions is growing and seemingly endless, and it can be 
envisioned that multi-disciplinary research is not only required but will grow and result in additional research topics.

The above may determine the current status of measuring Human Energy Expenditure as a wide-spread and important tool that nowadays may, sadly, lack local support and specialized know-how. Effectively, results may be contradictory and even detrimental to the solid foundation of information of the past. Moreover, application for the individual clinical assessment can be problematic.

"Many research workers in medicine and other fields of biology have embarked on calorimetry in the mistaken belief that measurement of oxygen consumption and hence energy expenditure is a very straightforward process. It is almost certain that results and conclusions which have been reported from some calorimetric systems are incorrect." (McLean and Tobin)

\section{The value for research in Maastricht}

With roots in classic calorimetry, progressing from chemical analysis of the past to electronic analysis of today, developments in human calorimetry at Maastricht University proved successful. Its value for research can only be recognized from the thousands of subjects that have been measured, the hundreds of papers that have been published, and the numeous industry contracts on topics of food, equipment and medicine that have been fulfilled.

Value also resulted from the actual calorimeter systems as developed in Maastricht, starting in 1983 with improvements to commercial bed-side calorimeters (under nondisclosure at the time), which financed PhD studies that were executed with the prototypes build in Maastricht. And resulting in today's commercial availability of Omnical branded calorimeters on the global market.

\section{Academic help versus commercial turn key systems}

From 1995 onward help to other research groups around the world was provided from Maastricht, a common academic practice, resulting in more or less successful whole room calorimeters around the world. In Madison (USA) dr. Keesey's lab built a true copy of the Maastricht system that was successful from the start. In Capetown (ZA) there was a failed calorimeter that gained functional status by modifying key parts to resemble the Maastricht system. In Japan (JP) there are 8 calorimeters similar to the Maastricht calorimeters yet with a different gas analysis system. In Wollongong (AU) a copy was built but never completed to full copy status or functionality.

Based on the partially negative experiences gained, the next projects were full turn-key systems delivered by the company "Maastricht Instruments" to medical schools in War- 
wick (UK) and Singapore (SG). Interest in these turn-key solutions is strong, yet the sizeable installation and cost in the end may allow 1 in 10 research groups to finalize funding. Aside from these high-performance whole room calorimeters the bed-side and sports type Omnical as applied in the MRUM (Metabolic Research Unit Maastricht) has now become commercially available, and first reactions from the field of calorimetry indicate interest in these small calorimeters as well.

The Omnical calorimeters are different from the competition regarding the chosen components and applied methods; high-end components are intended to provide a continuous $24 / 7$ quality of gas analysis, lowering drift over time and increasing quality over the duration of studies. Importantly, the devices can be checked on-site. The specifications are a direct result of the researchers needs as learned in 35 years of calorimetry in Maastricht, and delivering turn-key equipment eliminates the chances of failure that was experienced in part when groups where "building one up from components" with academic help from others. Caveat emptor: successfully building one remains the best course training, it is also the most expensive solution and especially if unsuccessful.

"Whether buying a complete system or building one up from components, it is necessary to have a full understanding of the basic principles and of the many sources of error that must be guarded against." (J. A. McLean \& G. Tobin)

\section{A counterweight to ignorance}

It has been stated that human indirect calorimeters have proliferated as "black boxes" and results may certainly suffer from absence of specialized know-how.

In some instances, literature, or papers submitted for review, dismiss biological reproducibility or have no biological data at all, which may be considered pure ignorance beyond a lack of know-how. It is a commercial routine to advise checking a calorimeter in one mode, and then let it be applied in a different mode; this certainly does not validate the calorimeter for the intended use.

In contrast, the calorimetric systems proposed in this thesis, now branded "Omnical", may be validated on-site, frequently, and in the identical mode as applied with subjects. This approach revealed near-identical variability on the technical and on the biological aspects (this thesis), and both technical and biological validity may be deemed a requirement for successful operation of human calorimeters.

Importantly, in a recent comparative study (just submitted by colleagues in the US) the Maastricht Omnical proved most reproducible and reliable of all calorimeters tested, which typically is of value for the individual assessment of a patient.

Please note that application of the presented calorimeters should not be considered a haughty claim to infallible measurements, instead it should be considered an eyeopener as to how much can and will go wrong; in this regard ignorance is not bliss! 
A common mistake that people make when trying to design something completely foolproof is to underestimate the ingenuity of complete fools.

(Douglas Adams)

\section{The emerging reality of calorimetry}

As human calorimetry evolves and proliferates the need for locally validated equipment will rise above the clouds of more or less useful validation studies. Researcher will require proof of suitability of their locally applied device, not simply rely on a paper that tested "a" unit at some point in time. No device can simply be deemed a gold-standard apparatus without periodically checking if it still operates correctly, and if anyone learned this lesson; we did and we still do.

Moreover, longitudinal application of calorimeters is an under-rated yet important aspect; a 6 month check with repairs may confound results of the before- and after repairs intervals; this will not do, results must be constant in quality over the duration of a study.

Recent co-operation between research groups shows the growing awareness about these aspects; it may be the dawn of truly validated research, even for the users of "black box" technology.

The calorimetry systems as applied in Maastricht are expected to take part in this emerging reality of continuous and longitudinal productivity of calorimetric measures. With 16 calorimeters up and running on a 24/7 basis the demands upon quality control and validation testing are higher than ever before, and even after 35 years of operation and innovations it is possible to find unexpected errors. The technical and operational lessons learned will continue to lead to solutions that find their way into day-to-day operations and guidelines.

Problematic in this process is the multi-disciplinary combination of technical and biological aspects; technical papers that are legible to biologist may be too low on biological content to be acceptable for the biological papers. Their already educated editors and reviewers may simply consider it required common knowledge, even if sadly this knowledge is no longer that common. This conundrum exists, and a solution to this problem may be to expand the availability of calorimeters that indeed can be validated on site, by the local researcher, and also to provide training together with the equipment. This is one reason for providing the calorimeters as applied in Maastricht to colleagues; proof of validity by being reproducible at other sites.

Innovative in this regard is the adherence to classic and proven methodology, augmented with the precision and accuracy of modern technology; it may cost more and take more space, but it will be reliable and validated.

The chances for this type of equipment and methodology on the market are good, although starting with small numbers the production can be easily scaled up as demand grows. With the advent of comparative papers and the option to test these devices 
before final purchase researchers and clinics may recognize the increased value of reliable results and long lifespan. A first problem will be the many papers on validity of other commercial equipment, yet they do not incorporate aspects of performance over time and cost of ownership regarding questionable results. This is the new frontier, and calorimeters, especially for "black box" application, must perform at a constant quality and prevent operator errors. They should simply work but also provide continuous proof of validity.

"Simplicity is the ultimate sophistication. It takes a lot of hard work to make something simple, to truly understand the underlying challenges and come up with elegant solutions." (Steve Jobs)

\section{In conclusion}

There is a large demand for simple yet accurate human calorimeters; thousands of units exist worldwide. There is also a demand for highly precise whole room calorimeters, this requires a level of infrastructure and funding to a degree that just a few sites will be able to realize in the near future; maybe more when time goes by and turn-key systems prove their value. Possibly a demand for a few direct calorimeters will return; they provide information on a different aspect on human energy expenditure.

"The measurement of respiratory gas exchange, or of metabolic rate as an alternative term, is something quite different from the measurement of heat from the body. It is an assessment of how much fuel has been oxidized, and with what proportions of fat to carbohydrate, if the oxidation of protein is known." (Paul Webb)

The results of studies performed with the current equipment in place will show its success or expectedly lack thereof, opening opportunities for selling, hiring out and building a reliable and simple to operate class of calorimeters. The latter is the class of equipment targeted by developments in Maastricht; we too require these simple yet accurate human calorimeters and have a need to validate them regularly.

After co-developing commercial units, that deviated from their original design over time and did no longer meet our requirements, the only option was to go back to our original prototypes and build upon those. This is now a requirement, and this time around we hope to keep calorimeters originating from Maastricht in line with the demands and possibilities of our metabolic research unit.

It will be interesting to see how commercial and research needs may come together and provide worthwhile solutions to a changing world of calorimetry.

"You can't look at the competition and say you're going to do it better. You have to look at the competition and say you're going to do it differently." (Steve Jobs) 

Aknowledgements

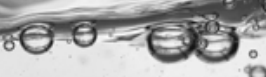

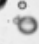

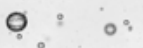

0

○

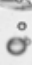
○ं $30-0$ $\because 0$ 0 211 .0 

The work I was allowed to do at the University of Maastricht changed my life in many ways. It was challenging, easy, difficult, pleasant, stressful, interesting, and provided many other experiences except for dull, sad or painful. In fact it fitted my personality and range of talents (or lack thereof). I feel truly blessed for having had, and still have, the opportunities and colleagues of the University in my life, and hopefully this will make me a better and smarter person by example.

It is in this spirit that I would like to remember and thank the founder of our department, Professor Foppe ten Hoor. I knew him as a kind person, forever with a bright smile and providing guidance and opportunities to all of us. Thanks Foppe.

To my promotors and co-promotor, one provided the wings, another provided flying lessons, and the third one co-piloted from wing-man to squadron leader.

Wim, as my first boss you provided the wings; no nonsense and no problems as long as things got accomplished; you stood firm behind me and I was enabled to understand and build calorimeters as well as other interesting methods and equipment. I particularly appreciated how discussions could go either way; if you were convinced otherwise you would turn on a dime, not many people can do that. Thanks for all the help and friendship, and the wings.....

Klaas, as my second boss you were the meticulous teacher providing an alternative view on many things scientific and on life itself. It was an interesting journey, starting in earnest with our trip to Louisiana and followed by more conferences, papers, discussions, and providing insights. I appreciated your ability to simplify matters (hard to do), your lateral views and your interesting presentations.

Thanks for all the help and friendship, and the flying lessons...

Guy, you were a friend long before becoming my boss and co-promotor, and you are a legend amongst PhD's and those still working to get there. I guess you are going for the Guinness record for being a great "Guy". From wing-man to squadron leader; you supported me when too much problems were on my plate, calmly providing suggestions that could be followed and keeping me from banging my head against "the Wall". Thanks for all the help and friendship, and for flying together.... 
A special thanks to the members of the assessment committee, for evaluating this thesis and for travelling to Maastricht to oppose at my PdD defence.

Wouter, Patrick, Luc, and Annemie; thank you for your support over many years, both personal and professional. I learned a lot from working with you.

Peter, you were light-years ahead when calorimetry started in Maastricht and you provided half the world with kind and professional help, an example to everyone in the field of calorimetry and certainly to me. Thanks for all your personal advice and for being a friend.

Kong, it was a pleasure discussing calorimetry with you during "the RACMEM years" (ongoing), your professional interest and kindness are very much appreciated; thank you!

Paranymphs Emmanuel and Tanja, thank you for your great help, I really appreciated your views, advice, and standing by my side.

Once more, our secretaries also proved invaluable, in this instance Desiree Morales took the lead, but I have always felt supported from Mary through to Truus and Marco onto today's excellent Desiree(s), Yolanda and Cleo. Thank's for the many times you saved the day!

Many more colleagues and friends at the university deserve a thank you, yet I can only mention a few:

Ronald for supporting me in building the MRUM and stimulating me to proceed with my $\mathrm{PhD}$ thesis, though at the time the MRUM took all the energy available.

Gerard, Erwin, Fred, Ellen and others (include full staff here!), thanks for your support.

A big thank you to our PhD students now and of the past, you provided and did a lot of work, comradery included. I'll skip the hundreds of names, but it has been the best of times working with you all.

No metabolic research group can function without lab facilities and expert analists, dieticians, research assistants, technician's and ict support. From Wendy to Jos, from Ed to Joan, from Loek to Laurens and Marc, Gabby to Freek, Antoine to Maurice, Paul to Harry and Leon, and too many others to mention; thank you all.

Of course, all of us can't function without all the more or less (in)visible services we take for granted: from engineers to cleaning crew to PhD office, facility and logistical services to purchasing, library to catering, ICT to financial services; Thanks!

Outside of Maastricht there are many colleagues that were helpful, professional, kind and friendly. Paul Webb MD, creator of space suits and calorimetric guru springs to mind, I enjoyed the late night (burned) Navy coffee as he called it; preferably taken with a drop of discussion about external work. I'll leave out the many other names as I may remember some famous experts better than they may recall me. 
In recent years, I enjoyed discussions about calorimetry and academic ethics with friends at the University of Warwick, thank you John Hattersley and Adrian Wilson for your support.

Naturally and importantly my family, friends and experiences shaped the path that I have followed.

Thanks to friends Maurice and Fenny, deken Frencken and Annie, Marlou, Truus and Rudy, Ger, Laurens, and many others.

Thanks to my family and especially my parents Bert and Therese Schoffelen-Knechten, and my brother Frans with his wife Julia and nieces Annika and Freya. It is a large family, thanks to my uncles and aunts Emile and Corry, Wil and Ger, Roel and Hermine, Alice and Wim, Jo and Carla, Har and Jenny, Cecile and Albert, Toos and Adrie, Jan and Inge, Maria, Rini and Door, Bert and Ans, Karel and Ans, Frans and Hermien, Diny, Leonie and to my many, many cousins.

With the good luck of having a second family, my family in law, I specifically thank my parents in law Jan and Lenie Maassen-Reuvers, my brother in-law Albert with his wife José and nephews Johan and Peter, and niece Mathilde, as well as other relatives close and far that so warmly welcomed me in their inner circle.

To my wife Carla and daughter Linda; you two are the most important persons in my life, and you supported me through each and every part of it. Linda has become a strong personality, matching our view on life and factually saving lifes at the red cross, goed zo!

Legend has it that Carla and I met the first time when our mothers visited the child consultation clinic, she wore a dress from mom's shop, blue if I remember correctly. Fact is that we had our first dance in 1969 and it made a lasting impression; as different as we are, our thoughts and feelings about the important things in life are beautifully intertwined.

Carla and Linda, I love you above everything else.

Thanking all the people I feel I should would fill another book, and still it would be incomplete.

So Long, and Thanks for All the Fish (Douglas Adams) 

About the author - $9-\mathrm{B}^{\circ} \mathrm{z}_{0}^{\circ}$
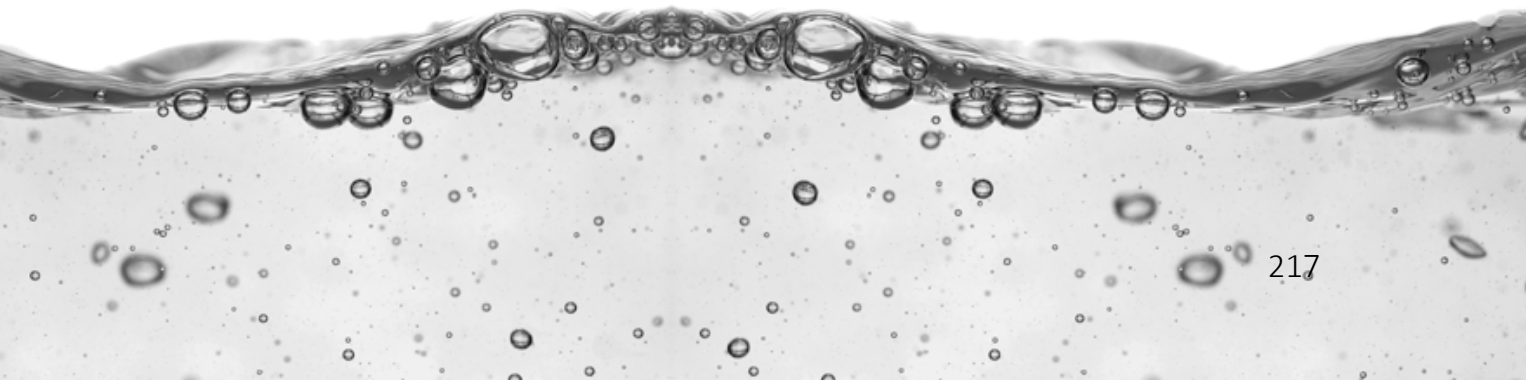

Paul F.M. Schoffelen was born on the 29th of January 1957 in Brunssum (NL). He completed secondary school in 1973 at the Rombouts College in Brunssum, followed by a post-secondary preparation program for engineering and physics at the Higher Technical School of Heerlen. After internships in 1979 in industry and at the universities of Nijmegen and Maastricht, he obtained his degree in Electronics, measurement and control at the Higher Technical School of Heerlen in 1981. His thesis was on the development and mathematics of a correlating in-vivo blood-velocity camera for the University of Maastricht. For the next year he worked at Philips Audio and Video in Eindhoven as product developer and the project leader for the design of CTX television sets. In 1982 he re-joined the University of Maastricht at the Department of Human Biology, where his primary mission became the development of methods and equipment for measuring Human Energy Metabolism, as well as to overview all technological aspects concerning the department. His involvement resulted in the Maastricht dual respiration chamber system, and a diversity of ventilated hood and sports physiology indirect calorimeters. He also build one of the first direct suit calorimeters for prof. Paul Webb, and helped develop the ventilated hood options for commercial systems Deltatrac and Oxycon. For the move of the department in 1992 to the new location at Randwijck, he redesigned laboratories and upgraded equipment, and this was followed by renewed developments in room, hood and sports calorimeters now named "Omnical". As a result of growth of the department, in 2007 he was enabled to design a third revision of metabolic laboratories, explicitly targeting optimal provisions for the broad research portfolio that had evolved. This resulted in the opening of the Metabolic Research Unit Maastricht in 2011, recognized in 2016 by NWO as a large-scale scientific infrastructure. At the 2014 RACMEM conference in Tokyo he received public acknowledgement for help in setting up whole room calorimeters in Japan, and over the decades he has also assisted colleagues in the UK, US, South Africa, Australia and other locations in setting up whole room calorimeters. He is (co-) author of several scientifically refereed articles on the topic of measurement of energy metabolism.

For the future, his goals remain to improve technology for metabolic research in Maastricht and elsewhere, with a particular interest in helping third world research. 



\section{Publications}
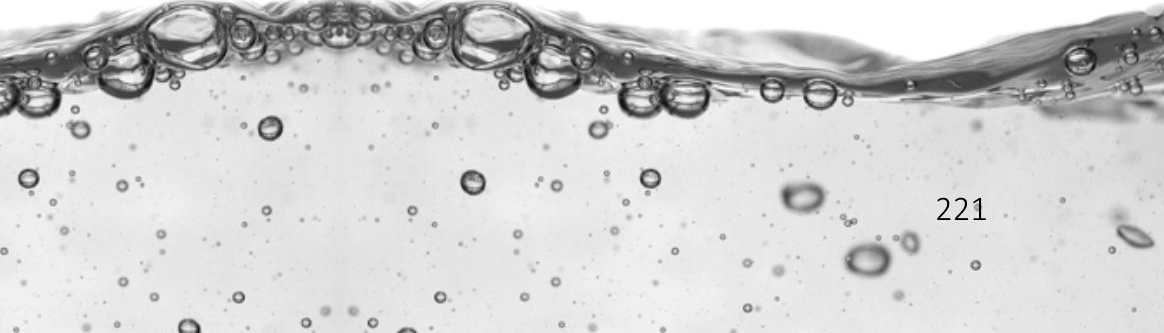

1. van Breda E, Schoffelen PFM, Plasqui G. Clinical Vo2peak is "part of the deal". J Appl Physiol (1985). 2017;122(5):1370.

2. Schoffelen PFM, Souren M, Plasqui G. Measurement of respiratory gas exchange derivation of equations for- and comments on true molar balance in whole room calorimetry. submitted. 2017.

3. Schoffelen PFM, Plasqui G. Utilization of different formulae to calculate substrate oxidation in whole room calorimeters; an updated equation for indirect calorimetry submitted. 2016.

4. Schoffelen PFM, den Hoed M, van Breda E, Plasqui G. Test-retest variability of VO2max using total-capture indirect calorimetry reveals linear relationship of VO2 and Power. Submitted. 2016.

5. Konings E, Schoffelen PF, Stegen J, Blaak EE. Effect of polydextrose and soluble maize fibre on energy metabolism, metabolic profile and appetite control in overweight men and women. Br J Nutr. 2014;111(1):111-21.

6. Gonnissen HK, Drummen M, Rosique Esteban N, Schoffelen PF, Westerterp-Plantenga MS. Overnight energy expenditure determined by whole-body indirect calorimetry does not differ during different sleep stages. Am J Clin Nutr. 2013;98(4):867-71.

7. Lemmens SG, Born JM, Rutters F, Schoffelen PF, Wouters L, Westerterp-Plantenga MS. Dietary restraint and control over "wanting" following consumption of "forbidden" food. Obesity (Silver Spring). 2010;18(10):1926-31.

8. Lemmens SG, Schoffelen PF, Wouters L, Born JM, Martens MJ, Rutters F, et al. Eating what you like induces a stronger decrease of 'wanting' to eat. Physiol Behav. 2009;98(3):318-25.

9. Dugas LR, Cohen R, Carstens MT, Schoffelen PF, Luke A, Durazo-Arvizu RA, et al. Total daily energy expenditure in black and white, lean and obese South African women. Eur J Clin Nutr. 2009;63(5):667-73.

10. Schoffelen PF, Westerterp KR. Intra-individual variability and adaptation of overnight- and sleeping metabolic rate. Physiol Behav. 2008;94(2):158-63.

11. Claessens-van Ooijen AM, Westerterp KR, Wouters L, Schoffelen PF, van Steenhoven $A A$, van Marken Lichtenbelt WD. Heat production and body temperature during cooling and rewarming in overweight and lean men. Obesity (Silver Spring). 2006;14(11):1914-20.

12. Adriaens MP, Schoffelen PF, Westerterp KR. Intra-individual variation of basal metabolic rate and the influence of daily habitual physical activity before testing. $\mathrm{Br}$ J Nutr. 2003;90(2):419-23. 
13. Schoffelen PF, Westerterp KR, Saris WH, Ten Hoor F. A dual-respiration chamber system with automated calibration. J Appl Physiol (1985). 1997;83(6):2064-72.

14. Westerterp KR, Meijer GA, Schoffelen P, Janssen EM. Body mass, body composition and sleeping metabolic rate before, during and after endurance training. Eur J Appl Physiol Occup Physiol. 1994;69(3):203-8.

15. Schols AM, Schoffelen PF, Ceulemans H, Wouters EF, Saris WH. Measurement of resting energy expenditure in patients with chronic obstructive pulmonary disease in a clinical setting. JPEN J Parenter Enteral Nutr. 1992;16(4):364-8.

16. Westerterp-Plantenga MS, Westerterp KR, Nicolson NA, Mordant A, Schoffelen PF, ten Hoor $F$. The shape of the cumulative food intake curve in humans, during basic and manipulated meals. Physiol Behav. 1990;47(3):569-76.

17. van Dale D, Beckers E, Schoffelen PFM, ten Hoor F, Saris WHM. Changes in sleeping metabolic rate and glucose induced thermogenesis during a diet or a diet/exercise treatment. Nutrition Research. 1990;10(6):615-26.

18. van Dale D, Schoffelen PF, ten Hoor F, Saris WH. Effects of addition of exercise to energy restriction on 24-hour energy expenditure, sleeping metabolic rate and daily physical activity. Eur J Clin Nutr. 1989;43(7):441-51.

19. Webb P, Saris WH, Schoffelen PF, Van Ingen Schenau GJ, Ten Hoor F. The work of walking: a calorimetric study. Med Sci Sports Exerc. 1988;20(4):331-7.

20. Van Dale D, Saris WH, Schoffelen PF, Ten Hoor F. Does exercise give an additional effect in weight reduction regimens? Int J Obes. 1987;11(4):367-75.

21. Schoffelen PFM. Evaluation of an automatic indirect calorimeter for measurement of energy balance in man. In: van Es AJH, editor. European Nutrition Report No 5. The Hague, The Netherlands: Koninklijke Bibliotheek1985. p. 51-4.

22. Westerterp K, De Boer J, Saris W, Schoffelen P, Ten Hoor F. Measurement of energy expenditure using doubly labelled water. International Journal of Sports Medicine. 1984;5(S 1):S74-S5.

23. Donjacour C, Schoffelen P, Overeem S, Lammers G, Pijl H, Westerterp K. Energy expenditure in narcolepsy patients and controls. Sleep Medicine.14:e109. 
